\title{
Feasibility Study of Hydrogen Production at Existing Nuclear Power Plants
}

July 2009

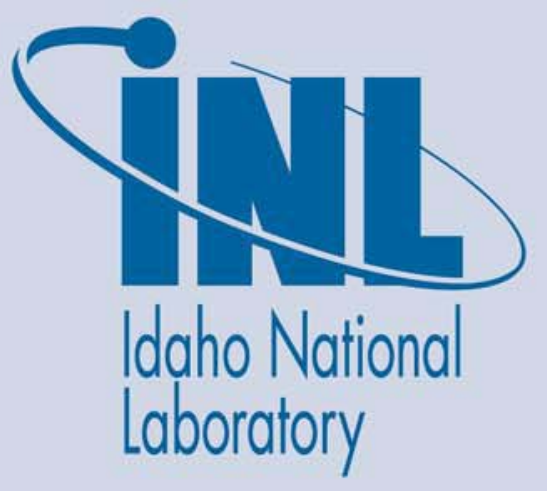

The INL is a U.S. Department of Energy National Laboratory operated by Battelle Energy Alliance 
INL/EXT-09-16326

\title{
Feasibility Study of Hydrogen Production at Existing Nuclear Power Plants
}

July 2009

\author{
Idaho National Laboratory \\ Idaho Falls, Idaho 83415
}

http://www.inl.gov

Prepared for the

U.S. Department of Energy

Assistant Secretary for Energy Efficiency and Renewable Energy

Under DOE Idaho Operations Office

Contract DE-AC07-05ID14517 


\title{
Feasibility Study of Hydrogen Production at Existing Nuclear Power Plants
}

\author{
Project Final Report
}

Electric Transportation Applications

July 2009

The Idaho National Laboratory is a U.S. Department of Energy National Laboratory Operated by Battelle Energy Alliance 


\section{Disclaimers}

This document highlights work sponsored by agencies of the U.S. Government. Neither the U.S. Government nor any agency thereof, nor any of its employees, makes any warranty, express or implied, or assumes any legal liability or responsibility for the accuracy, completeness, or usefulness of any information, apparatus, product, or process disclosed, or represents that its use would not infringe privately owned rights. Reference herein to any specific commercial product, process, or service by trade name, trademark, manufacturer, or otherwise does not necessarily constitute or imply its endorsement, recommendation, or favoring by the U.S. Government or any agency thereof. The views and opinions of authors expressed herein do not necessarily state or reflect those of the U.S. Government or any agency thereof. 


\section{EXECUTIVE SUMMARY}

Cooperative Agreement DE-FC07-06ID14788 was executed between the U.S. Department of Energy, Electric Transportation Applications, and Idaho National Laboratory to investigate the economics of producing hydrogen by electrolysis using electricity generated by nuclear power. The work under this agreement is divided into the following four tasks:

Task 1 - Produce Data and Analyses

Task 2 - Economic Analysis of Large-Scale Alkaline Electrolysis

Task 3 - Commercial-Scale Hydrogen Production

Task 4 - Disseminate Data and Analyses.

The final report for Task 1.3 of August 2008 summarized work conducted under Task 1. In Task 1.1, data from prior operations of the Arizona Public Service Alternative Fuel Pilot Plant (AFPP) were gathered and analyzed to identify operating strategies for developing costs of hydrogen production. Strategies were developed for operating production equipment in three modes. In winter mode, production equipment is operated continuously. In shoulder mode, production equipment is operated only when the price of electricity is below a preset maximum of $\$ 55.00 / \mathrm{MWhr}$. In summer mode, production equipment is operated only during off-peak electric cost periods.

In Task 1.2, the AFPP was operated for 3 months in each of the three production modes. Costs for hydrogen production were calculated using the actual price for electricity delivered at the Palo Verde Nuclear Generating Station electrical switchyard in 2006. The price of electricity at the Palo Verde switchyard was used for this simulation of hydrogen production cost because it represents the opportunity cost for using electricity to produce hydrogen rather than to sell in the wholesale market.

Lessons learned from Task 1 and operations of AFPP were applied during the specific Task 2 and 3 efforts. The economic assessment model (developed by the Idaho National Laboratory) was used to evaluate large-scale electrolysis plants. Completion of Tasks 2, 3, and 4 are simultaneous and included in this final report. 
Prior to this study, industry discussions focused on operation of large-scale hydrogen production facilities using existing nuclear power plants because of their low operating cost. This study shows that existing nuclear power plants are totally base loaded and not available for new hydrogen production facilities. In addition, the added safety analysis, emergency planning, license amendment work, and other topics would add significant cost and would likely be a strong deterrent against such plans. However, this study does show feasibility for new nuclear plants of current design and especially for new nuclear plant designs.

Currently, electrolysis equipment that is sized to produce $1 \mathrm{~kg}$ of hydrogen per second does not exist due to the lack of demand for such a plant. However, plant designs of increasing capabilities are making significant progress. Before this study, plants of this size were modeled but did not have the advantage of actual plant experience. Lessons learned from AFPP were used to directly size equipment and facilities that would be required in the $1 \mathrm{~kg}$ of hydrogen per second production plant. Plant design information is included in this report. Use of the most accurate design information is important in any economic assessment.

The cost of electricity is an important consideration in the economic feasibility of any hydrogen production facility. Prior to this study, much of the discussion on keeping electrical costs low centered on use of the production facility during utility off-peak hours when costs are generally lower. However, this study shows that off-peak only results in higher breakeven hydrogen pricing because the high capital cost plant is idle for many hours. Indeed there are times when the on-peak electrical cost is lower than some of the off-peak cost. The shoulder pricing techniques developed in Task 1 are important in maximizing plant efficiency while maintaining the lowest electrical costs.

Reports exist on the prospect that utility companies may benefit from having the option to produce electricity or produce hydrogen, depending on market conditions for both. This study advances that discussion in the affirmative by providing data and suggesting further areas of study.

While some reports have identified issues related to licensing hydrogen plants with nuclear plants, this study provides more specifics and could be a resource guide for further study and clarifications. At the same time, this report identifies other area of risks and uncertainties associated with hydrogen production on this scale. Suggestions for further study in some of these topics, including water availability, are included in the report.

The goals and objectives of the original project description have been met. Lack of industry design for proton exchange membrane electrolysis hydrogen production facilities of this magnitude was a roadblock for a significant period. However, recent design breakthroughs have made costing this facility much more accurate. In fact, the new design information on proton exchange membrane electrolyzers scaled to the $1 \mathrm{~kg}$ of hydrogen per second electrolyzer reduced the model costs from $\$ 500$ million to $\$ 100$ million. Task 1 was delayed when the original electrolyzer failed at the end of its economic life. However, additional valuable information was obtained when the new electrolyzer was installed. 
Products developed during this study include a process model and a N2H2 economic assessment model (both developed by the Idaho National Laboratory). Both models are described in this report. The N2H2 model closely tracked and provided similar results as the $\mathrm{H} 2 \mathrm{~A}$ model and was instrumental in assessing the effects of plant availability on price when operated in the shoulder mode for electrical pricing. Differences between the H2A and N2H2 model are included in this report. 


\section{CONTENTS}

EXECUTIVE SUMMARY iii

ACRONYMS xiii

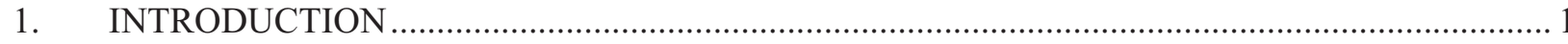

2. GENERATION SYSTEM PLANNING AND POWER CONTRACTS …................................. 2

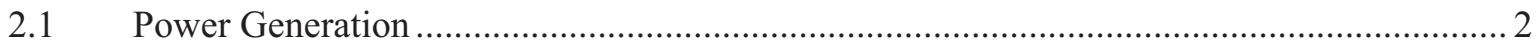

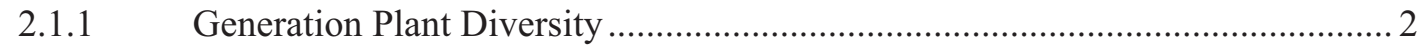

2.1.2 Base and Peak Demand Fulfillment .................................................................. 4

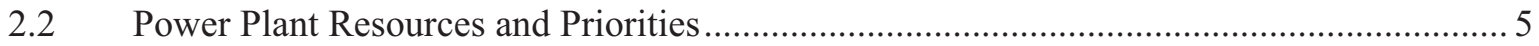

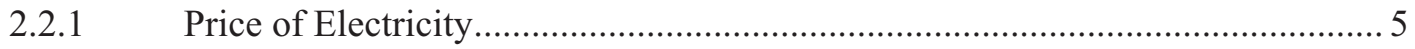

2.2.2 Nuclear Plant Availability for Hydrogen Production...................................... 7

2.3 Wholesale Power Trading at the Palo Verde Nuclear-Generating Station

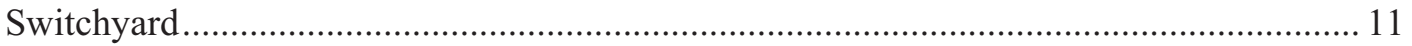

2.4 Electricity Price as Hydrogen Production Cost ........................................................... 13

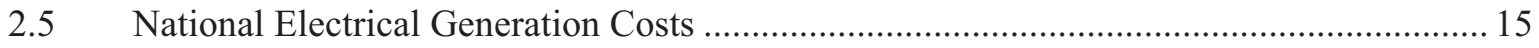

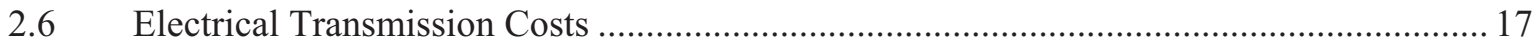

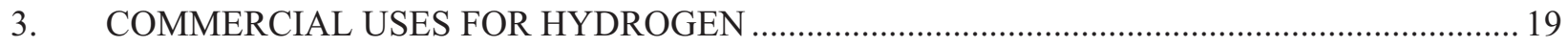

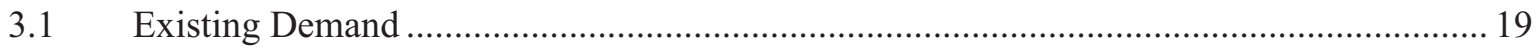

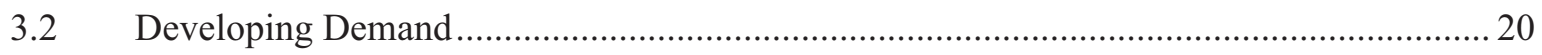

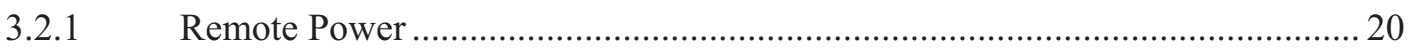

3.2.2 Utility Power Peaking ............................................................................. 20

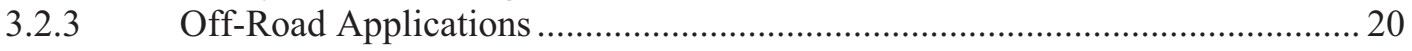

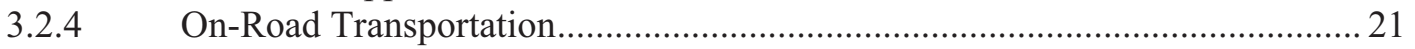

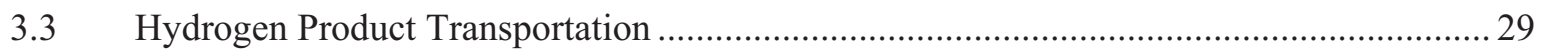

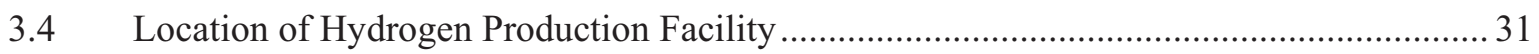

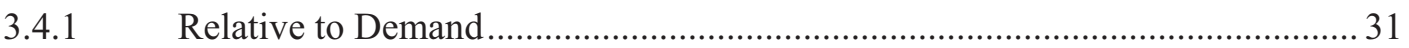

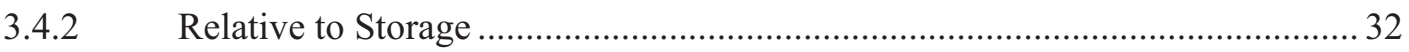

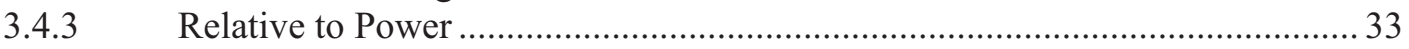

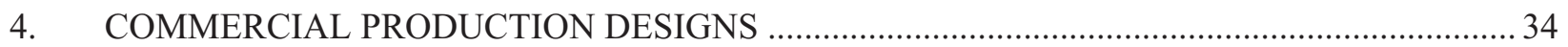

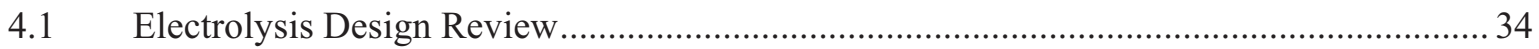




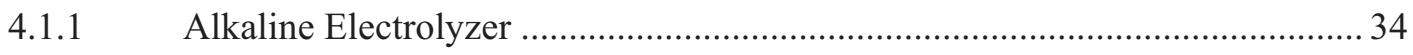

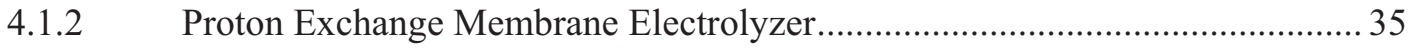

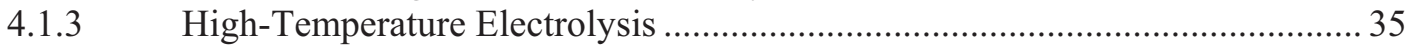

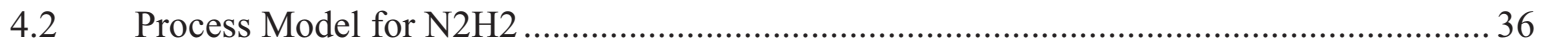

4.3 Arizona Public Service Alternative Fuel Pilot Plant - 13 kg/Day Plant - 50 kW -

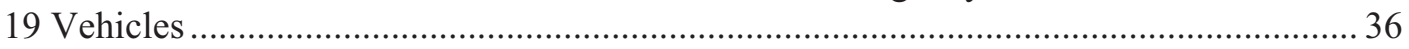

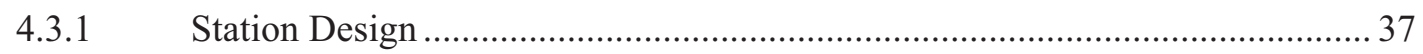

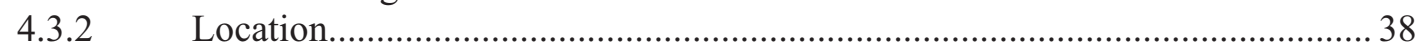

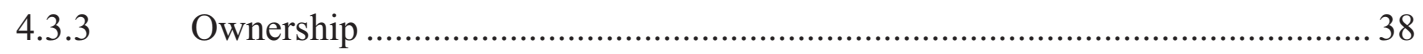

4.3.4 Alternative Fuel Pilot Plant Scaled Design Comments..................................... 38

$4.4100 \mathrm{~kg} \mathrm{H}_{2}$ /Day (Small Forecourt) - 575kW - 150 vehicles .......................................... 39

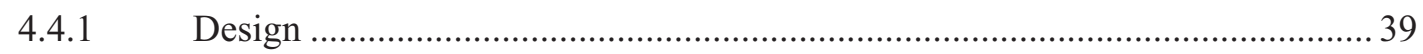

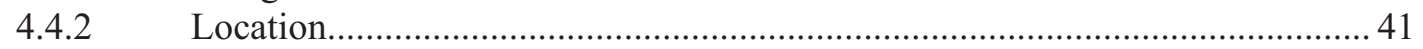

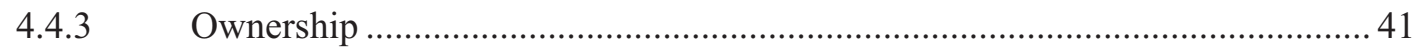

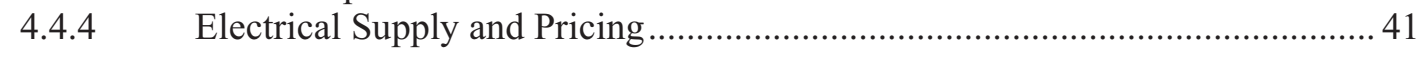

4.5 $1500 \mathrm{~kg} \mathrm{H}_{2} /$ Day (Large Retail) - 3.8 MWe - 2,200 Vehicles ....................................... 41

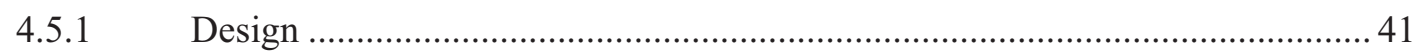

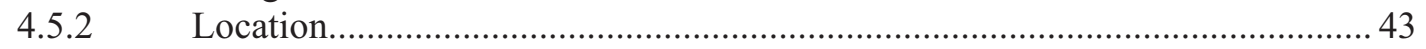

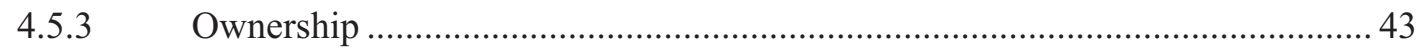

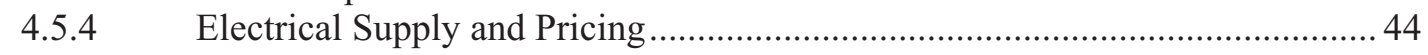

4.6 $1 \mathrm{~kg} \mathrm{H}_{2} / \mathrm{sec}$ (City Gate) - $215 \mathrm{MWe}-125,000$ Vehicles............................................. 44

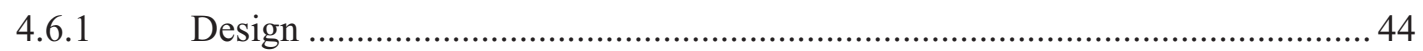

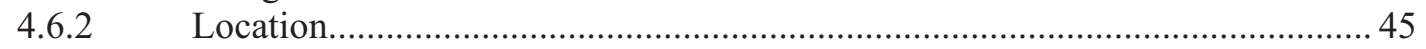

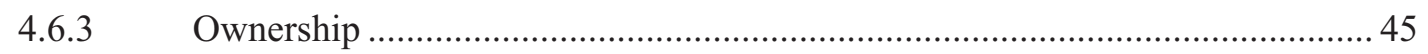

Electrical Supply and Pricing ................................................................... 45

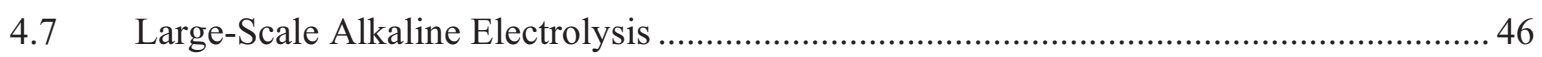

5. ECONOMIC ASSESSMENT OF HYDROGEN PRODUCTION FACILITIES .......................... 47

5.1 Idaho National Laboratory Model N2H2 Economic Assessment Model ........................... 47

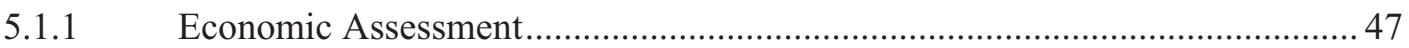

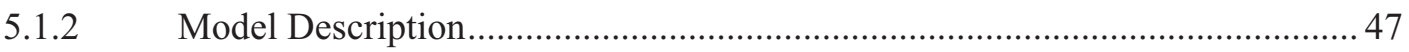

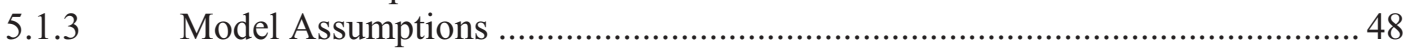

5.2 Alternative Fuel Pilot Plant 13-kg/Day Economic Assessment ....................................... 50

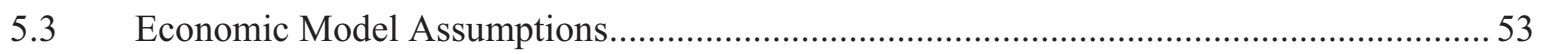

$5.4100 \mathrm{~kg} \mathrm{H}_{2}$ /Day (Small Forecourt) - 150 Vehicles ....................................................... 54

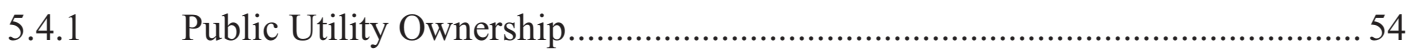




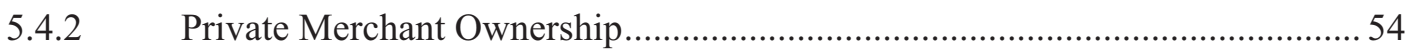

$5.5 \quad 1500 \mathrm{~kg} \mathrm{H}_{2} /$ Day (Large Retail/Small Forecourt) ..................................................... 55

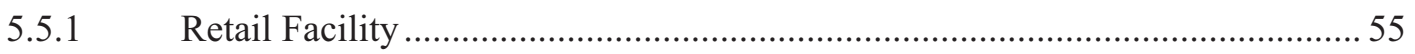

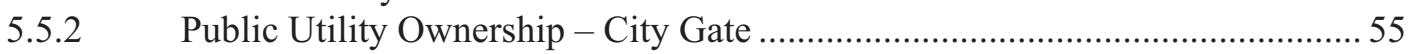

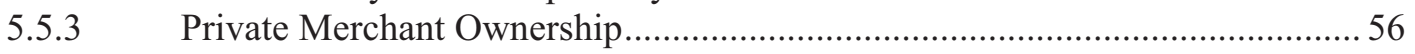

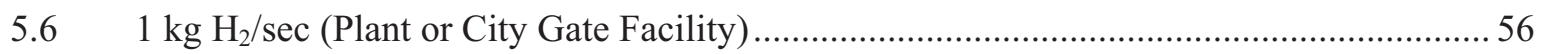

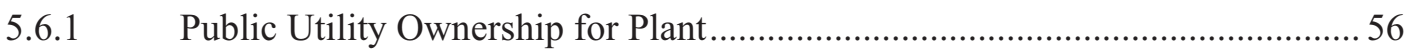

5.6.2 Private Merchant Ownership for Plant............................................................. 56

5.6.3 Public Utility Ownership for City Gate.............................................................. 57

5.6.4 Private Merchant Ownership for City Gate................................................... 58

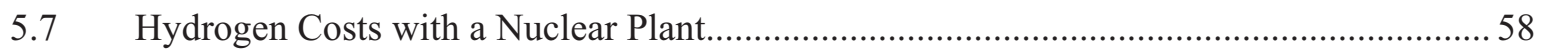

6. RISKS AND UNCERTAINTIES FOR NUCLEAR PRODUCTION OF HYDROGEN ............... 58

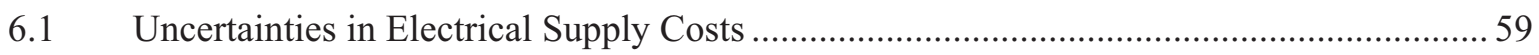

6.1.1 Seasonal/Daily Fluctuations in Electrical Demand ........................................59

6.1.2 United States Regional Variations in Electrical Demand .................................59

6.1.3 United States Regional Variations in Electrical Costs/Energy Availability ..... 59

6.1.4 Effects of Fluctuating Hydrogen Costs on Consumers .....................................59

6.2 Plant Owner Conflicts between Electricity and Hydrogen Production ............................ 60

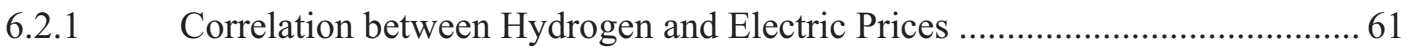

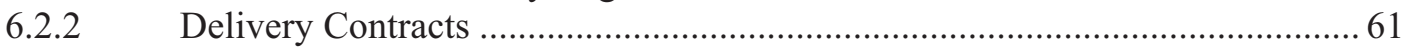

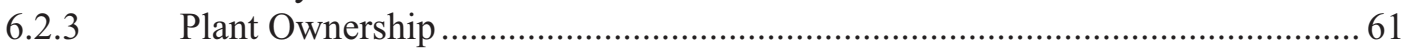

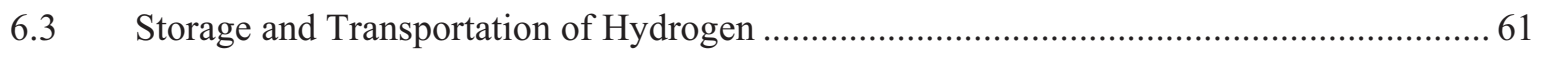

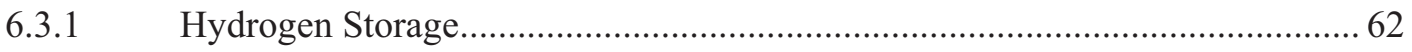

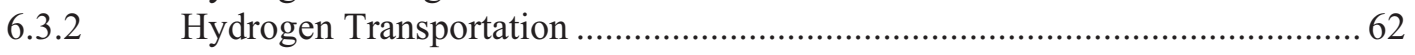

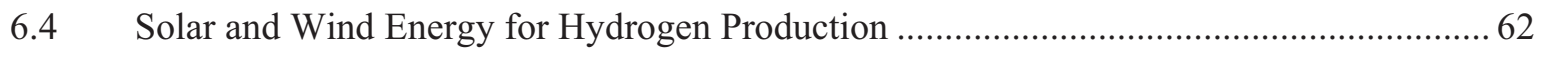

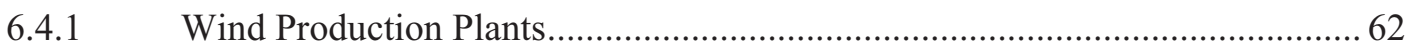

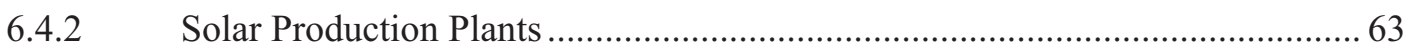

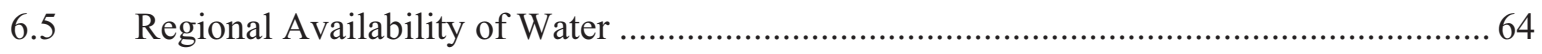

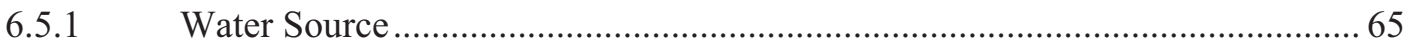

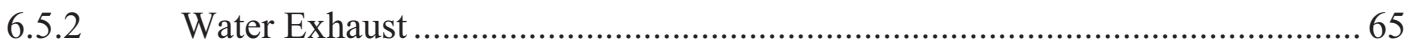

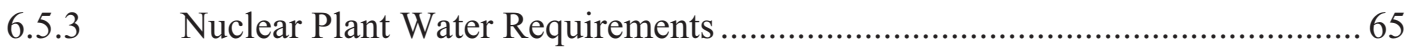

6.6 Captured Oxygen During Hydrogen Production ........................................................ 65

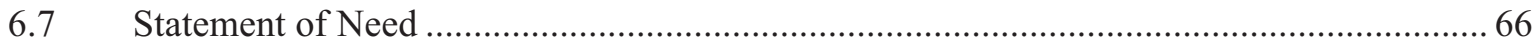


7. REGULATORY, ENVIRONMENTAL, AND LICENSING ASPECTS OF

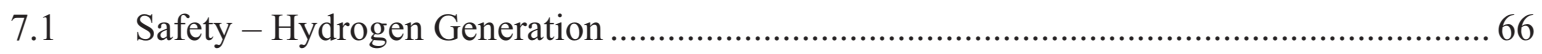

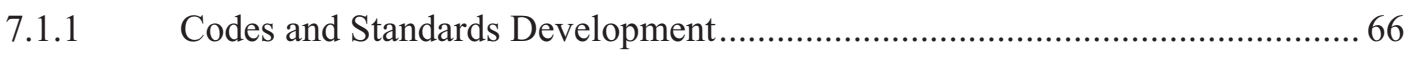

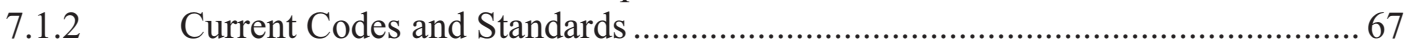

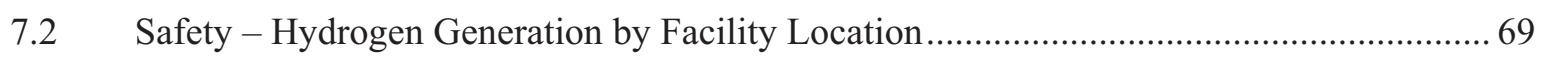

7.2.1 Hydrogen Production Facility Sited within Secured/Protected Area ................69

7.2.2 Hydrogen Production Facility Sited Adjacent to Secured/Protected Area........ 75

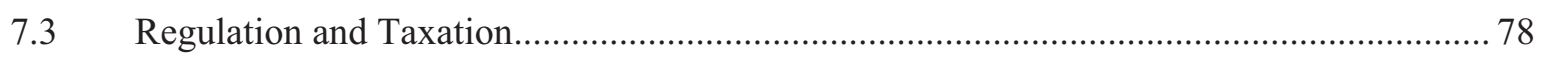

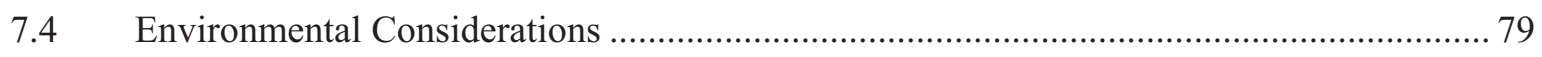

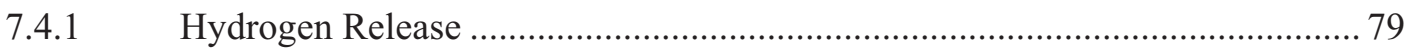

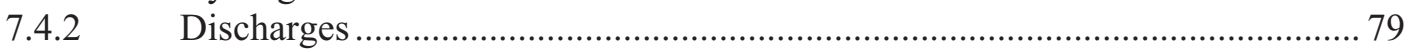

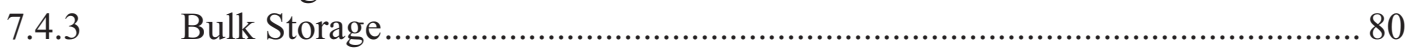

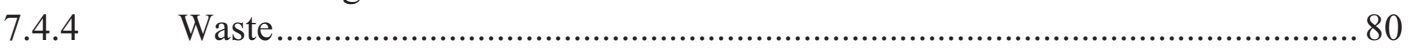

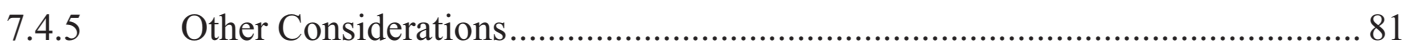

7.5 Licensing and Permitting of Hydrogen Production Facilities .......................................... 81

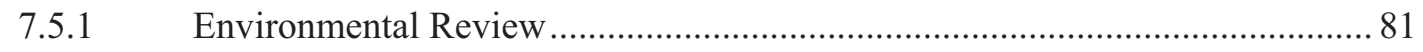

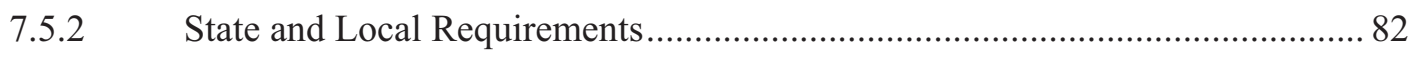

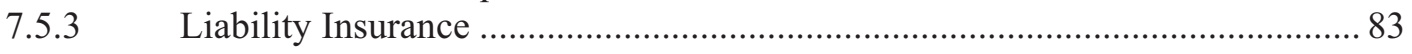

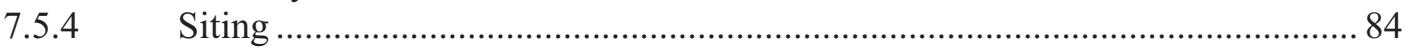

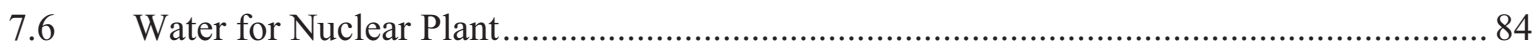

8. SUMMARY, OBSERVATIONS, AND RECOMMENDATIONS …......................................... 85

8.1 Feasibility of Hydrogen Production at Existing Nuclear Power Plant ............................ 85

8.2 Feasibility of Hydrogen Production at New Nuclear Power Plant of Current Design ....... 86

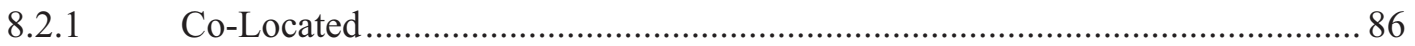

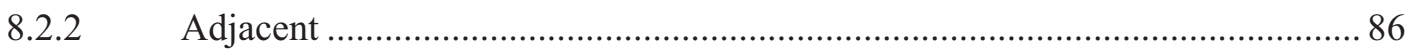

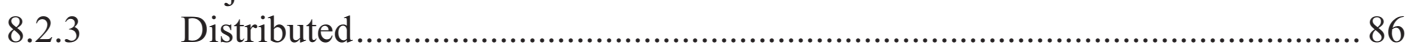

8.3 Feasibility of Hydrogen Production at Small Nuclear Power Plant ................................. 87

8.4 Feasibility of Hydrogen Production at Generation 4 Nuclear Power Plant....................... 87

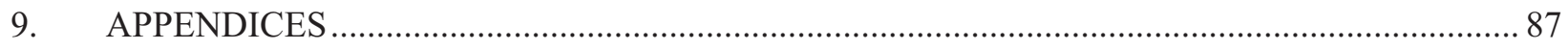

Appendix A, Palo Verde Nuclear Generating Station ............................................................... 89

Appendix B, APS Alternative Fuel Pilot Plant Design Report .................................................... 91 
Appendix C, CE-FC07-0ID14788 Task 1.3 Final Report

Appendix D, Electricity Costs for PVNGS Switchyard Delivery During Peak and Off-Peak Periods

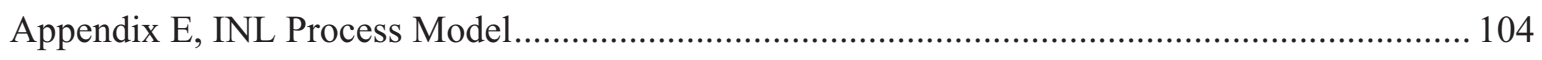

Appendix F, Plant Design for 100 kg H

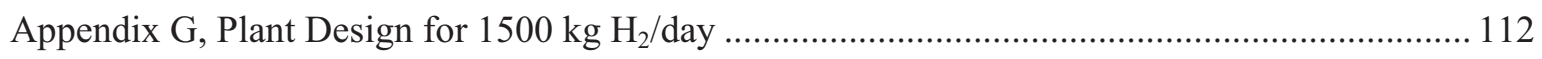

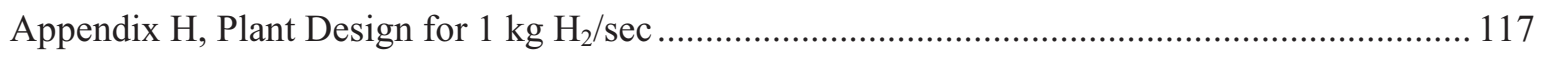

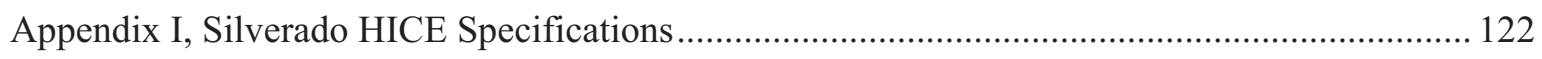

Appendix J, INL N2H2 Model Scenarios and Comments ................................................... 124

\section{FIGURES}

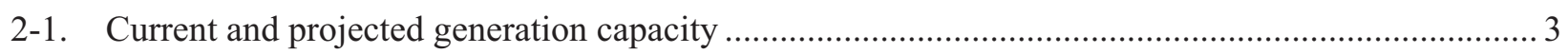

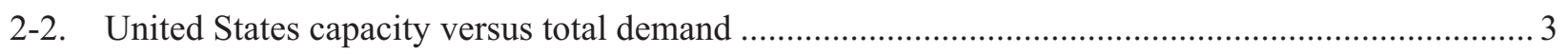

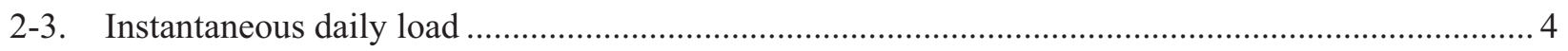

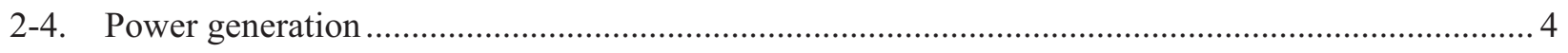

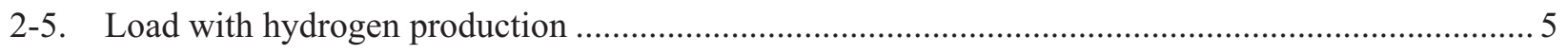

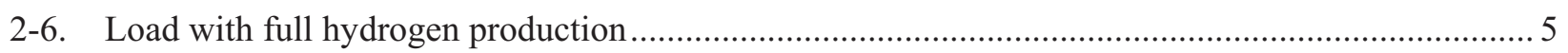

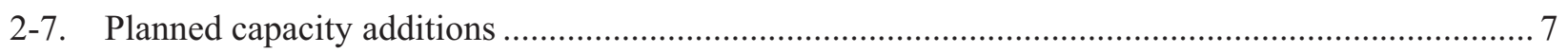

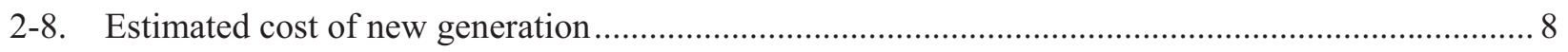

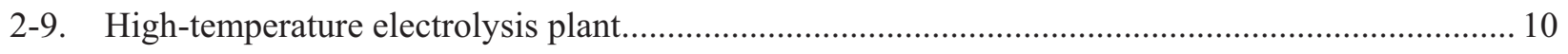

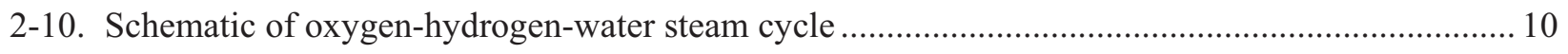

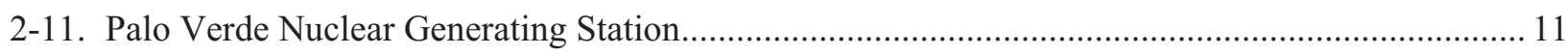

2-12. 2006 On-peak/off-peak electric price at the Palo Verde Nuclear-Generating Station

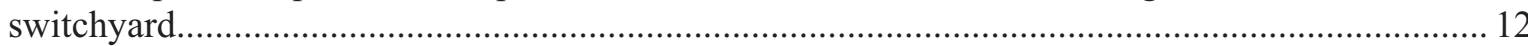

2-13. 2001 On-peak/off-peak electric price at the Palo Verde Nuclear-Generating Station

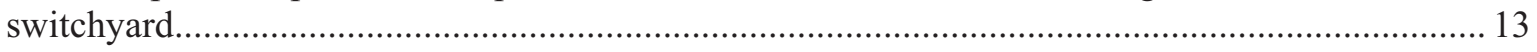

2-14. The Palo Verde Nuclear-Generating Station switchyard 2006 energy price versus availability...... 14

2-15. Palo Verde Nuclear-Generating Station maximum price and average electricity cost.................... 15 
2-16. Wholesale markets expansion. (ISO $=$ independent system operators)

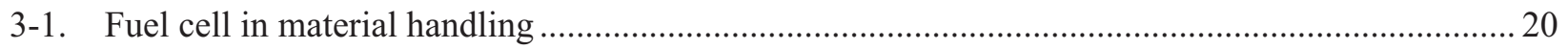

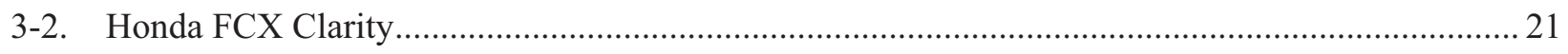

3-3. Silverado hydrogen internal combustion engine truck ........................................................... 21

3-4. Silverado hydrogen internal combustion engine truck hydrogen storage..................................... 22

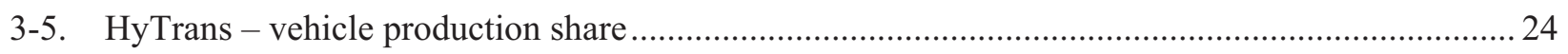

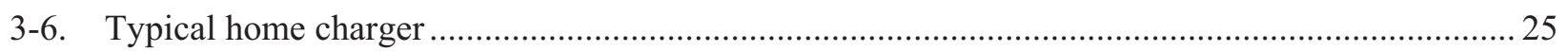

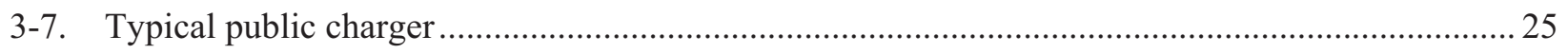

3-8. Hydrogen demand million in metric tons per year ................................................................. 27

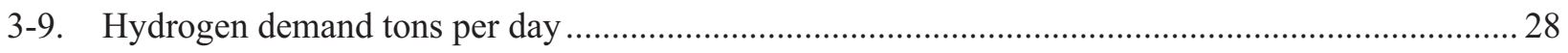

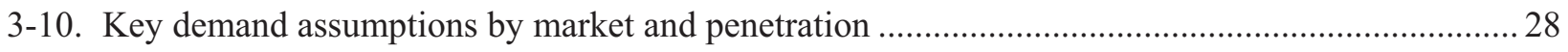

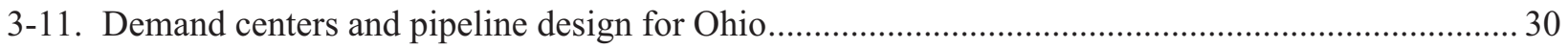

3-12. Demand centers, pipeline, and production stations in Ohio ..................................................... 30

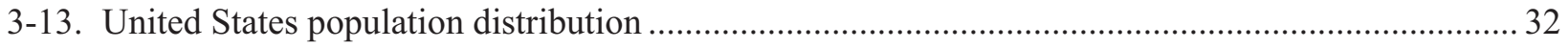

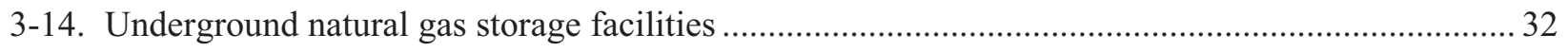

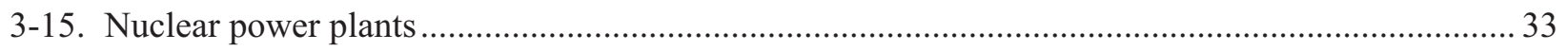

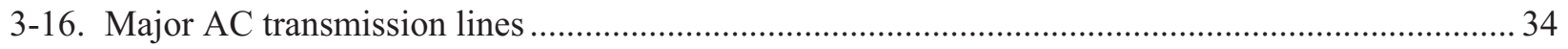

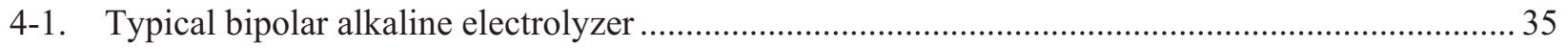

4-2. Idaho National Laboratory electrolysis model ….................................................................. 36

4-3. Arizona Public Service Alternative Fuel Pilot Plant ........................................................................ 37

4-4. Arizona Public Service Alternative Fuel Pilot Plant flow diagram .............................................. 37

4-5. Process flow diagram for large hydrogen production facility ….............................................. 42

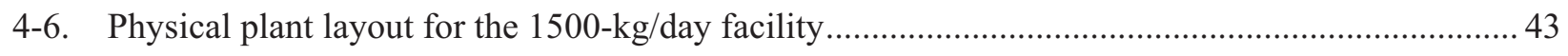

4-7. Equipment room layout for the $1500-\mathrm{kg} /$ day production facility ................................................ 44

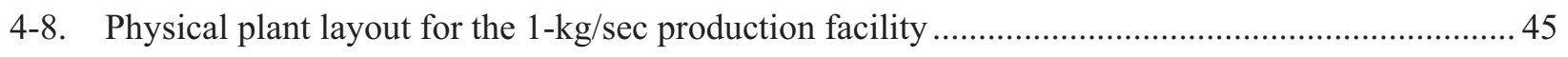

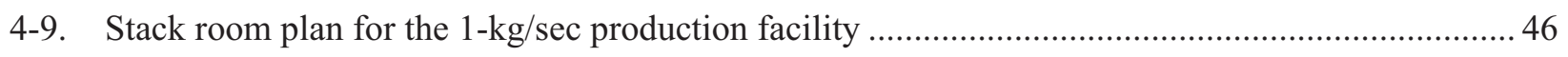


5-1. Hydrogen costs versus electricity cost for the Alternative Fuel Pilot Plant

6-1. Wind resources in the United States.

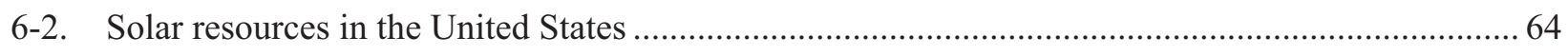

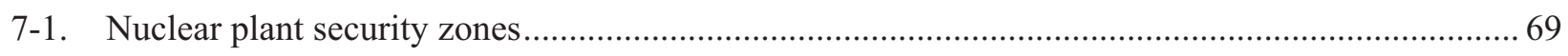

\section{TABLES}

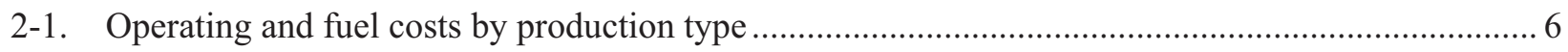

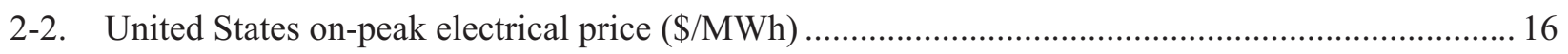

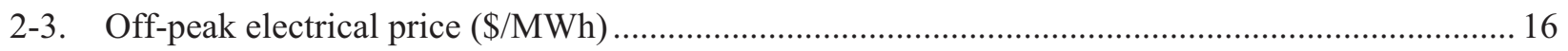

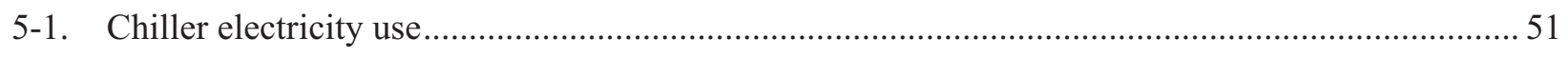

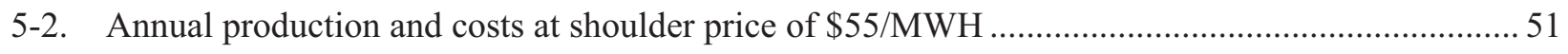

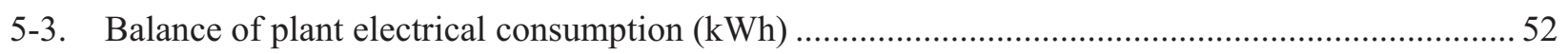

5-4. Water Requirements for the Alternative Fuel Pilot Plant ........................................................... 52

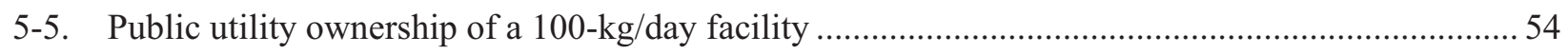

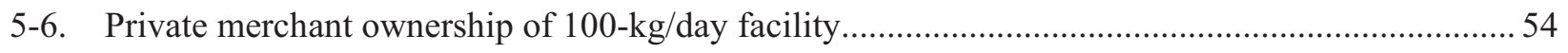

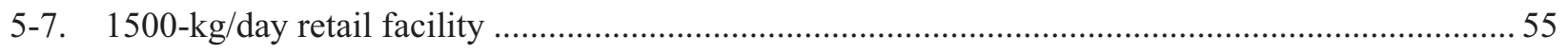

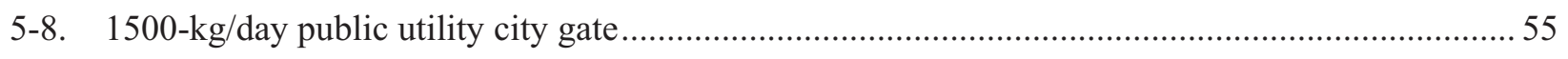

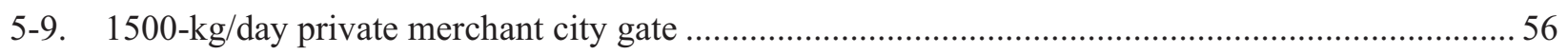

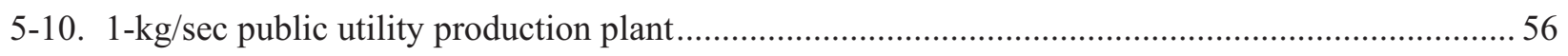

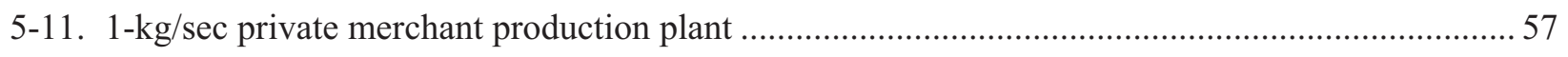

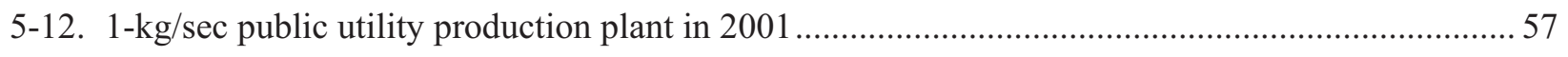

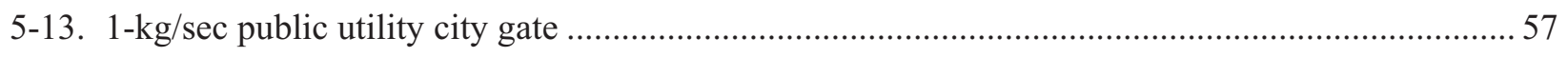

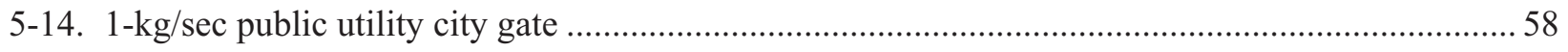

6-1. Variation in hydrogen cost across the United States ................................................................ 59 


\section{ACRONYMS}

$\begin{array}{ll}\text { AFPP } & \text { Alternative Fuel Pilot Plant } \\ \text { APS } & \text { Arizona Public Service } \\ \text { DOE } & \text { Department of Energy } \\ \text { EV } & \text { electric vehicle } \\ \text { FERC } & \text { Federal Energy Regulatory Commission } \\ \text { FSAR } & \text { final safety analysis report } \\ \text { HFCV } & \text { hydrogen fuel cell vehicle } \\ \text { HICE } & \text { hydrogen internal combustion engine } \\ \text { NGNP } & \text { Next Generation Nuclear Plant } \\ \text { NREL } & \text { National Renewable Energy Laboratory } \\ \text { NRC } & \text { Nuclear Regulatory Commission } \\ \text { PVNGS } & \text { Palo Verde Nuclear Generating Station }\end{array}$




\section{Feasibility Study of Hydrogen Production at Existing Nuclear Power Plants}

\section{INTRODUCTION}

Cooperative Agreement DE-FC07-06ID14788 was executed between the U.S. Department of Energy (DOE), Electric Transportation Applications, and the Idaho National Laboratory to investigate the economics of producing hydrogen by electrolysis using electricity generated by nuclear power.

Section 2 addresses the availability of existing nuclear power plants for use in the production of hydrogen. Electric Transportation Applications has experience working with the Palo Verde Nuclear Generating Station (PVNGS) near Phoenix and understands electricity availability and pricing. Understanding the electrical cost input to the hydrogen facility is important in making assumptions and assessments on economic performance. Although existing nuclear power plants show lower operating and fuel costs than most other high-capacity power plants, they are typically base-load units and their individual output is not available for direct use in providing power for hydrogen electrolyzers. If this low cost power is not available, then what electricity cost should be used in the modeling? This question also is addressed in Section 2. If existing nuclear power plants are not available for generating this power, what are the alternatives? New designs in nuclear power plants are underway and Section 2 addresses these designs. This information provided in Section 2 will be used in later sections.

Section 3 discusses the existing and future demand for hydrogen. When introducing hydrogen vehicles, there is always the discussion about providing the infrastructure for these hydrogen vehicles. The number of vehicles that be produced will be based on demand; demand will be dependent on the availability of hydrogen. Producers of hydrogen will be reluctant to build hydrogen plants until manufacturers deliver hydrogen vehicles and manufacturers will be reluctant to deliver vehicles unless the infrastructure is in place to provide them with hydrogen. Penetration rates for hydrogen vehicles have been introduced previously; however, the resulting demand for hydrogen has not been well publicized. Section 3 addresses these issues and provides a model for developing the initial infrastructure for a hydrogen economy, as well as identifying other models for wide-spread infrastructure.

Electric Transportation Applications has worked with Arizona Public Service (APS) in the design and operation of the APS Alternative Fuel Pilot Plant (AFPP) in Phoenix. This project recognized that operating the AFPP hydrogen electrolyzer and providing specific test and analysis information would be very valuable in designing hydrogen production facilities of much higher capacity. This information is addressed in Section 4. The AFPP is capable of producing $13 \mathrm{~kg} \mathrm{H}_{2} /$ day. To understand the breakeven hydrogen price for plants of this size and larger, it was determined that plant sizes of $100 \mathrm{~kg} \mathrm{H}_{2} /$ day, 1500 $\mathrm{kg} \mathrm{H}_{2} /$ day, and $1 \mathrm{~kg} \mathrm{H}_{2} / \mathrm{sec}\left(86,400 \mathrm{~kg} \mathrm{H}_{2} /\right.$ day) should be evaluated. Detailed design work was accomplished with quotes or industry best information used in capital cost and maintenance assessments. Specific design information on these plants and suggestions on location, plant ownership, and electrical pricing are included in Section 4.

Idaho National Laboratory provided the economic assessment model used to make the assessments of the hydrogen production plants identified in Section 4. The results of these assessments are summarized in Section 5 along with observations.

Many uncertainties are associated with hydrogen production, including issues of hydrogen storage and transportation. Electricity costs vary widely across the United States and have considerable variance not only from season to season but from year to year. An electrolyzer requires significant amounts of 
water and depending on the efficiency of the de-ionizer used to provide the input water clarity; water availability could be a major issue. Many of these risks and uncertainties are addressed in Section 6.

Combining a hydrogen facility with a new nuclear plant imposes new rules, regulations, and licensing tasks. Rules for a large hydrogen production facility are currently not well known or developed. What would be involved in trying to build a hydrogen production facility powered by a nuclear power plant? Section 7 attempts to identify the various licensing, emergency planning, environmental study, and safety assessments required of such a facility. Would it make more sense to build the hydrogen facility inside the nuclear-protected area or outside but nearby? These options make the best use of low cost power but increase the complexity of the licensing process. They also produce the hydrogen far from where the demand lies. Building the plant near the demand increases the electricity cost because of electrical transmission costs.

There are some very bright signs for this technology, specifically in the areas of refining and bringing down hydrogen production facility costs and in new smaller designs of nuclear power plants. Section 8 addresses combining these topics and recommendations for further study.

\section{GENERATION SYSTEM PLANNING AND POWER CONTRACTS}

\subsection{Power Generation}

\subsubsection{Generation Plant Diversity}

Electric utilities must provide generation resources capable of supplying its customer base through the variations of daily and seasonal energy demands. To accomplish this requirement, electrical utilities utilize various fuels, including nuclear, hydro, coal, gas, oil, wind, and solar, as the energy source for electric generation. This diversity provides the electric utility industry independence from any single source of fuel. Today's political and regulation environment encourages the use of renewable resources, such as wind and solar, for more electric generation. The capability of the electric utility industry to utilize a variety of energy sources to generate electric energy, and to move quickly to the most economical fuel resource, is an important factor in the planning of future generation resources.

The North American Electric Reliability Corporation provides an assessment of the reliability of the bulk electric power system and provides projections on future generating capabilities and trends. Figure 2-1 shows the current and planned generation capacity by fuel mix.

The projected growth in capacity is in response to anticipated increases in demand as shown in Figure 2-2. Note that these graphs provide overall United States capacity and demand figures. Locally, there can be dramatic differences in these figures as addressed in Section 2.3.

As U.S. policy and regulation efforts continue, the drive to reduce dependence on foreign oil and to reduce transportation emissions of greenhouse gasses from transportation vehicles will tend toward all electric vehicles, plug-in hybrid vehicles, fuel cell vehicles, and hydrogen combustion vehicles. The increase in electric and plug-in hybrid vehicles will increase the demand on utilities to become more efficient in power usage through Smart Grid, or similar efforts, or increase demand for more power production. The demand for fuel cell and hydrogen combustion vehicles will increase the demand for hydrogen production. The cleanest methods for hydrogen production will be through electrolysis, which again will increase the demand for electricity. These transportation demands have not been included in the capacity planning discussed above. Utility planners will closely monitor the transportation sector for trending in order to make wise and informed decision on future power generation. Public acceptance of alternative fuel vehicles will drive the demand for increased power production. 


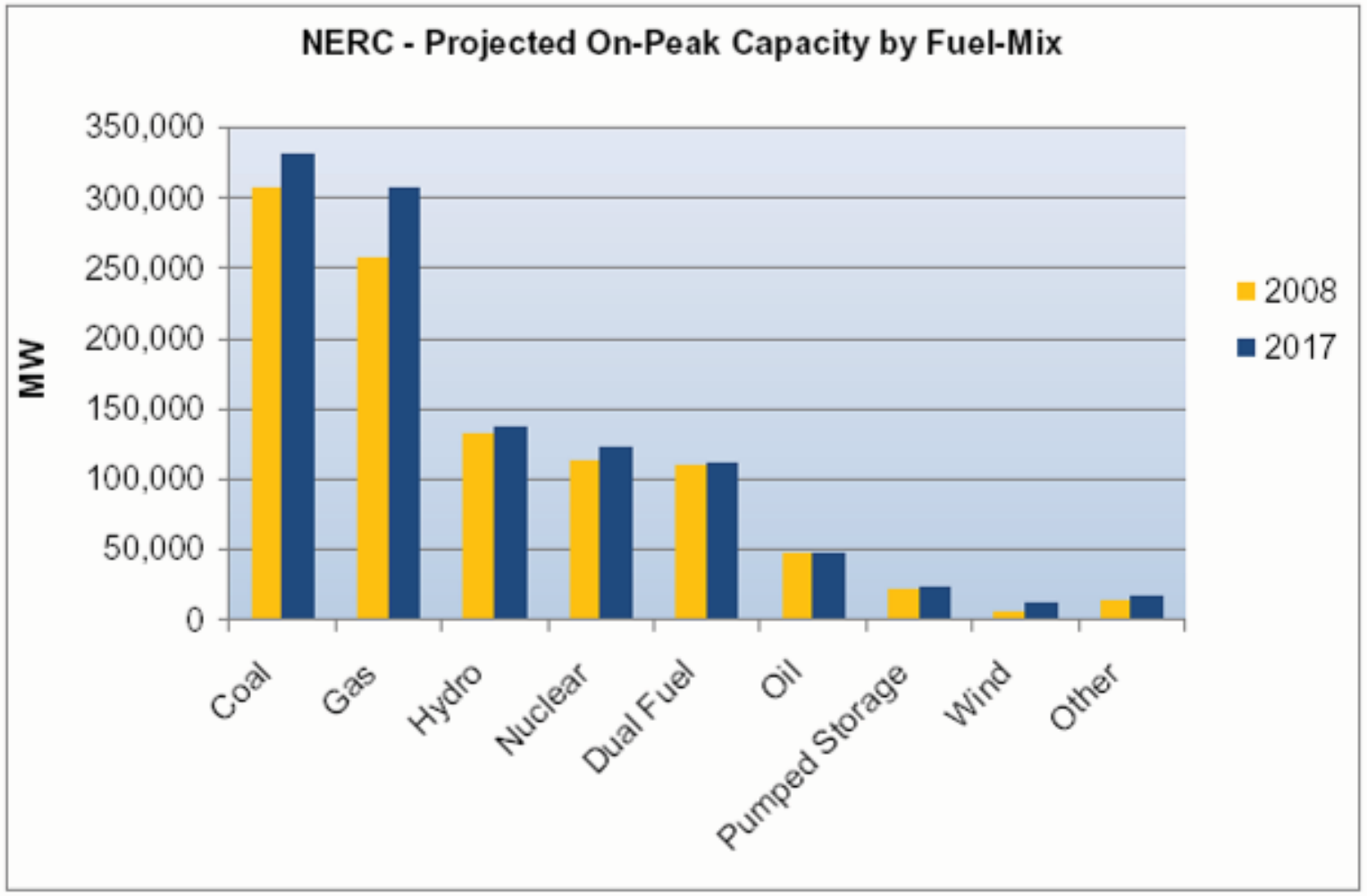

Figure 2-1. Current and projected generation capacity.

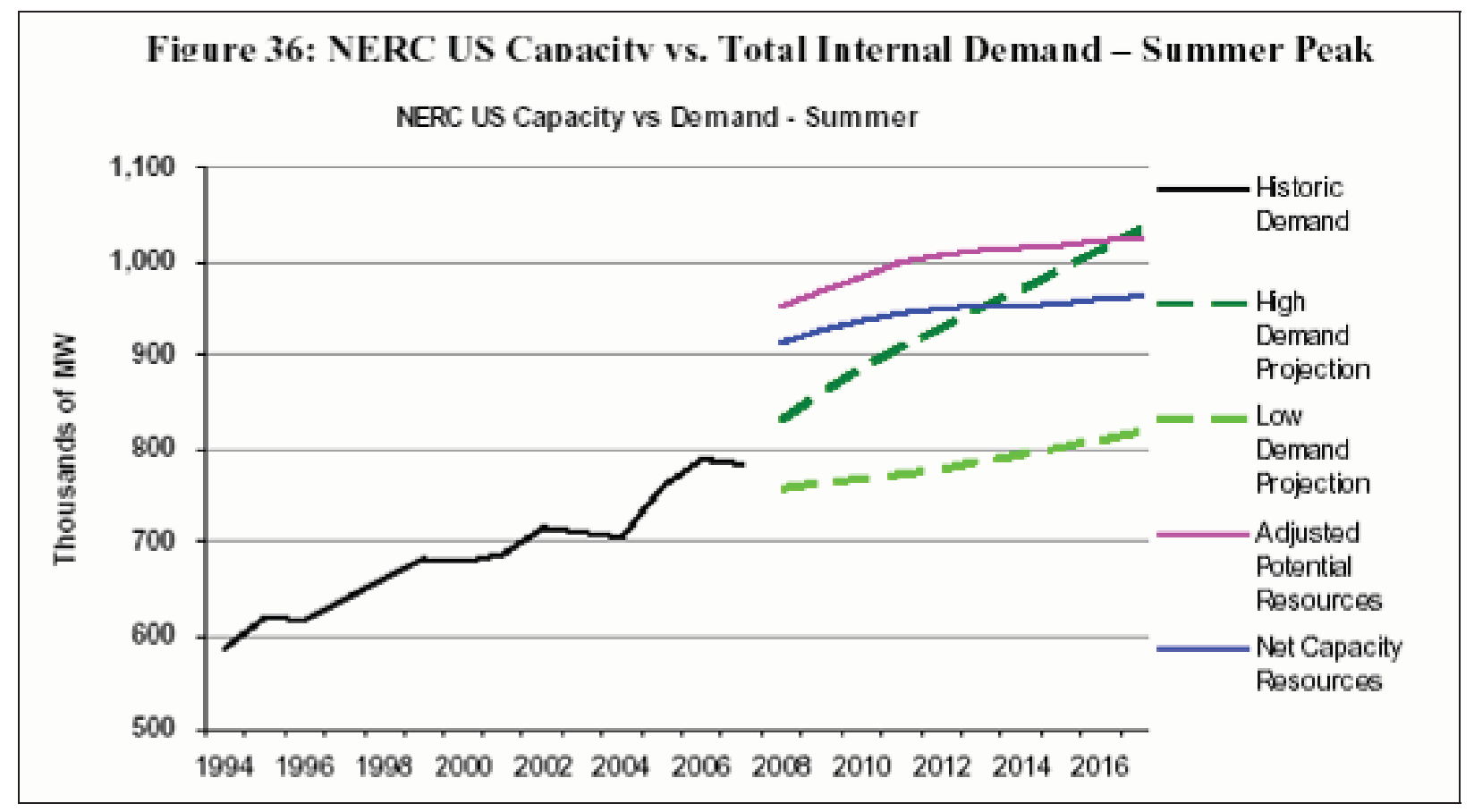

Figure 2-2. United States capacity versus total demand. 


\subsubsection{Base and Peak Demand Fulfillment}

All electric utilities must provide generation resources capable of supplying its system instantaneous peak load. From the individual consumer's home air conditioner cycling on or off to the large manufacturing center's daily start up and shut down, the peak load will have considerable variance from season to season and hour to hour. In any service territory, the utility will determine that there will be a "base" load demand that can be counted on to exist at all times and a "cycling" or "peak" load that will be in addition to the base load.

Planning for the base and peak loads involves a critical look at generation types. Some generation methods (most notable hydro, nuclear, and coal) are designed and run most economically at full capacity. Other generation types (such as oil and gas) can be cycled more easily to follow the instantaneous demand. Wind and solar energy generation is more difficult for planning purposes due to the uncertainty of production during calm versus windy days for wind energy or sunny versus cloudy days for solar. In fact, this uncertainty can become a major destabilizing effect on local electrical grids if a large fraction of the total electricity produced is produced by wind and solar. A typical day's instantaneous load can be simply illustrated by the following figures.

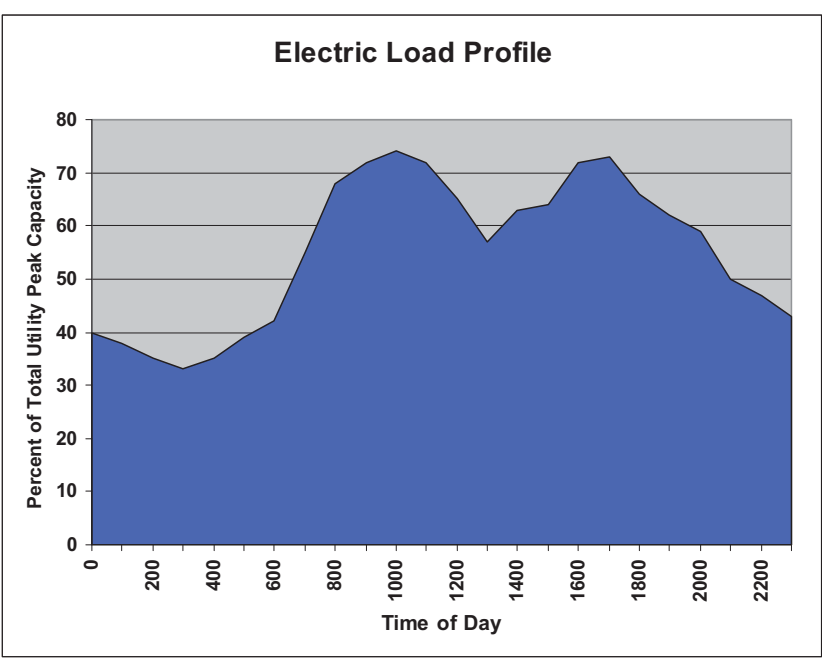

Figure 2-3. Instantaneous daily load.

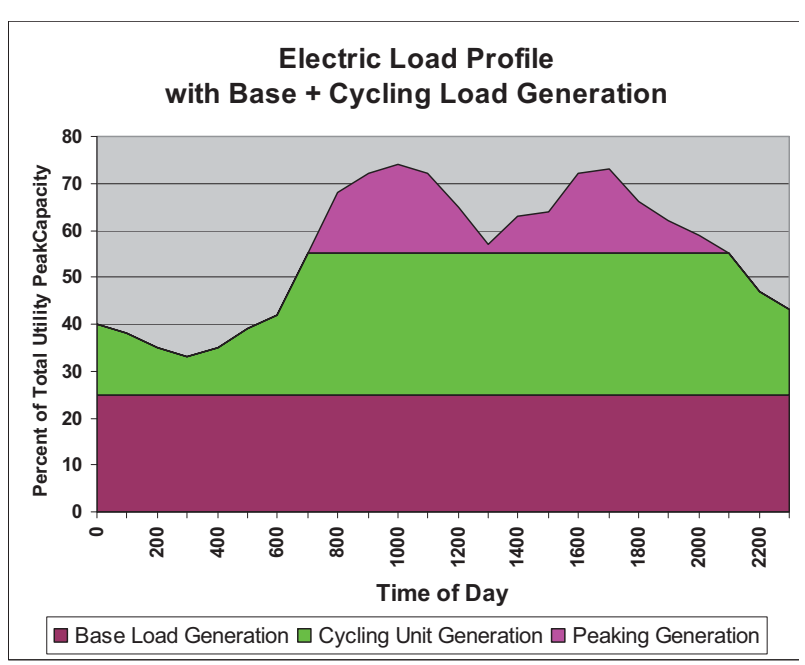

Figure 2-4. Power generation.

To allow for contingencies, this peak load is typically supplied with an excess margin of 10 to $20 \%$. As a result, a significant electric generation resource is under-utilized throughout much of the day and often much of the year. A review of the North American Electric Reliability Corporation Reliability Assessment ${ }^{\mathrm{a}}$ reveals that $954,872 \mathrm{MW}$ of generating capacity was operational in the United States in 2008. The actual energy demand in the United States for 2008 was 764,476 MW. That would indicate a total margin of $19.7 \%$. In 2017 , the capacity is planned for $1,025,579$, with a projected demand of 892,090 for a margin of $13 \%$. Again, this margin varies throughout the United States. Although margins are necessary to provide generating capabilities in unusual circumstances (i.e., unusually hot summer), the generating capability does provide for significant unused capacity that could be used for hydrogen production, especially in times of off-peak demand. A simplified illustration is shown in Figure 2-5.

\footnotetext{
a North American Electric Reliability Corporation, “2008 Long Term Reliability Assessment,” October 2008.
} 
In a full hydrogen economy, additional base loading for hydrogen generation may be possible to effectively provide additional capacity. In this situation, cycling and peaking generation would be replaced by base-loaded generation with the hydrogen production cycle to offset other loads as simplified in Figure 2-6. The economics of this approach will be explored later in this report.

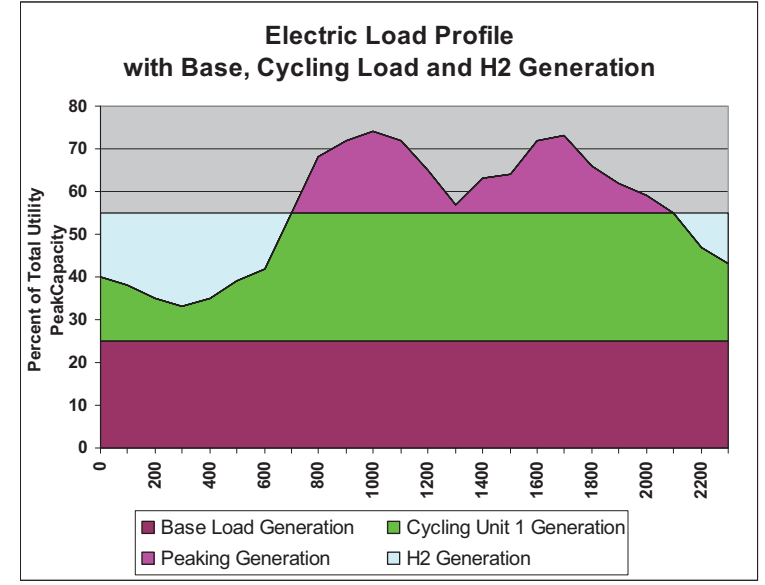

Figure 2-5. Load with hydrogen production.

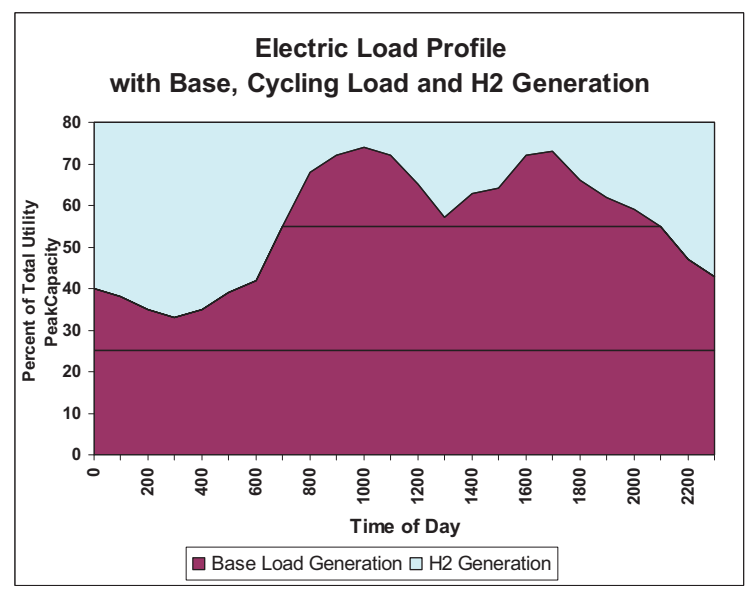

Figure 2-6. Load with full hydrogen production.

\subsection{Power Plant Resources and Priorities}

\subsubsection{Price of Electricity}

Hydrogen is abundant in nature but is found primarily in stable compounds. Significant energy is required to break the compounds to produce the hydrogen in usable form. An energy source to produce the hydrogen that does not generate greenhouse gases and has the potential to produce hydrogen at costs competitive with gasoline is essential for long-term public acceptance. Although there are energy sources today for producing this hydrogen, meeting the above-mentioned goals means the energy source will most likely be electricity and the generation process electrolysis. Therefore, the price of electricity sold to the electrolyzer user is a cost in the production of hydrogen. In fact, as shown later in the report, the price of electricity is a significant factor in the cost of producing hydrogen.

2.2.1.1 Price as Function of Plant Type. The price of electricity is dependent on its cost of production. As noted above, electric utilities operate a variety of power plant types to meet their production requirements. Base load plants should provide low stable costs of operation but may not be flexible enough or economical to vary output power as loads change. Peaking generating units need to be flexible in load following and in startup and shutdown, but may not be the lowest cost units to operate. Capital costs and fuel costs vary widely between generation types.

The Federal Energy Regulatory Commission (FERC) requires major electric utilities to submit an annual report using FERC Form 1. APS operates a mix of production types in Arizona and the information found in Table 2-1 was obtained from the 2005 report. 
Table 2-1. Operating and fuel costs by production type. ${ }^{\mathrm{b}}$

\begin{tabular}{|c|l|c|c|c|c|c|c|}
\hline \multicolumn{2}{|c|}{ FERC Form 1 Line \# \& Description } & Palo Verde & $\mathbf{4 C - 1 2 3}$ & $\mathbf{4 C - 4 \& 5}$ & Red Hawk & Yucca & Ocotillo \\
\hline 1 & Type of Plant & Steam & Steam & Steam & CC-GT & CT & Steam \\
\hline 36 & Type of Fuel & Nuclear & Coal & Coal & Gas & Gas & Gas \\
\hline 6 & Maximum Plant Output (APS MW) & 1,111 & 566 & 229 & 1,029 & 116 & 209 \\
\hline 18 & Installed Capacity $(\$ / k W)$ & 2085.45 & 543.89 & 637.05 & 397.53 & 129.47 & 228.11 \\
\hline 44 & Plant Heat Rate (BTU/kWh) & 10,636 & 10,858 & 9,857 & 7,457 & 17,936 & 12,270 \\
\hline 35 & Production Expense (\$/kWh) & 0.0230 & 0.0233 & 0.0193 & 0.0481 & 0.1019 & 0.1496 \\
\hline 42 & Fuel Cost (\$MMBTU) & 0.539 & 1.405 & 1.454 & 5.900 & 4.307 & 7.384 \\
\hline 43 & Fuel Cost $(\$$ MWh) & 5.73 & 15.26 & 14.33 & 44.00 & 77.25 & 90.60 \\
\hline
\end{tabular}

The lowest operating and fuel costs are in nuclear and coal plants, whereas the highest operating and fuel costs are in gas plants. The FERC report for Idaho Power shows the Bliss Hydroelectric Plant expenses per $\mathrm{kWh}$ at $\$ 0.0058$. It makes the greatest economic sense and best value to utility customers to be operating these types of units at their maximum capacity at all times, so they are used as base load units. In most cases, this means that there will be little unused capacity available from the nuclear plants in today's electricity supply market.

Electricity price is set by the utility within the constraints of local governing and regulating authority. Rate structures of the utilities can be quite complex and vary widely from one section of the country to another. The price charged to a customer can be a fixed rate or a negotiated rate that is generally reserved for large commercial customers. Some commercial customers are provided special rates with the condition that their service may be reduced by the utility if necessary during peak demand times. Utilities with excess capacity will often sell electricity to each other or other commercial users based on specific needs and availability.

On any given day, the price of electricity will be driven by (1) the generating resources available, (2) load on these resources, and (3) the marginal cost of generating the next MWhr of electricity from the available resources. A generation resource owner (i.e., electric utility or independent power producer) will attempt to maximize the price at which excess generating capability is sold. However, the price is governed by supply and demand, with generating resource owners (supply) bidding on sales to wholesale electricity consumers (demand). When supply significantly exceeds demand, generation resource owners typically will be willing to bid a price as low as their marginal cost of generation for the generating resource supplying the electricity (this price is typically very near the cost of fuel for the generating unit supplying the electricity). Depending on the time of year and the total generation mix available, the marginal generating resource may range from a natural gas-fired thermal generation to hydro generation, with marginal costs ranging from over $\$ 100 / \mathrm{MWhr}$ for the combustion turbine to only a few dollars per MWhr (and sometimes free) for hydro generation.

From the utility's perspective, electricity price is not its production cost but is the opportunity cost of lost sales. Therefore, the cost of generating hydrogen is based to a large extent on the availability and cost of electricity in the area. This fact has a significant impact on the economics of large-scale hydrogen production. These impacts are addressed later in this report.

2.2.1.2 Nuclear Plant Base Loading. As of December 31, 2007, there were 104 commercial nuclear plants located in 65 separate sites licensed by the Nuclear Regulatory Commission (NRC) to operate in the United States. Ninety-seven of these units are more than 20 years old. These units continue

${ }^{\mathrm{b}}$ APS FERC Form 1 2005/Qtr4, May 2006. 
to run as base-loaded units and only during refueling or unusual circumstances do they operate at less than full-licensed capacity. Therefore, electricity output of current nuclear reactors generally is not available for sale.

As of September 30, 2008, NRC has received 20 new license applications. Their actual construction and output production is many years away with much of this production planned for the year 2016 as shown in Figure 2-7. Therefore, it is not currently accurate to consider the nuclear plant operating costs as input to a hydrogen generation cost model.

\section{Figure 13. Planned Capacity Additions 2009-2017}

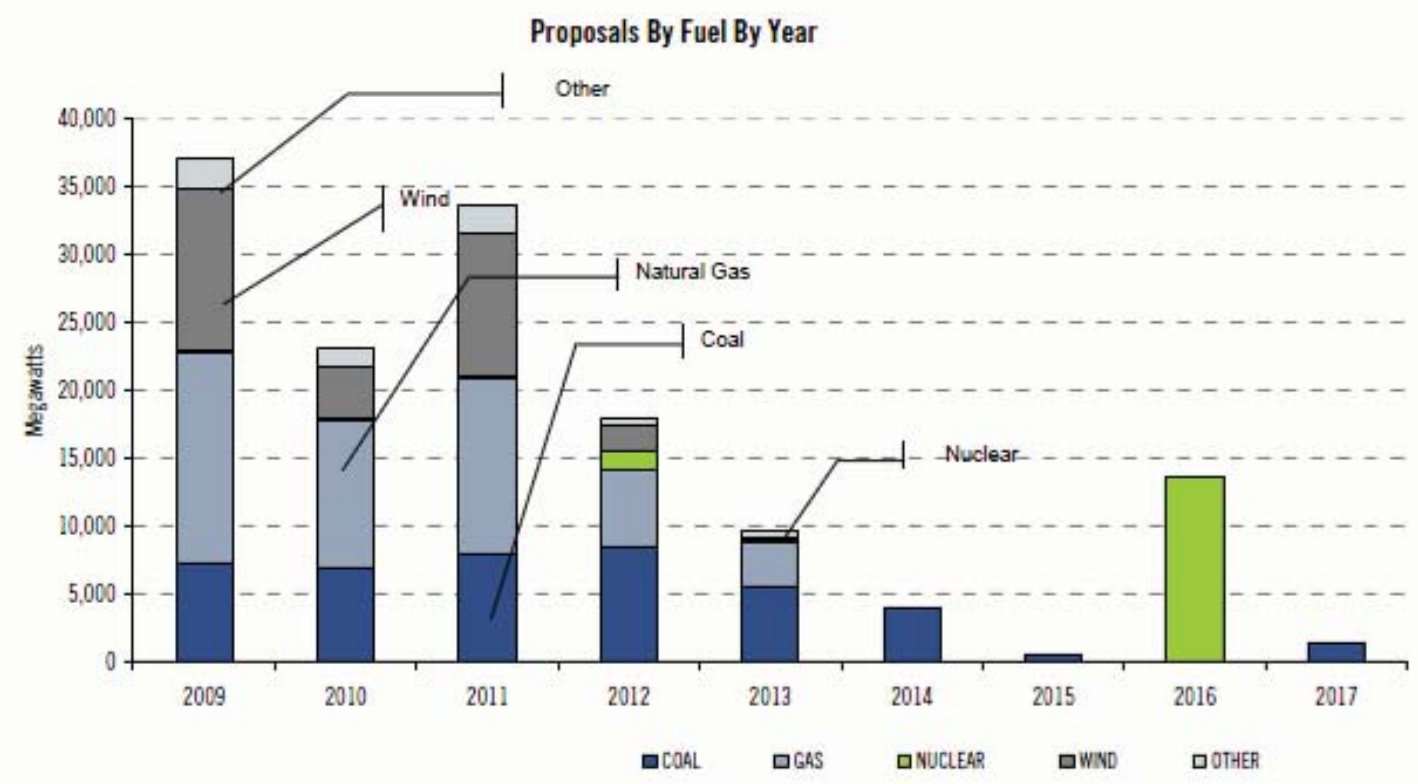

Source: Citi Investment Research and Analysis

Figure 2-7. Planned capacity additions. ${ }^{c}$

\subsubsection{Nuclear Plant Availability for Hydrogen Production}

2.2.2.1 As a Mix of Production Sources. Nuclear plants currently provide generation capability as part of the generation mix as shown in the APS FERC report. When they do, they reduce the local electrical cost. An example of this is the PVNGS switchyard, which is discussed further in Section 2.3.

2.2.2.2 Dedicated Nuclear Plant Design using Advanced Designs. Although nuclear resources may not exist today to support large-scale hydrogen production directly, construction and operation of new nuclear reactor designs may be able to match the growing demand for hydrogen. Challenges that face the new generation of nuclear plants include reducing the capital costs from about $\$ 1,500$ per kWe of generating capacity in 2002 to 2004 to about $\$ 1,000$ per kWe, which makes these

${ }^{\mathrm{c}}$ Citigroup Global Markets, Spark Spread Biweekly, March 23, 2009. 
nuclear plants competitive with the combined-cycle natural gas plants. In addition, the licensing and construction process must be shortened to about 3 years to keep financing costs to acceptable levels.

To achieve the cost objective, nuclear engineers are seeking to attain higher thermal efficiencies by raising operating temperatures and simplifying subsystems and components. Speeding up plant construction will require standardization of plant designs, factory fabrication, and certification procedures; division of plants into smaller modules that avoid the need for onsite construction; and use of computerized assembly-management techniques. In this way, the building work can be verified in virtual reality before it proceeds in the field. ${ }^{\mathrm{d}}$

Current estimates, however, show that nuclear costs are actually headed in a higher direction (see Figure 2-8).

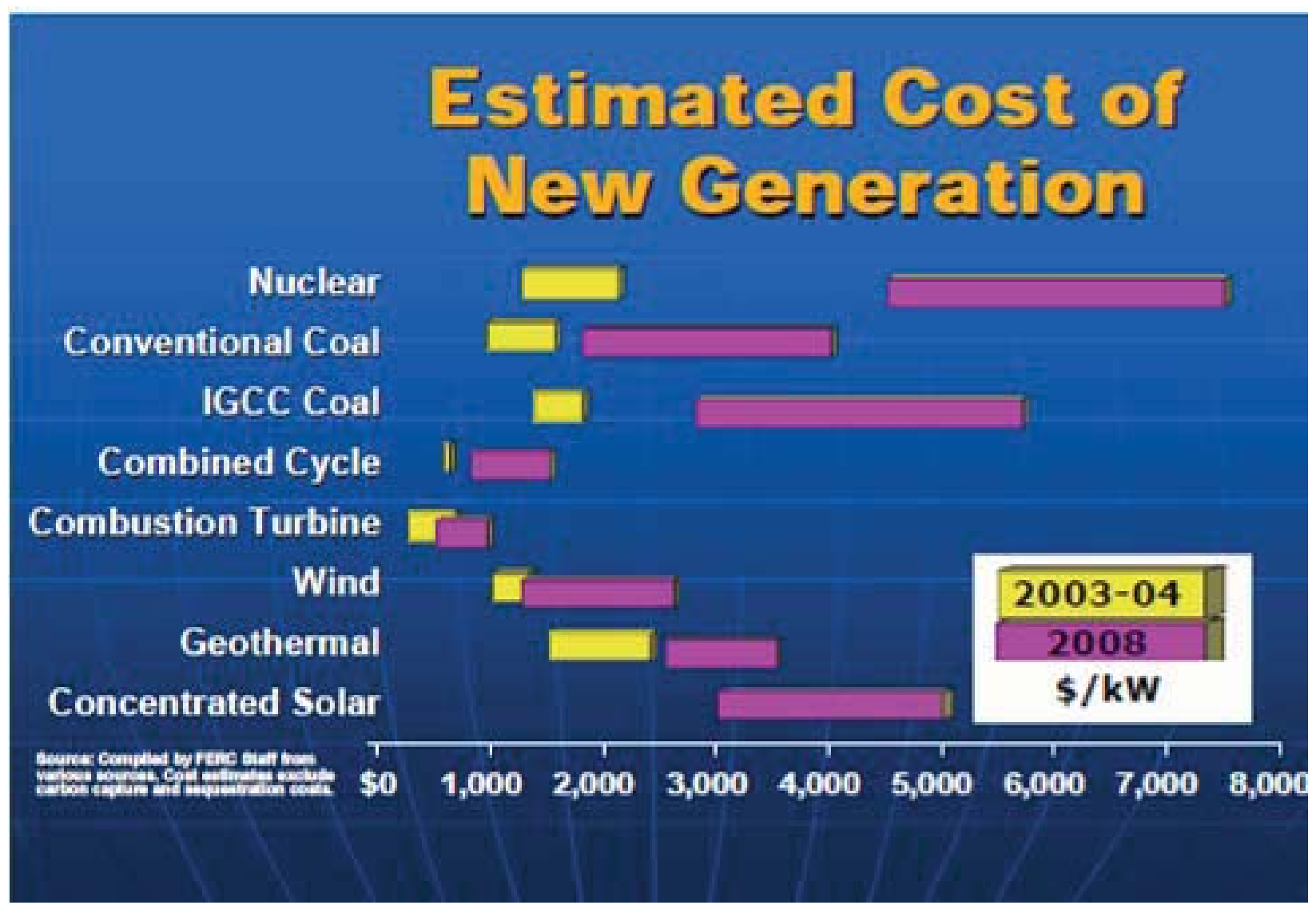

Figure 2-8. Estimated cost of new generation. ${ }^{\mathrm{e}}$

Timelines for such growth are presented later, but a short discussion of possible new reactor designs follows here.

The early nuclear reactors were small but grew in size through the 1960s, 1970s, and 1980s. The smallest commercial reactor in the United States is Fort Calhoun 1 rated at $476 \mathrm{MWe}$, which entered commercial operation in 1974. The largest is the 1335 MWe Palo Verde Unit 2, which entered

\footnotetext{
d Lake, Bennett, and Kotek, “Next-Generation Nuclear Power,” Scientific American, Energy's Future, January 2002.

${ }^{\mathrm{e}}$ FERC website, www.ferc.gov, Increasing Costs in Electric Markets, June, 2008.
} 
commercial operation in 1988. During the same timeframe, a significant number of smaller reactors were built especially for naval use.

Generally, modern small reactors for power generation are expected to have greater simplicity of design, economy of mass production, and reduced siting costs. Many are designed for a high level of passive or inherent safety in the event of malfunction. Some are conceived for areas away from transmission grids and with small loads; others are designed to operate in clusters in competition with large units. ${ }^{\mathrm{f}}$

Planning for future hydrogen generation may match small nuclear reactors to hydrogen generation plants for specific market penetrations. Steam methane reforming is currently the most economical process for hydrogen production. It requires temperatures in the range of 800 to $850^{\circ} \mathrm{C}$, which is usually provided by burning of natural gas. A very high temperature reactor is an advanced design reactor that is expected to produce a coolant temperature of $1000^{\circ} \mathrm{C}$. The benefit of this would be steam methane reforming without burning of fossil fuels.

Very high temperatures or high-efficiency electricity is required to drive the most promising hydrogen production processes. Advanced nuclear systems must be developed that provide the necessary high heat to enable these processes (Figure 2-9). The DOE Generation IV Nuclear Systems Initiative (Generation IV) is developing options to address this need with international collaboration. The focus of this effort is the very high temperature reactor, which would provide the advanced nuclear heat source for demonstrating nuclear hydrogen and electricity production. ${ }^{\mathrm{g}}$

2.2.2.3 Hydrogen Intermediate and Peak Electrical System. Following the significant swings in electrical demand on a daily, weekly, and annual basis takes a real-time, power-generating strategy. Few options exist for generating power during off-peak times and storing that energy for later use to follow the peaks. Two basic options are pumped storage and compressed air. Power generated in off-peak times pumps water from a low reservoir to an upper reservoir or runs air compressors to store high-pressure air. During the subsequent peak demand, water is discharged from the upper reservoir to the lower and power is generated through hydro-electric generation or the compressed air is released to power turbine generators. These are both short-term solutions because the amount of energy that is stored is limited. No real long-term storage solutions exist for electricity that might, as an example, use power generated in winter for electrical peaking in summer.

The Hydrogen Intermediate and Peak Electrical System is intended to accomplish that energy storage. The conceptual design includes a nuclear reactor(s) that is base loaded and supplies more energy than required during demand lows. Its output provides the demand loads, and excess capacity is used to generate hydrogen and oxygen through electrolysis. The hydrogen and oxygen are stored locally.

Electricity is produced by an advanced steam turbine with a burner that combines $\mathrm{H}_{2}, \mathrm{O}_{2}$, and water to produce $1500^{\circ} \mathrm{C}$ steam, which serves as feed to a special high-temperature steam turbine with actively cooled blades (Figure 2-10). No expensive boiler is required. ${ }^{\mathrm{h}}$

Underground caverns provide storage volume for hydrogen and oxygen in a manner similar to that used for compressed natural gas. The stored hydrogen and oxygen can be used in the next few hours for

\footnotetext{
f World Nuclear Association, “Small Nuclear Power Reactors,” February 2009, www.world-nuclear.org.

g “Nuclear Hydrogen R\&D Plan,” Department of Energy, Office of Nuclear Energy, Science, and Technology, March 2004.

${ }^{\mathrm{h}}$ Charles W. Forsberg, Economics of Meeting Peak Electrical Demand Using Nuclear Hydrogen and Oxygen, Oak Ridge National Laboratory, June 2007.
} 
following the daily load or stored for much longer periods to allow for seasonal variations in peak demand. Challenges exist in this approach in that, while hydrogen gas is very light and will quickly disperse if leaked, oxygen gas is much heaver and tends to remain near the surface in a dangerous combustible environment.

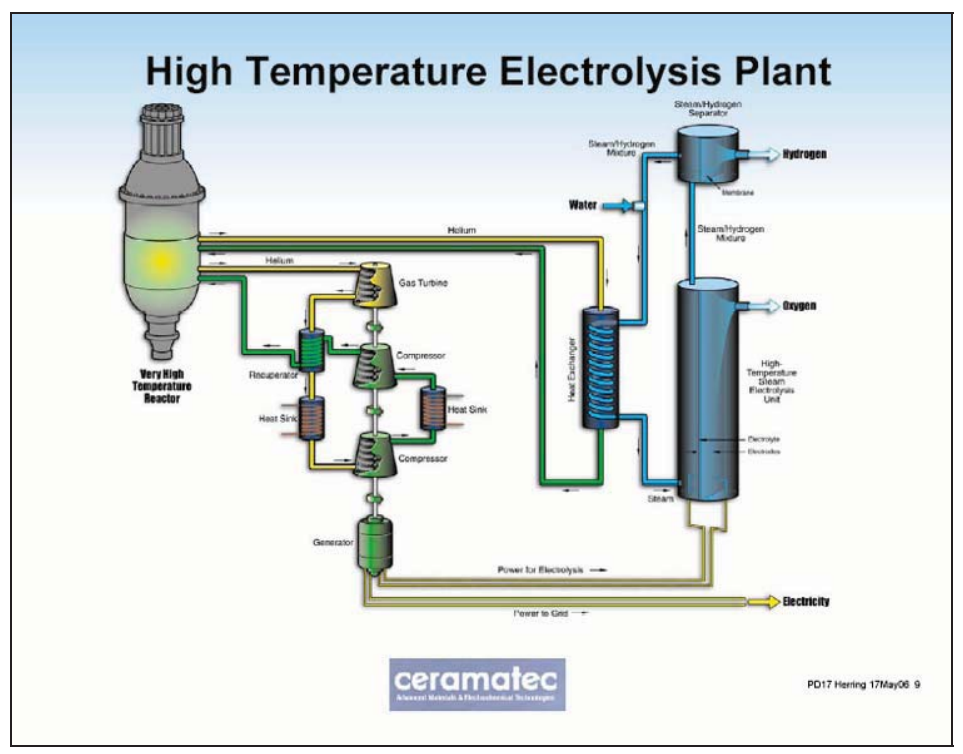

Figure 2-9. High-temperature electrolysis plant. ${ }^{\mathrm{i}}$

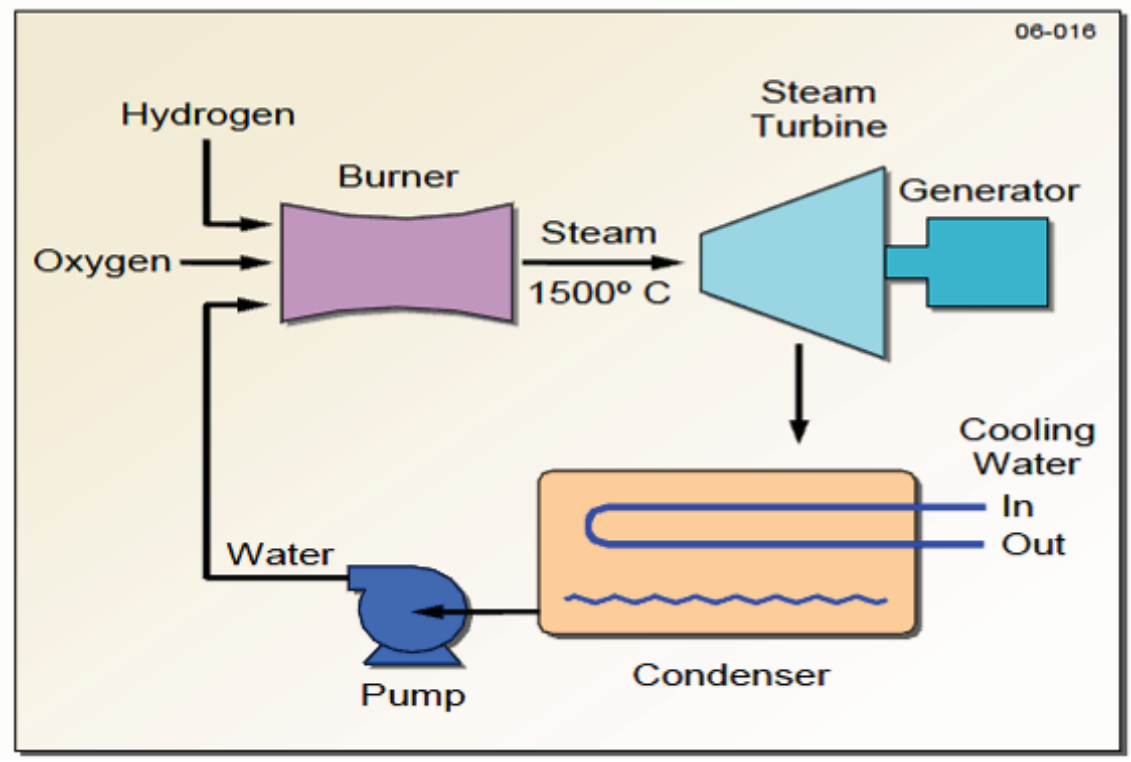

Figure 2-10. Schematic of oxygen-hydrogen-water steam cycle. ${ }^{j}$

\footnotetext{
i "Laboratory-Scale, High-Temperature Electrolysis System," 2006 Department of Energy Hydrogen, Fuel Cells and Infrastructure Technologies Program Review, May 2006.

${ }^{\mathrm{j}}$ ibid
} 
Other techniques for chemical storing of hydrogen are in development. The hydrogen generated is combined with other chemicals for long-term stable storage. When required, the hydrolysis reaction releases hydrogen through a chemical reaction and the chemical by-product is recycled for further hydrogenation.

\subsection{Wholesale Power Trading at the Palo Verde Nuclear-Generating Station Switchyard}

APS operates PVNGS, which is located in Maricopa County, Arizona (approximately 55 miles west of downtown Phoenix). The PVNGS (Figure 2-11) is a three-unit, 3,800-MWe, pressurized water reactor site. In 2002, PVNGS generated 30.9 billion kilowatt-hours of electricity at a production cost of 1.33 cents per kilowatt-hour, compared with an average production cost of 2.53 cents per kilowatt hour for the rest of the southwest energy market. ${ }^{k}$ PVNGS Unit 3 set a world record for generation in 2002, producing 11.1 billion kilowatt hours. ${ }^{1}$

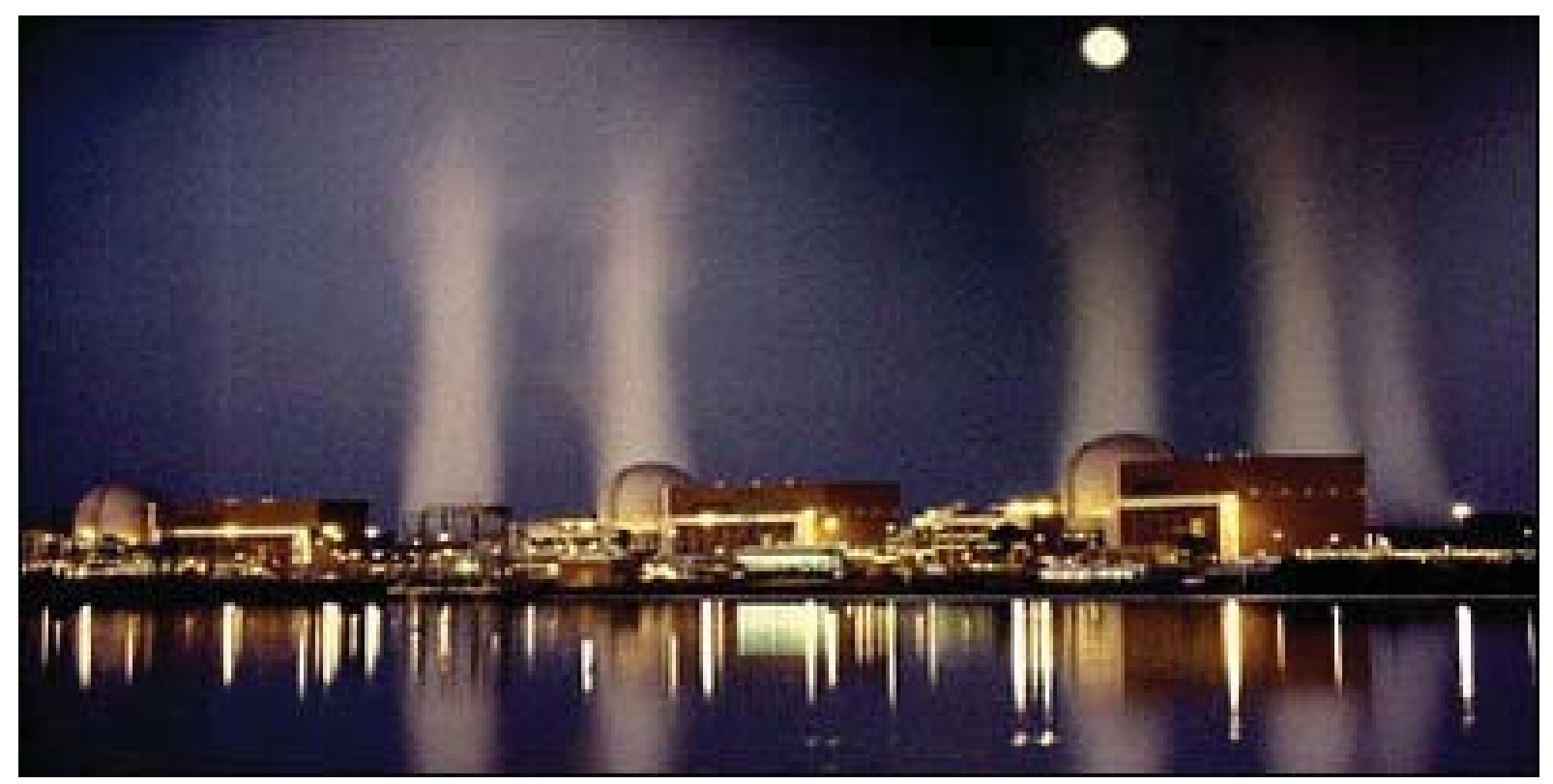

Figure 2-11. Palo Verde Nuclear Generating Station.

The PVNGS electrical switchyard was built to support the 3,800-MWe output of the PVNGS generating plant. Since commercial operation of PVNGS in 1989, several diverse power resources have developed near the PVNGS switchyard, making it an important delivery and transaction location for wholesale power markets. The switchyard connects five 500-kilovolt lines and has the capability to transfer almost 9,500 MWe to various connected transmission grids in the region. Area control operators connected to the PVNGS switchyard include the major southern California and southwestern utility systems.

Transmission facilities at PVNGS offer access to generating resources and demand centers throughout the southwest and southern California, and can serve markets in the Pacific Northwest and northern Rockies. One of the principal power transfer paths in the west is from the coal, nuclear, and

\footnotetext{
${ }^{\mathrm{k}}$ Economic Benefits of Palo Verde Nuclear Generation Station, Nuclear Energy Institute, November 2004.

${ }^{1}$ ibid.
} 
gas-fired generators of the desert southwest to the high load and population areas of southern California. Location, availability, and cost of these resources are critical factors in dispatch of existing generation and development of new generation resources. As a result, the PVNGS switchyard is used for delivery of wholesale power traded between electric utilities and is used as the basis for an electricity price index published by Dow Jones.

The volume of power that flows through Palo Verde, the wide area it serves, and the diversity of its supply and demand often result in volatile pricing. To help market participants better manage their risk and mitigate counterparty credit risk, the exchange provides a financially settled futures contract that is based on the average peak day price for the electricity market hub at Palo Verde reflected in the Dow Jones Palo Verde electricity index. ${ }^{\mathrm{m}}$

As noted in Sections 2.2.1.2 and 2.2.1.3, direct output from any existing nuclear plant is generally not available for sale. However, markets where nuclear power does provide a generating resource can benefit from the lower costs associated with that generation. For that reason, the PVNGS switchyard can provide a more accurate price for electricity in the current market than the price from PVNGS alone. With power trading at the PVNGS switchyard reported by Dow Jones, a significant body of data exists detailing the historical cost of delivered power.

On-peak and off-peak electric price information for 2001 and 2006 is shown in Figures 2-12 and $2-13$. The volatile nature of pricing is clearly illustrated between these 2 years and even from one season to the next.
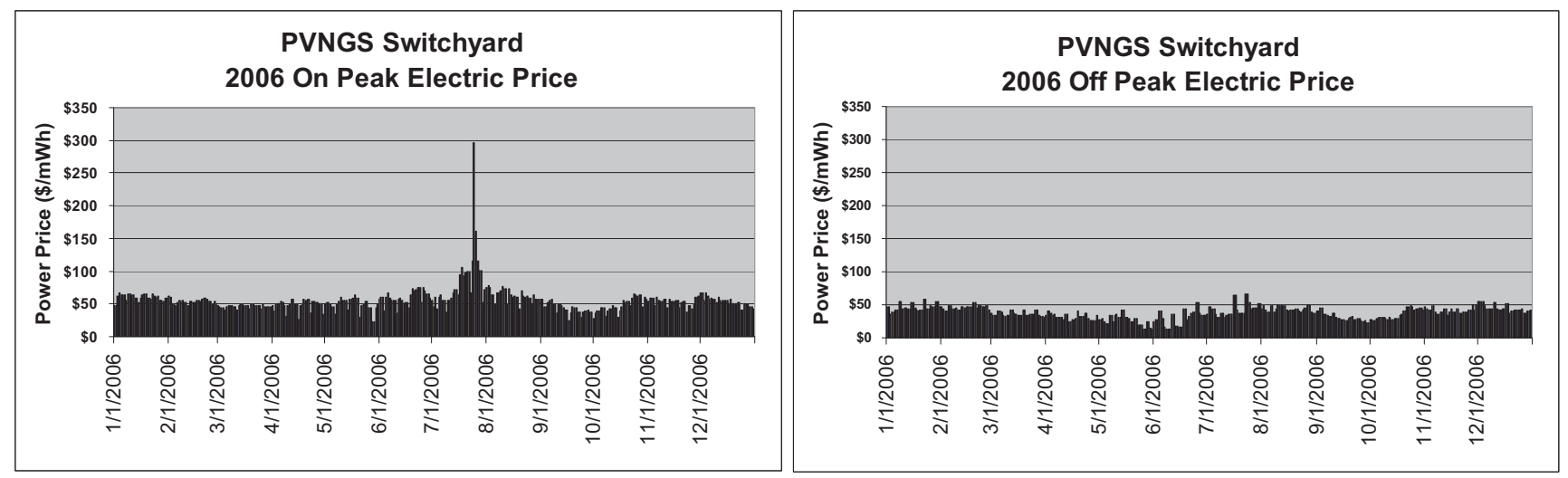

Figure 2-12. 2006 On-peak/off-peak electric price at the Palo Verde Nuclear-Generating Station switchyard.

\footnotetext{
${ }^{\mathrm{m}}$ Dow Jones Palo Verde Electricity Index Futures, New York Mercantile Exchange, Inc. 2008, www.nymex.com/DP_desc.aspx.
} 

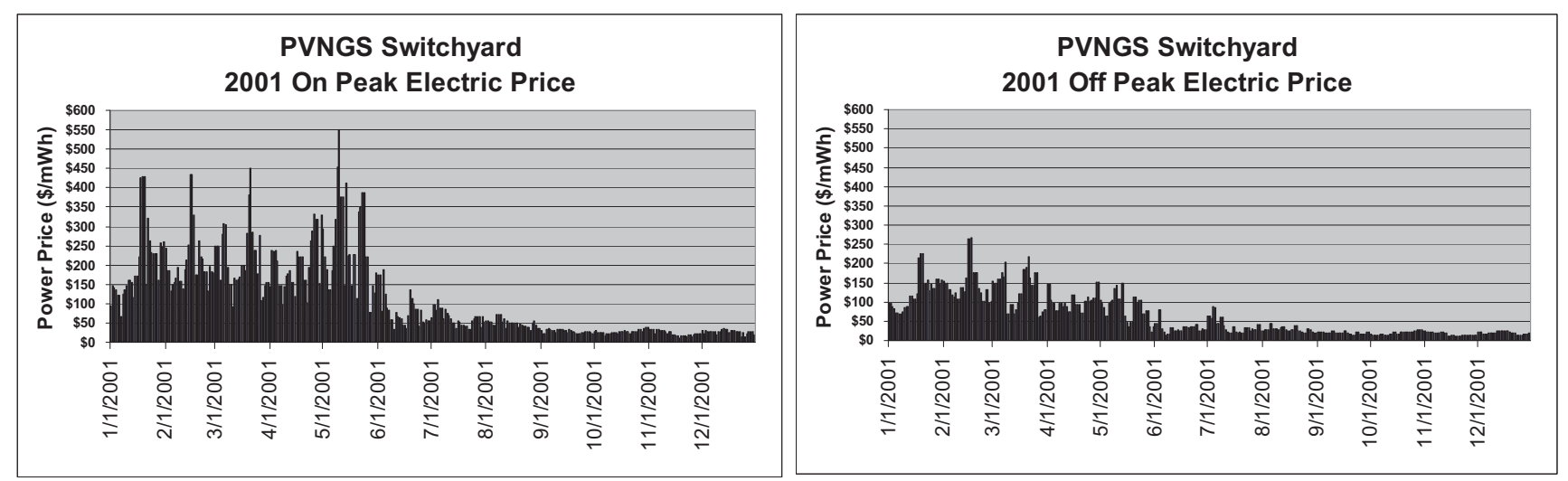

Figure 2-13. 2001 On-peak/off-peak electric price at the Palo Verde Nuclear-Generating Station switchyard.

\subsection{Electricity Price as Hydrogen Production Cost}

The driving cost factor for electrolysis production of hydrogen will be the price of the electricity provided. That price may differ on any given day if "sold" to a hydrogen producer affiliated with the utility or to an independent hydrogen producer. However, because the price is really the opportunity cost of lost sales, the difference to either the utility or the independent will be minor.

A large-scale hydrogen producer will likely negotiate rates with the local utility or power provider. As part of that negotiation, the utility will review the same pricing information to set the negotiated rate. Unless the large-scale project requires the utility to increase its base load generation and it can do so with lower cost generation, the Dow Jones index remains a valid indicator of electric price. Interest of the utility in developing additional low operating cost generation (such as nuclear) as a specific strategy for generating hydrogen will be discussed later in this report. Therefore, the discussion on price, especially in the southwestern United States, will center on pricing at the PVNGS switchyard.

Demand for hydrogen, along with the cost of electricity, will set the parameters for hydrogen plant operation. Hydrogen produced with low electricity cost will be more attractive than hydrogen produced with high electricity cost. The hydrogen producer will be faced with three possible alternatives for electric cost:

- $\quad$ Production plant is operated during off-peak hours only (i.e., summer mode)

- $\quad$ Production plant is operated at all times of the day (i.e., winter mode)

- $\quad$ Production is operated to maximize hydrogen production but only when electricity can be purchased at less than a preset price (i.e., shoulder mode).

Appendix B provides electricity costs for the PVNGS switchyard delivery during peak and off-peak periods for 2006 .

Summer mode in the PVNGS switchyard market restricts hydrogen plant operation to 8 hours per day from 10 p.m. to 6 a.m. plus Sundays and six holidays. Off-peak hours represented $44.1 \%$ of the total hours available in 2006. The average price for off-peak electricity for 2006 was $\$ 37.96$.

The average price for the winter mode of operation in 2006 was $\$ 49.41$. 
Shoulder mode looks at a combination of the two in a manner that selects a maximum price to be paid for the electricity and determines availability of power at that maximum for the entire year. If the hydrogen producer determined that they would only buy electricity if the cost was $\$ 45$ or less, a total 3,312 hours of production (284 days off-peak and 65 days on-peak) time would have been available in 2006. This represents $38 \%$ of the total time available in 2006. Because some of the on-peak days show a price less than the $\$ 45$ and some of the off-peak days show a price greater than $\$ 45$, the overall average price of electricity during this time is $\$ 35.81$. By selecting the maximum price to be paid, the average price and availability can be determined (Figure 2-14).

It can be seen in Figure 2-14 that availability of electricity breaks sharply over a narrow range of maximum price. This is indicative of the cost of generation for marginal generating resources connected to the PVNGS switchyard. For year 2006, assuming fuel cost of the average marginal generating resource is represented by fuel cost required to make purchased electricity available $50 \%$, the fuel cost of the average marginal generating resource was $\$ 48.50 / \mathrm{MWh}$. In Table 2-1 (i.e., the FERC report), it can be seen that the APS Red Hawk combined-cycle gas turbine fuel cost is $\$ 44.00 / \mathrm{MWh}$ and the Ocotillo gas fired thermal plant fuel cost is $\$ 90.60 / \mathrm{MWh}$. Therefore, it is apparent that marginal generation in the year 2006 was provided predominately from the combined-cycle gas turbine plants typical of the APS Red Hawk plant, and at times from more expensive generation resources typical of the APS Yucca Plant gas-fired combustion turbine or the APS Ocotillo gas-fired thermal plant.

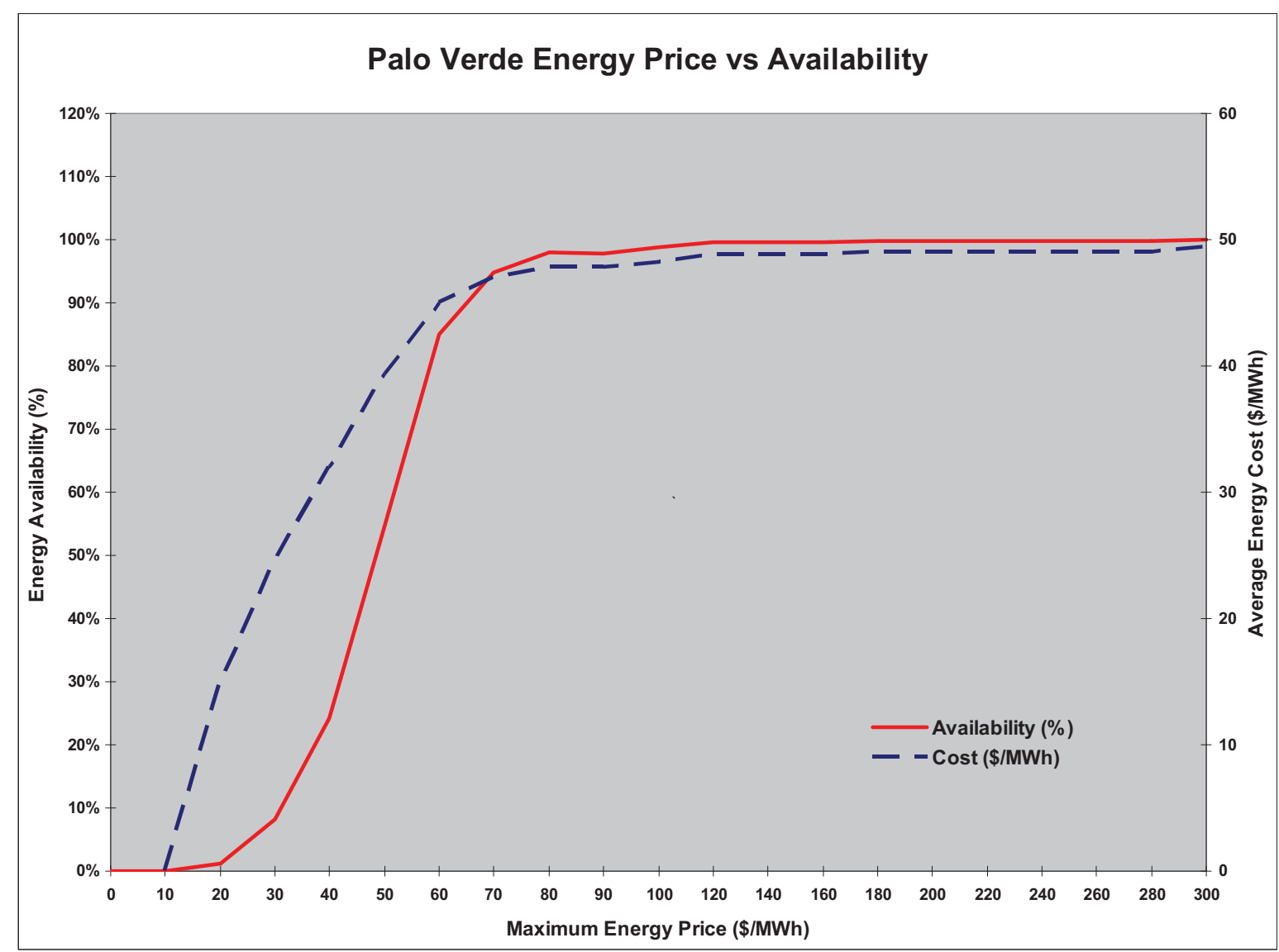

Figure 2-14. The Palo Verde Nuclear-Generating Station switchyard 2006 energy price versus availability. 
Setting the maximum price at $\$ 48.50 / \mathrm{MWh}$ provides $50 \%$ availability (4,368 hours of operation). The average energy cost is $\$ 38.45 / \mathrm{MWh}$. Should the hydrogen producer require $60 \%$ availability (5,232 hours), the maximum price acceptable would be $\$ 52 / \mathrm{MWh}$, which yields an average energy cost of $\$ 40.35 / \mathrm{MWh}$. The hydrogen plant would operate 340 evenings and holidays off-peak and 157 days on-peak. On the other hand, should the hydrogen producer set the maximum price at typical nuclear plant fuel costs of $\$ 5.73 / \mathrm{MWh}$, there would be no available power throughout the year for hydrogen production.

In a hydrogen transportation economy, the demand for hydrogen will depend more on vehicle use than hydrogen price, although substantial price fluctuations will ultimately affect demand. Assuming that the hydrogen producer requires a constant $50 \%$ availability (4,368 hours) to meet consumer demand, the price the producer pays for that electricity can vary dramatically from year to year. This becomes one of the risk factors in operating hydrogen production facilities.

Greater flexibility on part of the hydrogen producer is available when production is combined with hydrogen storage techniques. The hydrogen producer may be able to set a lower maximum price or may be able to obtain lower rates if interruption in service is allowed during especially high peak demand periods. The stored hydrogen can then make up the production difference.

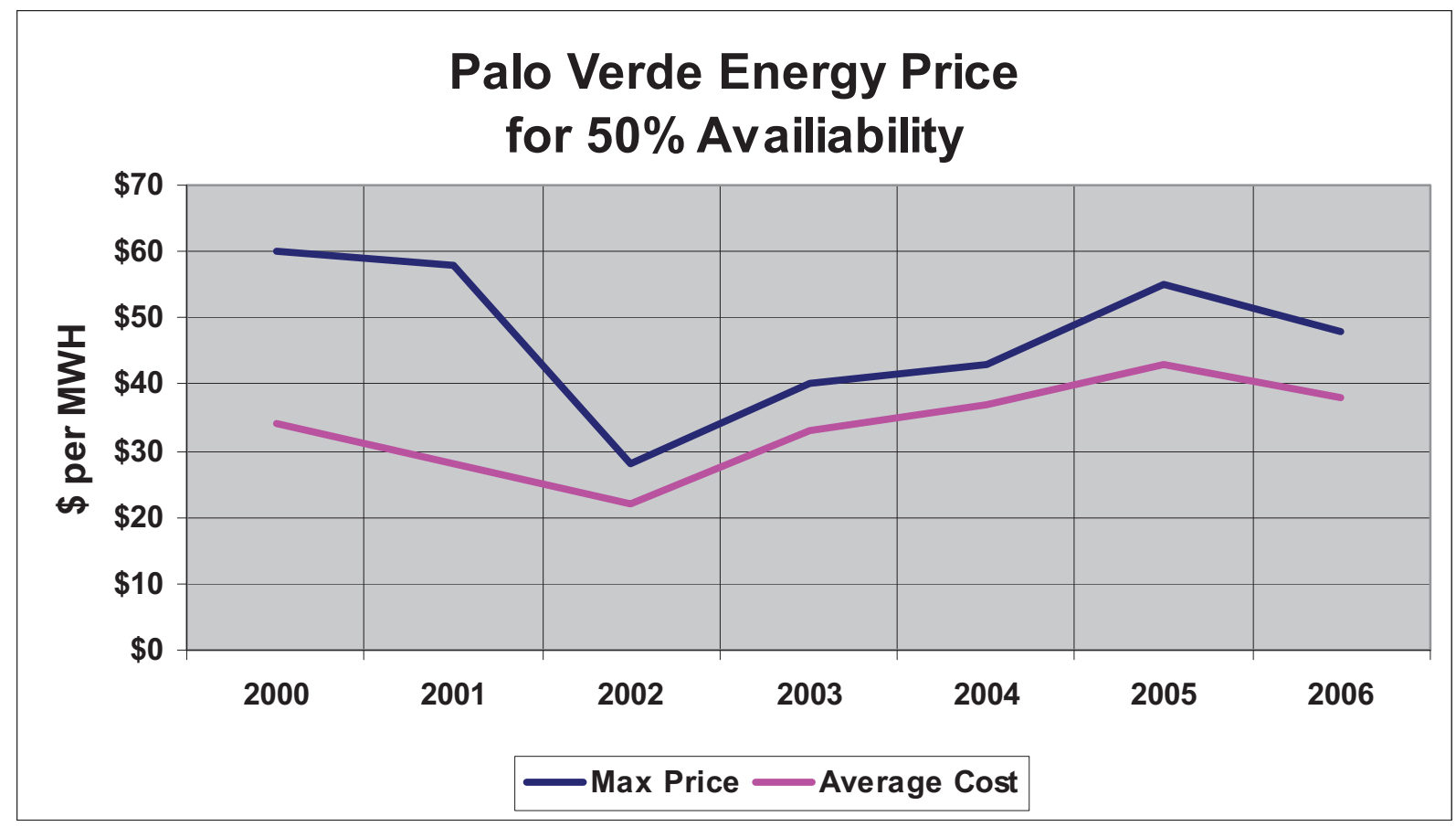

Figure 2-15. Palo Verde Nuclear-Generating Station maximum price and average electricity cost.

\subsection{National Electrical Generation Costs}

Electrical costs vary across the United States based on regional resources and utility production sources mixes. Table 2-2 illustrates the differences in actual and estimated electrical peak power (values are rounded to nearest dollar). 
Table 2-2. United States on-peak electrical price (\$/MWh). ${ }^{\mathrm{n}}$

\begin{tabular}{|l|c|c|c|c|c|c|c|}
\hline & $2006 \mathrm{~A}$ & $2007 \mathrm{~A}$ & $2008 \mathrm{E}$ & $2009 \mathrm{E}$ & $2010 \mathrm{E}$ & $2011 \mathrm{E}$ & $2012 \mathrm{E}$ \\
\hline National Average & $\$ 56$ & $\$ 62$ & $\$ 75$ & $\$ 39$ & $\$ 45$ & $\$ 50$ & $\$ 54$ \\
\hline New England & $\$ 70$ & $\$ 76$ & $\$ 91$ & $\$ 52$ & $\$ 60$ & $\$ 66$ & $\$ 69$ \\
\hline New York & $\$ 73$ & $\$ 79$ & $\$ 94$ & $\$ 55$ & $\$ 62$ & $\$ 68$ & $\$ 71$ \\
\hline Penn/Jersey/Maryland & $\$ 61$ & $\$ 71$ & $\$ 85$ & $\$ 54$ & $\$ 61$ & $\$ 66$ & $\$ 69$ \\
\hline Midwest & $\$ 51$ & $\$ 61$ & $\$ 68$ & $\$ 38$ & $\$ 41$ & $\$ 47$ & $\$ 55$ \\
\hline Illinois & $\$ 52$ & $\$ 59$ & $\$ 67$ & $\$ 37$ & $\$ 38$ & $\$ 41$ & $\$ 48$ \\
\hline Southeast/Gulf Coast & $\$ 56$ & $\$ 60$ & $\$ 70$ & $\$ 40$ & $\$ 51$ & $\$ 56$ & $\$ 58$ \\
\hline Texas & $\$ 58$ & $\$ 60$ & $\$ 88$ & $\$ 37$ & $\$ 48$ & $\$ 54$ & $\$ 58$ \\
\hline Desert Southwest & $\$ 58$ & $\$ 62$ & $\$ 72$ & $\$ 35$ & $\$ 45$ & $\$ 51$ & $\$ 54$ \\
\hline Southern California & $\$ 62$ & $\$ 66$ & $\$ 80$ & $\$ 41$ & $\$ 53$ & $\$ 59$ & $\$ 62$ \\
\hline North California & $\$ 61$ & $\$ 67$ & $\$ 80$ & $\$ 43$ & $\$ 53$ & $\$ 59$ & $\$ 63$ \\
\hline Pacific Northwest & $\$ 50$ & $\$ 57$ & $\$ 64$ & $\$ 35$ & $\$ 43$ & $\$ 48$ & $\$ 51$ \\
\hline
\end{tabular}

As shown in Table 2-2, variations can be as much as 47\% from each other. Note that Desert Southwest (PVNGS) is very close to the national average and again points to the PVNGS switchyard as a good yardstick for utility pricing. Table 2-3 provide the off-peak electrical price for areas in the United States.

Table 2-3. Off-peak electrical price (\$/MWh). ${ }^{\circ}$

\begin{tabular}{|l|c|c|c|c|c|c|}
\hline & $2007 \mathrm{~A}$ & $2008 \mathrm{E}$ & $2009 \mathrm{E}$ & $2010 \mathrm{E}$ & $2011 \mathrm{E}$ & $2012 \mathrm{E}$ \\
\hline National Average & $\$ 37$ & $\$ 43$ & $\$ 29$ & $\$ 33$ & $\$ 38$ & $\$ 54$ \\
\hline New England & $\$ 54$ & $\$ 68$ & $\$ 42$ & $\$ 49$ & $\$ 54$ & $\$ 69$ \\
\hline New York & $\$ 50$ & $\$ 64$ & $\$ 42$ & $\$ 48$ & $\$ 52$ & $\$ 71$ \\
\hline Penn/Jersey/Maryland & $\$ 42$ & $\$ 52$ & $\$ 43$ & $\$ 44$ & $\$ 47$ & $\$ 69$ \\
\hline Midwest & $\$ 29$ & $\$ 31$ & $\$ 27$ & $\$ 29$ & $\$ 34$ & $\$ 55$ \\
\hline Illinois & $\$ 29$ & $\$ 31$ & $\$ 24$ & $\$ 24$ & $\$ 28$ & $\$ 48$ \\
\hline Southeast/Gulf Coast & $\$ 32$ & $\$ 36$ & $\$ 30$ & $\$ 37$ & $\$ 41$ & $\$ 58$ \\
\hline Texas & $\$ 41$ & $\$ 51$ & $\$ 25$ & $\$ 34$ & $\$ 38$ & $\$ 58$ \\
\hline Desert Southwest & $\$ 42$ & $\$ 52$ & $\$ 20$ & $\$ 25$ & $\$ 30$ & $\$ 54$ \\
\hline Southern California & $\$ 47$ & $\$ 58$ & $\$ 28$ & $\$ 36$ & $\$ 41$ & $\$ 62$ \\
\hline North California & $\$ 47$ & $\$ 58$ & $\$ 31$ & $\$ 38$ & $\$ 44$ & $\$ 63$ \\
\hline Pacific Northwest & $\$ 44$ & $\$ 50$ & $\$ 28$ & $\$ 33$ & $\$ 38$ & $\$ 51$ \\
\hline
\end{tabular}

${ }^{\mathrm{n}}$ Citigroup Global Markets, Spark Spread Biweekly, March 23, 2009.

${ }^{\circ}$ ibid. 


\subsection{Electrical Transmission Costs}

The electric power industry is evolving from a highly regulated industry where a utility would provide generation, transmission, and delivery of electricity to its customer base to a less regulated, competitive industry where generated power may be delivered to customers well outside the traditional utility territory. Increasingly, electricity customers are being provided options about choosing their electricity provider with pricing that is competitively based.

At the federal level, Congress and FERC continue to work on the wholesale legal and regulatory framework. These activities focus on promoting efficient expansion of the Nation's high-voltage transmission system to alleviate transmission constraints that impact reliability and efficient operation of regional wholesale markets. Refinement of market structures and rules in organized wholesale markets will enhance efficiency in (1) the supply of electricity and (2) purchasing decisions by entities responsible for purchasing power to meet obligations to retail consumers. ${ }^{\mathrm{p}}$

In 1996, FERC Order No. 888 established guidelines for formation of independent system operators, and in 1999, FERC Order No. 2000 encouraged transmission utilities to form and participate in a regional transmission organization. While both organizations control and monitor transmission systems, the regional transmission organization typically manages this transmission across a wider area, including state borders.

The order encouraged competition in wholesale electricity markets by establishing independent organizations with operational control of utility transmission systems to preclude utilities from operating and providing access to their transmission systems to the advantage of their own generation assets. These organizations have broad operational control of participating utilities' transmission systems, ensuring non-discriminatory access to market participants. Additionally, they operate competitive wholesale markets for energy services, demand response, and have authority over transmission system planning. ${ }^{\mathrm{q}}$

Currently, eight independent system operators and four regional transmission organizations operate in North America. With the separation of transmission from generation, the owners of transmission lines set rates (approved by FERC) for those who would use these transmission lines to deliver power to consumers. The following four methods are used to set these transmission rates:

1. Pancaked rates: these rates occur when the transmitted power uses several transmission systems and each system adds it full rate. Overall, rates are higher and tend to drive the supplier to deliver closer to home.

2. Postage stamp pricing: within a single transmission system pricing is the same, with the higher cost for longer distance transmission being averaged with the lower cost for shorter distance transmission.

3. License plate pricing: transmission costs vary based on geographic area and age of the transmission system. Transmission over large open areas and newly constructed transmission is more expensive

\footnotetext{
p “Electric Power Industry Overview 2007," Energy Information Administration, www.eia.doe.gov/electricity/page/prim2/toc2.html.

${ }^{\mathrm{q}}$ ibid.
} 
than short distance transmission and old systems. The price for each user is based on the costs where they access the transmission system.

4. Distance sensitive pricing: price is based on the distance in miles where the user is actually using the transmission system. ${ }^{\mathrm{r}}$

The above methods may seem straight-forward; however, times of high demand and transmission congestion add complexities. When demand exceeds supply, some users will be dropped.

Two different market designs are used for transmission services. The first approach assumes that it is more trouble than it is worth to charge each system user for the cost it imposes on the system. In this case, external costs are apportioned to users according to local rules and FERC-approved transmission tariffs. If congestion cannot be fully managed using redispatch, the transmission operators use a priority system to decide who remains on line. Transmission costs are "socialized" (shared out to everyone) in this approach.

The second approach (used by PJM) associates) includes transmission charges with the costs each user imposes on the system. The transmission system controller calculates a "shadow price" of transmission on every congested line and then charges users according to their marginal contributions to congestion. When a line becomes overloaded, system controllers increase the implicit price of using the line until market participants voluntarily reduce the line loadings. A priority system for allocating transmission is not employed.

The chief disadvantage of the PJM approach is that the transmission price calculation is complex, ex post, and can lead to significant price variations, depending on the level of system congestion. To reduce the price risk to users, PJM also markets financial transmission rights contracts, which allow users to lock in a transmission cost more than a day in advance.

Most of the U.S. market currently "socializes" transmission costs."

Calculation of these transmission costs is highly complex. FERC Order 890 established methods for calculation and these were further modified in FERC Order 890-A, "Preventing Undue Discrimination and Preference in Transmission Service," on December 28, 2007. New services and pricing structures that allow for day-ahead and hour-ahead auctions for available power are continuing to be developed as identified in Figure 2-16.

\footnotetext{
${ }^{\mathrm{r}}$ Electricity Transmission, A Primer, National Council on Electricity Policy, June 2004.

${ }^{s}$ Energy Information Administration, Derivatives and Risk Management in the Petroleum, Natural Gas, and Electricity Industries, SR-SMG/2002-01, October 2002.
} 


\section{Centrally Administered Wholesale Markets Expand in 2009}

- Midwest ISO's integrated ancillary service market started January 6, 2009

- California ISO's new market design commenced April 1, 2009

- Nebraska public power utilities join SPP on April 1, 2009

- Southern Company's wholesale auction starts April 23, 2009

Figure 2-16. Wholesale markets expansion. ${ }^{\mathrm{t}}(\mathrm{ISO}=$ independent system operators).

The impact of transmission services on hydrogen production facilities can be substantial as they compete for available power. The owner of a generating facility may be required to build the transmission system from that generator to the local grid and to pay the transmission fee to deliver power to their customers. This can become an important factor for nuclear generating stations in delivering power to a hydrogen production facility that may be some distance away. Likewise, transmission costs can be much lower if the two facilities are located nearby.

\section{COMMERCIAL USES FOR HYDROGEN}

\subsection{Existing Demand}

Approximately 9 million tons of hydrogen are produced annually in the United States. Most of this hydrogen is used for refining of petroleum products, treating metals, and processing food. Additional uses include production of ammonia, methanol, fertilizers, glass, vitamins, cosmetics, soaps, lubricants, and other products. Some hydrogen is used for lifting of balloons and for rocket fuel. Hydrogen also is used for conversion of tar sand, heavy crude oil, oil shale, or coal to liquid fuel. A growing demand for hydrogen exists in these areas primarily related to the refining of petroleum.

\footnotetext{
${ }^{\mathrm{t}}$ FERC, State of the Markets 2008, April 16, 2009.
} 


\subsection{Developing Demand}

\subsubsection{Remote Power}

Fuel cells are being used in remote locations where access to the electrical grid is difficult or not available. Such applications include temporary military bases, mining operations, or remote cabins. Backup power and uninterruptible power supply are other applications that are required when a highly reliable power source is critical to keep equipment in operation without interruption, even if grid power is lost. The increasing availability of hydrogen at reduced prices will add to the demand.

\subsubsection{Utility Power Peaking}

Use of hydrogen by utilities for power peaking was discussed in Section 2. This includes producing hydrogen for distribution during off-peak times when electrical costs are lower and for hydrogen storage for electrical power production in times of high demand. As the size of the hydrogen generating facilities increases, the likelihood of combining a nuclear plant with a hydrogen-generating facility (like the Hydrogen Intermediate and Peak Electrical System) also increases.

\subsubsection{Off-Road Applications}

Attention is being given to hydrogen fuel cell usage in material handling equipment and airport ground support equipment. This equipment is currently powered by internal combustion (i.e., diesel, gasoline, or propane) or by battery. The fuel cell is designed to fit the battery compartment of the appropriate equipment and make the transition to a fuel cell easier (see Figure 3-1).

The power delivered to the lift truck or ground support equipment is the same as the power previously supplied by the battery. Instead of exchanging a battery when depleted, the fuel cell is refueled locally.

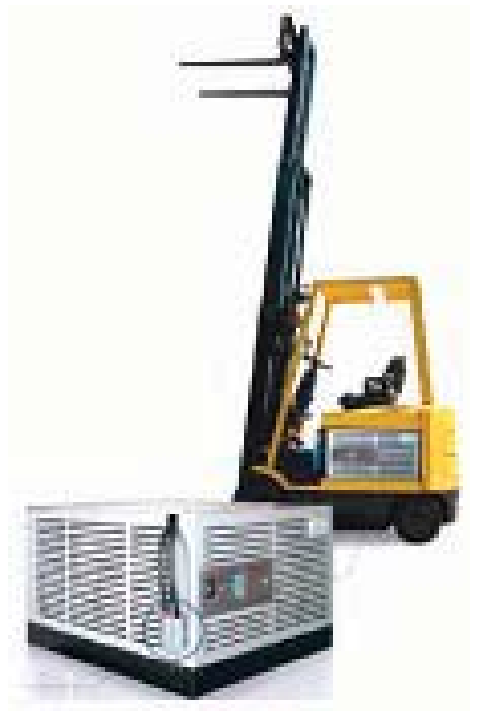

Figure 3-1. Fuel cell in material handling. ${ }^{u}$

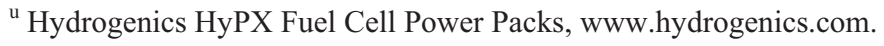


Aircraft ground support equipment is a good candidate for a hydrogen-powered pilot project for two reasons. First, ground support equipment is a major contributor to the carbon dioxide emissions problem. Airport traffic is responsible for 2 to $3 \%$ of carbon dioxide emissions in the U.S. metropolitan areas, and this number is expected to increase as the air transportation industry grows. Of the three categories of airport traffic (including aircraft, ground support equipment, and commuter traffic into and out of airports), ground support equipment and commuter automotive vehicles are the most feasible candidates for conversion. Possible ground support equipment candidates for hydrogen fuel cells include any self-propelled vehicles, such as tow tractors or loading equipment, and electrical power and hydraulic carts. ${ }^{\mathrm{v}}$

Strong incentives exist to promote adoption of fuel cells in these applications. Challenges to full penetration of these markets exist, including the higher cost and shorter life of the fuel cell stack along with the higher cost of hydrogen delivery or onsite production. Continued development of these fuel cell stacks will increase life and reduce cost. The increasing demand found in on-road transportation will drive down the hydrogen cost.

\subsubsection{On-Road Transportation}

3.2.4.1 Fuel Cells and Hydrogen Internal Combustion. Like electricity, hydrogen is an energy carrier. As oil becomes more expensive (as it has on several occasions) and as public policy steers transportation to less dependence on oil and reduced emissions, hydrogen use in transportation is likely to increase dramatically.

Hydrogen is available to support fuel cell power generation, as well as the primary fuel for hydrogen internal combustion engine (HICEs). Interest in fuel cells for automotive applications has had it ebbs and flows; however, gasoline prices at or near \$4 per gallon in 2008 increased interest in both fuel cell and electric or plug-in electric hybrid vehicles (see Figures 3-2 and 3-3).

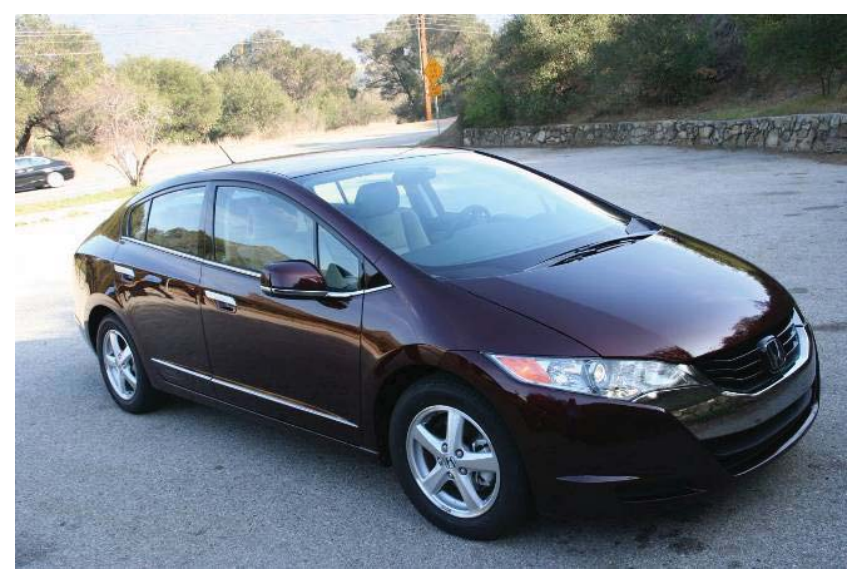

Figure 3-2. Honda FCX Clarity.

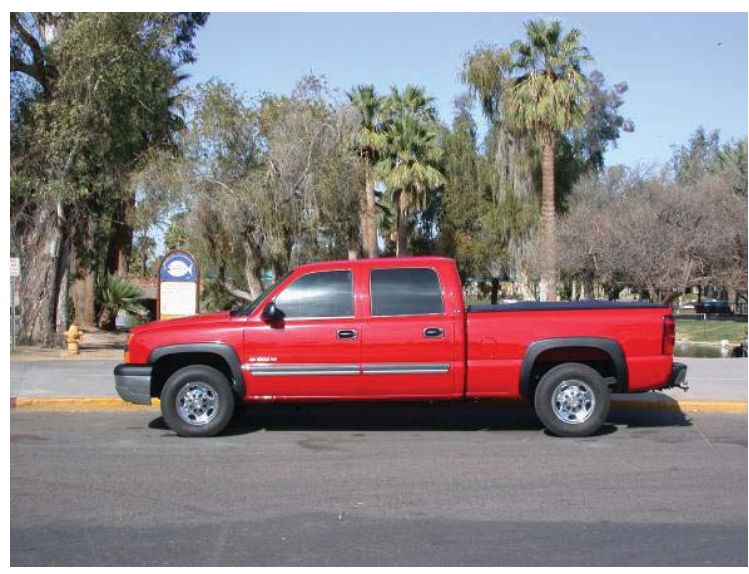

Figure 3-3. Silverado hydrogen internal combustion engine truck.

Several automotive companies have developed demonstration hydrogen fuel cell vehicles (HFCV). The Honda FCX Clarity, Chevy Equinox Fuel Cell, and others have been demonstrated. Other original equipment manufacturers (e.g., Toyota) have announced plans for fuel cell vehicles. The rarity of the platinum currently used in fuel cells may be a problem for wide-spread adoption, along with the expense

\footnotetext{
${ }^{v}$ Maxwell, Alton, Gates, and Doerr, On the Brink, Ground Support Worldwide, October 2007.
} 
of the fuel cell itself. However, incentives and political focus can push development forward and prices down.

At the same time, hydrogen is being demonstrated as a fuel for HICE vehicles. The Electric Transportation Engineering Corporation, Roush Industries, and Powertech Labs developed the HICE Chevrolet Silverado 1500HD, 6 passenger, 100\% HICE truck (i.e., HICE Silverado). Testing of this 2005 vehicle is conducted by the DOE Advanced Vehicle Testing Activity with results published on the Advanced Vehicle Testing Activity website: http://avt.inel/gov/.

Other conversions of existing car/truck frames to run on hydrogen have been accomplished, and testing of buses and aircraft on HICEs continues. Automotive manufacturers have demonstrated HICE vehicles but none are currently in production.

Certain properties of hydrogen make it a very effective fuel, although it does have some challenges. In addition, storage of hydrogen in both the fuel cell and HICE vehicles can be an issue (see Figure 3-4). Options for storage include very low temperature at high pressure or chemically as a hydride. Currently, high pressure is the storage choice being used; however, it has the drawback of requiring a considerable amount of space in order to maintain vehicle range fairly consistent with gasoline. Storage space requirements can be reduced using higher pressure, but costs for production at higher pressures also increase. Also, the weight of the storage tanks adds considerable weight to the vehicle.

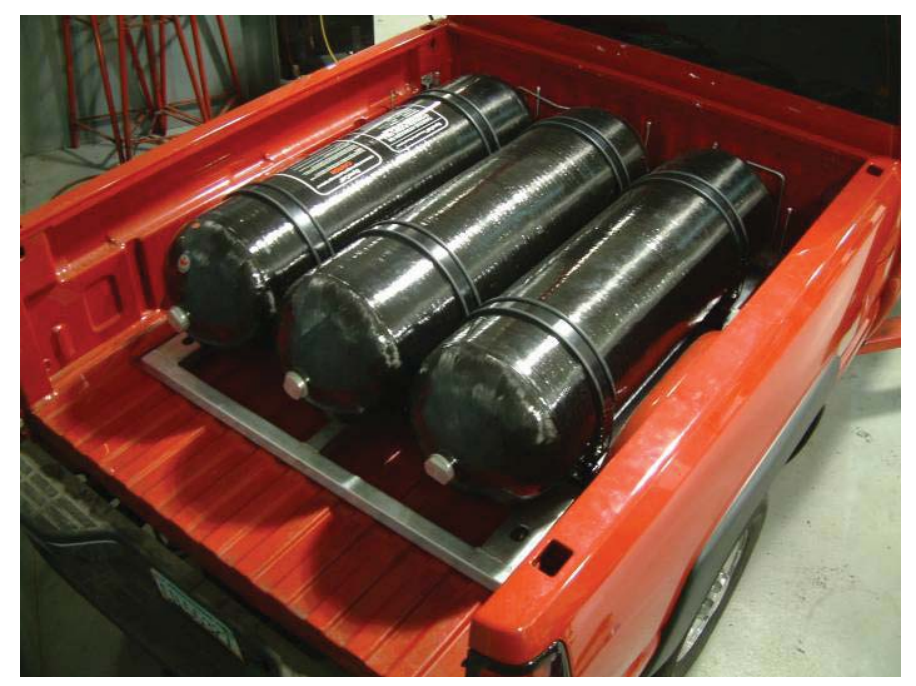

Figure 3-4. Silverado hydrogen internal combustion engine truck hydrogen storage.

Electrochemical storage is possible whereby hydrogen is combined with a hydride or other chemical compound for long-term storage. A catalyst is used to release the hydrogen when needed and the resulting material is stored for later reprocessing to again carry hydrogen. Carbon nanotubes have been suggested as another storage medium. As with other technologies, continued development will lead to more efficient solutions.

Continued development of fuel cell technology and HICE vehicles will be largely driven by governmental policies and direction. However, assuming that the focus will continue to be reduction of petroleum usage, transportation vehicles will be focused on electric or hydrogen vehicles.

Developing a market penetration plan for hydrogen vehicles often gets to the dilemma of the chicken or the egg. Consumers will not likely buy hydrogen vehicles unless the infrastructure is there to 
support it, and the infrastructure is not likely to be built unless the demand by consumers is there to support it.

The political instability of acquiring oversea oil resources, the need to reduce greenhouse gas emissions, and the desire for inexpensive energy have recently driven a shift of focus toward hydrogen energy. It has become increasingly evident that there are significant barriers facing development of a hydrogen-based energy system - a system commonly referred to as the "hydrogen economy." Small quantities of HFCVs that have been deployed to date are not numerous enough to facilitate the growth of a substantial refueling infrastructure. Additionally, the underdeveloped and extremely limited infrastructure has imposed significant convenience costs upon consumers. These convenience costs, in turn, inhibit further purchases of HFCVs. To analyze the vehicle/infrastructure chicken and egg phenomenon and assist in creation of future hydrogenrelated policies, this document presents the H2VISION systems model. H2VISION is designed to explore the following: (1) the role of various government policies aimed at hydrogen deployment (e.g., vehicle procurement, monetary incentives, or mass-station building); (2) the specific role of government as a first-use and innovative adopter of hydrogen technologies; (3) the effect of consumer preferences regarding vehicles and convenience costs regarding infrastructure on hydrogen markets; and (4) the short and long-term results of mainstream hydrogen technology diffusion. Using H2VISION, multiple scenarios with varying demographic, market, and policy conditions were analyzed with an aim to isolate specific factors inhibiting the growth hydrogen markets. It was found that investments in infrastructure may yield more rapid market growth in comparison to investments in vehicles. However, it was concluded that funding cannot be applied solely to infrastructure and must be systematically applied to all aspects of hydrogen markets (e.g., vehicles, fuel, and infrastructure). Only with a systematic and widespread application of funding will government policies facilitate successful growth of the hydrogen economy. ${ }^{\mathrm{w}}$

To date, a few hundred HFCVs and HICE vehicles are in use for demonstration or test. Barriers that exist to full-scale production include improving the fuel cell stack life (although significant progress is being made), reducing fuel cell cost (expected to improve with scaling up production), solving hydrogen storage issues, and reducing the cost of hydrogen. Nevertheless, economic and political pressures are anticipating the shift of on-road vehicles to HFCVs and HICE vehicles and that HFCVs and HICE vehicles will overtake petroleum-based vehicles within 40 years.

3.2.4.2 Vehicle Introduction and Penetration. Oak Ridge National Laboratory has developed a market model of all major components of the hydrogen fuel and vehicle system called HyTrans. This simulation tool is used to develop and analyze scenarios of the transition to hydrogen vehicles. This report assumes vehicle introduction and penetration as simulated by this program.

In the absence of policy actions, HyTrans predicts a transition to advanced gasoline hybrid vehicles, even with the achievement of the Hydrogen Program's technical goals. However, if decisive actions are taken to place between 2 and 10 million HFCVs on the road by 2025, no further incentives would be needed to complete the transition to hydrogen if the program's technology goals are achieved. ${ }^{\mathrm{x}}$

Assuming 10 million HFCVs on the road by 2025, HyTrans project's production of vehicles would be as seen in Figure 3-5.

\footnotetext{
w "Modeling technology diffusion of complementary goods: The case of hydrogen vehicles and refueling infrastructure", Meyer, Winebrake, Technovation 29 (2009) 77-91

x "Fact Sheet: HyTrans - Hydrogen Transition Model, Scenarios of the Early Transition," ORNL, June 2007.
} 


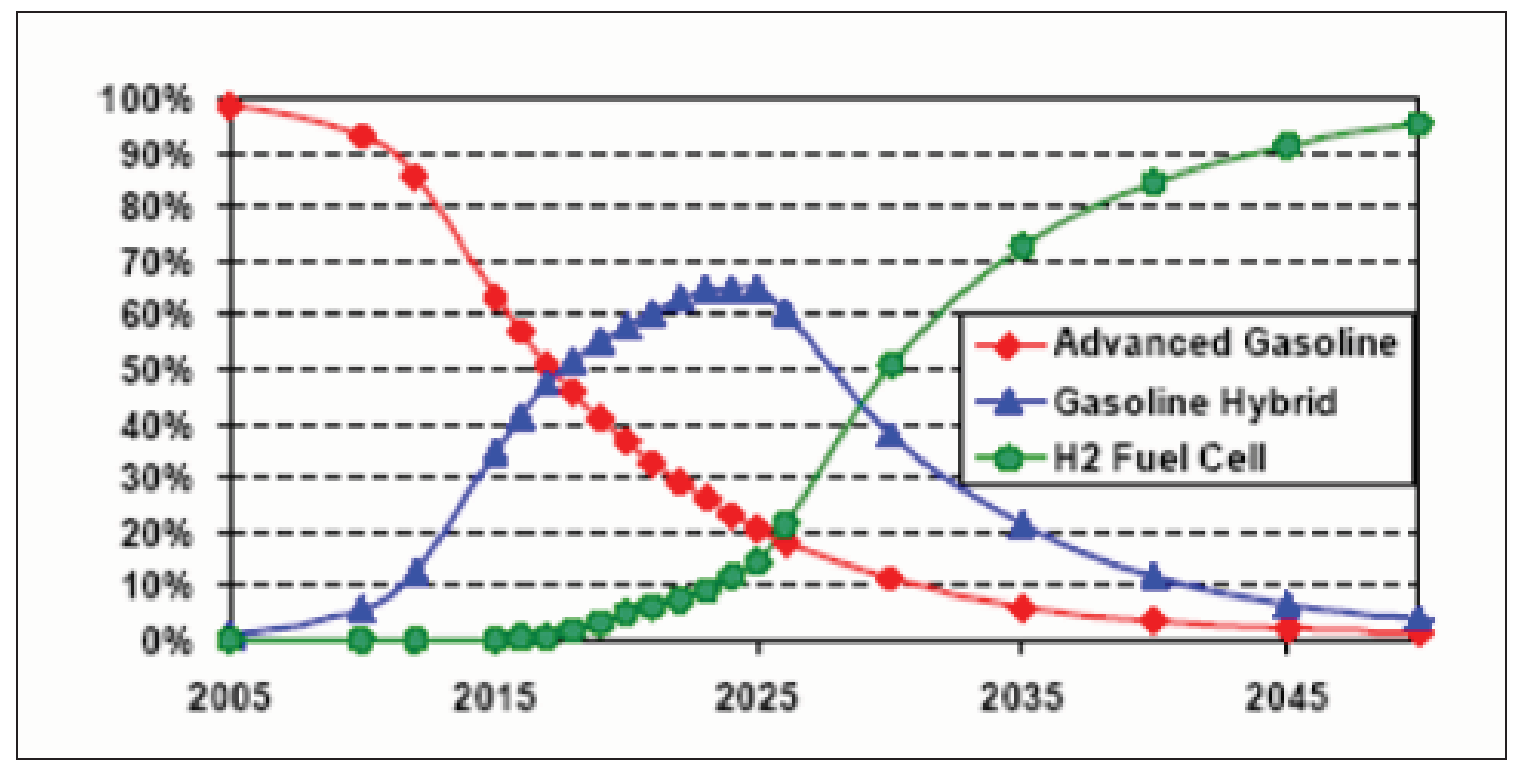

Figure 3-5. HyTrans - vehicle production share. ${ }^{\mathrm{y}}$

Additional work on HFCV penetration has been performed by the National Research Council. Assuming that development programs are successful and policies are implemented to ensure commercial deployment, HFCVs would number ".... a few thousand vehicles (HFCV) in 2012, growing to a fleet of almost 2 million by 2020, 60 million in 2035 and 220 million in 2050... By 2050, 80 percent of new vehicles sold are assumed to be HFCVs...This is consistent with other recent modeling studies."

These studies do not include the additional market potential of blended fuels using a combination of hydrogen and diesel or hydrogen and compressed natural gas. Current tests show excellent results, and although long distance tractor-trailers or railroad locomotives may not be able to run only on hydrogen, the blended fuel may be an option that could add a significant demand on hydrogen.

This penetration is similar to that experienced by hybrid gasoline vehicles. Many automotive suppliers are currently focusing on full electric vehicles (EVs) and plug-in hybrid electric vehicles. In many ways, the introduction and penetration of EVs and plug-in hybrid electric vehicles are similar to that of HFCVs and HICE. Both have technical barriers to cross and infrastructure to develop. The numbers of HFCVs seen here may be reduced by successful adoption of the EV and plug-in hybrid electric vehicles. Nevertheless, serious deployment of these quantities of HFCVs will necessitate introduction, development, and penetration of the hydrogen supply infrastructure.

\subsubsection{Hydrogen Infrastructure Introduction and Penetration. Rapid introduction of} HFCVs requires a return to the chicken and egg dilemma. Consumers interested in HFCVs will require an infrastructure of hydrogen supply in order to feel confident in their selection of the vehicle. Suppliers of hydrogen will face years of low consumer usage while the inventory of HFCVs builds. In many ways, this scenario is similar to that seen by the EVs delivered in the mid $1990 \mathrm{~s}$, which may be a model for the introduction and penetration of hydrogen fueling stations.

\footnotetext{
${ }^{\mathrm{y}}$ ibid.

${ }^{\mathrm{z}}$ National Research Council, Transition to Alternative Transportation Technologies - A Focus on Hydrogen, Committee on Assessment of Resource Needs for Fuel Cell and Hydrogen Technologies, 2008.
} 
The introduction of EVs in the 1990s was conducted through a planned and targeted release. Cities were selected for the introduction and if/when successful, additional cities could be added. This allowed the local dealerships to be trained and equipped to support the EV introduction. These EVs had a limited range and in order to avoid "range anxiety" on the part of the user, several charging options were made available. Each EV was delivered with an "emergency" cordset that allowed the battery to be recharged from 110-volt circuits that are readily available. Battery recharge times were quite long but at least, the driver was not fully stranded in any location. Residential battery chargers operating on 220-volt power (see Figure 3-6) were highly recommended and purchased by most EV drivers. This allowed a faster recharge so that in a few hours, the battery was fully recharged. This was typically done overnight in the user's home.

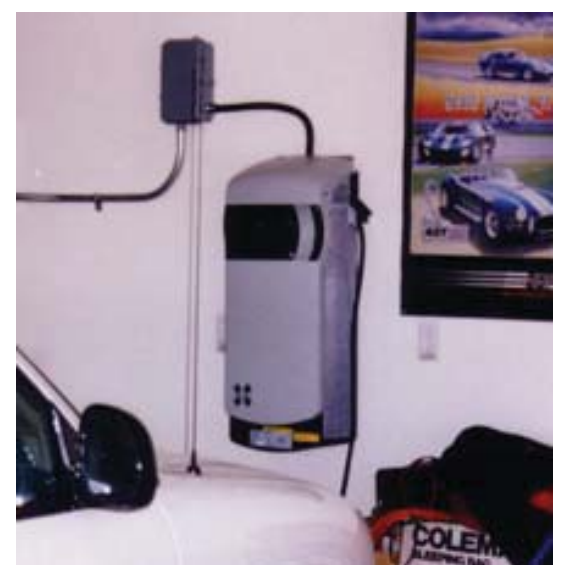

Figure 3-6. Typical home charger.

Because the EV had a limited range, a public charging infrastructure (see Figure 3-7) was developed through the support of government incentives and grants. Locations where an EV might be parked for an extended time (e.g., theaters, restaurants, movie theaters, museums, and shopping malls) would be excellent choices. A few gasoline stations also invested in charging stations. The 220 -volt chargers would restore a significant battery charge in the time the vehicle was parked. Selection of the locations required input from municipal planners, utility planners, private company owners, and EV users. This approach did not address the long distance usage of the EV to allow the EV to travel between cities. The EV market of the 1990s dissolved before the next phase of infrastructure, the fast charger, could be introduced.

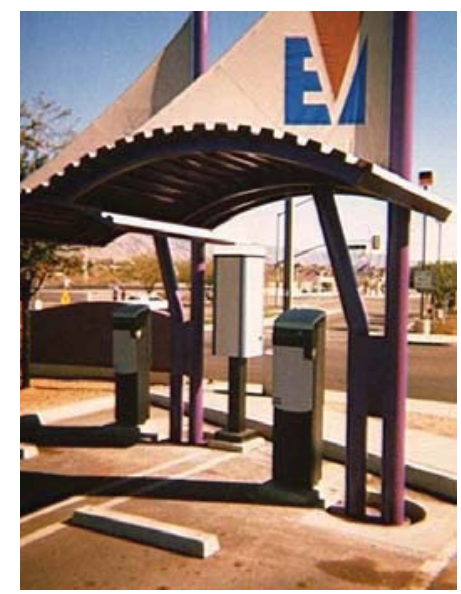

Figure 3-7. Typical public charger. 
While the EV introduction of the 1990s did not result in full market penetration, the current focus on EVs and PHEVs are again looking at this model for development of the charging infrastructure.

In a like manner, development of the hydrogen infrastructure could follow this model. Many automotive suppliers are investigating small hydrogen electrolyzers for use in private homes. In this manner, the vehicle could be refueled at home. While these units would be small and not of an "emergency" nature, they could act as in a similar fashion so that the owner has local fueling options. Selection of target cities for vehicle introduction allows a planned growth to the market. Local dealers will be equipped and trained to handle the new vehicles. During the initial transition phases, public availability of hydrogen will be required. This will require municipal planning to strategically locate these sources in geographically planned areas. Inclusion of hydrogen sources in current gasoline stations is anticipated. HFCV owners will organize to quickly identify and promote these locations.

Because the initial demand will be low, the hydrogen source could be from a small local electrolyzer. As the demand grows, these electrolyzers could be transitioned to other locations while the original source adds capability through larger electrolyzers or hydrogen delivery and storage means as is currently done for gasoline.

As the demand continues to grow, municipal areas may begin to develop larger capacity hydrogen production facilities, and, through the delivery truck or pipeline methods, deliver hydrogen to the service stations.

At the same time, introduction of HFCVs and HICE vehicles to additional cities will continue. Hydrogen supply infrastructure between cities will develop in a manner similar to the current highway exit service stations. The size of the hydrogen production facilities and storage containers is dependent on the hydrogen demand.

3.2.4.4 Hydrogen Demand. In 2004, the National Renewable Energy Laboratory (NREL) published a study in which several sizes of production units were classified based on the number of vehicles that they were expected to support with fuel. It determined the number of cars served by calculating that a typical car travels about 12,000 miles per year and that a vehicle will achieve 60 miles per kg of hydrogen. (12,000 miles per year relates to about 32 miles per day, which is close to that projected for EVs.) Therefore, each HFCV is expected to require approximately $200 \mathrm{~kg}$ of hydrogen per year.

Note that because $1 \mathrm{~kg}$ of hydrogen contains approximately the same energy as 1 gal of gasoline, discussion of vehicle mileage will still be appropriate in the hydrogen economy. For example, various vehicles will achieve different miles per $\mathrm{kg}$ of hydrogen based on their weight and other vehicle efficiencies. The above assumption that a vehicle achieves 60 miles per $\mathrm{kg}$ may or may not be an accurate assumption but it does not affect the production capability of plants. It is interesting that discussions of miles per $\mathrm{kg}$ will be not be a discussion based on the emission of greenhouse gases but a discussion of cost of vehicle ownership. If the average HFCV achieves 45 miles per $\mathrm{kg}$, it means that plant designs will be able to service fewer vehicles than those identified here.

The five sizes identified are as follows:

- The home size will serve the fuel needs of 1 to 5 cars with a hydrogen production rate of 200 to $1,000 \mathrm{~kg} \mathrm{H}_{2} /$ year.

- The small neighborhood size will serve the fuel needs of 5 to 50 cars with a hydrogen production rate of 1,000 to $10,000 \mathrm{~kg} \mathrm{H}_{2} /$ year. 
- The neighborhood size will serve the fuel needs of 50 to 150 cars with a hydrogen production rate of 10,000 to $30,000 \mathrm{~kg} \mathrm{H}_{2} /$ year.

- The small forecourt (refueling station) size, which could be a single hydrogen pump at an existing station, will serve the fuel needs of 150 to 500 cars with a hydrogen production rate of 30,000 to $100,000 \mathrm{~kg} \mathrm{H} /$ year.

- A full hydrogen forecourt size will serve more than 500 cars per year with a hydrogen production rate greater than $100,000 \mathrm{~kg} \mathrm{H}_{2} /$ year. ${ }^{a a}$

Manufacturers of electrolytic hydrogen generators already have production equipment that delivers the quantities of hydrogen identified above. However, introduction of HFCVs and HICE vehicles identified in Section 3.2.4.3 will require greater production capabilities. Figure 3-8 identifies the growth in hydrogen demand as a result of the vehicles delivered. Note that delivery of $100,000 \mathrm{~kg} \mathrm{H}_{2} /$ year (small forecourt size) is the equivalent of 100 metric tons (Tonne) of $\mathrm{H}_{2}$.

By 2025, demand would be approximately 2 million metric tons. Production facilities exceeding the forecourt size will be required. Section 4 investigates additional sizes of hydrogen production facilities up to $1 \mathrm{~kg} / \mathrm{sec}$, which is equivalent to $86,400 \mathrm{~kg}$ /day leading to 31,500 metric tons per year or 0.032 million metric tons. Production facilities of this magnitude will be required to meet the projected demands. Another way to view production requirements is in Tons of $\mathrm{H}_{2}$ per day.

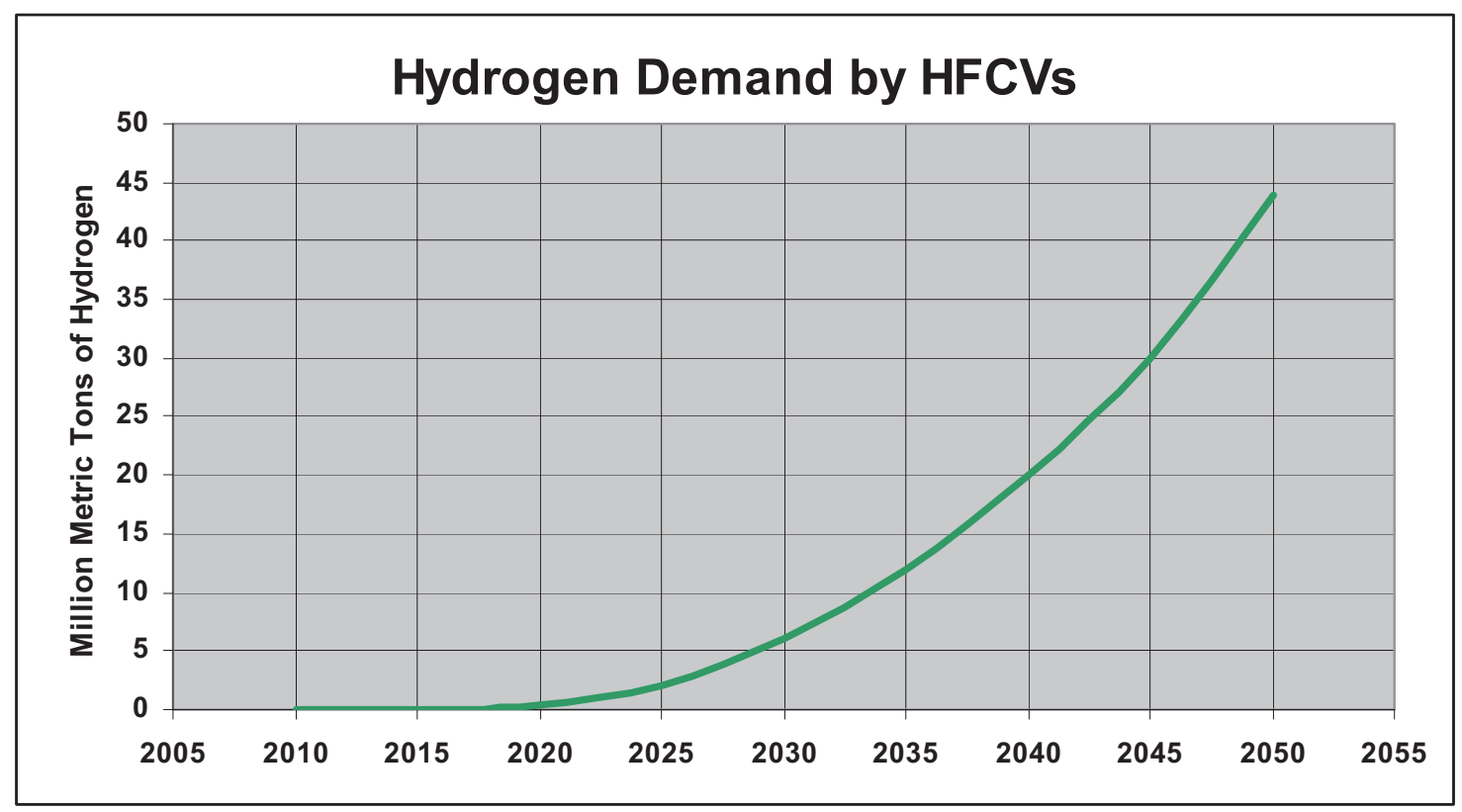

Figure 3-8. Hydrogen demand million in metric tons per year.

aa NREL, "Summary of Electrolytic Hydrogen Production," September 2004. 


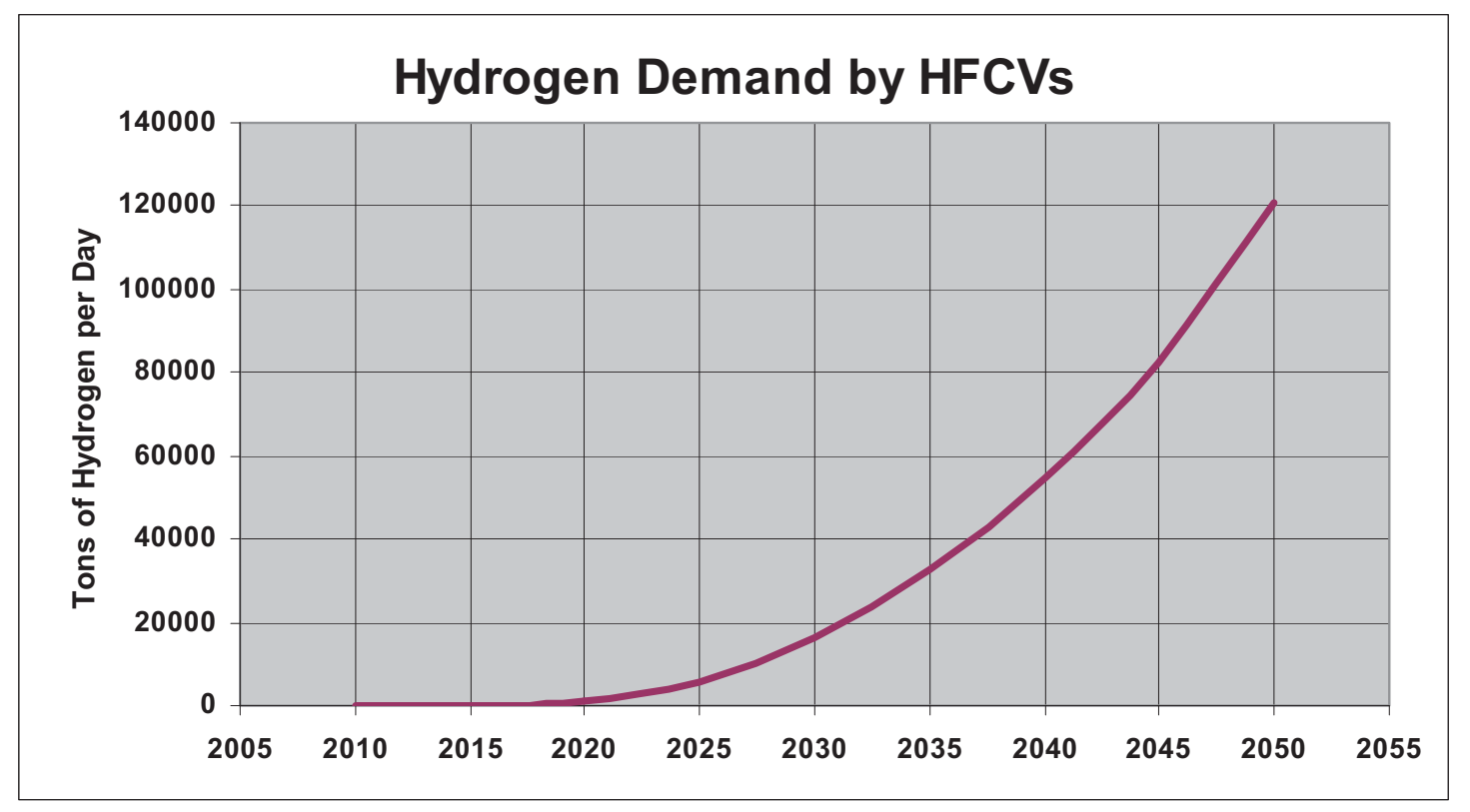

Figure 3-9. Hydrogen demand tons per day.

Demand for hydrogen will be driven by the local user. Figure 3-10 provides the demand increase for various market sizes based on HFCV market penetration.

\begin{tabular}{|l|c|c|c|c||}
\hline Market Penetration & & & & \\
\hline Small Urban & $1 \%$ & $10 \%$ & $30 \%$ & $70 \%$ \\
\hline Population & & & & \\
\hline Vehicles & 100,000 & 100,000 & 100,000 & 100,000 \\
\hline $\mathrm{H}_{2}$ fueled vehicles & 116,000 & 116,000 & 116,000 & 116,000 \\
\hline $\mathrm{H}_{2}$ fuel stations & 1,160 & 11,600 & 34,800 & 81,200 \\
\hline $\mathrm{H}_{2}$ demand (tpd) & $12^{\mathrm{a}}$ & $6^{\mathrm{b}}$ & $17^{\mathrm{b}}$ & $39^{\mathrm{b}}$ \\
\hline Large Urban & 1 & 8.3 & 2.5 & 58 \\
\hline Population & & & & \\
\hline Vehicles & $1,000,000$ & $1,000,000$ & $1,000,000$ & $1,000,000$ \\
\hline $\mathrm{H}_{2}$ fueled vehicles & 890,000 & 890,000 & 890,000 & 890,000 \\
\hline $\mathrm{H}_{2}$ fuel stations & 8,900 & 89,000 & 267,000 & 623,000 \\
\hline $\mathrm{H}_{2}$ demand (tpd) & $86^{\mathrm{a}}$ & $43^{\mathrm{b}}$ & $128^{\mathrm{b}}$ & $298^{\mathrm{b}}$ \\
\hline
\end{tabular}

a. $100 \mathrm{~kg} / \mathrm{d}$ station (home size)

b. $1,500 \mathrm{~kg} / \mathrm{d}$ station (small neighborhood)

Figure 3-10. Key demand assumptions by market and penetration. ${ }^{\text {bb }}$

Using a comparison to today's gasoline stations, the estimated population of Waco, Texas in 2007 was 101,261 and Berkeley, California was 101,377. Both would be considered "Small Urban" by Figure 3-10. They had 31 and 32 gas service stations, respectively. Likewise, San Jose, California had an estimated population of 939,899 and Detroit, Michigan was 916,952 in 2007. They had 291 and 431

\footnotetext{
${ }^{\mathrm{bb}}$ Mintz and Gillette, H2A Delivery Scenario Model and Analyses, Argonne National Laboratory, February 8, 2005.
} 
gasoline service stations, respectively. Therefore, in a fully developed hydrogen economy, the availability of hydrogen stations would need to be about the same as the current availability of gasoline stations.

The dispensing ability of a small neighborhood-size hydrogen facility does not mean that it would generate the hydrogen locally. In fact, the amount of hydrogen produced by 298 small neighborhood facilities could be produced by five $1-\mathrm{kg} / \mathrm{sec}$ facilities.

Analysis of existing gasoline station networks in four major U.S. cities has been carried out to determine general trends in station sizes and geographic distributions. In each city, stations of different sizes are more or less uniformly distributed across the urban area, though there is a slight tendency for larger stations to be located away from the city center in three of the four cities. When normalized by average station size and total number of outlets in each city, relative station size distributions are nearly identical in each city. This result is preserved during cluster analysis, which simulates reduced station networks that might resemble early hydrogen station networks. The relative station size distributions for both existing gasoline networks and simulated early hydrogen networks suggest that some $10 \%$ of the stations will be at least twice as large as the average station size, and some $30 \%$ of stations will be smaller than half the average station size. ${ }^{\mathrm{cc}}$

The mix of home, neighborhood and forecourt sizes will evolve as the demand changes. The flexibility of a location to adapt with the demand will be important.

\subsection{Hydrogen Product Transportation}

Current methods for transportation of hydrogen include gaseous form through tube trailers and pipelines or liquid form on tank trucks. Approximately 700 miles of pipelines are currently in use (mostly where hydrogen is used in petroleum refining or chemical plants). The pipelines represent the lowest cost distribution method for delivering high volumes of hydrogen. However, distances are relatively short and construction is expensive. Transportation beyond 200 miles of the source is currently not cost effective. Certain technical concerns also exist because hydrogen embrittles the steel. Notwithstanding the embrittlement issue, leakage is always a concern for hydrogen (the lightest of elements), and building and maintaining a containing pipeline is difficult. Nevertheless, significant work is being performed on the efficiency and effectiveness of the early hydrogen infrastructure development. One such study by the University of California Davis concentrated on the State of Ohio. It identified 12 major demand centers in the state; the most efficient distribution network for pipelines within each demand center is noted in Figure 3-11.

The model also identified strategic locations for intercity stations, which maximized average daily traffic flow at the station, was located close to large demand clusters, and resulted in a maximum stretch without a hydrogen station of 60 miles. Ten such stations, producing 2,000 kg/day (730,000 kg/year), were identified. These types of production facilities have not yet been built and are discussed further in Sections 4 and 5. The combination of pipeline and production stations for Ohio is shown in Figure 3-12.

\footnotetext{
${ }^{\mathrm{cc}}$ M.W. Melaina, Estimating Relative Station Sizes in Early Hydrogen Station Networks.
} 


\section{Intracity Distribution and Station Siting "Idealized City" Model}
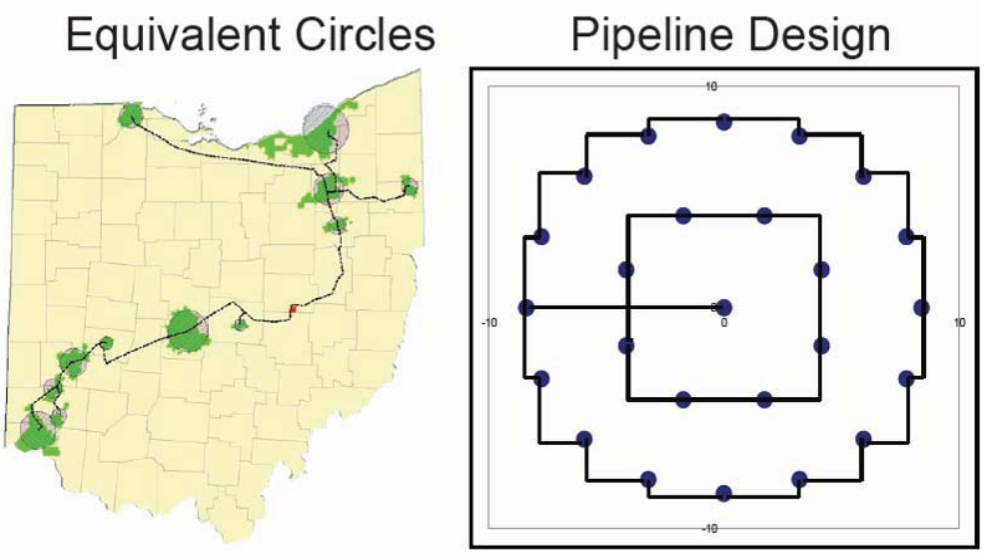

Figure 3-11. Demand centers and pipeline design for Ohio. ${ }^{\mathrm{dd}}$

Liquefied hydrogen can be transported greater distances in specially insulated tanks. Transportation by trailer or railcar is possible, but the venting or boil-off will result in losses. Costs for liquefaction are high and efficiency is low. Local delivery of liquid hydrogen to dispense in pressurized gaseous storage tanks at the service station is a possibility.

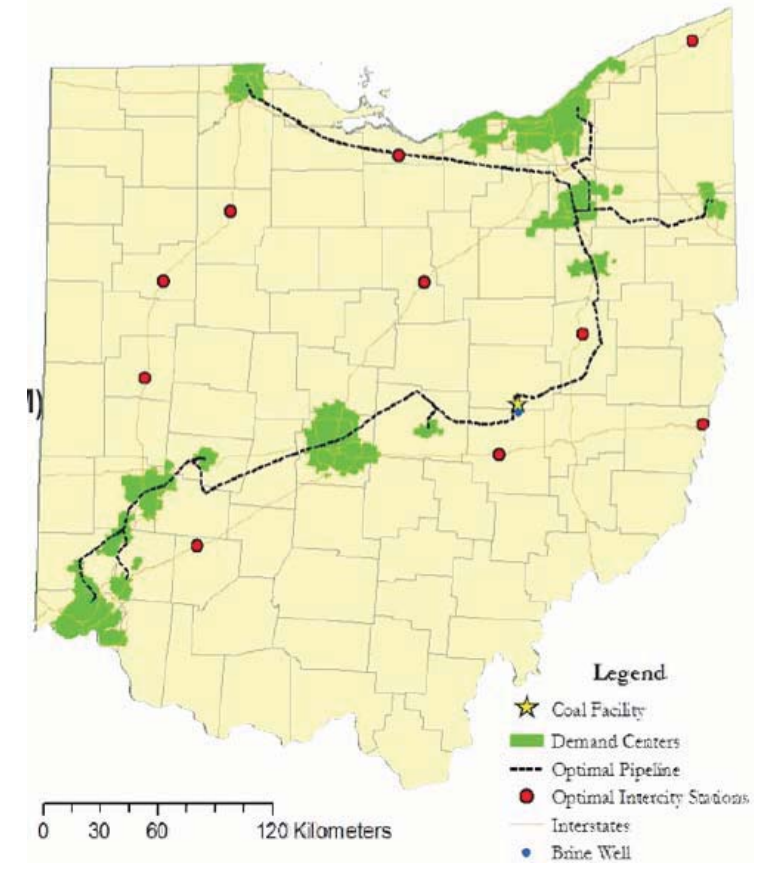

Figure 3-12. Demand centers, pipeline, and production stations in Ohio. ${ }^{\text {ee }}$

${ }^{\mathrm{dd}}$ Technical and Economic Studies of Regional Transition Strategies Toward Widespread Use of Hydrogen Energy, Ogden, Institute of Transportation Studies, University of California, Davis, 2005. 
Research into solid hydrogen storage is continuing as noted in Section 2. Transportation of hydrogen in this manner is easier and less expensive but the technology has not been fully developed.

Consideration also is given to transportation of hydrogen with compressed natural gas in existing compressed natural gas pipelines.

One possibility for rapidly expanding the hydrogen delivery infrastructure is to adapt part of the natural gas delivery infrastructure to accommodate hydrogen. Converting natural gas pipelines to carry a blend of natural gas and hydrogen (up to about 20\% hydrogen) may require only modest modifications to the pipeline; converting existing natural gas pipelines to deliver pure hydrogen may require more substantial modifications. Current research and analyses are examining both approaches. ${ }^{\mathrm{ff}}$

Costs for transportation of hydrogen cannot be determined for the volume of hydrogen to be produced and supplied that was identified by the demand above. Public policy emphasis on HFCVs and its infrastructure development must include technology development in transportation methods.

\subsection{Location of Hydrogen Production Facility}

\subsubsection{Relative to Demand}

Public adoption of HFCVs will drive demand on a local basis. While home hydrogen generators may be available, owners will expect to be able to refuel near where they live or work. Owners will be confident when 20 to $25 \%$ of available existing service stations provide hydrogen. That number may be significantly lower if strategically placed public refuel stations are developed.

The local service station may start with local delivery of gaseous hydrogen by tube trailer, progress to a neighborhood size production unit and increase to a small forecourt size as more vehicles are serviced. Public acceptance also will depend on availability on highways to allow major distance travel. Just as service stations are sized and located today based on local demand, the production of hydrogen will depend on local demographics.

The introduction of production HFCVs will likely be focused on specific municipal areas. Once infrastructure and vehicle demand are on a steady course, additional cities can be addressed. A model of hydrogen production growth will likely focus on production increases in the vicinity of these major municipal or metropolitan areas (see Figure 3-13). Demand growth will lead to local studies of the most efficient and cost effective means of local distribution of the hydrogen whether by transport or pipeline.

The density population of the United States also will present a challenge in developing the infrastructure. The demand centers will be in areas of high population; however, demand in even the largely unpopulated areas of the western United States will require fulfillment. Significant work on modeling this transition has been conducted by the University of California, Davis, NREL, Argonne National Laboratory, Oak Ridge National Laboratory, and others.

\footnotetext{
${ }^{\text {ee }}$ ibid.

${ }^{\mathrm{ff}}$ Hydrogen, Fuel Cells and Infrastructure Technologies Program, Current technology, Energy Efficiency and Renewable Energy (EERE), December 2008, www1.eere.energy.gov.
} 


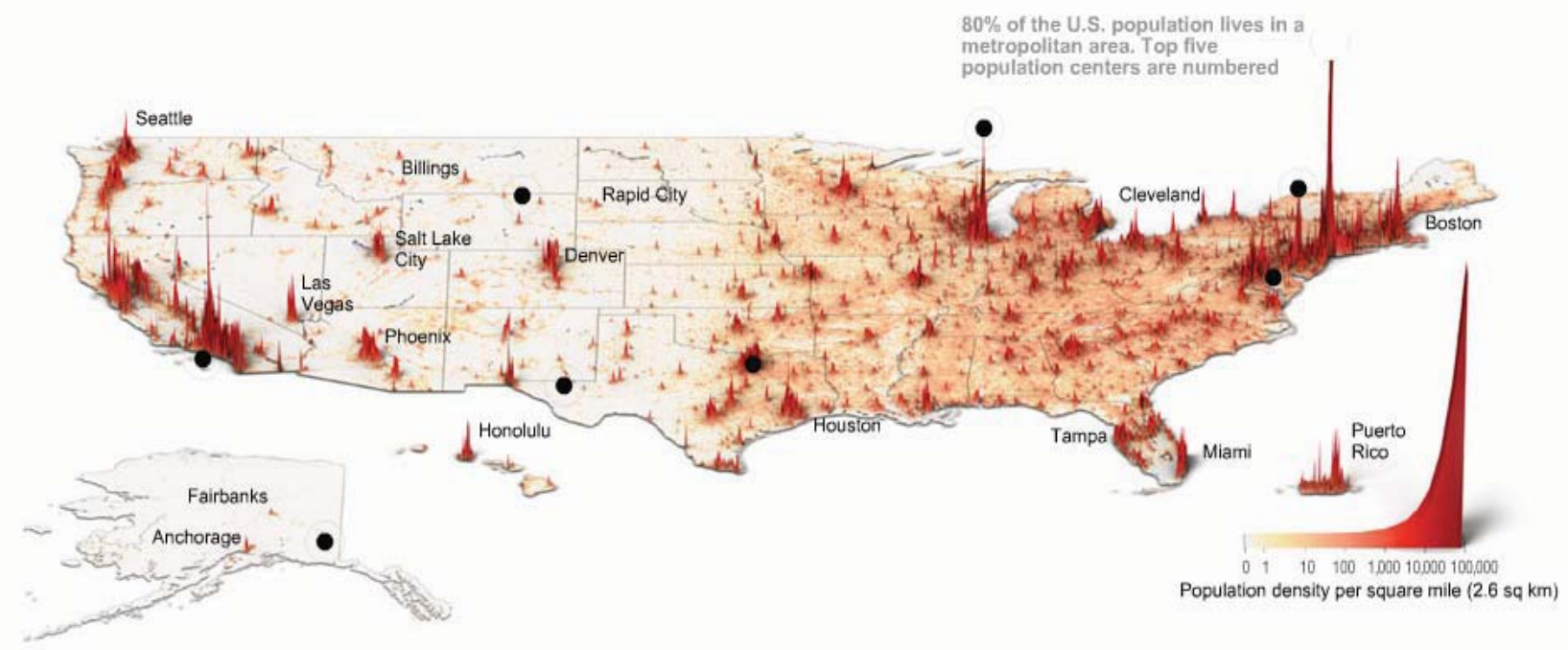

Figure 3-13. United States population distribution..$^{\mathrm{gg}}$

\subsubsection{Relative to Storage}

Many hydrogen proponents suggest that major amounts of hydrogen can be stored underground in a manner similar to natural gas. Underground storage would be much less expensive than above ground storage. The major storage sites include depleted oil or natural gas fields, aquifers, and salt cavern formations. Retention characteristics of such locations are important, especially for hydrogen, because of its nature to easily leak from containment. An impermeable cap-rock would be required to prevent the gas from escaping. Salt caverns may be the most likely to be capable of hydrogen retention. Figure 3-14 shows locations of natural gas underground storage.

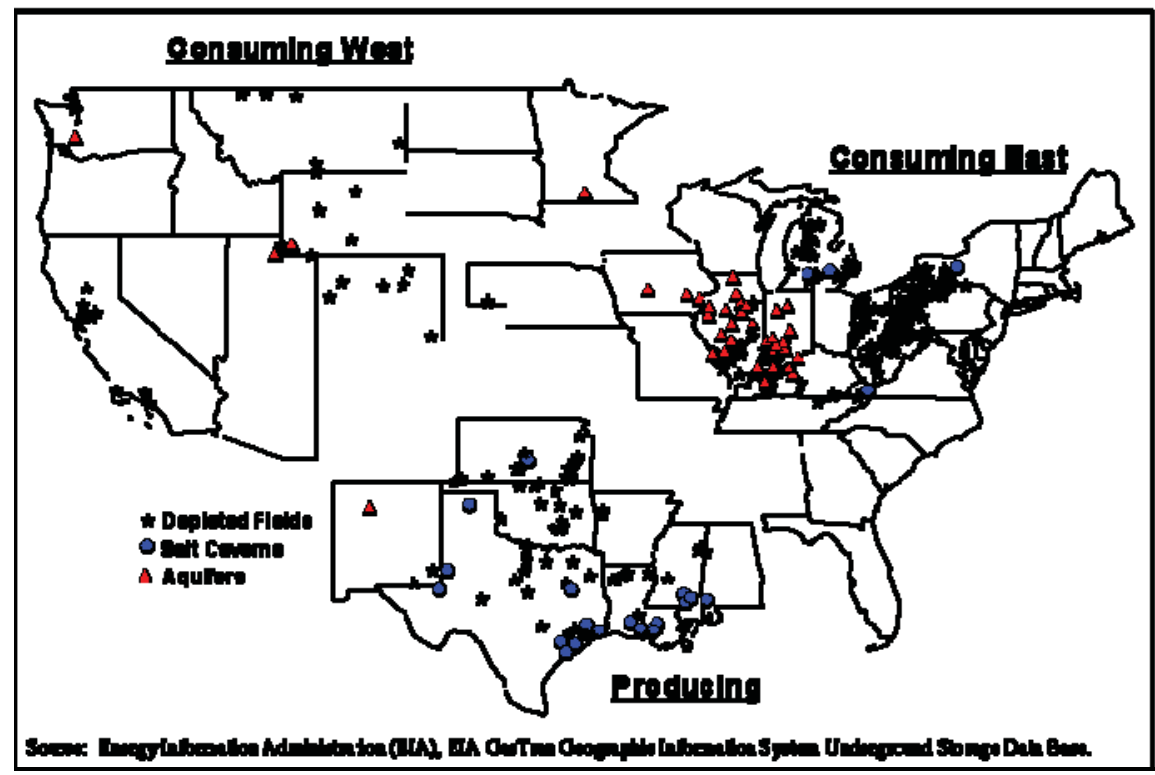

Figure 3-14. Underground natural gas storage facilities. ${ }^{\text {th }}$

\footnotetext{
gg Time Multimedia, www.time.com.
} 
In most cases, these locations are far from major metropolitan areas. Transportation of the hydrogen then becomes an issue. It is more likely that hydrogen will be produced closer to the demand. However, hydrogen generation for electrical peaking or demand control may be placed where the underground storage is available. Power plants can be located near the salt caverns and storage used for peaking generation.

In above ground applications, hydrogen does not store well. Being the lightest element, it leaks easily from equipment, tanks, and pipelines. When stored in liquid form, venting is required that can allow the loss of significant quantities. Continued development of mechanisms for storage, including chemical storage, will be required. Storage of hydrogen at service stations may encounter high losses in the early stages of adoption when the quantity of vehicles per day is low. Efficiency will be gained with lower relative losses when the volume of vehicles increases.

\subsubsection{Relative to Power}

Electrolysis production of hydrogen requires electrical power. As seen in Section 2, the cost of that power can vary from peak to off-peak, season to season, and one geographic area to another. Service station electrolyzers will be using electricity at consumer rates. Local large producers may be able to negotiate special lower rates for higher volume. The highest production plants will require the most power, and it is likely they will be located near major power plants (nuclear) or their transmission lines. Existing nuclear power plants (see Figure 3-15) are already generally located near the major population centers.

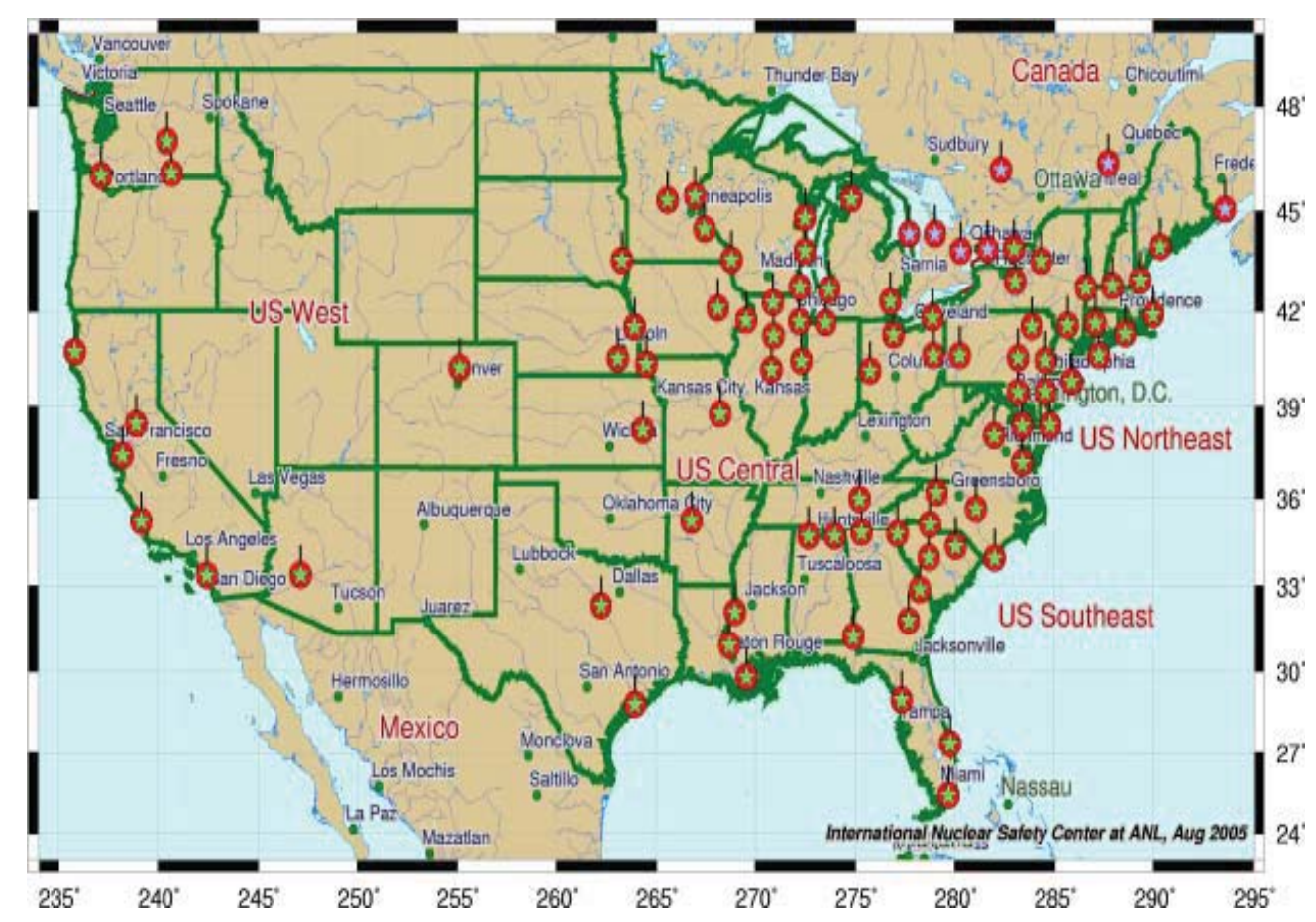

Figure 3-15. Nuclear power plants. ${ }^{\text {ii }}$

\footnotetext{
hh The Basics of Underground Natural Gas Storage, Energy Information Administration/Natural Gas Division, www.eia.doe.gov.

${ }^{i i}$ International Nuclear Safety Center, Argonne National Laboratory, www.insc.anl.gov/
} 
As demand reaches the levels of 2020 and later, co-locating hydrogen and nuclear plants will be a consideration. This is addressed further in Sections 4 and 7.

Unlike gasoline, where fuel is produced at a few isolated refineries, the availability of the electrical transmission grid will allow production facilities for hydrogen to be located where demand requires. Figure 3-16 also shows the major electrical transmission lines concentrated in areas of high population and demand concentration.

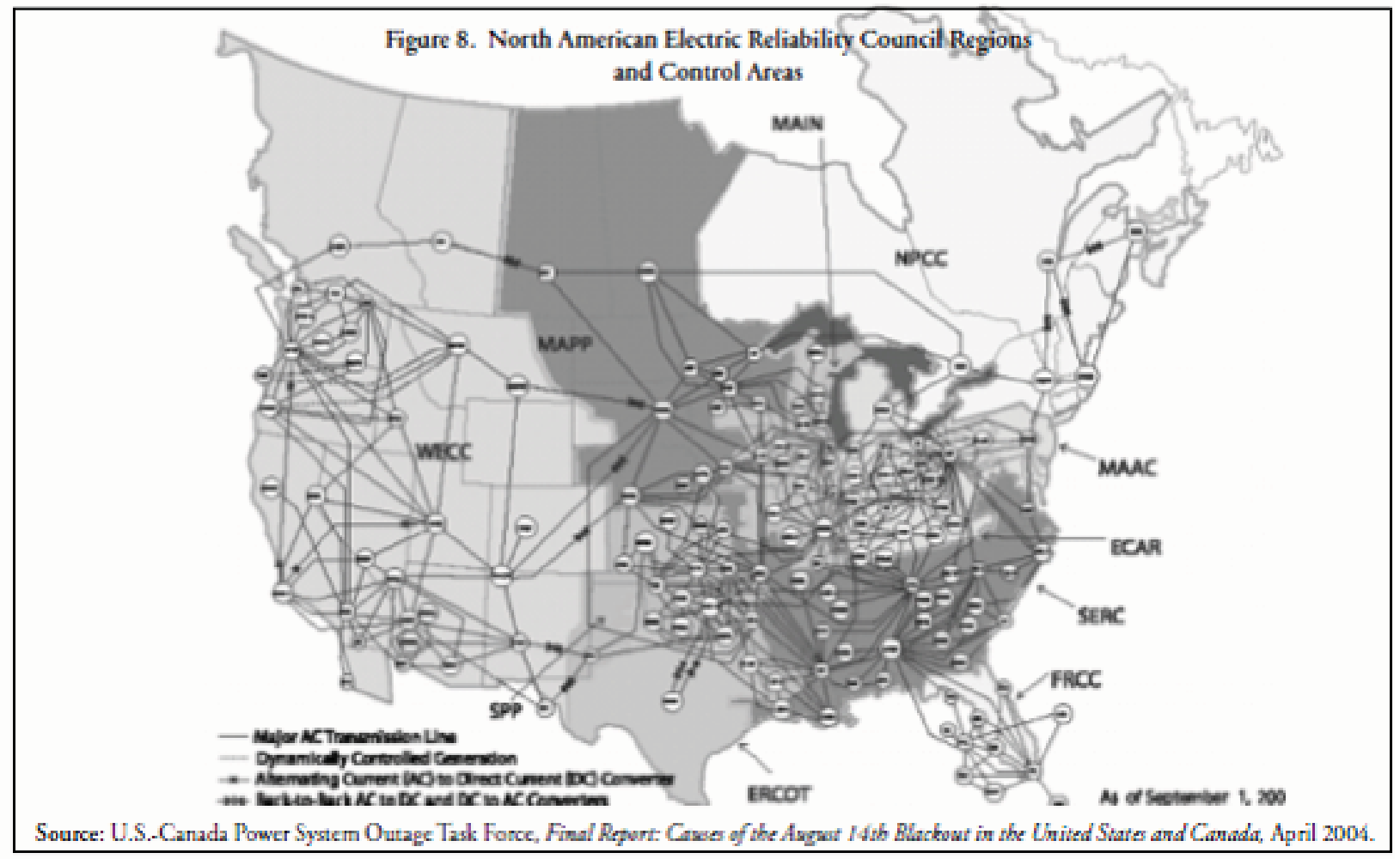

Figure 3-16. Major AC transmission lines. ${ }^{\mathrm{jj}}$

\section{COMMERCIAL PRODUCTION DESIGNS}

Hydrogen is produced in electrolysis by passing an electric current through two electrodes in water. The water molecule splits into its hydrogen element at the cathode and oxygen element at the anode. Three basic commercial methods are used in electrolysis: alkaline electrolyzers, high-temperature electrolyzers, and proton exchange membrane (PEM) electrolysis.

\subsection{Electrolysis Design Review}

\subsubsection{Alkaline Electrolyzer}

There are two basic types of alkaline electrolyzers. The unipolar or tank design alternates suspend anodes and cathodes in a tank filled with a solution of electrolyte usually potassium hydroxide in pure

\footnotetext{
${ }^{\mathrm{jj}}$ Brown and Sedano, Electricity Transmission, A Primer, National Council on Electricity Policy, www.ncouncil.org.
} 
water. The bipolar or filter-press alkaline electrolyzer has the alternating layers of electrodes and separation diaphragms that are clamped together. Figure 4-1 shows a typical bipolar design.

The unipolar electrolyzer is rather simple to manufacture and repair, but temperatures and current densities are lower. The advantages to the bipolar design are the reduced stack footprints, higher current densities, and generally higher output hydrogen gas pressure. Maintenance can be more of an issue because the cells are clamped together. In both electrolyzers, hydrogen is produced at the cathode and oxygen is produced at the anode.

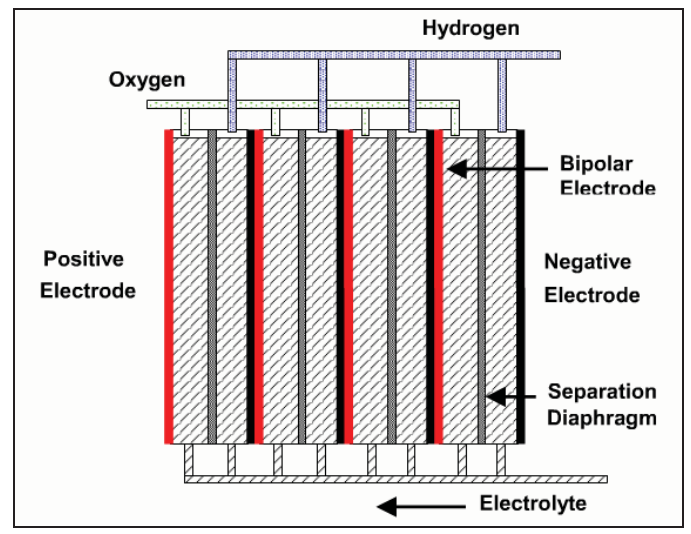

Figure 4-1. Typical bipolar alkaline electrolyzer. ${ }^{\mathrm{k}}$

\subsubsection{Proton Exchange Membrane Electrolyzer}

The solid polymer electrolyte electrolyzer also is known as the PEM electrolyzer. In this design, the electrolyte is contained in a thin, solid ion-conducting membrane that allows the $\mathrm{H}+$ ion (i.e., proton) to transfer from the anode side of the membrane to the cathode side where it combines with electrons to form hydrogen. The membrane separates the hydrogen and oxygen gases. This design eliminates the potassium hydroxide solution.

The membrane must be gaseous impervious to maintain separation of the hydrogen and oxygen. It must be resistive to hydrogen embrittlement and it must be highly conductive for the hydrogen ion. Considerable design efforts are underway to produce the most efficient membrane at the lowest cost. The PEM cells are combined into stacks for production.

Both electrolyzer designs for hydrogen production systems would typically include a water source, water purification systems, electrical power supply, hydrogen gas dryer, hydrogen gas purifier, hydrogen gas compressor, and hydrogen storage tanks. Other equipment typically required would be a nitrogen system for purging piping and components, chilled water for cooling, an oxygen collection system (if desired), and instrument air for controls.

\subsubsection{High-Temperature Electrolysis}

Tests of a solid ceramic membrane electrolyzer have been shown to achieve higher efficiencies than PEM or alkaline electrolyzers when operated at very high temperatures. High-temperature electrolysis is generally considered only in combination with a high-temperature nuclear source because

\footnotetext{
${ }^{\mathrm{kk}}$ Electrolysis: Information and Opportunities for Electric Power Utilities - Technical Report NREL/TP-581-40605, Kroposki, Levene, Harrison, NREL, Sen, Colorado School of Mines, Novfachek, Xcel Energy, September 2006
} 
other methods to produce that high temperature may not be consistent, convenient or cost effective. The very high temperature reactor was discussed in Section 2 as one of the Generation IV reactor designs.

\subsection{Process Model for N2H2"}

A process model for plant design was developed by Idaho National Laboratory using Honeywell UniSim process modeling software. The electrolysis model was developed as part of this project and is shown in Figure 4-2. Appendix E provides additional information on this model.

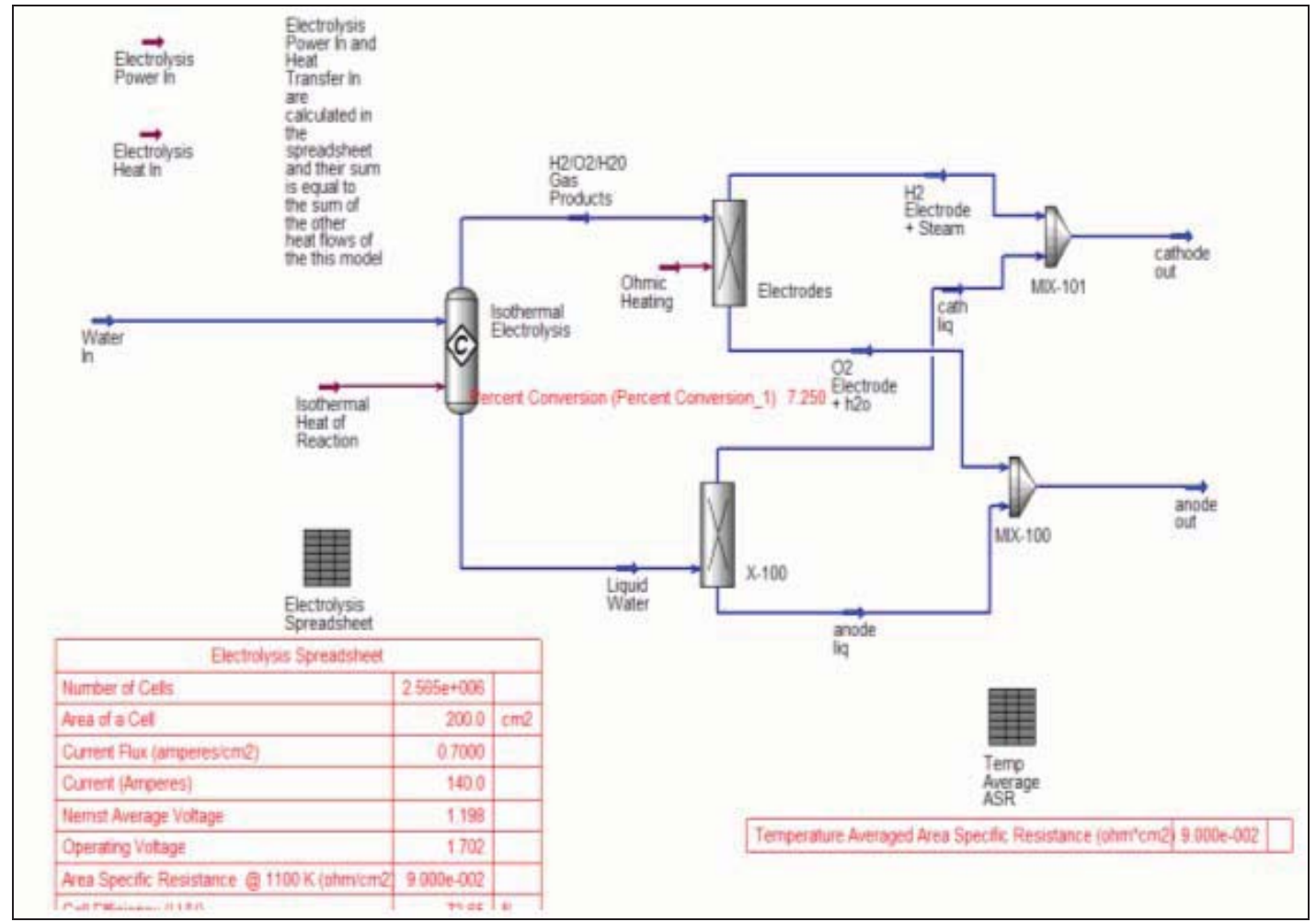

Figure 4-2. Idaho National Laboratory electrolysis model.

\subsection{Arizona Public Service Alternative Fuel Pilot Plant - 13 kg/Day Plant - 50 kW - 19 Vehicles}

APS currently operates a hydrogen production and fueling station in Phoenix, Arizona. This station, known as AFPP (see Figure 4-3), is a model alternative fuel refueling system, consisting of hydrogen, compressed natural gas, and compressed natural gas/hydrogen blends. The plant distinctly separates the hydrogen system from the compressed natural gas system, but can blend the two fuels at the filling system. The plant uses a PEM electrolyzer to produce hydrogen. The hydrogen produced is $99.997 \%$ pure and is compressed to 5,000 psi for delivery to hydrogen fuel vehicles operating in the APS fleet.

\footnotetext{
${ }^{11}$ Process Model for N2H2 Project, Michael McKellar, Idaho National Laboratory, August 2007
} 


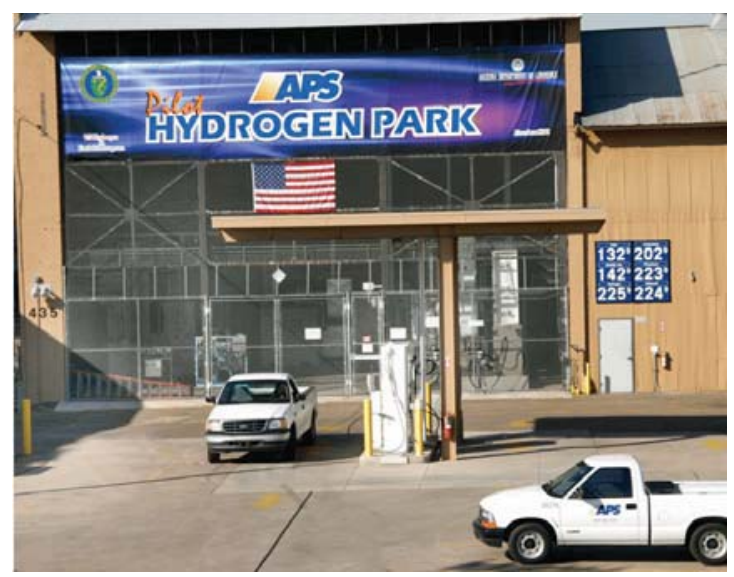

Figure 4-3. Arizona Public Service Alternative Fuel Pilot Plant.

\subsubsection{Station Design}

Appendix B contains the AFPP Station Design Report. The hydrogen system has six primary functions: water purification, production, compression, storage, dispensing, and venting. The equipment can be categorized as electrolyzer (PEM provided by Proton Energy Systems), chilled water system, deionized water system, compressors, air conditioning, hydrogen dryer, hydrogen storage and dispensing, instrument air system, and nitrogen purge system. The process flow diagram is shown in Figure 4-4.

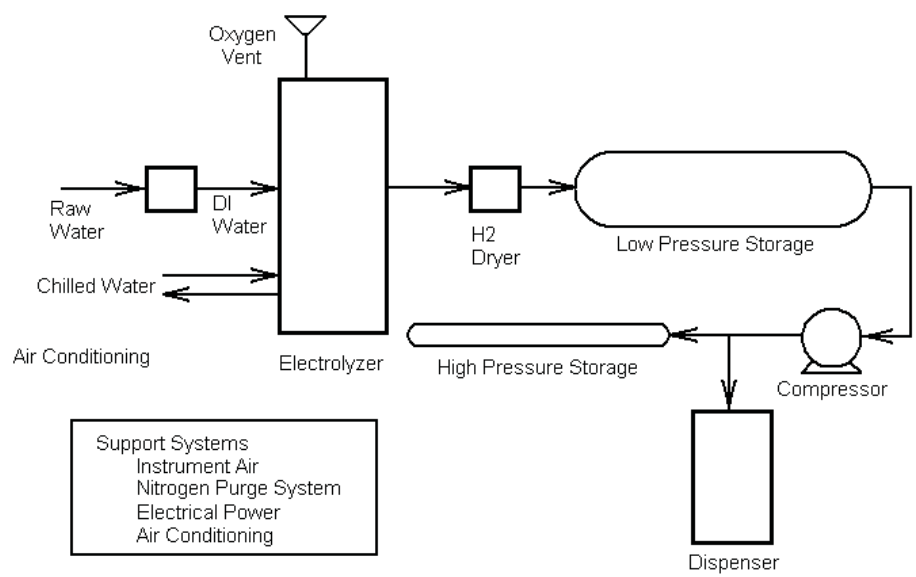

Figure 4-4. Arizona Public Service Alternative Fuel Pilot Plant flow diagram.

This facility began operation in 2003. The initial Proton Energy System Hogen-300 Electrolyzer (18 kg/day) has been replaced with the H-Series Hogen Generator $(13 \mathrm{~kg} /$ day $)$ when the first reached its end of life. Hydrogen is produced at $150 \mathrm{psi}$ and compressed to 5,800 psi for dispensing. The minimum hydrogen purity goal is $99.999 \%$, and the upper limit of purity is $99.99999 \%$ to allow dispensing into fuel cell vehicles.

The H-Series Hogen electrolyzer delivers $228 \mathrm{scf} / \mathrm{hr}$ or $12.9 \mathrm{~kg}$ /day at $215 \mathrm{psi}$. It requires $1.42 \mathrm{gal} /$ hour of de-ionized water and $92.3 \mathrm{kWh} / \mathrm{kg} \mathrm{H}$ produced. This output would classify this unit as a small neighborhood size unit. Currently, the unit is used to support a small fleet of HICE vehicles for use and testing. The $12.9 \mathrm{~kg} \mathrm{H}_{2}$ daily would serve the needs of approximately 24 cars. At an assumed $80 \%$ capacity factor, this would be reduced to 19 vehicles. 
As assumed earlier, the average HFCV travels 32 miles per day and achieves 60 miles $/ \mathrm{kg}$. It is reasonable to assume that car manufacturers would provide enough hydrogen capacity to achieve about the same range as a gasoline car or about 300 miles. That would require an on-board storage of about $5 \mathrm{~kg}$ and would mean that the average car would visit the station about every 6 or 7 days. Therefore, a hydrogen station of this size would expect traffic of about three vehicles per day. While this traffic may be too low for a retail service center, it may be ideal for fleet use. Fleet vehicles typically may travel 150 miles per day or 37,500 miles per year. At 60 miles $/ \mathrm{kg}, 625 \mathrm{~kg} \mathrm{H}_{2}$ would be required per vehicle. This facility would support about six fleet vehicles.

Section 2 addressed other emerging markets for hydrogen and included material handling applications. A recent study showed that a typical sit-down fork truck would use about $2 \mathrm{~kg} \mathrm{H}_{2}$ per day in a heavy duty application or $600 \mathrm{~kg}$ per year. ${ }^{\mathrm{mm}}$ This $13 \mathrm{~kg} \mathrm{H}_{2} /$ day facility would support the operation of six such fork trucks and is likely cost prohibitive. Lighter use trucks would allow more trucks to be serviced. Still, local supply of hydrogen would be more likely.

\subsubsection{Location}

APS chose to construct AFPP in an urban setting to determine the full impact of existing codes and standards and building inspector requirements on station design and the siting process. This approach is unique to fueling station design in the United States and provides unique insight into the requirements for hydrogen fueling stations to be constructed and operated in commercial, rather than industrial, areas. The site is on APS property near the heart of Phoenix in commercially zoned property.

The process of siting began by conducting an occupancy review to determine zoning requirements that would impact design. Because the facility was to be located within an existing building enclosed on three sides, particular attention was given to requirements for indoor facilities. Numerous conflicts between code requirements and station objectives were revealed. In particular, requirements for setbacks between hydrogen and natural gas fuels, and between fuel storage equipment and occupied structures would, if followed, make construction of the APS AFPP on the site impossible. In addition, using the standards governing natural gas installations, the site was considered an outdoor facility (only three walls; see Figure 3-1). However, using the standards governing hydrogen installations, the site was considered an indoor facility. Licensing and permitting used the worst-case scenario (indoor facility). Lessons learned from this installation are included below and in Section 5.

\subsubsection{Ownership}

The facility is owned and operated by the utility APS. The hydrogen (and compressed natural gas) produced at this facility is available to support APS' and other's HICE vehicles. A typical station this size would likely be owned by relatively small fleet users.

\subsubsection{Alternative Fuel Pilot Plant Scaled Design Comments}

Several design aspects of AFPP are considered over-designed either to assist in the original permitting process before such plants were common or to support the specific purpose of this facility. For example, the continuous nitrogen purge into the vent system was designed to eliminate the possibility of hydrogen contacting oxygen in the vent piping. It was included in the design to ease the permitting process but is not commonly used in later designs. The proposed plant models do, however, include onsite nitrogen generators. In each case, use of the nitrogen generator is for generating nitrogen for purging the

\footnotetext{
${ }^{\mathrm{mm}}$ Powering Electric Material Handling Equipment with PEM Fuel Cells, Fast Charged Batteries or Battery Exchange Methods, A Case Study, Electric Transportation Engineering Corporation, 2008.
} 
generator(s) and piping before and after repairs to ensure that the hydrogen concentration is well below the lower flammable limit.

High-pressure hydrogen storage supports disbursing of hydrogen to the local vehicles; however, storage capabilities beyond a few minutes would not normally be a feature of a high throughput production facility. The hydrogen compressor in the model is specified to boost the hydrogen pressure from approximately $150 \mathrm{psig}$ up to $6,000 \mathrm{psig}$ at the full production rate of the plant (e.g., $1 \mathrm{~kg} / \mathrm{sec})$. At this capacity, the compressor matches the fueling rate for the vehicles. High-pressure storage provides a buffer to this direct fill model. In addition, the AFPP system used a diaphragm-style compressor. This style was selected to maintain the purity level of the hydrogen. Over the past several years, several compressor suppliers have developed reciprocating compressors that also maintain hydrogen purity. These reciprocating compressors have lower initial costs and lower operating costs and are available as air-cooled.

Another aspect of performance determined during the test phase is the importance of the hydrogen dryer. When moist hydrogen (even $-40^{\circ} \mathrm{F}$ dew point) is compressed to $6,000 \mathrm{psig}$, the dew point of the gas increases to +40 to $+60^{\circ} \mathrm{F}$. Even in warm climates, this can result in condensation of liquid water in the high-pressure hydrogen lines, which will freeze when the ambient drops below $32^{\circ} \mathrm{F}$. This icing will interfere with operation of downstream flow and pressure controls components and can result in unsafe conditions and operational problems. The dew point of the hydrogen should be -80 to $-100^{\circ} \mathrm{F}$ at the outlet of the dryer.

The AFPP design also uses a chilled water system for cooling the hydrogen compressor. While this was an effective way to cool the diaphragm compressor, it is not a cost-effective solution for larger systems. The hydrogen compressor should be an air-cooled design. The AFPP project has experience with an air-cooled compressed natural gas compressor. This design was very effective even during peak summer temperatures in Phoenix, Arizona.

The AFPP hydrogen generator includes a dedicated fresh air fan. This fan circulates fresh air through the generator enclosure to keep the hydrogen level (and oxygen level) well below the lower flammable limit. In the proposed, scaled-up models, the cell stack rooms will be ventilated and monitored to ensure safe operation. The dedicated fresh air blower will be replaced by a more efficient plant heating, ventilation, and air conditioning system.

Other components of AFPP are capable of performance beyond that required by the actual output. A detailed evaluation of the $1-\mathrm{kg} \mathrm{H}_{2} / \mathrm{sec}$ plant was conducted with costs identified from this evaluation. It is recognized that costs cannot be simply scaled up from AFPP, nor scaled down directly from the $1-\mathrm{kg} / \mathrm{sec}$ plant. Cost estimates for components, along with input to the model, are found in Appendices F, $\mathrm{G}$, and $\mathrm{H}$.

\section{$4.4100 \mathrm{~kg} \mathrm{H}_{2}$ /Day (Small Forecourt) - 575kW - 150 vehicles}

\subsubsection{Design}

This facility would be classified as a small forecourt production facility. The $100 \mathrm{~kg} \mathrm{H}_{2}$ daily would serve the needs of approximately 180 cars. At an assumed $80 \%$ capacity factor, this would be reduced to 150 vehicles. $100 \mathrm{~kg} \mathrm{H}_{2}$ daily requires an electrolyzer capable of approximately $46 \mathrm{Nm}^{3} / \mathrm{hr}$. These are typically self-contained units that are pre-packaged into cabinets or mounted on skids. They contain the electrolyzer and hydrogen dryer, but require chilled water, de-ionized water, purge air, and electrical power to be supplied. Output pressure is typically low (165 to 245 psig historically) and would require compressors and low or high pressure local storage. In addition, they provide no means for 
oxygen capture. A nitrogen purge system would be required to purge the hydrogen or oxygen out of the piping prior to and following maintenance periods. This could be an onsite nitrogen generator, but more likely would be provided as a high-pressure cylinder by an outside source when purging is required. Hydrogen gas output is of purity acceptable to fuel cell use, typically $99.9995 \%$ pure with the contaminants being water, nitrogen, and oxygen at the parts per million level. Advertised power requirements for the electrolyzer are only in the range of 190 to $215 \mathrm{~kW}$. Uptime for such electrolyzers is 99\%. These PEM electrolyzers can be ramped up and down rapidly, usually within 15 seconds.

The $100 \mathrm{~kg} \mathrm{H}_{2} /$ day design is based on existing commercial PEM units. These units are self-contained and generate 50 to $65 \mathrm{~kg} /$ day. The $100-\mathrm{kg} /$ day plant requires two units. Each system contains a control system, power control module, cell stack array, fresh air blower, enclosure, oxygen separator, and de-ionized water management systems. These pre-packaged units can be described as plug-and-play designs. The generator requires $76 \mathrm{kWh} / \mathrm{kg}$ of hydrogen for the cell stacks and another $41 \mathrm{kWh} / \mathrm{kg}$ for the balance of plant systems.

The plant configuration includes a de-ionized water system, PEM hydrogen generator, hydrogen dryer, low-pressure hydrogen gas storage, a high-pressure hydrogen compressor, and high-pressure hydrogen storage vessels. The plant process is similar to AFPP shown in Figure 4-4 above.

The de-ionized water system produces a water quality in excess of 5 mega-ohms resistivity. The system includes water softeners, carbon filters, reverse osmosis module, and circulating pump. The system produces $25 \mathrm{GPH}$.

Current designs produce hydrogen at 165 to 250 psig, but the next generation will produce 400 to 450 psig hydrogen. Each $50 \mathrm{~kg} /$ day hydrogen generator also will produce about 10,600 SCF/day of oxygen at 0 to $40 \mathrm{psig}$. This oxygen may be used onsite for combustion enhancement or similar application if the plant is co-located near such facility. It could be captured and packaged for shipment to an alternate site, but that is a capital intensive requirement that typically requires scale to achieve breakeven economics. The PEM unit generates heat. The cooling requirement is about $5 \mathrm{kWh} / \mathrm{kg}$ of hydrogen produced. A chilled water system is included in the plant design to meet this need.

The hydrogen dryer is a dual bed desiccant-type dryer. This unit regenerates the drying bed with heat and either a hydrogen or nitrogen purge. Approximately $1 \%$ of the hydrogen product is lost to vent to regenerate the dryer bed. The dryer generates -80 to $-100^{\circ} \mathrm{F}$ dew point hydrogen. The vent hydrogen is saturated. It is not suitable for vehicle applications.

The dry hydrogen is stored in a low pressure carbon steel American Society of Mechanical Engineers pressure vessel. Typically, these vessels are designed for 250 to 450 psig MAWP. A cost-effective storage size is 9,000 gal (water volume) horizontal tank. A 250-psig tank will hold about $21,600 \mathrm{SCF}$ of hydrogen. Also, this size and pressure rating is the "building block" for larger systems. This capacity tank will hold approximately 12 hours of production hydrogen.

Vehicle fueling applications typically require a minimum of 5,000 psig delivered into the vehicle storage tank. In most cases, the tanks are filled to 6,200 psig and then allowed to "settle" to 5,000 psig. Consequently, the hydrogen must be stored at 6,000 to 6,500 psig to fill a vehicle. The hydrogen compressor takes hydrogen from the low pressure storage at nominally 250 psig and boosts the pressure to $6,500 \mathrm{psig}$. The compressor is an air-cooled reciprocating design, eliminating the requirement for chilled water for the compressor.

The high-pressure storage vessels are American Society of Mechanical Engineers Section VIII, SA372 Grade J Class 70, Size: 24 in. O.D. $\times .817$ in. M.W. $\times 24 \mathrm{ft} 0 \mathrm{in}$. long. These vessels are available 
in numerous operating pressures. For vehicle fueling, typically the high-pressure storage consists of two or more high-pressure vessels. Vessel one is used for the first part of the fill and then vessel two "tops off" the fill. Another option, typically used in compressed natural gas fueling systems, is a direct fill from the compressor. In this model, the high-pressure storage provides only about 5 hours of buffer storage.

An onsite nitrogen generator is included in the model. Nitrogen is not required to operate any part of the hydrogen system. Nitrogen is, though, used to purge all piping and vessels prior to filling them with hydrogen. This same nitrogen purge is used to purge hydrogen from the system prior to performing maintenance and to purge the system of air after maintenance is performed. High-pressure nitrogen cylinders may be used in lieu of an onsite nitrogen generator.

A compressed air system is included as auxiliary equipment. The air can be used for air-drive tools and pneumatic controls.

A hydrogen station of this size would expect traffic of about 30 vehicles per day or about three vehicles per hour. A station this size could also be used for fleet vehicles. This facility would support about 45 fleet vehicles. This size of station could also support about 50 heavy duty fork trucks.

\subsubsection{Location}

Traffic as light as three vehicles per hour would not be sufficient on its own for retail outlets. Additional services would be required, such as convenience shopping or dispensing gasoline or diesel in addition to the hydrogen. One dispensing unit at a service station may be sufficient. This size unit may be considered part of an early hydrogen infrastructure development. As noted in Section 3, early infrastructure is designed to generate confidence in the availability of hydrogen for the HFCVs before it becomes commercially attractive. Some retailers may wish to install a system as part of a marketing program on company values toward clean transportation. Grants that offset equipment and installation costs also may contribute toward acceptance of this size unit.

\subsubsection{Ownership}

Ownership of the production facility would likely be a private merchant. Fleet users or service station owners would be likely owners. Manufacturers using significant quantities of material handling equipment, such as distribution centers, also may be owners. If it is part of the infrastructure development, other retailers could be owners. It is unlikely that utilities would be interested in ownership in this size of production facility.

\subsubsection{Electrical Supply and Pricing}

As a comparatively small production plant, this facility would likely be powered from the local grid. Electricity pricing likely would be commercial rates.

\section{$4.51500 \mathrm{~kg} \mathrm{H}_{2} /$ Day (Large Retail) - 3.8 MWe - 2,200 Vehicles}

\subsubsection{Design}

This facility would be classified as a large retail/forecourt production facility. The $1500 \mathrm{~kg} \mathrm{H}_{2}$ daily would serve the needs of approximately 2,740 cars, again reduced to 2,200 with an $80 \%$ capacity factor. The $1,500 \mathrm{~kg} \mathrm{H}_{2}$ daily requires an electrolyzer capable of approximately $695 \mathrm{Nm}^{3} / \mathrm{hr}$. This is beyond the current capability of any PEM manufacturer without paralleling the outputs of several units. One PEM 
manufacturer has initial plans for electrolyzers producing $500 \mathrm{~kg} \mathrm{H}_{2} /$ day. Three of these units are assumed in the design of the $1500-\mathrm{kg} \mathrm{H}_{2} /$ day unit.

A $1500-\mathrm{kg} \mathrm{H}_{2}$ /day facility would provide the hydrogen needs for about 2,200 vehicles. Again, assuming that the average vehicle would visit a station about every 6 or 7 days, a hydrogen station of this size would expect traffic of about 367 vehicles per day or about 37 vehicles per hour. At an average fill time of about 10 to 15 minutes, six to nine dispensing locations would be required. Naturally, there are busier times of the day; therefore, demand would increase the number of dispensing locations to about 15. This would be about the maximum any service location could handle. This production design could function for a local disbursement location and for a supply center for hydrogen to be distributed elsewhere.

The flow sheet for a $1500-\mathrm{kg} /$ day system is shown in Figure 4-5. At $1500 \mathrm{~kg} /$ day, capturing the oxygen volume (about 13,000 SCFH) is more attractive. An oxygen blower or compressor can be added to the plant.

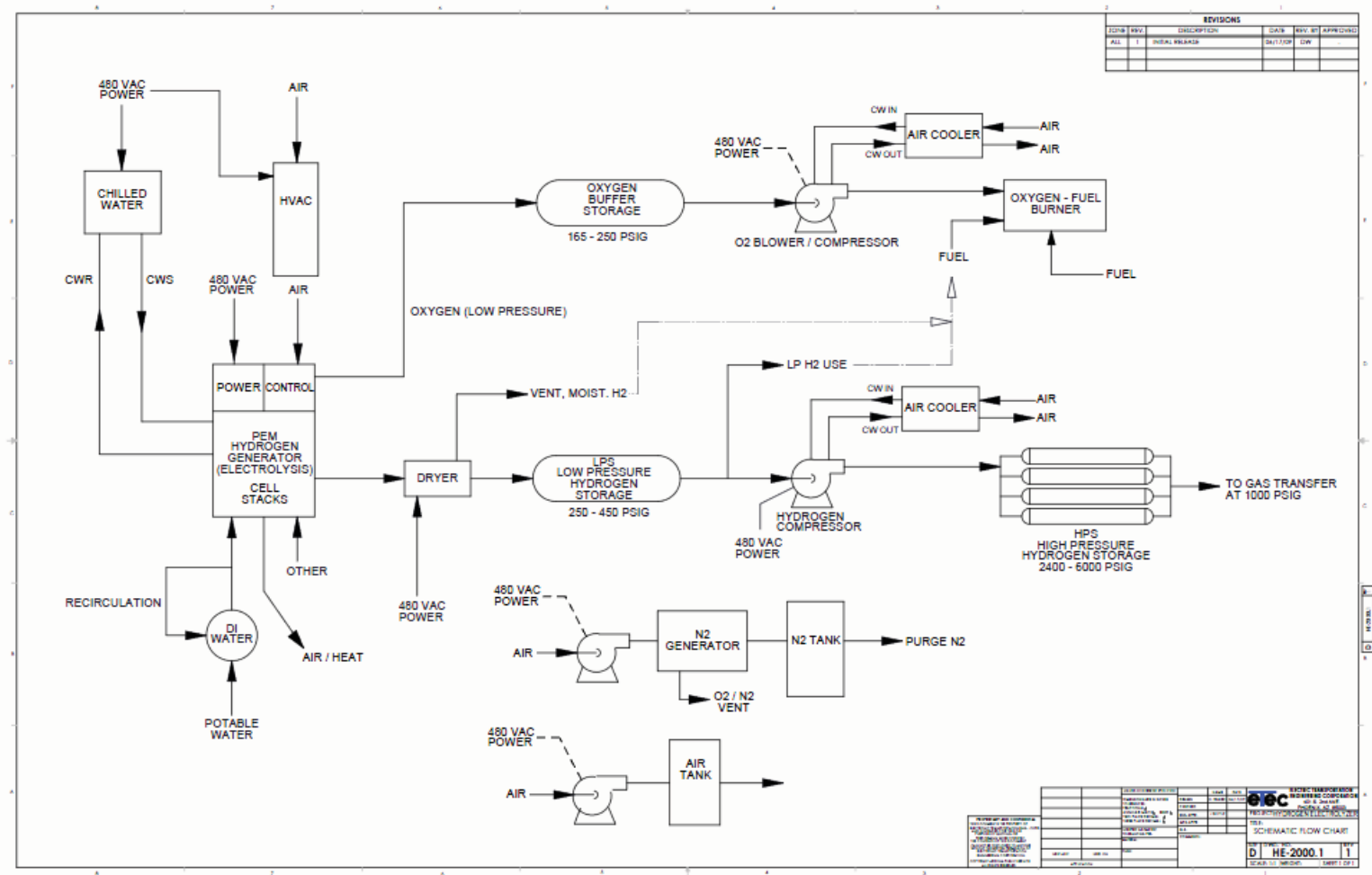

Figure 4-5. Process flow diagram for large hydrogen production facility.

The basis for the hydrogen plant is still a pre-packaged, self-contained PEM generator. In large part, the controls and balance of plant are modestly larger than the scale for the $100-\mathrm{kg}$ /day generator. However, additional cell stacks and a large power supply are added to the $1500 \mathrm{~kg}$ /day system to obtain the desired output. The generator is still a plug-and-play design like the 100-kg/day unit (Figures 4-6 and $4-7)$.

The downstream subsystems are scaled proportionate to the generator output. There are economies of scale as indicated in Appendices F through H. The capital cost model includes low-pressure and high-pressure increments of storage: 45 minutes of low-pressure hydrogen storage, 60 minutes of high- 
pressure hydrogen storage, and 1.5 hours of oxygen low-pressure storage. The low-pressure storage vessels are 9,000-gal, 250 psig MAWP carbon steel tanks. The high-pressure storage vessels are American Society of Mechanical Engineers Section VIII, SA372 Grade J Class 70, Size: 24 in. O.D. × .817 in. M.W. $\times 24 \mathrm{ft} 0$ in. long. The high-pressure storage consists of three of these vessels manifolded together. The vessels are mounted on a steel horizontal frame in one row, three across configuration.

\subsubsection{Location}

This would be a very large facility and, as a disbursing station, would be a stand-alone station. It would likely be built in a high traffic area along a major freeway in a metropolitan area for easy access. It could be located at a service island on a major freeway servicing traffic in both directions. In a full hydrogen economy, it may also provide blended-diesel fuel.

\subsubsection{Ownership}

A service station this size would likely be privately owned by a major vehicle fuel supplier or other merchant.

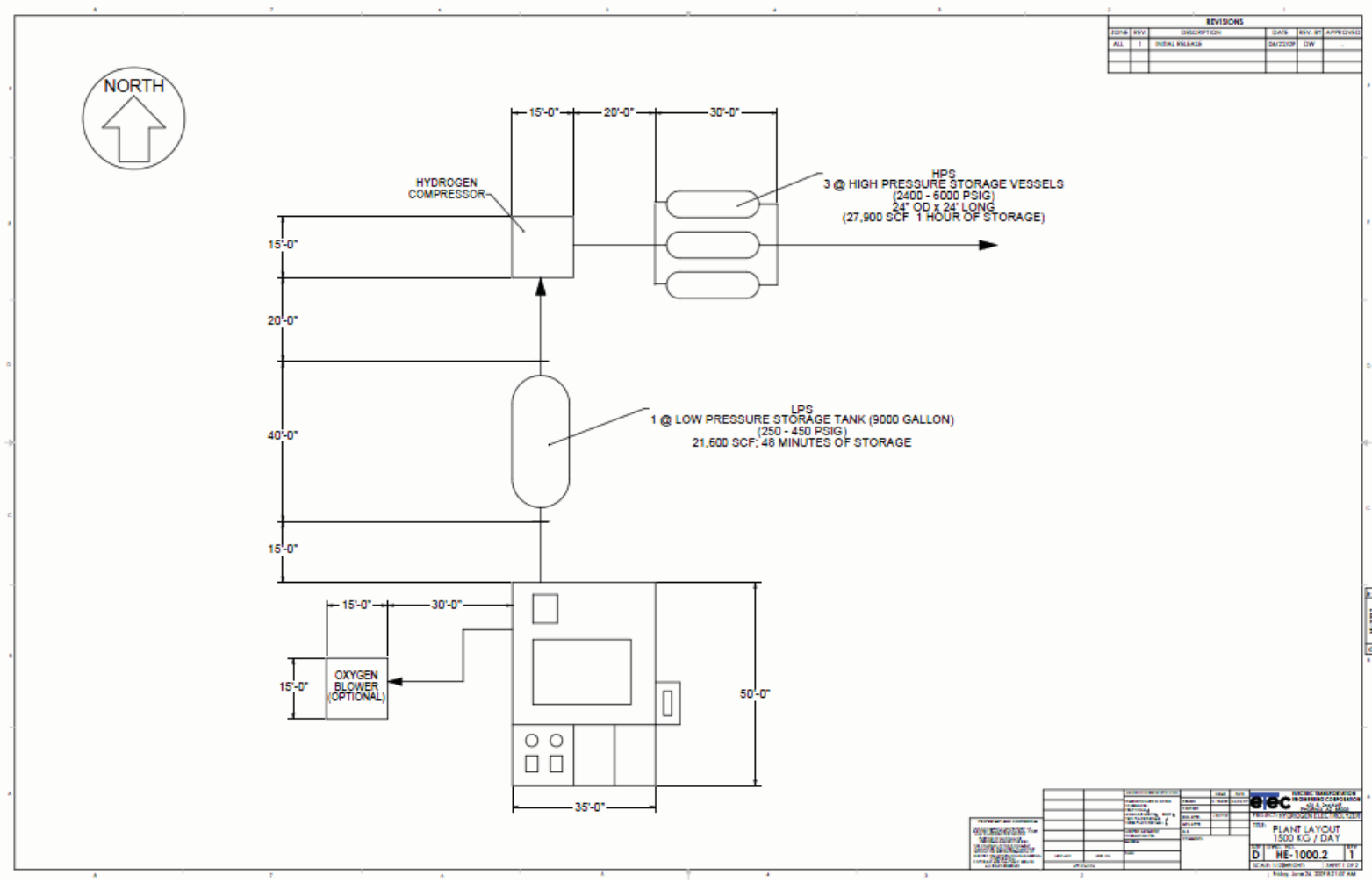

Figure 4-6. Physical plant layout for the $1500-\mathrm{kg}$ /day facility. 


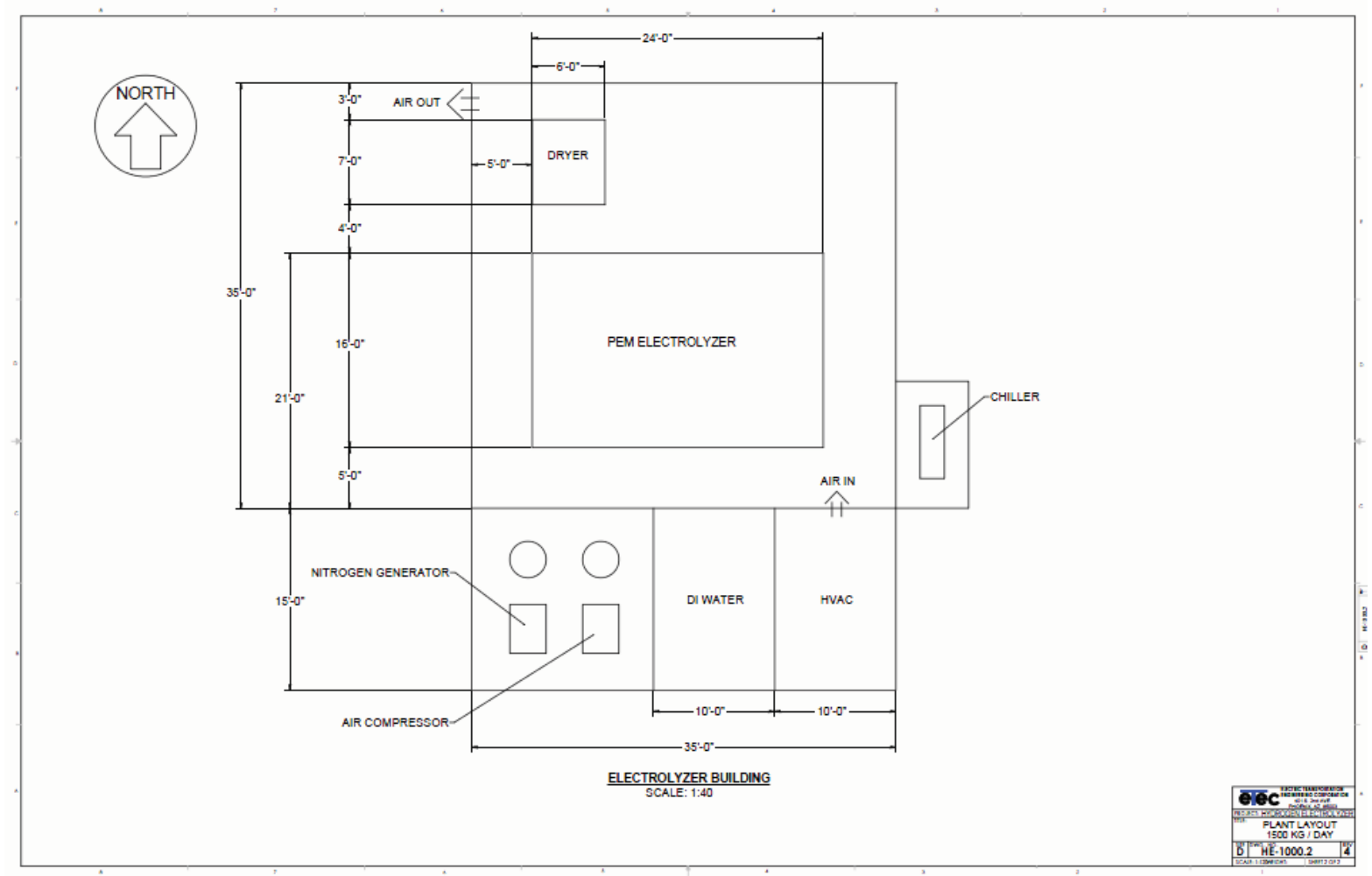

Figure 4-7. Equipment room layout for the 1500-kg/day production facility.

\subsubsection{Electrical Supply and Pricing}

This facility would likely be powered from the local grid. Electricity pricing likely would be industrial or negotiated rates, and the rates might include smart grid features such as agreed upon roll-back of production at times of peak power. In addition, this facility may likely take advantage of the shoulder mode for purchasing power in a combination of on-peak and off-peak periods. The required production of hydrogen may drive the shoulder price set point. See Section 5 for price models.

\section{6 $1 \mathrm{~kg} \mathrm{H}_{2} / \mathrm{sec}$ (City Gate) - $215 \mathrm{MWe}-125,000$ Vehicles}

\subsubsection{Design}

This facility would be classified as a large forecourt production facility. The $1 \mathrm{~kg} \mathrm{H}_{2} / \mathrm{sec}$ or $86,400 \mathrm{~kg} \mathrm{H}_{2}$ daily would serve the needs of approximately 157,680 cars; reduced to about 125,000 with an $80 \%$ capacity factor. This size of facility is beyond the current capability of any PEM manufacturer. The largest proposed design is a $1500-\mathrm{kg} /$ day system that in essence is three $500-\mathrm{kg} /$ day units mounted on a common shipping skid. The $1-\mathrm{kg} / \mathrm{sec}$ plant would require 60 such systems. One embodiment of a $1-\mathrm{kg} / \mathrm{sec}$ plant is to install 60 stand-alone, plug-and-play units. However, this concept results in significant duplication of infrastructure and PEM balance of plant subsystems. A more cost-effective configuration would resemble a large chlor-alkali plant. This configuration would locate the cell stacks/arrays in a separate hydrogen generation room. The power supplies, controls, dryer(s), and other balance of plant items would be located in separate rooms as shown in Figure 4-6. With this configuration, the generator enclosures are eliminated and economies of scale on the plant control system are possible. 
This facility would not be a local disbursing facility, but would be a production center for the distribution of hydrogen. That distribution could be through pipeline or delivery truck so onsite hydrogen storage is minimal. From lessons learned from AFPP, the hydrogen compressor is an air-cooled compressor and not a chilled water system, thus the chilled water is sized only for the electrolyzer. Again, based on lessons learned, the nitrogen system is much smaller and is sized for maintenance purges only. The functional process flow would be similar to that of Figure 4-5 above. A more detailed plant layout is shown in Figures 4-8 and 4-9.

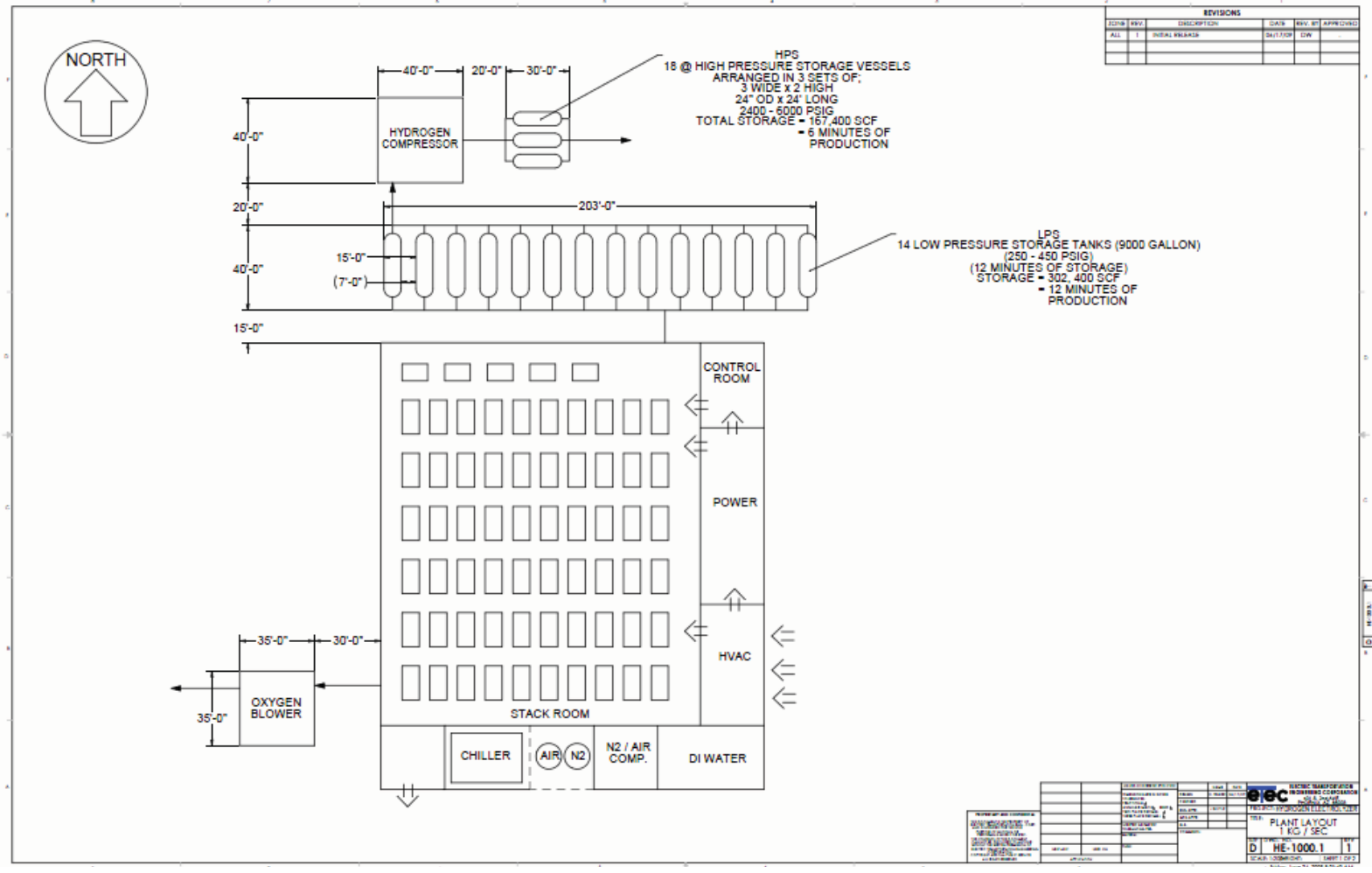

Figure 4-8. Physical plant layout for the $1-\mathrm{kg} / \mathrm{sec}$ production facility.

\subsubsection{Location}

The size and complexity of this station would necessitate its construction in an area specifically selected and permitted for this application (see Section 7 for more specifics on licensing and environmental issues.) It would require access to the electrical power grid and a significant source of water (see Section 6 for a further discussion on water.)

\subsubsection{Ownership}

This facility will likely be owned by the utility, non-profit cooperatives, or large public or private companies. Public policy in areas of regulation and taxation may drive ownership in one direction or another.

\subsubsection{Electrical Supply and Pricing}

As a significant user of electricity, the rates charged will be negotiated. It is likely that demand response will be a large factor in pricing. If the facility is utility owned, it is likely that production will 
occur at low electricity demand times to reduce the cost of the input power. Merchant owners will likely balance production requirements with the cost of power.

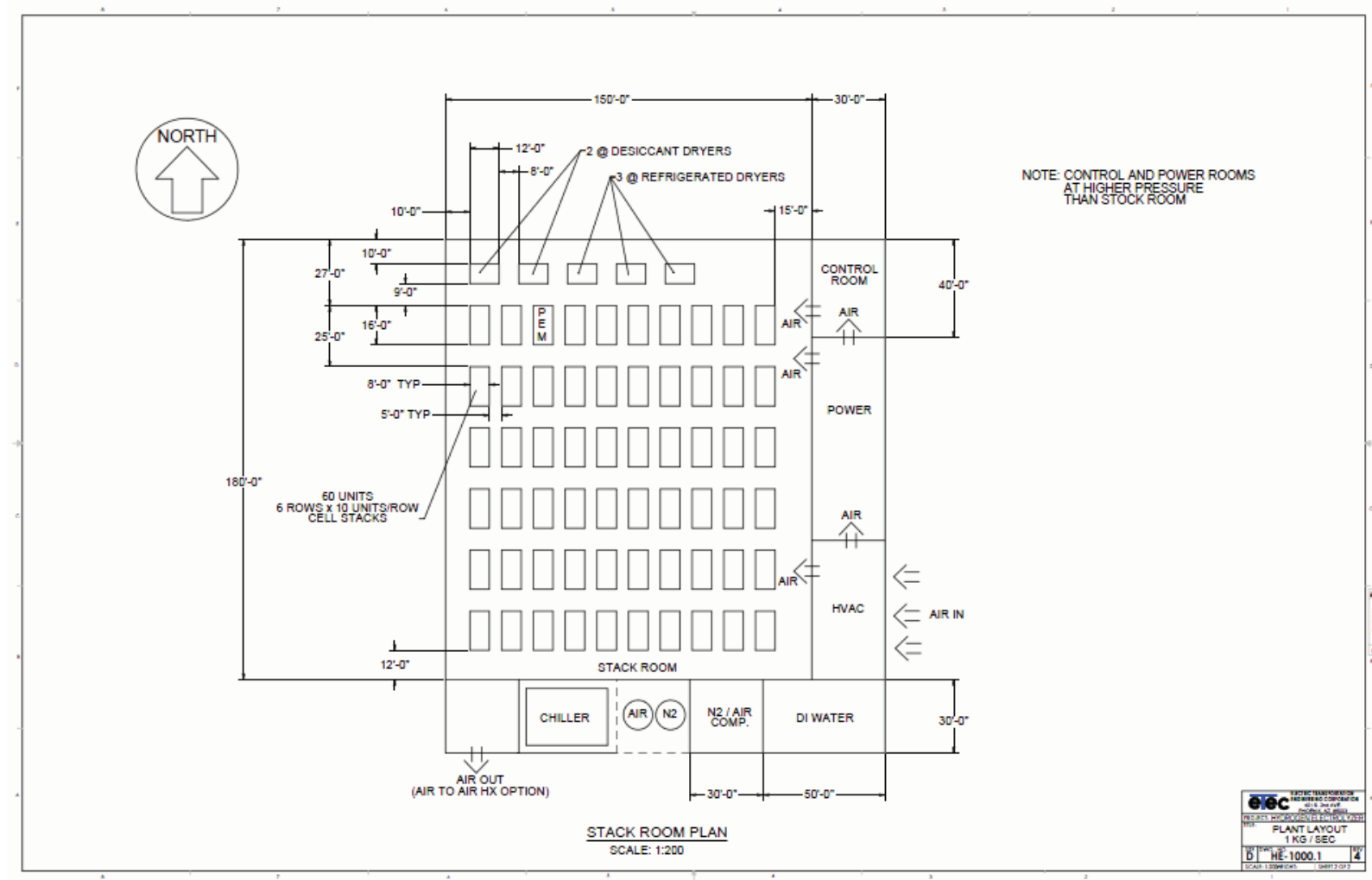

Figure 4-9. Stack room plan for the $1-\mathrm{kg} / \mathrm{sec}$ production facility.

\subsection{Large-Scale Alkaline Electrolysis}

Alkaline-based electrolysis systems have significant operating history and proven reliability. Compared to PEM electrolyzers, alkaline-based systems have a lower initial cost and lower specific power requirements $(\mathrm{kWh} / \mathrm{kg}$ of H2) than PEM. Alkaline systems produce hydrogen having a purity of 99.998\%. Product from an alkaline unit contains up to 70 PPB of CO/CO2/THC that is not typically found in PEM-generated hydrogen. Ramp up and ramp down time is very short (i.e., under 15 seconds). Alkaline systems can produce hydrogen at up to $440 \mathrm{psig}$, though 165 psig is more typical. A drawback of alkaline systems versus PEM is the need for alkaline solution (approximately 200 gal for a $100-\mathrm{kg} / \mathrm{day}$ unit). The de-ionized water requirements are similar to that for a PEM unit. Environmental requirements are similar to the PEM. Alkaline units require replacement of the alkaline solution at regular service intervals.

The balance of plant downstream of the alkaline generator is identical to that for the PEM. The alkaline systems are usually configured as plug-and-play but they also can be engineered to separate the stack array from the controls, power supplies, and other balance of plant subsystems. 


\section{ECONOMIC ASSESSMENT OF HYDROGEN PRODUCTION FACILITIES}

Hydrogen production through electrolysis for the larger size facilities identified in the previous section has not been designed or constructed yet. A significant amount of operational data has been collected at APS AFPP. That data and system design are very helpful in scaling up a balance of plant design for use in economic analysis. In order to complete the analysis, a model for making the economic assessment was prepared, along with a specific engineering effort to size equipment to obtain accurate equipment costs. The equipment costs were input to the model as identified in Appendices F through $\mathrm{H}$. Results of the specific assessments are identified in Appendix J.

\subsection{Idaho National Laboratory Model N2H2 Economic Assessment Model ${ }^{\mathrm{nn}}$}

\subsubsection{Economic Assessment}

The model prepared by the Idaho National Laboratory is an economic assessment rather than a financial assessment. Financial assessments evaluate the economic performance of an investment with the consideration of organizational specific, financial issues. An economic assessment evaluates the economic performance of an investment within the context of a generic market and a generic organization without consideration of organizational specific financial issues. This assessment tool seeks to answer the problem statement: How can we determine with reasonable confidence, the economic viability of the proposed N2H2 technology system?

Economic viability is the ability of the investment to recover all costs of production over its lifetime through the sale of beneficial hydrogen and other products. The $\mathrm{N} 2 \mathrm{H} 2$ technology system is the summation of production and distribution assets and associated operations required for hydrogen sales at the target pressure. The primary benefit of the production facility will be derived from the sale of hydrogen. However, other products and services may be available as by-products or tax-credits: hydrogen as an industrial feedstock at lower quality and pressure, oxygen, and carbon credit.

\subsubsection{Model Description}

The economic assessment uses a pro forma model. This models the year-to-year costs and benefits associated with the investment. It uses Excel software to provide columns to tally costs and benefits year-to-year and rows to tally subject and identifiable costs or benefits. This format easily allows for present value discounting. Discount or present value analysis is the preferred assessment method because the timing of cash flows is accounted for with respect to risk.

Costs and benefits are organized according to the investment life cycle: pre-operations, operations, and post-operations as follows

- $\quad$ Pre-operations assume technology is mature and research and development costs would not be recovered through a capital recovery charge. Site acquisition and development is site specific and time intensive but not costly and would probably be heavily influenced by the deployment strategy. Capital acquisition and deployment are based on the product distribution strategy and site-specific

\footnotetext{
${ }^{n n}$ M. M. Plum, Proposed Economic Assessment for Conceptual Design in the Deployment of the N2H2, Idaho National Laboratory, August 2007.
} 
issues such as local labor, regulations, and seismic issues. This total is considered the "capital investment."

- $\quad$ Operations include commissioning and startup, operating costs, operating revenues, planned downtimes, unplanned downtimes, annual maintenance, capital maintenance, and final shut-down.

- $\quad$ Post-operations include decommissioning costs, post-operations planning and engineering costs, and post-operation revenues. It is assumed that there will be a salvage value and this will be sufficient to fund the post-operations phase.

Costs primarily are a function of production output, revenues are primarily a function of the local market, and the "net" is determined by these differences year to year. The return is determined by the internal rate of return on cash flows before taxes are considered. Therefore, a pre-tax discount or rate of return of $15 \%$ would be competitive.

\subsubsection{Model Assumptions}

The H2A model has been widely used in these types of evaluations. However, at the time of these systems evaluations, the H2A assumptions were out of date. This methodology is identical as an economic assessment but may be deficient in that financial issues are ignored as these are typically specific. This deficiency in financial assessment has been accounted for using a more robust, pre-tax discount rate. Model assumptions, like the $\mathrm{H} 2 \mathrm{~A}$ assumptions, include the following:

- $\quad$ Analysis methodology - discounted cash flow model that calculates a levelized hydrogen price that yields a prescribed internal rate of return

- $\quad$ Reference financial structure $-100 \%$ equity with $10 \%$ internal rate of return and includes levelized hydrogen price plot for 1 to $25 \%$ internal rate of return

- $\quad$ Reference year dollars - 2005 to be adjusted at half-decade increments (e.g., 2005 and 2010)

- Technology development state - all central and forecourt cost estimates are based on mature, commercial facilities

- Inflation rate $-1.9 \%$ but with resultant price of hydrogen in reference year constant dollars

- Income taxes $-35 \%$ federal, $6 \%$ state, and $38.9 \%$ effective

- $\quad$ Property taxes and business insurance $-2 \%$ year of the total initial capital cost

- Sales tax - not included on the basis that facilities and related purchases are wholesale and through a general contractor entity

- Working capital rate $-15 \%$ of the annual change in the total operating costs

- $\quad$ Analysis period - 40 years for central and 20 years for forecourt

- $\quad$ Facility life -40 years for central with case exceptions and 20 years for forecourt with case exceptions 
- $\quad$ Depreciation type and schedule for initial depreciable capital cost - MACRS - 20 years for central with case exceptions and 76 years for forecourt

- $\quad$ Construction period and cash flow - varies per case for central and 0 for forecourt

- $\quad$ Planned replacement capital - post startup capital costs spread over time based on specific replacement estimates. Depreciation is based on MACRS schedule and 7 years or the same as the replacement period if it is shorter than 7 years.

- Unplanned replacement capital - specific percentage of initial depreciable capital cost meant to handle unplanned replacement capital expenses that occur during an operating year of the plant. Depreciation is based on MACRS schedule and 7 years.

- Project contingency - percent adjustment to the total initial capital cost so the result represents the mean or expected cost value. Periodic replacement capital includes project contingency.

- $\quad$ Process contingency - percent adjustment to the total initial capital cost so the result incorporates the mean or expected overall performance

- $\quad$ Land cost $-\$ 5,000 /$ acre purchase for central and $\$ 0.50 / \mathrm{sq} \mathrm{ft} /$ month for long-term lease for forecourt

- $\quad$ Capital factor $-90 \%$ for central with case exceptions and $70 \%$ for forecourt

- $\quad$ Average burdened labor rate for staff $-\$ 50 /$ hour for central and $\$ 15 /$ hour for forecourt

- General and administrative rate $-20 \%$ of the staff labor costs above

- $\quad$ Forecourt maintenance and repair - 5\%/year of initial depreciable capital cost for small capacity and $3 \% /$ year for large capacity

- Co-produced and co-generated electricity price - \$30/MWh with sensitivities based on \$20/MWh low and \$50 MWh high (see also specific "shoulder" pricing in the examples below)

- $\quad \mathrm{CO}_{2}$ incentive (when $\mathrm{CO}_{2}$ sequestration is not plausible) - not included in base cases, sensitivity included at $\$ 100 /$ tonne $\mathrm{C}\left(\$ 27.30 /\right.$ tonne $\left.\mathrm{CO}_{2}\right)$ for central and forecourt

- $\quad \mathrm{O}_{2}$ credit - not included in base cases, sensitivities included at $\$ 20 /$ tonne for central and forecourt

- $\quad$ Salvage value $-10 \%$ of initial capital with case exceptions and $0 \%$ for forecourt

- Decommissioning - $10 \%$ of initial capital with case exceptions $0 \%$ for forecourt

- Hydrogen pressure at central gate - 300 psig; if higher pressure is inherent to the process, apply pumping power credit for pressure greater than 300 psig

- $\quad$ Central storage - buffer only as required for efficient operation

- Hydrogen storage pressure at forecourt - 6,250 psig 
- $\quad$ Forecourt compressed hydrogen storage $-87.5 \%$ of maximum daily production (based on $35 \%$ of production divided by an assumed $40 \%$ dispensable hydrogen fraction)

- $\quad$ Hydrogen purity - 98\% minimum; CO less than $10 \mathrm{ppm}$, and sulfur less than $10 \mathrm{ppm}$

- $\quad$ Sensitivity variables and ranges - based on applying best judgment of $10 \%$ and $90 \%$ confidence limit extremes to the most significant baseline cost and performance parameters.

Before applying this model to the plant designs of $100 \mathrm{~kg} \mathrm{H} 2 /$ day, $1500 \mathrm{~kg} \mathrm{H} 2 /$ day and $1 \mathrm{~kg}$ $\mathrm{H} 2 / \mathrm{sec}$, the next section will review the economics of the existing AFPP.

\subsection{Alternative Fuel Pilot Plant 13-kg/Day Economic Assessment}

Five months of data from operation of the APS AFPP were gathered and analyzed to identify operating strategies for developing costs of hydrogen production. Strategies were developed for operating production equipment in three modes. In winter mode, production equipment is operated continuously. In shoulder mode, production equipment is operated only when the price of electricity is below a preset maximum of $\$ 55.00 / \mathrm{MWhr}$ (refer to Section 2.4). In summer mode, production equipment is operated only during off-peak electric cost periods. Subsequently, AFPP was operated for 3 months in each of the three production modes. Costs for hydrogen production were calculated using the actual price for electricity delivered at the PVNGS electrical switchyard in 2006. The price of electricity at the PVNGS switchyard was used for this simulation of hydrogen production cost, as it represents the opportunity cost for using electricity to produce hydrogen rather than to sell in the wholesale market. The AFPP cost of electricity for hydrogen production in each mode was as follows:

- $\quad$ Winter mode $\$ 9.16 / \mathrm{kg}$

- $\quad$ Shoulder mode $\$ 3.63 / \mathrm{kg}$

- $\quad$ Summer mode $\$ 11.80 / \mathrm{kg}$.

These costs were significantly influenced by the efficiency of the electrolyzer and by efficiency improvements achieved by implementing lessons learned from operation of AFPP. Using historical data from AFPP operation and the price of electric energy at PVNGS electrical switchyard in 2006, the following hydrogen production costs were estimated for AFPP:

- $\quad$ Winter mode $\$ 5.90 / \mathrm{kg}$

- $\quad$ Shoulder mode $\$ 5.68 / \mathrm{kg}$

- $\quad$ Summer mode $\$ 7.57 / \mathrm{kg}$.

It can be seen that while the shoulder mode is the least expensive production period, the variation between the shoulder mode and the winter and summer modes is small in comparison to the variation resulting from operation in the three production modes of Task 1.2. The predominate cause for the significant reduction in shoulder mode costs over those achieved in summer and winter modes was the replacement of the electrolyzer at the beginning of the shoulder production mode and the resultant elimination of the losses associated with the hydrogen dryer. Nevertheless, the shoulder mode remains the least expensive production strategy. 
A detailed evaluation of the other components of the system during operation revealed a significant contribution to overall cost of the chilled water system (see Table 5-1).

Table 5-1. Chiller electricity use.

\begin{tabular}{|c|c|c|c|c|c|c|c|c|c|}
\hline & \multicolumn{2}{|c|}{ Chiller (kWh) } & \multicolumn{2}{|c|}{ Electrolyzer (kWh) } & \multicolumn{2}{|c|}{ Total (kWh) } & \multirow{2}{*}{$\begin{array}{c}\mathrm{H} 2 \\
(\mathrm{~kg})\end{array}$} & \multirow{2}{*}{$\begin{array}{c}\text { Chiller } \\
(\% \text { of Elyzr) }\end{array}$} & \multirow{2}{*}{$\begin{array}{c}\text { Chiller } \\
(\% \text { of Total })\end{array}$} \\
\hline & On Peak & Off Peak & On Peak & Off Peak & On Peak & Off Peak & & & \\
\hline Shoulder & $7,576.3$ & $5,346.7$ & $25,812.8$ & $22,741.7$ & $35,747.0$ & $29,972.6$ & 712.3 & $26.6 \%$ & $19.7 \%$ \\
\hline Summer & $9,506.6$ & $1,508.2$ & 836.7 & $21,163.7$ & $18,995.8$ & $38,804.2$ & 216.1 & $50.1 \%$ & $19.1 \%$ \\
\hline Winter & $21,852.4$ & $9,426.5$ & $59,140.2$ & $28,035.6$ & $89,774.9$ & $40,343.3$ & 720.6 & $35.9 \%$ & $24.0 \%$ \\
\hline Total & $38,935.3$ & $16,281.4$ & $85,789.7$ & $71,941.0$ & $1444,517.7$ & $109,120.1$ & $1,649.0$ & $35.0 \%$ & $21.8 \%$ \\
\hline
\end{tabular}

If the chiller energy use is eliminated during the shoulder mode, when the high-efficiency electrolyzer is employed, an energy efficiency of $74.1 \mathrm{kWh} / \mathrm{kg}$ is achievable. This would increase AFPP efficiency to $45 \%$. It is estimated that AFPP would operate at this efficiency if the following designs were adopted:

- Use air cooling or an evaporative cooling tower for plant cooling water

- $\quad$ Minimize the use of nitrogen in plant operations

- Use electronic controls rather than pneumatic controls

- Minimize hydrogen losses during dryer regeneration

- $\quad$ Limit electrolyzer stack life to its economic life.

The total electrical energy required for the shoulder mode was $65,719.6 \mathrm{kWh}$ for these 3 months. The electrical cost for this mode was $\$ 2,449.85$ for an average cost of $\$ 0.0373 / \mathrm{kWh}=\$ 37.30 / \mathrm{MWH}$. Recall, that it was noted above that the shoulder electric price was picked to be no greater than \$55/MWH.

During the 3 months of shoulder mode, the plant required $92.3 \mathrm{kWh}$ for each $\mathrm{kg} \mathrm{H}_{2}$ produced. The electrolyzer total was $48,554.4 \mathrm{kWh}$ for an electrolyzer efficiency of $68.2 \mathrm{kWh} / \mathrm{kg}$. This is very close to the advertised efficiency. The overall cost of hydrogen production was an average of $\$ 3.63 / \mathrm{kg}$.

Setting the shoulder price at $\$ 55$ in 2006 would have provided a total of $60 \%$ unit availability. That is, the unit would have operated 5,256 hours to produce $2,847 \mathrm{~kg}$ hydrogen for an effective delivery rate of $7.8 \mathrm{~kg} \mathrm{H}_{2}$ per day. The average cost would have been $\$ 42.32 / \mathrm{MWh}$ for the entire year.

The 5 months of plant data provide great insight into annual production rates and costs associated with each of the operating modes using PVNGS cost data from 2006. Results are shown in Table 5-2.

Table 5-2. Annual production and costs at shoulder price of \$55/MWH.

\begin{tabular}{|l|r|r|r|r|r|r|r|r|}
\hline \multicolumn{1}{|c|}{ Mode } & \multicolumn{1}{|c|}{$\begin{array}{c}\text { Availability } \\
(\%)\end{array}$} & $\begin{array}{c}\text { Average } \\
\text { Cost } \\
(\$ / \mathrm{MWH})\end{array}$ & $\begin{array}{c}\text { Production } \\
\text { Rate } \\
(\mathrm{kg} / \text { day })\end{array}$ & $\begin{array}{c}\text { Total kg H2 } \\
(100 \% \mathrm{CP})\end{array}$ & $\begin{array}{c}\text { Total } \\
\text { Power } \\
(\mathrm{MWH})\end{array}$ & $\begin{array}{c}\text { Daily Eff. } \\
\text { Rate } \\
(\mathrm{kg} / \text { day })\end{array}$ & $\begin{array}{c}\text { Cars } \\
\text { Served }\end{array}$ & $\begin{array}{c}\text { Cost } \\
(\$ / \mathrm{kg})\end{array}$ \\
\hline All Conditions & 100 & $\$ 49.41$ & 13 & 4745 & 437.96 & 13 & 23.7 & $\$ 4.56$ \\
\hline Off-Peak Only & 44 & $\$ 42.10$ & 13 & 2093 & 193.14 & 5.7 & 10.5 & $\$ 3.89$ \\
\hline Shoulder & 60 & $\$ 43.32$ & 13 & 2847 & 262.78 & 7.8 & 14.2 & $\$ 4.00$ \\
\hline
\end{tabular}


Setting the shoulder price at $\$ 60 / \mathrm{MWH}$ in 2006 instead of $\$ 55 / \mathrm{MWH}$ would have provided a total of $85 \%$ unit availability. That is, the unit would have operated 7,448 hours to produce $4034 \mathrm{~kg}$ hydrogen for an effective delivery rate of $11.1 \mathrm{~kg} \mathrm{H}_{2}$ per day. The average cost would have been $\$ 44.99 / \mathrm{MWh}$ and hydrogen production $\$ 4.15 / \mathrm{kg}$ for the entire year.

The trade-off between the hydrogen produced and the cost of electricity is clear. Limiting the cost of electricity reduces the cost of production, but also reduces the quantity of hydrogen produced.

The 5 months of test also provide great insight into electrical consumption for the balance of plant. This consumption on an annual basis is shown in Table 5-3.

Table 5-3. Balance of plant electrical consumption (kWh).

\begin{tabular}{|l|c|c|c|c|c|c|c|c|}
\hline & $\mathrm{Kg} \mathrm{H}_{2}$ & $\begin{array}{c}\text { Chiller } \\
\text { System }\end{array}$ & $\begin{array}{c}\text { De-ionized } \\
\text { Water }\end{array}$ & $\mathrm{H}_{2}$ Compressor & $\begin{array}{c}\text { Air } \\
\text { Conditioner }\end{array}$ & $\begin{array}{c}\text { Instrument } \\
\text { Air System }\end{array}$ & $\begin{array}{c}\text { Nitrogen } \\
\text { System }\end{array}$ & Total \\
\hline Annual & 3484 & 162246 & 1042 & 17161 & 3835 & 2407 & 19545 & 206236 \\
\hline
\end{tabular}

The information in Table 5-3 will be used in the following discussion on economics of larger units. Of additional interest is the de-ionized water requirement. The usage and cost is summarized in Table 5-4 along with an annualized amount.

Table 5-4. Water Requirements for the Alternative Fuel Pilot Plant.

\begin{tabular}{|l|r|r|r|}
\hline \multicolumn{1}{|c|}{ Mode } & $\mathrm{Kg} \mathrm{H}_{2}$ Produced & Water Use (gal) & \multicolumn{1}{c|}{ Water Cost } \\
\hline All Conditions & 1425 & 62,152 & $\$ 288$ \\
\hline Off-Peak Only & 618 & 18,666 & $\$ 69$ \\
\hline Shoulder & 1441 & 74,145 & $\$ 188$ \\
\hline Annualized & 3484 & 154,963 & $\$ 485$ \\
\hline
\end{tabular}

It should be pointed out that the measured water requirements show it takes about 44.5 gal of water to produce $1 \mathrm{~kg}$ hydrogen. The ideal is about $2.5 \mathrm{gal}$ per $\mathrm{kg}$. The difference here is the efficiency of the water purification system which is $6 \%$ in delivering the water meeting the electrolyzer specifications. Efficiencies of equipment vary with cost and can reach as high as $40 \%$.

Plant and equalizer efficiencies determine how cost of electricity affects the cost of hydrogen as shown in Figure 5-1. 


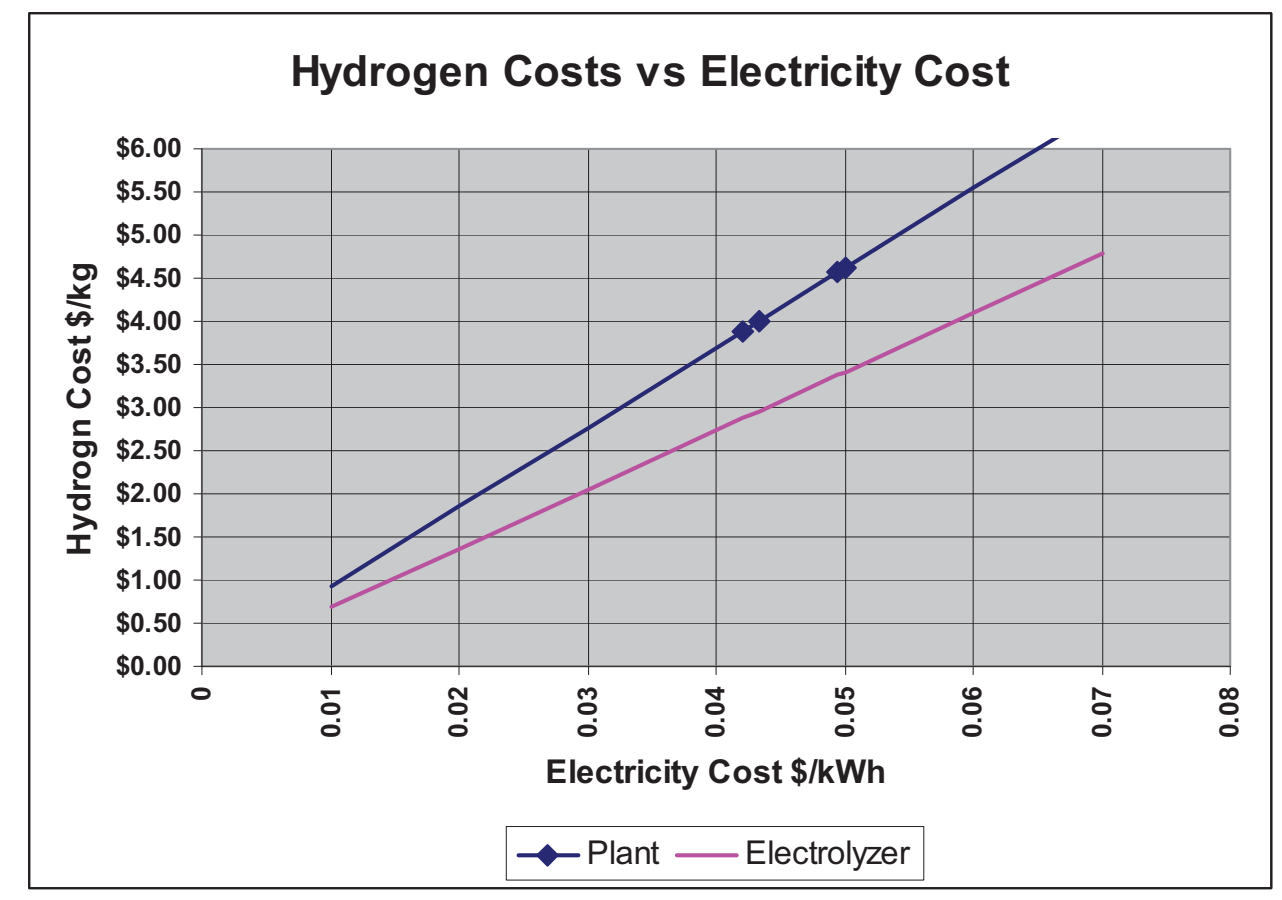

Figure 5-1. Hydrogen costs versus electricity cost for the Alternative Fuel Pilot Plant.

\subsection{Economic Model Assumptions}

In Section 2, it was pointed out that existing nuclear plants are base-load units and it is not accurate to refer to their operating costs as input to economic models determining hydrogen production costs. Rather, the nuclear plant contributes to the overall marginal cost of electricity that is available for large consumers. Details were provided of these costs in 2006 based on the PVNGS switchyard. In that discussion, it was noted that several options exist for hydrogen production facilities and the best approach would be to select a "shoulder" price that would be set as the maximum price that would be paid for electricity. That shoulder price would then set the limit throughout the year for selecting when the production plant would operate. That electricity price is, in reality, not production cost but is the opportunity cost of lost sales for the utility. Therefore, the cost of generating hydrogen is based, to a large extent, on the availability and cost of electricity in the area. This would be true for both the public utility ownership of a production facility and a private merchant ownership of a similar facility. The public utility may consider this to be the point when they may loose sales of electricity, and that would be the point when the hydrogen production plant is put into service. It could also work in reverse for the utility in that the market price of hydrogen may determine at what electricity price it is more profitable to produce hydrogen than electricity. The assessment that follows assumes the electricity price to the facility will be the same whether public utility or private merchant.

Also in Section 2, it was discussed that setting the shoulder price may be based on required plant availability in order to meet the production demand requirements. In the following assessments, three options were selected for the hydrogen production facility: $85 \%$ availability, $60 \%$ availability, and 50\% availability. Each would set the specific shoulder price (based on 2006 prices at the PVNGS switchyard) and result in a set number of hours of operation and an average price as noted in each section below. 
The following assessments do not take credit for oxygen sales or carbon credits. It is anticipated that the $1-\mathrm{kg} / \mathrm{sec}$ and $-1500 \mathrm{~kg} /$ day facilities will be able to take advantage of the reduced electricity rates, but the retail locations and 100-kg/day unit will likely be paying retail electricity rates.

\section{$5.4100 \mathrm{~kg} \mathrm{H}_{2} /$ Day (Small Forecourt) - 150 Vehicles}

Appendix F provides input to the N2H2 model based on the plant-specific equipment. Appendix J provides specifics of the cases run using this model for the $10-\mathrm{kg} \mathrm{H}_{2} /$ day production facility.

The model showed that it did not make financial sense for a utility or private merchant to specifically make this size of a unit into a dedicated plant for hydrogen production. Rather it might serve best for a local retail outlet or a dedicated purpose such as a fleet vehicle source.

\subsubsection{Public Utility Ownership}

The assumptions for a public utility ownership of this size facility are shown in Table 5-5. This facility assumes $97 \%$ availability at all times using typical retail electric rates of $\$ 0.0646 / \mathrm{kWh}$.

Table 5-5. Public utility ownership of a 100-kg/day facility.

\begin{tabular}{|c|c|c|c|c|}
\hline Availability & Price $\$ / \mathrm{kWh}$ & $\begin{array}{c}\text { Total } \\
\text { Hours }\end{array}$ & $\begin{array}{c}\text { Total } \mathrm{kg} \\
\text { H2/year }\end{array}$ & $\begin{array}{c}\text { Break Even } \\
\$ / \mathrm{kg}\end{array}$ \\
\hline $97 \%$ & $\$ 0.0646$ & 8,497 & 35,404 & $\$ 19.76$ \\
\hline
\end{tabular}

As noted previously, it is not likely that a public utility would be interested in owning and operating this size of unit for public consumption.

The break even price for the facility is very high, indicating the capital cost of the facility would make this facility unlikely to be profitable. Additional work would be required to develop a facility of this size at lower capital cost.

\subsubsection{Private Merchant Ownership}

The assumptions for private merchant ownership of this size facility are shown in Table 5-6. This facility assumes $97 \%$ availability at all times using typical retail electric rates of $\$ 0.0646 / \mathrm{kWh}$.

Table 5-6. Private merchant ownership of $100-\mathrm{kg}$ /day facility.

\begin{tabular}{|c|c|c|c|c|}
\hline Availability & Price $\$ / \mathrm{kWh}$ & $\begin{array}{c}\text { Total } \\
\text { Hours }\end{array}$ & $\begin{array}{c}\text { Total } \mathrm{kg} \\
\mathrm{H} 2 / \mathrm{yr}\end{array}$ & $\begin{array}{c}\text { Break Even } \\
\$ / \mathrm{kg}\end{array}$ \\
\hline $97 \%$ & $\$ 0.0646$ & 8497 & 35,404 & $\$ 21.75$ \\
\hline
\end{tabular}

Again, the minimum break-even price for hydrogen is too high based on the high cost of capital equipment. 


\section{$5.51500 \mathrm{~kg} \mathrm{H}_{2} /$ Day (Large Retail/Forecourt)}

Appendix G provides input to the $\mathrm{N} 2 \mathrm{H} 2$ model based on plant-specific equipment. Appendix $\mathrm{J}$ provides specifics of the cases run using this model for the $1500-\mathrm{kg} \mathrm{H}_{2} /$ day production facility.

The model was run to use this forecourt size unit both for a retail facility and for a city gateway facility. As a retail facility, it would be subject to normal utility rates. As a city gateway facility, it was assumed that it was able to negotiate utility rates to use the shoulder mode for electrical cost, but would be susceptible to electrical transmission cost.

\subsubsection{Retail Facility}

Economics show the improved hydrogen price over the $100-\mathrm{kg}$ /day plant, resulting from the economy of scale in the capital equipment. The cost of electricity can be seen between the retail facility (Table 5-7) that buys retail electricity prices and that of the following models (Tables 5-8 and 5-9) that take advantage of lower purchased rates.

Table 5-7. 1500-kg/day retail facility.

\begin{tabular}{|l|r|r|r|r|r|}
\hline & Availability & \multicolumn{1}{|c|}{ Price $\$ / \mathrm{kWh}$} & \multicolumn{1}{c|}{$\begin{array}{c}\text { Total } \\
\text { Hours }\end{array}$} & \multicolumn{1}{c|}{$\begin{array}{c}\text { Total } \mathrm{kg} \\
\mathrm{H}_{2} / \mathrm{year}\end{array}$} & $\begin{array}{c}\text { Break Even } \\
\$ / \mathrm{kg}\end{array}$ \\
\hline Public Utility & $97 \%$ & $\$ 0.0646$ & 8,497 & 531,062 & $\$ 8.70$ \\
\hline Private Merchant & $97 \%$ & $\$ 0.0646$ & 8,497 & 531,062 & $\$ 9.19$ \\
\hline
\end{tabular}

\subsubsection{Public Utility Ownership - City Gate}

Table 5-8. 1500-kg/day public utility city gate.

\begin{tabular}{|r|r|r|r|r|r|}
\hline \multicolumn{1}{|c|}{$\begin{array}{c}\text { Plant } \\
\text { Availability } \\
\text { Target }\end{array}$} & \multicolumn{1}{|c|}{$\begin{array}{c}\text { Shoulder Price } \\
\$ / \mathrm{kWh}\end{array}$} & $\begin{array}{c}\text { Average Price } \\
\$ / \mathrm{kWh}\end{array}$ & \multicolumn{1}{c|}{ Total Hours } & \multicolumn{1}{c|}{$\begin{array}{c}\text { Total kg } \\
\mathrm{H}_{2} / \text { year }\end{array}$} & $\begin{array}{c}\text { Break Even } \\
\$ / \mathrm{kg}\end{array}$ \\
\hline $97 \%$ & $\mathrm{NA}$ & $\$ 49.41$ & 8,497 & 531,062 & $\$ 7.04$ \\
\hline $85 \%$ & $\$ 60$ & $\$ 44.99$ & 7,448 & 465,500 & $\$ 7.03$ \\
\hline $60 \%$ & $\$ 52$ & $\$ 40.35$ & 5,232 & 327,000 & $\$ 7.97$ \\
\hline $50 \%$ & $\$ 48.50$ & $\$ 38.45$ & 4,368 & 273,000 & $\$ 8.78$ \\
\hline
\end{tabular}

As can be expected, the cost to produce hydrogen is reduced when the cost of the input electricity is reduced. However, in order to take advantage of the lower electrical cost, the amount of hydrogen produced is reduced as well. As with a nuclear plant, this City Gate facility is most efficient when it is running at full capacity. It would not make sense to build a facility of this capacity and only run it on off-peak hours where its availability may be $33 \%$. 


\subsubsection{Private Merchant Ownership}

Table 5-9. 1500-kg/day private merchant city gate.

\begin{tabular}{|r|r|r|r|r|r|}
\hline \multicolumn{1}{|c|}{$\begin{array}{c}\text { Plant } \\
\text { Availability } \\
\text { Target }\end{array}$} & \multicolumn{1}{|c|}{$\begin{array}{c}\text { Shoulder Price } \\
\$ / \mathrm{kWh}\end{array}$} & \multicolumn{1}{c|}{$\begin{array}{c}\text { Average Price } \\
\$ / \mathrm{kWh}\end{array}$} & Total Hours & \multicolumn{1}{c|}{$\begin{array}{c}\text { Total kg } \\
\mathrm{H}_{2} / \text { year }\end{array}$} & \multicolumn{1}{c|}{$\begin{array}{c}\text { Break Even } \\
\$ / \mathrm{kg}\end{array}$} \\
\hline $97 \%$ & $\mathrm{NA}$ & $\$ 49.41$ & 8,497 & 531,062 & $\$ 7.47$ \\
\hline $85 \%$ & $\$ 60$ & $\$ 44.99$ & 7,448 & 465,500 & $\$ 7.52$ \\
\hline $60 \%$ & $\$ 52$ & $\$ 40.35$ & 5,232 & 327,000 & $\$ 8.62$ \\
\hline $50 \%$ & $\$ 48.50$ & $\$ 38.45$ & 4,368 & 273,000 & $\$ 9.54$ \\
\hline
\end{tabular}

\section{$5.61 \mathrm{~kg} \mathrm{H}_{2} / \mathrm{sec}$ (Plant or City Gate Facility)}

Appendix $\mathrm{H}$ provides input to the $\mathrm{N} 2 \mathrm{H} 2$ model based on plant-specific equipment. Appendix $\mathrm{J}$ provides specifics of the cases run using this model for the $1-\mathrm{kg} \mathrm{H}_{2} / \mathrm{sec}$ production facility.

The model was run to use this large forecourt size unit for a plant production facility and for a city gateway facility (Tables 5-10 through 5-14). The model shows it would be impractical to develop this size facility as a retail facility. The rates used were per the shoulder mode for electrical cost.

\subsubsection{Public Utility Ownership for Plant}

Table 5-10. 1-kg/sec public utility production plant.

\begin{tabular}{|c|c|c|c|c|c|}
\hline Availability & $\begin{array}{c}\text { Shoulder Price } \\
\$ / \mathrm{kWh}\end{array}$ & $\begin{array}{c}\text { Average Price } \\
\$ / \mathrm{kWh}\end{array}$ & Total Hours & $\begin{array}{l}\text { Total kg } \\
\mathrm{H}_{2} / \text { year }\end{array}$ & $\begin{array}{l}\text { Break Even } \\
\quad \$ / \mathrm{kg}\end{array}$ \\
\hline $97 \%$ & NA & $\$ 49.41$ & 8,497 & $30,589,200$ & $\$ 4.81$ \\
\hline $85 \%$ & $\$ 60$ & $\$ 44.99$ & 7,446 & $26,805,600$ & $\$ 4.37$ \\
\hline $60 \%$ & $\$ 52$ & $\$ 40.35$ & 5,256 & $18,921,600$ & $\$ 4.25$ \\
\hline $50 \%$ & $\$ 48.50$ & $\$ 38.45$ & 4,380 & $15,768,000$ & $\$ 4.34$ \\
\hline
\end{tabular}

\subsubsection{Private Merchant Ownership for Plant}

The economy of scale is evident in this plant. By sharing many systems, capital costs can be reduced. It is interesting to note that variations in electricity cost are somewhat masked by the capital investment and that plant costs remain (e.g., personnel and maintenance) even if the plant is shutdown to avoid high electricity costs.

However, for this size of facility, there is an advantage of watching the electric prices. As the electricity cost is reduced, the production of hydrogen decreases but the break-even price also drops (to a point). With several more iterations, the ideal input electricity cost will match the production rate that provides the lowest break even $\$ / \mathrm{kg}$. That point is about the $60 \%$ availability price. ( $70 \%$ availability produced a break-even $\$ 4.28 / \mathrm{kg}$ ). It is noted that the $60 \%$ availability would have been provided $48 \%$ by on-peak energy and 52\% by off-peak energy. As noted before, the off-peak energy cost is not consistently 
lower than on-peak throughout the year; therefore, it would not make sense to only operate this plant on off-peak electrical usage.

Table $5-11.1-\mathrm{kg} / \mathrm{sec}$ private merchant production plant.

\begin{tabular}{|r|r|r|r|r|r|}
\hline Availability & \multicolumn{1}{|c|}{$\begin{array}{c}\text { Shoulder Price } \\
\$ / \mathrm{kWh}\end{array}$} & $\begin{array}{c}\text { Average Price } \\
\$ / \mathrm{kWh}\end{array}$ & Total Hours & Total kg $\mathrm{H}_{2}$ & \multicolumn{1}{c|}{$\begin{array}{c}\text { Break Even } \\
\$ / \mathrm{kg}\end{array}$} \\
\hline $97 \%$ & $\mathrm{NA}$ & $\$ 49.41$ & 8,497 & $30,589,200$ & $\$ 5.05$ \\
\hline $85 \%$ & $\$ 60$ & $\$ 44.99$ & 7,446 & $26,805,600$ & $\$ 4.62$ \\
\hline $60 \%$ & $\$ 52$ & $\$ 40.35$ & 5,256 & $18,921,600$ & $\$ 4.57$ \\
\hline $50 \%$ & $\$ 48.50$ & $\$ 38.45$ & 4,380 & $15,768,000$ & $\$ 4.69$ \\
\hline
\end{tabular}

The most economical operating point may vary from year to year depending on the fluctuating electricity prices. Using the PVNGS switchyard prices in 2001 yields the information found in Table 5-12.

Table 5-12. 1-kg/sec public utility production plant in 2001 .

\begin{tabular}{|c|c|c|c|c|c|}
\hline Availability & $\begin{array}{c}\text { Shoulder Price } \\
\$ / \mathrm{kWh}\end{array}$ & $\begin{array}{c}\text { Average Price } \\
\$ / \mathrm{kWh}\end{array}$ & Total Hours & Total $\mathrm{kg} \mathrm{H}_{2}$ & $\begin{array}{c}\text { Break Even } \\
\$ / \mathrm{kg}\end{array}$ \\
\hline $97 \%$ & NA & $\$ 97.12$ & 8,497 & $30,589,200$ & $\$ 8.88$ \\
\hline $85 \%$ & $\$ 60$ & $\$ 65.47$ & 7,446 & $26,805,600$ & $\$ 6.42$ \\
\hline $60 \%$ & $\$ 52$ & $\$ 35.60$ & 5,256 & $18,921,600$ & $\$ 4.24$ \\
\hline $50 \%$ & $\$ 48.50$ & $\$ 28.53$ & 4,380 & $15,768,000$ & $\$ 3.82$ \\
\hline $45 \%$ & $\$ 44$ & $\$ 26.07$ & 3,942 & $14,191,200$ & $\$ 3.97$ \\
\hline
\end{tabular}

As was noted in Section 2, 2001 was a very unusual year for the first several months, which drove up the electricity prices. Those prices dropped dramatically for the remainder of the year. The $60 \%$ availability for both years occurred with a shoulder price of $\$ 52$ and yielded a breakeven price of about $\$ 4.25 / \mathrm{kg}$. This plant would have been essentially idle for the first 4 months of 2001 .

\subsubsection{Public Utility Ownership for City Gate}

Table $5-13.1-\mathrm{kg} / \mathrm{sec}$ public utility city gate.

\begin{tabular}{|c|c|c|c|c|c|}
\hline Availability & $\begin{array}{c}\text { Shoulder Price } \\
\$ / \mathrm{kWh}\end{array}$ & $\begin{array}{c}\text { Average Price } \\
\$ / \mathrm{kWh}\end{array}$ & Total Hours & Total $\mathrm{kg} \mathrm{H}_{2}$ & $\begin{array}{l}\text { Break Even } \\
\quad \$ / \mathrm{kg}\end{array}$ \\
\hline $97 \%$ & NA & $\$ 49.41$ & 8,497 & $30,589,200$ & $\$ 4.95$ \\
\hline $85 \%$ & $\$ 60$ & $\$ 44.99$ & 7,446 & $26,805,600$ & $\$ 4.50$ \\
\hline $60 \%$ & $\$ 52$ & $\$ 40.35$ & 5,256 & $18,921,600$ & $\$ 4.40$ \\
\hline $50 \%$ & $\$ 48.50$ & $\$ 38.45$ & 4,380 & $15,768,000$ & $\$ 4.50$ \\
\hline
\end{tabular}




\subsubsection{Private Merchant Ownership for City Gate}

Table $5-14.1-\mathrm{kg} / \mathrm{sec}$ public utility city gate.

\begin{tabular}{|r|r|r|r|r|r|}
\hline \multicolumn{1}{|c|}{ Availability } & \multicolumn{1}{|c|}{$\begin{array}{l}\text { Shoulder Price } \\
\$ / \mathrm{kWh}\end{array}$} & \multicolumn{1}{c|}{$\begin{array}{c}\text { Average Price } \\
\$ / \mathrm{kWh}\end{array}$} & Total Hours & Total kg $\mathrm{H}_{2}$ & \multicolumn{1}{c|}{$\begin{array}{c}\text { Break Even } \\
\$ / \mathrm{kg}\end{array}$} \\
\hline $97 \%$ & $\mathrm{NA}$ & $\$ 49.41$ & 8,497 & $30,589,200$ & $\$ 5.20$ \\
\hline $85 \%$ & $\$ 60$ & $\$ 44.99$ & 7,446 & $26,805,600$ & $\$ 4.76$ \\
\hline $60 \%$ & $\$ 52$ & $\$ 40.35$ & 5,256 & $18,921,600$ & $\$ 4.73$ \\
\hline $50 \%$ & $\$ 48.50$ & $\$ 38.45$ & 4,380 & $15,768,000$ & $\$ 4.87$ \\
\hline
\end{tabular}

Again, there would appear to be an advantage to establishing a shoulder electricity cost point at about $60 \%$ availability.

\subsection{Hydrogen Costs with a Nuclear Plant}

Although nuclear resources may not exist today to support large-scale hydrogen production directly, construction and operation of new nuclear reactor designs may be able to match the growing demand for hydrogen. As noted in Section 2, the challenges that face the new generation of nuclear plants include reducing the capital costs from about $\$ 1,500$ per $\mathrm{kWe}$ of generating capacity in 2002 to 2004 to about $\$ 1,000$ per $\mathrm{kWe}$, which makes these nuclear plants competitive. However, current cost projections are $\$ 4,700$ to $\$ 8,700$ per $\mathrm{kWe}$. Innovative designs for small nuclear reactors may head costs back in the right direction.

The $1-\mathrm{kg} / \mathrm{sec}$ hydrogen plant is estimated to require $215 \mathrm{MWe}$. A nuclear reactor sized to this requirement is a small reactor and nearing the size of new compact designs. One manufacturer is promoting a new design for underground burial of their small reactor and by combining them together, the requirements can be met. At $\$ 1,000 / \mathrm{kw}$, the $215-\mathrm{MW}$ reactor cost would be $\$ 215,000,000$.

In Section 2, it was noted that in 2002, the PVNGS had a production cost of $\$ 0.0133 / \mathrm{kWh}$. A much smaller plant (that is pre-designed and shipped as a complete unit) would be expected to have much lower operating expenses.

It may be an over-simplification of the situation but using the N2H2 model with the 215-MWe nuclear plant at $\$ 1,000 / \mathrm{kw}$, with operating expenses at $\$ 0.0133 / \mathrm{kwh}$, the break-even price for this $1-\mathrm{kg} / \mathrm{sec}$ hydrogen plant is $\mathbf{\$ 2 . 8 1} \mathbf{~ k g}$. Additional detailed study of this combination should be considered.

Plants this size or larger may change the role of nuclear in the electricity grid. These plants may be designed and run to produce hydrogen, but during peak load stress situations, divert their output from hydrogen to provide peaking power to utilities. In this manner, nuclear plants are no longer base load only. These plants may find a shoulder price above which it is more profitable to sell electricity than hydrogen.

\section{RISKS AND UNCERTAINTIES FOR NUCLEAR PRODUCTION OF HYDROGEN}

Many papers and analyses have been prepared to discuss how nuclear power plants can be used to produce hydrogen. The feasibility of producing hydrogen from nuclear power plants is really related to 
whether it can be done economically and what are the risks and uncertainties. This section focuses on business and market risks. The next section will focus on the licensing and environmental risks.

\subsection{Uncertainties in Electrical Supply Costs}

\subsubsection{Seasonal/Daily Fluctuations in Electrical Demand}

Figures 2-12 and 2-13 in Section 2 illustrated the wide variation in electrical pricing for the same geographic area in two different years. A sudden heat wave in the southwest can cause a rapid rise in electrical prices. If the hydrogen production facility is depending on available energy for price, that price can widely fluctuate and affect the hydrogen cost. Negotiations for favorable rates may include demand response actions such as reducing production rates. Plant production could well be planned around these seasonal and daily variations. Such plans could require the use of storage facilities to be able to meet hydrogen demands. Storage is discussed in the following sections. Frequently, a heat wave affects a large geographic area; therefore, during that time, when the demand for electricity may be high and availability of power for hydrogen is reduced, the reduced production of hydrogen would be a regional problem.

\subsubsection{United States Regional Variations in Electrical Demand}

Tables 2-3 and 2-4 in Section 2 also illustrated that electrical demand varies between sections of the United States. A mild spring in the Midwest could occur during a heat wave in the Southwest. Because the cost of power is an input to the cost of hydrogen, the hydrogen price could fluctuate widely between different parts of the country. Comparing parts of the country with the average and using the $\mathrm{N} 2 \mathrm{H} 2$ model shows the variation in the production cost of hydrogen for the $1-\mathrm{kg} / \mathrm{sec}$ production plant.

Table 6-1. Variation in hydrogen cost across the United States.

\begin{tabular}{|l|c|c|}
\hline \multicolumn{1}{|c|}{ Location } & $\begin{array}{c}\text { Off-Peak Price } \\
(\$ / \mathrm{MWH})\end{array}$ & $\begin{array}{c}\text { Hydrogen } \\
(\$ / \mathrm{kg})\end{array}$ \\
\hline National Average & $\$ 37$ & $\$ 3.68$ \\
\hline Southern California & $\$ 47$ & $\$ 4.54$ \\
\hline Midwest & $\$ 29$ & $\$ 2.99$ \\
\hline
\end{tabular}

\subsubsection{United States Regional Variations in Electrical Costs/Energy Availability}

Figure 2-7 in Section 2 shows the varying cost of operation of different power plants. Hydroelectric, solar, and wind are low cost while gas will be high. Certain regions of the country have a greater availability of these lower cost sources; therefore, again the input cost of power will be affected in the hydrogen production facilities.

\subsubsection{Effects of Fluctuating Hydrogen Costs on Consumers}

These fluctuations in energy costs will be reflected in the cost of hydrogen for the consumer. This may or may not be an issue since the consumer is faced with fluctuations in gas prices today that vary from parts of the country to another and from season to season. 


\subsection{Plant Owner Conflicts between Electricity and Hydrogen Production}

Commercial nuclear power plants in the United States are focused on supplying electrical power for utilities to distribute to consumers. New nuclear power plants can be designed and built specifically for generation of hydrogen or for a combination of generating hydrogen and electrical power (i.e., delivering protons and electrons). If built for co-generation, decisions will be made whether to shift production between the two outputs. That decision can be market based (which output is most profitable at the time), contract based (requirements to deliver quantities of hydrogen or electricity), or a combination of the two. Investors in these plants will be driven by profitability assessments.

Argonne National Laboratory assessed the profitability of three nuclear hydrogen production technologies under various price uncertainties. ${ }^{\circ}{ }^{\text {Uo }}$ Using the real options theory to more accurately identify risks and uncertainties and decision possibilities, they concluded that investors will find significant value in the ability to switch plant output between electricity and hydrogen. The following are the three types of technologies:

- $\quad$ High-pressure, low-temperature water electrolysis available from advanced light water reactors

- $\quad$ High-temperature steam electrolysis available from high-temperature gas-cooled reactors

- $\quad$ High-temperature sulfur-iodine cycle available from high-temperature gas-cooled reactors.

The sulfur-iodine cycle is not able to switch outputs from hydrogen production; therefore, the results focused on the first two types of technologies. The following conclusions were reached:

- $\quad$ The profitability analysis under uncertainty gives a different picture of the relative viability of the nuclear hydrogen production technologies compared to a standard levelized cost analysis.

- $\quad$ The high-pressure, low-temperature water electrolysis available from advanced light water reactors and high-temperature steam electrolysis available from high-temperature gas-cooled reactors configurations have an advantage in being able to switch between hydrogen and electricity output.

- $\quad$ The option to switch output product adds value for the investor. The added value must be weighed against potential increases in capital and operating costs. For the flexible plants, we assumed they are capable of switching their entire production from hydrogen to electricity instantaneously and frequently without additional cost.

- $\quad$ Our findings suggest that research should be directed toward developing better and more durable materials for the hydrogen production processes that are better able to handle switching in production output.

\footnotetext{
${ }^{\text {oo }}$ Botterud, Yildiz, Conzelmann, and Petri, The Value of Product Flexibility in Nuclear Hydrogen Technologies, Argonne National Laboratory, 2007, www.anl.gov.
} 
- $\quad$ Plant owners should carefully consider how much hydrogen production to sell on longterm contracts, at the expense of losing the value of the option to switch between electricity and hydrogen production. ${ }^{\mathrm{p}}$

The decision to switch outputs can create uncertainties for markets.

\subsubsection{Correlation between Hydrogen and Electric Prices}

Low correlation between hydrogen and electric prices would occur when the demand for electricity is high while demand for hydrogen is low or vice versa. This is an advantage because plant management can choose which product to deliver. The output can favor which product can deliver the most profit at the time. Plants that can easily switch outputs will again be the most favorable. This correlation is possible because we have seen the direct correlation between electricity pricing and the cost of hydrogen. At times of high electric prices, the cost of hydrogen will increase and market response may be to lower demand. Likewise at low hydrogen prices, when electricity price is low, demand may rise.

High correlation will occur when both products have the same demand (either high or low). This decision will be more difficult for the plant manager and will have a greater impact on the public. If demand for electricity is high (such as in the southwest during summer) and electricity prices are high, the reduced supply of hydrogen in a constant demand economy will drive prices up. Likewise, in times of low electricity price, an oversupply of hydrogen can drive prices lower. The advantage for nuclear hydrogen producers here would be the ability to store hydrogen.

The demand for both hydrogen and electricity will be greater in a future transportation system where the majority of vehicles are HFCVs or electric vehicles (or plug-in hybrid electric vehicles), Shortages of either with the concurrent higher prices will reduce consumer confidence.

\subsubsection{Delivery Contracts}

Contracts for delivery of hydrogen will be carefully developed. The fluctuating prices for electricity can cause a significant variation in the hydrogen cost and price. Contracts during high electricity pricing may be unfavorable for greatest profitability. Storage of hydrogen produced during low electricity pricing can be a benefit.

\subsubsection{Plant Ownership}

Utilities that may own these nuclear hydrogen plants will face other challenges in that local regulations already place demands on the outputs of utility power plants. This may restrict the utility in making switches between electricity and hydrogen production. The Public Utilities Commissions may have no regulatory authority over private investors who own these nuclear plants and sell electricity to the utilities. This would clearly give the advantage to the private investors in being able to switch outputs.

\subsection{Storage and Transportation of Hydrogen}

The long-term and short-term storage of hydrogen is critical to developing and supporting the delivery infrastructure. It also is critical to the economic viability of a new nuclear power plant co-producing electricity and hydrogen.

pp ibid. 


\subsubsection{Hydrogen Storage}

Several sources, primarily focusing on underground storage, suggest that long-term storage of hydrogen is currently feasible. However, other sources suggest that storage is much more difficult. The ease with which hydrogen leaks from all environments and containers supports the idea that additional research and actual testing must be accomplished. Chemical bonding of hydrogen may be the best solution to both the questions of storage and transportation. More research and actual testing of these methods is necessary.

The Offices of Energy Efficiency and Renewable Energy and Fossil Energy are working to develop innovative materials for reversible hydrogen storage, including high surface area adsorbents, metal organic frameworks, and metal hydrides, as well as approaches that are regenerable offboard such as chemical hydrides and liquid carriers. ${ }^{\mathrm{qq}}$

\subsubsection{Hydrogen Transportation}

Several miles of hydrogen pipeline are currently in operation. Most of this pipeline is of relatively short lengths and for local purposes. As stated above, hydrogen can easily leak from piping and valves, and, over a long distance, the leakage can be a significant factor. Additional development of containment metals and methods is required to actually build the transportation infrastructure envisioned.

To enable introduction of hydrogen as an energy carrier, a key initial focus of the Office of Energy Efficiency and Renewable Energy is on hydrogen delivery research challenges at refueling stations and stationary power sites. Research is being conducted to improve the reliability and lower the cost of hydrogen compression and to reduce the cost and footprint of hydrogen storage.

The Office of Energy Efficiency and Renewable Energy, Fossil Energy, and the Office of Science are working to lower the cost and energy use of the hydrogen delivery infrastructure. This includes developing improved lower cost materials for pipelines, breakthrough approaches to hydrogen liquefaction, lighter weight stronger materials and structures for high-pressure hydrogen storage and transport, and novel low pressure solid and liquid carrier systems for hydrogen delivery and storage. ${ }^{\text {rr }}$

\subsection{Solar and Wind Energy for Hydrogen Production}

Significant research is being devoted to using renewable resources, such as solar and wind, for the production of hydrogen. The variability of this power during cloudy or calm days could lead to instability in the electrical grid but could be used for hydrogen production. Combining this renewable power with advanced hydrogen storage or delivery systems may result in low cost production. This may be an uncertainty for the nuclear hydrogen production facility that has to compete.

\subsubsection{Wind Production Plants}

The U.S. wind industry installed over 2,800 MW of new wind capacity in the first quarter of 2009, according to the American Wind Energy Association. Thirty-one new plants over 1-MW capacity each

\footnotetext{
${ }^{\mathrm{qq}}$ Hydrogen Storage, U.S. Department of Energy, Hydrogen Program, www.hydrogen.energy.gov

${ }^{\text {rr }}$ Hydrogen Delivery, U.S. Department of Energy, Hydrogen Program, www.hydrogen.energy.gov.
} 
went online in the first quarter. The new plants vary in design output from 10 to $300 \mathrm{MW}$. The total generating power from all wind plants is now $28,200 \mathrm{MW} .^{\mathrm{ss}}$

A hydrogen plant producing $1 \mathrm{~kg} / \mathrm{sec}$ would require about $30 \mathrm{MW}$ power. Typical capacity factors for wind production plants range from 0.25 to 0.3 due to the variable nature of wind. Figure 6-1 shows the wind resources in the United States. Although wind might be a resource in these areas, there are land use restrictions and topography that would make certain areas undesirable. These areas were identified in the technical report prepared by NREL. "The majority of the excellent wind resources are in the Midwest and away from population centers. Again, development of advanced storage and transportation systems and methods is of great importance.

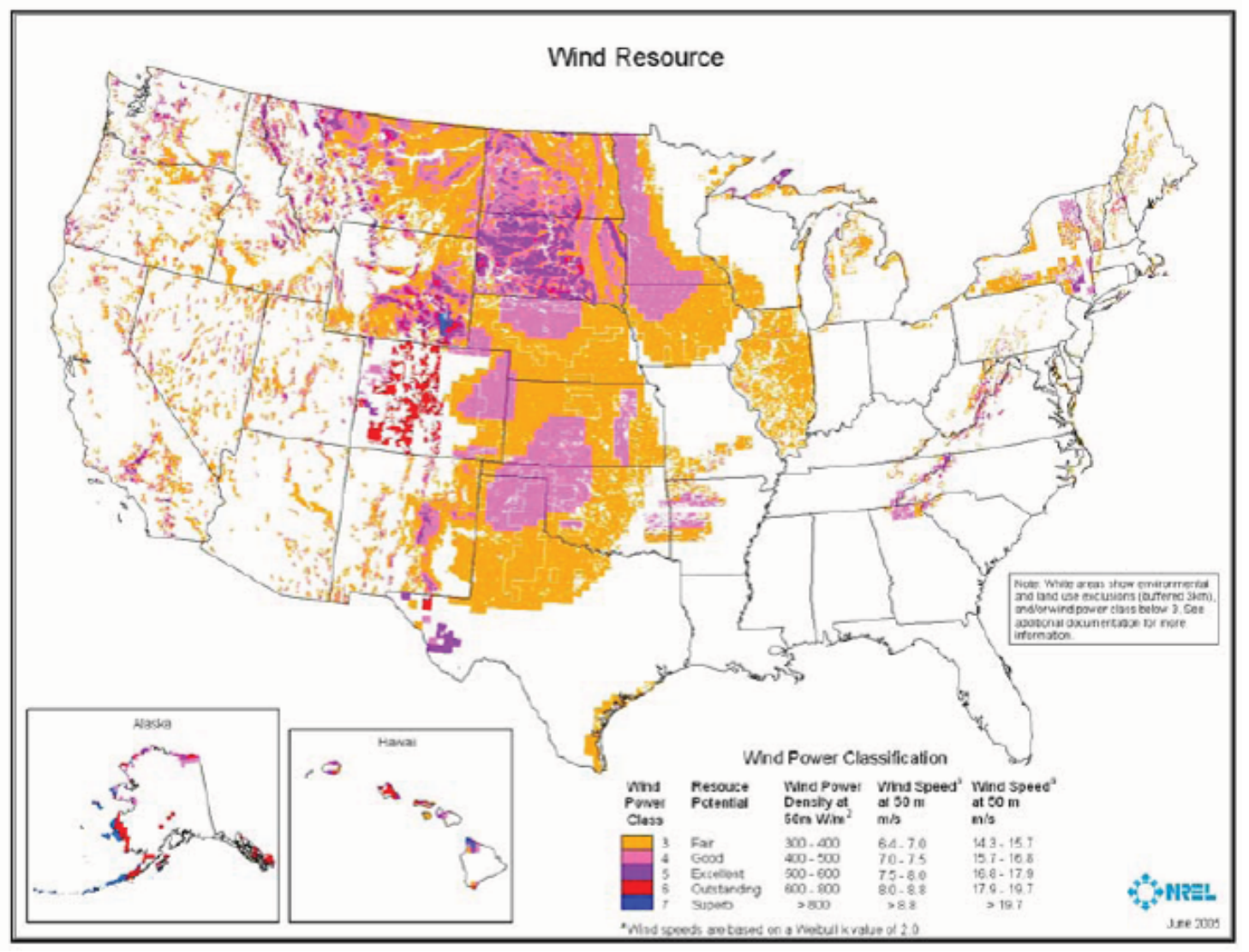

Figure 6-1. Wind resources in the United States. ${ }^{\text {uu }}$

\subsubsection{Solar Production Plants}

Solar photovoltaic and concentrated solar plants also are undergoing rapid development and deployment. Recently, APS announced planned construction of two concentrating solar plants, Solana Generation Station and Starwood Solar I. Each plant, on its own, would be the largest solar plant in the

\footnotetext{
ss AWEA First Quarter 2009 Market Report, April 2009, www.awea.org.

${ }^{\text {tt } M i l b r a n d t}$ and Mann, Potential for Hydrogen Production from Key Renewable Resources in the United States, NREL, February 2007.

uu ibid.
} 
world (Solana, 280 MW; Starwood Solar I, 290 MW). Combined they will provided APS with 570 MW of solar energy. ${ }^{\mathrm{vv}}$

Typical efficiencies for solar photovoltaic are 2.2 to $7.0 \mathrm{kWh} / \mathrm{m}^{2} /$ day. Figure $6-2$ shows the solar resources in the United States. Again, although solar might be a resource in these areas, there are land use restrictions and topography that would make certain areas undesirable. As mentioned above, the NREL report considers these areas and adjusts availability accordingly. While solar resources are generally available throughout the United States, the greatest concentration will again be in the plains and southwest, far away from population centers. As mentioned above, advanced methods for storage and transportation will be required to allow a significant portion of hydrogen production from solar power.

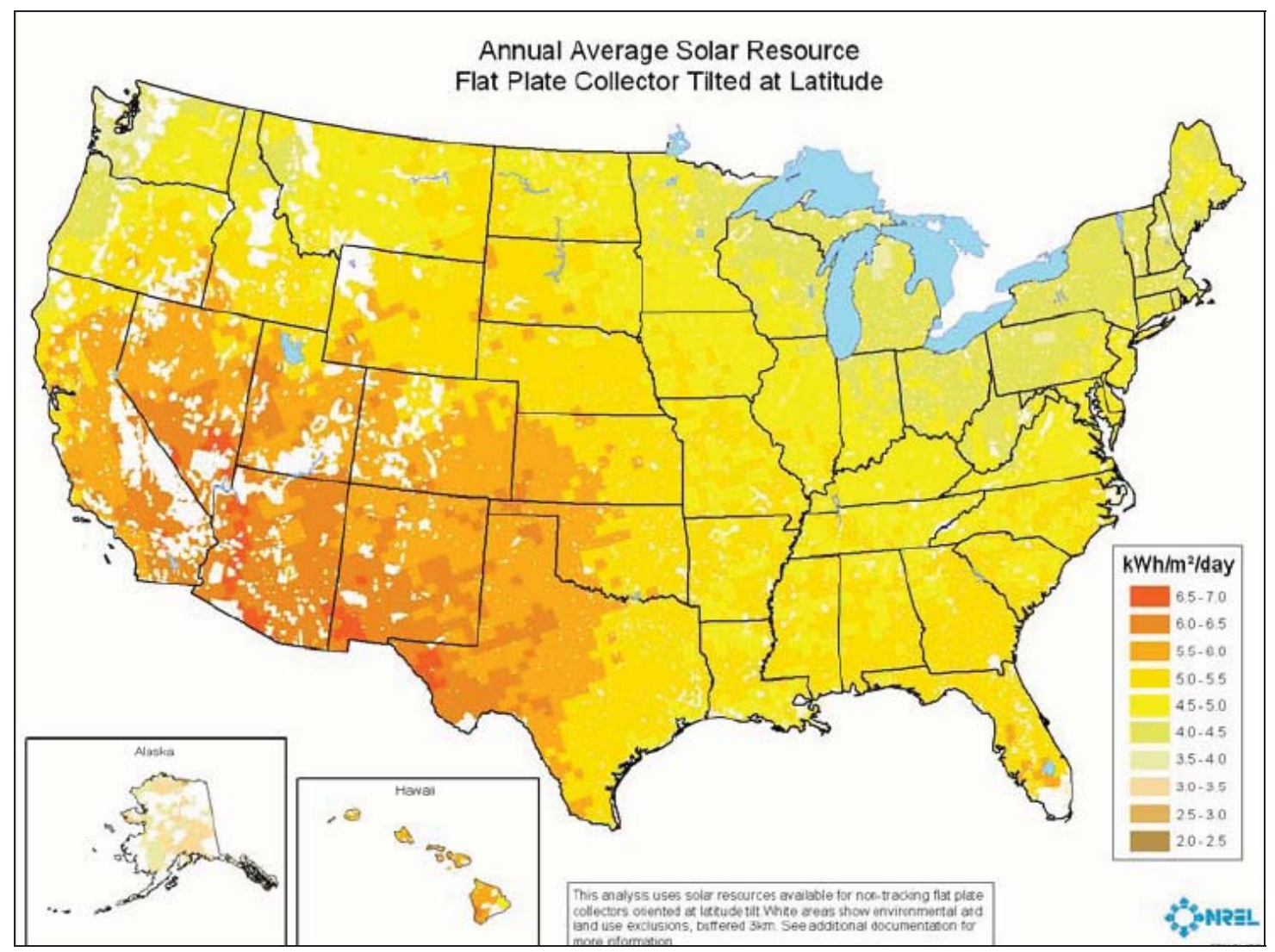

Figure 6-2. Solar resources in the United States. ${ }^{\text {ww }}$

\subsection{Regional Availability of Water}

The availability of water as a resource and feedstock for hydrogen production is an important issue. In an ideal situation, $1 \mathrm{~kg}$ hydrogen should require approximately 2.4 gal of water. A plant producing $1 \mathrm{~kg} / \mathrm{sec}$ would require 207,360 gal of water per day or $60,549,120$ gal per year at $80 \%$ capacity factor. This figure is actually the amount of de-ionized water required. Because de-ionizers are between 6 and $40 \%$ efficient, the minimum requirement would be $151,372,800$ gal per year or approximately 465 acre feet per year.

\footnotetext{
${ }^{\mathrm{vv}}$ Solar Energy at APS, APS GREEN CHOICE, www.aps.com.

${ }^{w w}$ Milbrandt and Mann, Potential for Hydrogen Production from Key Renewable Resources in the United States, NREL, February 2007.
} 


\subsubsection{Water Source}

The greater Phoenix area had an estimated population in 2005 of 3.7 million people. If HFCVs had achieved a $70 \%$ penetration in 2005, daily hydrogen demand would have been approximately 1.6 million $\mathrm{kg}$. Eighteen plants producing $1 \mathrm{~kg} / \mathrm{sec}$ would be required to satisfy the demand for this area. The annual water requirement for these 18 plants would be a minimum of 2,724,710,400 gal or 8,370 acre feet. That is about $12 \%$ of the capacity of Saguaro Lake, ${ }^{\mathrm{xx}}$ one of several reservoirs on the Salt River and source of water for the metropolitan area or about $0.6 \%$ of the annual flow of the Central Arizona Project canal. Water resources in Arizona and in all western states are a great concern and this number is not insignificant.

\subsubsection{Water Exhaust}

The exhaust of an HICE vehicle or HFCV is water. With a significant penetration of hydrogen vehicles, the amount of water exhausted and how that is exhausted should be studied. Water exhaust in freezing temperatures may create an icing situation for roadways.

In the Phoenix area example identified above, exhaust would be about 1,401,600,000 gal of water or 4,301 acre feet per year. Annual evaporation from Saguaro Lake near Phoenix is about 5,400 acre feet per year. ${ }^{\text {yy }}$ This exhaust is not insignificant. Further study of the effects of water exhaust should be conducted.

\subsubsection{Nuclear Plant Water Requirements}

The nuclear plant supplying the proposed hydrogen production facility will be required to produce a minimum of $150 \mathrm{MW}$. Like all thermoelectric power plants, water is required for cooling. Based on water withdrawal values reported by the Electric Power Research Institute, the cooling water or withdrawal requirement for a nuclear plant is 25,000 to 60,000 gal/MWh. Depending on the type of cooling system used (i.e., cooling tower or pond-based), the mid-point water consumption requirement is approximately 720 gal/MWh. ${ }^{2 z}$ Using these values for withdrawal and consumption, the $150-\mathrm{MW}$ nuclear plant would require water withdrawal of about 33 to 79 billion gallons per year and consume almost 1 billion gallons per year. Co-locating or locating a nuclear plant adjacent to a hydrogen production facility will require a significant water source.

\subsection{Captured Oxygen During Hydrogen Production}

Significant quantities of oxygen are produced during electrolysis. In most cases, this oxygen is vented to the atmosphere. The economics of producing hydrogen may be enhanced if the capture of oxygen also can be accomplished. In producing power, most fuel cells and HICE vehicles take oxygen from the surrounding air. It has already been seen that the advanced system Hydrogen Intermediate and Peak Electrical System can greatly benefit from the captured purity of oxygen.

If hydrogen and oxygen are available, an alternative steam cycle exists. Hydrogen, oxygen, and water are fed directly to a burner to produce high-pressure, very high-temperature steam. Because the combustion temperature of a pure hydrogen-oxygen flame is far beyond that acceptable for

\footnotetext{
${ }^{\mathrm{xx}}$ Arizona Department of Water Resources, Salt River Watershed, www.adwr.state.az.us/.

yy ibid.

${ }^{z z}$ Electric Power Research Institute, Water and Sustainability (Volume 3): U.S. Water Consumption for Power Production - The Next Half Century, Topical Report, March 2002, www.epriweb.com/public/000000000001006786.pdf.
} 
current materials of construction, water is added to lower the peak temperatures. The technology is that of a low-performance rocket engine. The resultant steam is fed directly to a very hightemperature turbine that drives an electric generator. Through use of advancing gas turbine technology with actively cooled blades, it is expected that peak steam temperatures at the inlet of the first turbine will approach $1500^{\circ} \mathrm{C}$. The projected heat-to-electricity efficiency for advanced turbines approaches about $70 \%$ when high pressure hydrogen and oxygen are supplied. ${ }^{\text {aaa }}$

This may be most economical in the largest production facilities. Oxygen sells for about $\$ 0.25$ to $\$ 1.00$ per SCF, depending on volume. A $1,500-\mathrm{kg} \mathrm{H}_{2} /$ day plant would make about $14,000 \mathrm{SCFH}$. That would be about $\$ 140$ /hour at the high end of pricing. It may not be able to justify the higher costs for compression and storage. If it were possible to directly use it for oxygenating other materials, a better price may be possible.

High concentrations of oxygen promote rapid combustion and there would be technical hurdles in the large-scale storage of oxygen.

\subsection{Statement of Need}

Other issues potentially limiting the siting and permitting of a hydrogen production facility include the "determination of need" for hydrogen as required by state environmental reviews and water availability. Water requirements and water availability are discussed above and in Section 7.6. The need for hydrogen must be demonstrated and the need for a nuclear plant to provide that hydrogen also must be demonstrated. Without a strong hydrogen economy, that need may be difficult to justify.

Availability of hydrogen for the consumer does not necessarily create a demand for hydrogen transportation. On the other hand, the lack of hydrogen can prevent that demand from taking root. Building a large hydrogen production facility to replace a methane plant may have public benefit in reducing the greenhouse gasses and demonstrating the feasibility of such a plant. Such plants could be introduced as the hydrogen demand increases and at the same time help reduce the methane production process.

\section{REGULATORY, ENVIRONMENTAL, AND LICENSING ASPECTS OF LARGE-SCALE HYDROGEN PRODUCTION}

Concurrent with the design and construction of a large-scale hydrogen production facility are the requirements for codes and standards and consideration of the regulatory, environmental, and licensing aspects of these facilities. The task becomes greater when considering co-locating this hydrogen facility with an existing or new nuclear reactor or even locating the hydrogen facility adjacent to a nuclear site.

\subsection{Safety - Hydrogen Generation}

\subsubsection{Codes and Standards Development}

Development of codes and standards are essential for safe generation of hydrogen. DOE through the Hydrogen, Fuel Cells, and Infrastructure Technologies Program, with the NREL are coordinating a collaborative effort with leading standards-development organizations, code-development organizations,

\footnotetext{
${ }^{\text {aaa }}$ Forsberg, Economics of Meeting Peak Electrical Demand Using Nuclear Hydrogen and Oxygen, Oak Ridge National Laboratory, 2007.
} 
and other national laboratories "to prepare, review, and promulgate hydrogen codes and standards needed to expedite hydrogen infrastructure development.",bbb

As part of the DOE program, "national templates" were developed and implemented to coordinate the national codes and standards effort and "have been key to the emergence of a national agenda for hydrogen and fuel cell codes and standards development in the U.S." ${ }^{\text {ccc }}$ The national template for stationary and portable systems indicates the following for codes and standards associated with hydrogen generators:

1. Controlling Authority:

OSHA, Emissions - EPA

Pipeline: DOT/PHMSA

State, Local Government Zoning, Building Permits

2. Standards Development:

Electrolyzers: $\underline{\mathrm{UL}}, \underline{\mathrm{CSA}^{*}}$

Reformers: $\underline{\mathrm{UL}}, \underline{\mathrm{CSA}}, \mathrm{API}$

Performance Test Procedures: ASME, CSA

Chemical Hydrides: $\underline{\text { UL, }} \underline{\text { CSA, NFPA }}$

* Leads will change depending on type of environment. ${ }^{\text {ddd }}$

\subsubsection{Current Codes and Standards}

Most of the codes and standards efforts to date are focused on infrastructure for hydrogen fueling stations, with little attention by the standards-development organizations and code-development organizations for development of codes and standards for large-scale commercial hydrogen production by electrolysis. The current codes and standards directed at the safety of hydrogen production are as follows:

1. UL 2264B (Ed. 1), Hydrogen Generators, Water Reaction Type, addresses non-vehicular hydrogen generators and is written to cover "products that generate hydrogen for use as a fuel by chemical reactions with water and other chemical substances (e.g., sodium borohydride and sodium hydride)." The standard is not intended to cover hydrogen generators that can also be used to generate electricity or for hydrogen generators rated greater than $600 \mathrm{~V}$. This standard was approved by UL in July 2006.

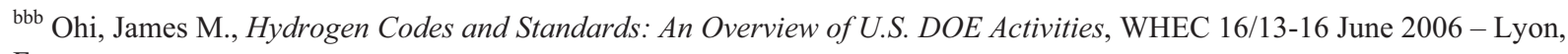
France, www.cder.dz/A2H2/Medias/Download/Proc\%20PDF/PARALLEL\%20SESSIONS/\%5BS02\%5D\%20Safety,\%20RCS/14-0606/569.pdf.

ccc ibid.

ddd ibid.
} 
2. UL 2264A, Gaseous Hydrogen Generation Appliances -Electrolyzer Technology. The current status of this standard is UL is waiting publication of ISO 22734 to adopt as a U.S. standard.

3. UL 2264C, Gaseous Hydrogen Generation Appliances - Fuel Processing Technology (joint activity with CSA America FC5). The current status of this standard is UL is waiting publication of ISO 16110 to adopt as a U.S. standard

4. ANSI/CSA America FC1 - 2004, Stationary Fuel Cell Power Systems, applies to stationary fuel cell power systems that are packaged, self-contained or factory matched packages of integrated systems with an output voltage not exceeding $600 \mathrm{VAC}$ or VDC, and at a power output not exceeding $10 \mathrm{MW}$.

5. NFPA 2, Hydrogen Technology, Pre-ROP Draft (proposal closing date 5-29-09) consolidates all of the current NFPA hydrogen safety requirements from NFPA 52, Vehicular Fuel Systems, 2005 Edition, and NFPA 55, Standard for the Storage, Use and Handling of Compressed Gases and Cryogenic Fluids in Portable and Stationary Containers, Cylinders and Tanks, 2005 Edition. The consolidation of these standards into a single document should ease the process of revising existing requirements and developing new requirements as hydrogen technologies develop and operating experience is obtained.

6. ASME STP-PT-006, Design Guidelines for Hydrogen Piping and Pipelines, 2008, is a report that provides recommendations and guidance to the ASME B31.12 Hydrogen Piping and Pipelines Section Committee for design factors for metallic and non-metallic materials when used in a dry hydrogen gas environment; design life considerations; nondestructive examination recommendations; in-service inspection recommendations; research needs; and recommendations.

7. ASME B31.12, Hydrogen Piping and Pipelines, February 2009, is a new code developed for hydrogen piping and pipelines. Part IP covers industrial piping in hydrogen plants and filling stations. Part PL addresses hydrogen pipelines and a distribution system. A future edition adding Part CR is planned. This part will cover commercial and residential pipeline.

8. ISO TC197 (Hydrogen Technologies) Technical Committee has published ISO 22734 - 1:2008, Hydrogen Generators Using Water Electrolysis Process Part 1: Industrial and Commercial Application. This standard defines the construction, safety, and performance requirements of packaged or factory-matched hydrogen gas generation appliances, referred to as hydrogen generators, using electrochemical reactions to electrolyze water to produce hydrogen and oxygen gas.

As currently written, these standards would not be applicable to the generators necessary to achieve $1 \mathrm{~kg} / \mathrm{sec}$ of hydrogen. Therefore, development of new codes and standards are necessary to support the design, construction, and operation of a large commercial hydrogen production facility. It was reported in the DOE Hydrogen Program 2008 Annual Progress Report that completion of the codes and standards necessary for the "early commercialization and market entry of hydrogen technologies" is projected to be in fourth quarter $2012 .{ }^{\text {eee }}$ It is not clear from the information available whether work is planned to develop the codes and standards required for the design, construction, and safe operation of a large commercial hydrogen production facility.

\footnotetext{
${ }^{e e e}$ U.S. Department of Energy, DOE Hydrogen Program 2008 Annual Progress Report, VIII.1 Hydrogen Safety Codes and Standards, November 2008, www.hydrogen.energy.gov/pdfs/ progress08/viii_1_rivken.pdf.
} 
The codes and standards currently being developed are generally focused on public safety and to a lesser degree on worker safety; essentially none focus on the design, construction, and operation of a large-scale hydrogen production facility. In most cases, codes and standards have limited applicability to power production applications.

Most states have a certification or permitting process for large power production facilities, but this process does not rely on onsite inspection, it relies on industry experience and industry good practices to ensure that a power plant is designed, constructed, and operated in a manner consistent with ensuring the safety of the public. These good industry practices are not available for the hydrogen production industry. Therefore, in order to accelerate the hydrogen production industry the standards-development organizations and code-development organizations will need to develop and codify industry good practice to ensure safe commercial large-scale hydrogen production.

\subsection{Safety - Hydrogen Generation by Facility Location}

\subsubsection{Hydrogen Production Facility Sited within Secured/Protected Area}

The feasibility of siting a commercial-size hydrogen production facility within the secured/protected area of an existing nuclear facility is examined in this section. The security zones of a nuclear plant are shown in Figure 7-1.

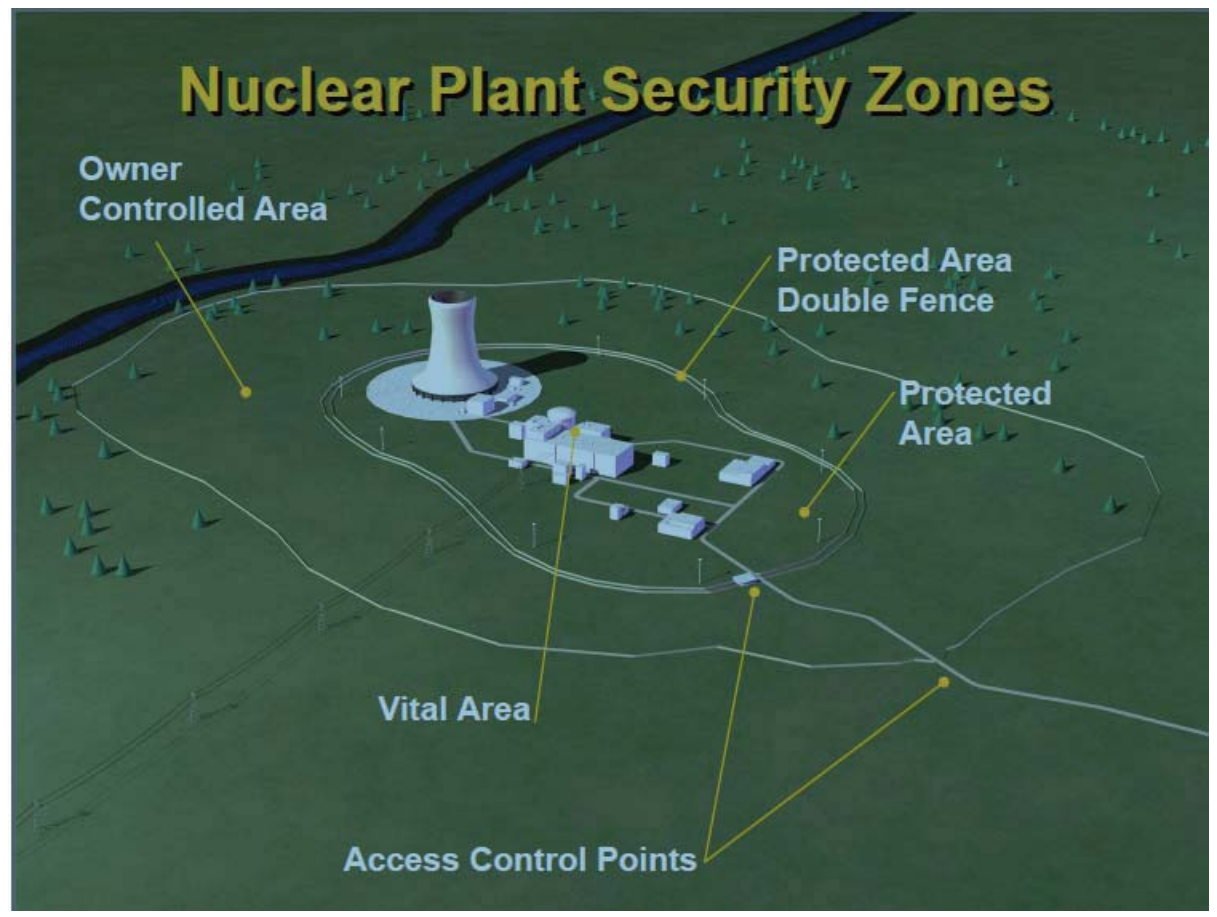

Figure 7-1. Nuclear plant security zones. ${ }^{\text {fff }}$

7.2.1.1 Nuclear Licensing. All current operating U.S. nuclear power generating facilities are granted operating licenses by the NRC under 10 CFR Part 50. As required, each particular nuclear facility is described in its Final Safety Analysis Report (FSAR). Included in the FSAR description of the facility is a description of the activities conducted at the site, "including the products and materials likely to be

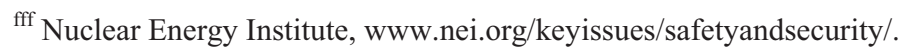


processed, stored, or transported." ${ }^{\text {ggg }}$ Therefore, co-locating a hydrogen production facility within the secured/protected area of an existing nuclear facility would be considered by the NRC as a change to the facility as described in the facility's FSAR.

Licensees make changes to their facility in accordance with the requirements of 10 CFR 50.59. Pursuant to 10 CFR 50.59, a change to the facility is evaluated by the licensee to determine its affect on the facility. For any change that a licensee determines would either result in more than a minimal increase in frequency or the consequences of an accident previously evaluated or create the possibility for an accident of a different type not previously evaluated, the licensee must obtain a license amendment prior to implementing the change. Because of the hazards associated with hydrogen production and storage, it is likely that a licensee would determine that co-locating a hydrogen production facility within the secured/protected area of an existing nuclear facility requires an amendment to their license.

A licensee must make application for a license amendment in accordance with the requirements of 10 CFR 50.90. The license amendment process involves having the licensee evaluate the proposed changes to the facility for their effects on the licensing basis of the plant, as described in the FSAR. This includes evaluating the potentially affected safety analyses, plans for coping with emergencies, the physical security plan, fire protection program, and the environmental impacts of the proposed license amendment. In order for NRC to support a license amendment to the license of an existing nuclear facility for the co-location of a hydrogen production facility, NRC must find that the co-location of the hydrogen production facility poses no statistically significant increased risk to the nuclear plant. Therefore, any incremental risk imposed by the hydrogen production facility must be determined and evaluated for its effects on the nuclear facility.

This risk assessment requires the licensee to determine the reliability of the hydrogen production facility and evaluate the possible accident scenarios posed by the hydrogen facility. At this time, it is difficult to predict the reliability of the hydrogen production facility because of the lack of data from a commercial-sized facility and, therefore, predict the frequency of any adverse event. The major safety analysis concern at a nuclear facility is the release of radioactive materials. Therefore, accident scenarios caused by operation or malfunction of the hydrogen production facility that may result in the release of radioactive materials need to be determined and the consequences evaluated. Without actual design specifics, reliability, and operating experience of a commercial hydrogen production facility, it is difficult to assess the specific potential hazards posed to the nuclear plant. Other factors that will determine the impact of the hazards include separation distance and physical barriers.

There have been limited studies regarding the safety of coupling nuclear plants with chemical plants as documented in Next Generation Nuclear Plant Phenomena Identification and Ranking Tables, NUREG/CR-6944. ${ }^{\text {hhh }}$ The Energy Policy Act of 2005, Public Law 109-58, mandates DOE and NRC develop a licensing strategy for the Next Generation Nuclear Plant (NGNP), a very high-temperature gas-cooled reactor for generating electricity, and co-generating hydrogen using process heat from the reactor. In order to address the analytical tools needed to develop the licensing strategy for NGNP, NRC conducted a Phenomena Identification and Ranking Table. The Phenomena Identification and Ranking Table was performed in five major topical areas of NGNP: (1) accident analysis and thermal-fluids, including neutronics, (2) fission product transport, (3) high-temperature materials, (4) graphite, and (5) process heat and hydrogen production. The findings of the Phenomena Identification and Ranking

\footnotetext{
${ }^{\text {ggg }}$ NUREG-0800, 2.2.1-2.2.2, Rev. 3, March 2007.

${ }^{\text {hhh }}$ U.S. Nuclear Regulatory Commission, Office of Nuclear Regulatory Research, Next Generation Nuclear Plant Phenomena Identification and Ranking Tables (PIRTs), NUREG/CR-6944, Vols.1-6 (ORNL/TM-2007/147) Oak Ridge National Laboratory, March 2008.
} 
Table for hydrogen co-generation are reported in Volume 6 of NUREG-/CR-6944. ${ }^{\text {iii }}$ In the area of process heat and hydrogen production, the "panel found that the most significant external threat from the chemical plant to the nuclear plant is from ground-hugging gases that could be released. ${ }^{, j \mathrm{jj}}$ The gas determined to be the most important was oxygen. The accidental release of hydrogen was considered of lesser concern because of its high buoyancy and its tendency to be easily diluted by air. The panel reported that oxygen presents a special concern because "(1) it is the by-product from all hydrogen production processes that start with water, and (2) it may be released continuously as a 'waste' if there is no local market. This is due to its combustion aspects, plume behavior, and allowable concentration with the chemical safety aspects and known risks of oxygen plants." "kkk The panel reports that "[t]he safety uncertainties associated with collocation of nuclear and chemical plants are significantly larger than the uncertainties associated with internal reactor safety challenges since there have been only limited studies in the area."111

The studies conducted for NGNP can be drawn from to help identify possible accident scenarios that may be applicable to the co-location of a commercial hydrogen production facility with an existing nuclear plant or new nuclear plants of existing design.

7.2.1.2 Other Plans/Programs. In addition to the nuclear plant FSAR, other nuclear facility plans and programs will likely require revision. These include the physical security plan, the emergency plan, and the fire protection program. Any modification necessary to any of these plans or programs will require evaluation for safety significance and approval by NRC, as required. Additionally, modification of a nuclear facility's emergency plan requires evaluation and input by state and local emergency preparedness organizations. New nuclear plant designs, including a co-located hydrogen production facility, also will need to consider hydrogen aspects to these plans.

7.2.1.3 Nuclear Liability Insurance. The NRC requires all licensees of nuclear power generating facilities to maintain financial protection through primary and secondary liability insurance coverage mandated by the Price-Anderson Act. The purpose of the Price-Anderson Act is to compensate the public in the event of a nuclear incident and "to limit the potential liability of companies involved in certain nuclear activities, and by doing so encourage the commercial use of nuclear energy." ${ }^{\text {,mm }}$ The primary insurance coverage requirement is currently $\$ 300$ million for reactors rated at $100 \mathrm{MWE}$ or more. Secondary coverage in the form of a retrospective premium is to be contributed by all licensees to cover claims that exceed the primary insurance amount. The secondary premium is currently limited to a maximum of $\$ 117,495,000 .^{\text {nnn }}$

Both the primary and secondary insurance coverage is obtained through American Nuclear Insurers. This liability insurance is purchased by the nuclear facility owner/operator under a "nuclear liability Facility Form policy" written by American Nuclear Insurers. The insured under the facility form policy includes the following:

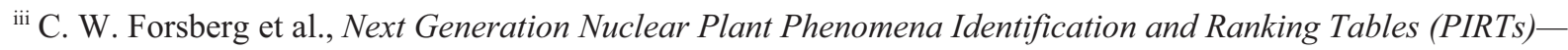
Volume 6: Process Heat and Hydrogen Co-Generation PIRTs, NUREG/CR-6944, Vol. 6 (ORNL/TM-2007/147, Vol. 6), Oak Ridge National Laboratory, March 2008.

jij Ball, S.J. and Fisher, S.E. Next Generation Nuclear Plant Phenomena Identification and Ranking Tables (PIRTs)—Volume 1: Main Report, NUREG/CR-6944, Vol. 1 (ORNL/TM-2007/147, Vol. 1), Oak Ridge National Laboratory, March 2008 , pg. 69.

kkk ibid.

111 ibid, pg. 70.

${ }^{\mathrm{mmm}}$ American Nuclear Insurers, Need for Nuclear Liability Insurance, January 2009, www.nuclearinsurance.com/library/Nuclear\%20Liability\%20in\%20the\%20US.pdf, last viewed June 19, 2009.

nnn 10 CFR 140.11. 


\section{The named insured (usually the facility operator)}

2. Any other person or organization with respect to their legal responsibility for damages because of bodily injury, property damage, or environmental damage caused by the 'nuclear energy hazard,' which is defined as 'the radioactive, toxic, explosive or other hazardous properties of nuclear material.' Nuclear material includes source, special nuclear, and byproduct material. $^{\text {ooo }}$

These nuclear liability policies only apply to the nuclear energy hazard and specifically exclude nuclear property damage to a nuclear facility. "The NRC ... requires power reactors to purchase property insurance at minimum limits of $\$ 1.06$ billion."ppp

In order to reduce risk and secure underwriting and rating information American Nuclear Insurers conducts onsite inspections of insured facilities. These inspections are in addition to those performed by NRC and the Institute of Nuclear Power Operations (an industry organization) and are intended to evaluate risks, make recommendations to reduce the probability of loss and the consequences of accidents that occur, and support the claims investigation process.

Any proposed change to an existing insured facility would need to be evaluated by American Nuclear Insurers to identify any new or increased risk posed by the change. Therefore, in addition to any review and approval required by NRC, American Nuclear Insurers also would need to evaluate any new or added risk to the "nuclear energy hazard" that co-locating a hydrogen production facility might pose. Based on the current lack of actuarial data on large commercial hydrogen production facilities would likely be very difficult for American Nuclear Insurers to assess the risk. This may result in American Nuclear Insurers either raising the premiums significantly or determining that the risk is too great and not insuring the nuclear facility with a co-located hydrogen production facility within the secure/protected area of the nuclear plant.

7.2.1.4 Property Insurance. In addition to nuclear liability insurance, the property insurance requirements for the nuclear facility also would have to be evaluated. Because limited actuarial information is available on large hydrogen production facilities, the property insurance provider may either raise the premiums significantly or determine that it cannot insure the nuclear facility with a co-located hydrogen production facility within the secure/protected area or the nuclear plant.

Because both nuclear liability and property insurance is required by $\mathrm{NRC}$, ${ }^{\mathrm{qqq}}$ it is important that not only American Nuclear Insurers, but nuclear property insurers, be brought into the planning phase early so that the insurance issues are properly addressed. Furthermore, this may be an area that the federal government may need to address with legislation similar to that of the Price-Anderson Act that creates a limit on liability associated with hydrogen production to encourage its commercial use.

7.2.1.5 Electrical System Stability. The stability of the electrical system associated with a nuclear power plant is a major nuclear safety concern. Unlike most conventional sources of power (e.g., oil or coal), nuclear plants have long-term shutdown cooling requirements that consume power and have restrictive voltage and frequency limitations. If the co-located hydrogen production facility is provided electricity directly from the nuclear plant and not from the grid, then the shutdown or degraded operation of the hydrogen facility would cause a load rejection, loss of load, or degraded voltage/frequency event. Even if the hydrogen production facility is powered from the grid, a shutdown or

\footnotetext{
${ }^{\text {ooo }}$ American Nuclear Insurers, pg. 2.

ppp American Nuclear Insurers, pg. 5.

qqq American Nuclear Insurers, pg.5.
} 
degraded operation could cause a grid disturbance adversely impacting the nuclear plant load. The nature of hydrogen generation is that it can go very quickly from full production to zero. This type of load rejection is a feasible occurrence.

Nuclear plants are currently designed and licensed for a loss of load event. However, depending on the power distribution provided to the hydrogen production facility (dedicated or off the grid) and the reliability and frequency of load disturbances, the licensee will likely need to review the electrical system stability. If it is determined that the frequency of a loss of external load event is increased, the licensee would need to evaluate the change under 10 CFR 50.59, as previously discussed in Section 7.2.1.1, and request a license amendment from $\mathrm{NRC}$ and approval, as required.

According to NUREG-0800, Branch Technical Position 8-3, NRC has determined that for most plants on the U.S. mainland, the offsite power systems with supporting grid interties meet the availability criterion with some margin. However, with more demand and no additional generating capacity these capacity margins are diminishing. If the load from the hydrogen production facility is considered the largest unit on the grid, the licensee may need to provide for additional onsite power system capability and margin. This would not only be costly but would necessitate license modification and NRC approval.

7.2.1.6 Emergency Planning. Emergency planning is a key element in licensing a nuclear power plant. Licensees are required, as a condition of their license, to maintain an emergency plan to ensure that "adequate protective measures can and will be taken in the event of a radiological emergency." "rrr These measures include quality design and construction of nuclear plants, including safety systems and containment structures, and actions to be taken to protect the public in the area around a nuclear power plant in the event of a release of radioactive materials. The licensee, NRC, Federal Emergency Management Agency, and State and local organizations have responsibilities in emergency planning for a nuclear facility.

Emergency planning is performed in two major zones. The plume exposure pathway emergency planning zone consists of an area about 10 miles in radius. This emergency planning zone is where it is possible for people to be harmed by direct radiation exposure. The ingestion pathway emergency planning zone is an area consisting of up to a 50-mile radius where radioactive materials could contaminate water supplies, food crops, and livestock. Emergency planning zones may vary in size and configuration depending on local response needs, including land characteristics, topography, access routes and demography, and local response capabilities.

With the hydrogen production facility co-located within the secured/protected area of the nuclear facility the existing emergency plan for the nuclear facility will need to be evaluated to determine what changes are required. This evaluation should include the effect of the hydrogen production facility on onsite evacuation strategies. This evaluation should include the potential effect on onsite evacuation from possible damage to the hydrogen production facility due to the radiological emergency. At a minimum, the emergency plan will require revision to include notification and evacuation of those non-nuclear, hydrogen production facility workers. Additionally, if the effect on onsite evacuation due to damage to the hydrogen production facility is determined by NRC to adversely impact the ability to implement the emergency plan, NRC may not approve revision to the emergency plan.

7.2.1.7 Environmental Review. When issuing an amendment to a license it is necessary for NRC to make a determination as to whether an environmental review is required. An environmental review may be conducted in the form of an environmental assessment or an environmental impact statement. If

\footnotetext{
${ }^{\mathrm{rrr}}$ U.S. Nuclear Regulatory Commission, Fact Sheet on Emergency Planning and Preparedness, www.nrc.gov/reading-rm/doccollections/fact-sheets/emer-plan-prep.html, viewed May 22, 2009.
} 
the amendment involves no significant hazards consideration, then no environmental review is required. However, it is likely that NRC will determine that the installation and operation of a hydrogen production facility within the secured/protected area of a nuclear facility involves significant hazards. Therefore, pursuant to 10 CFR 51.21, NRC will be required to perform an environmental assessment. Furthermore, if the proposed license amendment is determined by NRC to be a "major Federal action significantly affecting the quality of the human environment" an environmental impact statement is required. ${ }^{\text {sss }}$

The environmental assessment process for a license amendment includes review of the need for the proposed action; environmental impacts of the proposed action; alternatives to the proposed action; and alternative use of resources. Also included in the assessment is the evaluation of the radiological and non-radiological impacts associated with the proposed change, the effect on listed species or critical habitat, and a determination as to whether the proposed action has the potential to cause effects on historic properties. Therefore, the specific issues addressed in an environmental assessment for the co-location of a hydrogen production facility within the secured/protected area of an existing nuclear facility would likely include the need for co-locating the facility within the secured/protected area. Also included in the assessment by NRC is the requirement to assess the determination of need for the proposed change. Therefore, the change to the facility, the co-location of a commercial hydrogen production facility within the protected area of the nuclear facility, will be assessed by NRC based on its need. The proposed hydrogen production facility requires only electrical transmission from the nuclear facility. The only benefit to co-locating the hydrogen production facility so close to the nuclear facility is the ability to bus power directly from the transmission yard at the nuclear facility while minimizing transmission costs. There are other alternatives available for providing nuclear generated electricity to the hydrogen production facility, such as dedicated transmission lines or locating the hydrogen production facility close to a high voltage transmission yard. Therefore, it may be difficult for NRC to determine that the hydrogen production facility's co-location within the secured/protected area is needed when there are alternatives available that provide the same benefits without posing risk to the nuclear facility.

After the performance of the environmental assessment, if NRC finds that the proposed amendment to the license will have a significant effect on the quality of the human environment, then an environmental impact statement is required. If an environmental impact statement is required, NRC will need to assess the proposed action with respect to various issues, including: the environmental impact of the proposed action; the environmental impacts of alternatives to the proposed action; and alternatives available for reducing or avoiding adverse environmental effects and consideration of the economic, technical, and other benefits and costs of the proposed action and alternatives and indicate what other interests and considerations of federal policy, including factors not related to environmental quality if applicable, are relevant to the consideration of environmental effects of the proposed action. ${ }^{\text {ttt }}$

NUREG-1555, Environmental Standard Review Plan, provides NRC with guidance for conducting environmental reviews of applications related to nuclear power plants. ${ }^{\text {uu }}$ The scope of the environmental standard review plans includes guidance for construction permits (10 CFR 50), initial operating licenses (10 CFR 50), early site permits (10 CFR 52, Subpart A), and application for combined licenses (10 CFR 52, Subpart C). In addition to the environmental impacts, including surface and groundwater uses, the power demand, energy alternatives and need for power (generating capacity) associated with the application for a new nuclear power plant (i.e., the proposed action) are reviewed. It is unclear if or how

\footnotetext{
sss 10 CFR 51.20.

ttt 10 CFR 51.71

${ }^{\text {uи }}$ U.S. Nuclear Regulatory Commission, Environmental Standard Review Plan: Standard Review Plans for Environmental Review for Nuclear Power Plants, NUREG-1555, October 1999, www.nrc.gov/reading-rm/doccollections/nuregs/staff/sr1555/sr1555.pdf, viewed June 13, 2009.
} 
the environmental standard review plans would be applicable to the review for a proposed license amendment for the co-location of a hydrogen production facility with an existing nuclear plant.

However, the environmental standard review plans would be applicable if a new nuclear facility is considered for generating the power required for a large commercial hydrogen production facility. The need for power generated by the proposed nuclear plant would likely be an important issue in determining the acceptability of the nuclear plant. This is especially true if the power generated from the nuclear plant was to be dedicated to the production of hydrogen and the current or projected demand for the production of hydrogen was not evident.

\subsubsection{Hydrogen Production Facility Sited Adjacent to Secured/Protected Area}

7.2.2.1 Nuclear Licensing. Depending on proximity to the nuclear plant, the siting of the hydrogen facility adjacent to the a nuclear facility's secured/protected area may constitute a change to the nuclear facility because industrial facilities located in the vicinity of the nuclear facility are described in Chapter 2 of the nuclear plant's FSAR. The standard review plan acceptance and review criteria for potential hazards in the vicinity of the site include facilities and activities within 5 miles of the plant. "Facilities and activities at a distance greater than 8 kilometers ( 5 miles) should be considered if they have the potential for affecting plant safety-related features."

If the siting of the hydrogen production facility is determined to constitute a change to the nuclear facility, then all requirements associated with the licensee's need to request a license amendment apply, as discussed in Section 7.2.1.1. As seen in Figure 7-1, siting the hydrogen production facility adjacent to the protected area of the nuclear facility may not result in any significant separation, thus, only minimally reducing the risk posed to the nuclear facility. However, as the separation between the nuclear plant and the hydrogen production facility increases the potential for adverse impact to the nuclear plant decreases. Unlike the NGNP coupled to a hydrogen production plant, which uses process heat from the nuclear plant to generate hydrogen, minimizing the separation distance between the facilities is not necessary. When co-locating the hydrogen production facility with an existing nuclear plant, the separation distance is only limited by the cost of the transmission of electricity.

In order for NRC to approve an amendment to the nuclear facility license, they must find that co-locating a hydrogen production facility adjacent to the nuclear facility poses no statistically significant increased risk to the nuclear plant. If the licensee does not have the opportunity to obtain prior approval for the co-location of the hydrogen facility adjacent to the nuclear facility (i.e., when the hydrogen facility is not owned by the licensee utility), NRC may require the licensee to make modifications to the nuclear facility to minimize any risk posed by the adjacent hydrogen facility or make a determination that the operating license be revoked. Either situation could be financially devastating to the licensee.

Because there is limited design, construction, or operating experience with large-scale hydrogen production facilities, it is unlikely NRC will find no statistically significant increased risk to the nuclear facility due to the co-location of a hydrogen facility. Studies, such as those conducted for NGNP coupled to a hydrogen production plant, need to be conducted to identify possible accident scenarios that may be applicable to co-locating a large hydrogen production facility adjacent to a nuclear facility before nuclear regulatory considerations can be properly addressed.

In addition to requirements associated with the assessment of risk posed by the hydrogen production facility, there are regulatory requirements and considerations associated with siting the nuclear

\footnotetext{
${ }^{\mathrm{vvv}}$ Standard Review Plan, 2.2.1-2.2.2 Identification of Potential Hazards in Site Vicinity, NUREG-0800, March 2007.
} 
facility. These include the determination of an exclusion area and a low population zone. The exclusion area is defined in 10 CFR 100.3 as follows:

Exclusion area means that area surrounding the reactor, in which the reactor licensee has the authority to determine all activities including exclusion or removal of personnel and property from the area. This area may be traversed by a highway, railroad, or waterway, provided these are not so close to the facility as to interfere with normal operations of the facility and provided appropriate and effective arrangements are made to control traffic on the highway, railroad, or waterway, in case of emergency, to protect the public health and safety.

Residence within the exclusion area shall normally be prohibited. In any event, residents shall be subject to ready removal in case of necessity. Activities unrelated to operation of the reactor may be permitted in an exclusion area under appropriate limitations, provided that no significant hazards to the public health and safety will result. ${ }^{w w w}$

In accordance with this definition, a hydrogen production facility co-located adjacent to the secured/protected area of an existing nuclear plant would likely be located in the "exclusion area" and, as such, would require the licensee to have authority over the activities at the hydrogen production facility, including the "exclusion or removal of personnel and property from the area." ${ }^{\text {,xx }}$ As defined, this requirement would be very difficult for a licensee to meet unless they had ownership interest in the hydrogen production facility.

7.2.2.2 Nuclear Liability Insurance. As previously discussed in Section 7.2.1.2, NRC requires all licensees of nuclear power generating facilities to maintain financial protection through primary and secondary liability insurance coverage mandated by the Price-Anderson Act. Even though in this scenario the hydrogen production facility is co-located adjacent to the nuclear plant and not within the protected area, there may still be potential risk posed to the nuclear facility. American Nuclear Insurers currently insures all U.S. commercial nuclear facilities.

American Nuclear Insurers would likely be interested in the co-location of a hydrogen production facility adjacent to an insured nuclear facility from two aspects. First, they would be interested, as discussed in Section 7.2.1.2, because the hydrogen production facility may introduce an increased risk to the insured nuclear plant that may result in bodily injury or environmental or property damage due to the "nuclear energy hazard." And second, an incident at the nuclear plant may lead to damage of the hydrogen facility, increasing the liability to the nuclear plant and American Nuclear Insurers.

Even though the associated risk to the nuclear plant would be expected to be less than that posed by the hydrogen production facility co-located within the secured/protected area of the nuclear facility, there is a lack of actuarial data on large commercial hydrogen production facilities and operating experience. This would make it difficult for American Nuclear Insurers to assess risk associated with co-locating a hydrogen production facility adjacent to a nuclear plant and may result in American Nuclear Insurers either raising the premiums significantly or determining that the risk is unknown or too great and not insuring the nuclear facility.

7.2.2.3 Property Insurance. In addition to nuclear liability insurance, the property insurance for the nuclear facility would also have to be evaluated. Again, since limited actuarial information is

\footnotetext{
www 10 CFR 100.3

xxx ibid.
} 
available on large hydrogen production facilities, the property insurance provider may also either raise the premiums significantly or determine that it can not insure the nuclear facility with a co-located hydrogen production facility adjacent to the secured/protected area of the nuclear plant.

As previously discussed in Section 7.2.1.2, because nuclear liability and property insurance are required by NRC, it is important that not only American Nuclear Insurers, but nuclear property insurers, be brought into the planning phase early so that the insurance issues are properly addressed. Furthermore, this may be an area that the federal government may need to address with legislation similar to that of the Price-Anderson Act that creates a limit on liability associated with hydrogen production to encourage its commercial use.

7.2.2.4 Emergency Planning. As discussed in Section 7.2.1.4, licensees of nuclear power plants are required to maintain an emergency plan that provides protective measures to the nuclear plant workers and members of the public in the event of a radiological emergency. The licensee, NRC, Federal Emergency Management Agency, and state and local organizations have responsibilities in the emergency planning for a nuclear facility and should be involved in any proposed revision to the nuclear facility's emergency plan.

With the proposed hydrogen production facility co-located adjacent to the nuclear facility and within the plume exposure emergency planning zone (an area of about 10 miles in radius), the emergency plan for the nuclear facility will require evaluation for revision. This evaluation should include emergency notification, emergency communication, evacuation strategy, and shelter requirements. Additionally, because of the close proximity of the hydrogen production facility, the evaluation also should include the potential effect on the ability to implement the emergency plan in the event the radiological emergency causes damage to the hydrogen production facility. At a minimum, the emergency plan will require revision to include notification and evacuation of those non-nuclear, hydrogen production facility workers. If the evaluation of the proposed siting of the hydrogen production facility with respect to revision of the nuclear facility emergency plan adversely impacts the ability to implement the plan in the event of a radiological emergency, NRC may not approve the proposed revision to the emergency plan or may require the licensee to modify the nuclear facility to minimize any adverse effects due to the hydrogen production facility.

7.2.2.5 Environmental Review. Prior to issuing a license amendment to an operating license, NRC will determine if an environmental review is required. An environmental review may be conducted in the form of an environmental assessment or an environmental impact statement. If the amendment involves no significant hazards consideration, then no environmental review is required. It is likely that NRC will determine that the installation and operation of a hydrogen production facility adjacent to the secured/protected area of a nuclear facility involves significant hazards. For this discussion, it is assumed that the hydrogen production facility is proposed to be located within the exclusion area, as defined in Section 7.2.2.1. Therefore, pursuant to 10 CFR 51.21, NRC will be required to perform an environmental assessment. However, if NRC determines that the proposed license amendment is a "major Federal action significantly affecting the quality of the human environment," an environmental impact statement is required..$^{\text {yy }}$

As described in Section 7.2.1.5, the environmental assessment process includes the review of the need for the proposed action, environmental impacts of the proposed action, alternatives to the proposed action, and alternative use of resources. Also included in the assessment is the evaluation of the radiological and non-radiological impacts associated with the proposed change, the effect on listed species or critical habitat, and a determination as to whether the proposed action has the potential to cause

\footnotetext{
yyy 10 CFR $\S 51.20$.
} 
effects on historic properties. Therefore, the specific issues addressed in an environmental assessment for the co-location of a hydrogen production facility within the secured/protected area of an existing nuclear facility would likely include the need for co-locating the hydrogen production facility adjacent to the secured/protected area of the nuclear facility. Also included in the assessment by NRC is the requirement to assess the determination of need for the proposed change. Therefore, the proposed action (co-location of a commercial hydrogen production facility adjacent to the secured/protected area of the nuclear facility) will be assessed by NRC based on its need.

The proposed hydrogen production facility requires only electrical transmission from the nuclear facility. The benefit of co-locating the hydrogen production facility adjacent to the nuclear facility is minimizing transmission costs, either by bussing power directly from the transmission yard of the nuclear facility or minimizing transmission needs. There are other alternatives available for providing nuclear generated electricity to the hydrogen production facility, such as dedicated transmission lines or locating the hydrogen production facility close to a high voltage transmission yard. Therefore, it may be difficult for NRC to determine that the hydrogen production facility's co-location adjacent to the secured/protected area is needed when there are alternatives available that provide the same benefits without posing risk to the nuclear facility.

\subsection{Regulation and Taxation}

Public utilities, such as electric gas and telecommunications, are controlled by state utility commissions. In some states, the officials serving on the commissions are elected while in most they are appointed by either the legislature or the governor. The purpose of the utility commissions is to regulate the intrastate rates and services of the public utilities, including electricity, natural gas, water, and telecommunications.

Duties of a utility commission can include activities such as the following:

- $\quad$ Approving rates and regulation of service quality

- Approving resource plans that include consideration of environmental affects of energy use

- $\quad$ Granting Certificates of Need, or equivalent, as applicable, for large energy facilities

- $\quad$ Approving mergers, acquisitions, and transactions between affiliates

- $\quad$ Approving securities issuances, stock purchases, and other major financial transactions with rate impacts.

Several questions remain unexplored in this area. As an energy carrier, would hydrogen be subject to regulation as electricity is? Would hydrogen be taxed as a fuel because it would be used for transportation on public highways? How would the regulation apply to private or non-utility ownership of the hydrogen facilities? How would the taxation and regulation affect a utility's decision on production of hydrogen and/or electricity from a nuclear - hydrogen production facility? A developing hydrogen economy would require resolution of these and many additional questions to determine the feasibility of building a production facility. 


\subsection{Environmental Considerations}

Environmental considerations, including the accidental release of hydrogen, hydrogen production facility discharges, bulk storage of hydrogen, waste generation, and water are examined in the following sections.

\subsubsection{Hydrogen Release}

Hydrogen, gaseous or liquid, is classified as highly flammable, can ignite over a wide range of concentrations and has low minimum ignition energy. Additionally, hydrogen is colorless, tasteless, and odorless, making a release virtually undetectable by humans. Therefore, releases of all sizes are of concern. When hydrogen burns, it burns with a pale blue flame that is nearly invisible and does not produce smoke. Hydrogen is a small molecule with a low viscosity that is prone to leakage and can be absorbed into materials. Because of this characteristic, hydrogen embrittles certain metals, which can result in structural failure of system piping. Hydrogen is a light gas, and when released into an open environment, it quickly rises and dissipates fairly rapidly. Therefore, precautions should be taken to detect hydrogen leaks and to ensure that if leaks occur that hydrogen accumulation does not result. Therefore, whether hydrogen is either stored onsite in tanks or cylinders or is distributed via pipelines, the release of hydrogen can become a hazard to humans and the surrounding environment.

\subsubsection{Discharges}

Discharges, other than the desired hydrogen, expected from a hydrogen production facility are oxygen and process water.

Oxygen is an odorless, colorless, non-flammable gas and is considered nontoxic and environmentally safe. Liquid oxygen can cause skin burns and tissues burns. Oxygen is a heavy gas that if released or discharged under accident conditions causes unique safety challenges. Oxygen will vigorously accelerate combustion and increase the risk of fire and explosion when in contact with combustible or flammable materials. To avoid these harmful effects, strict safety guidelines should be followed for storage and handling. Additionally, the effects and characteristics of an accidental oxygen release need to be examined. In particular, the effects on nuclear plant safety-related structures, systems, and components.

Process water discharge from the proposed commercial hydrogen production facility, unless reclaimed, will likely require permitting. Under the National Pollution Discharge Elimination System, ${ }^{\text {zzz }}$ any point source discharge of industrial water into a water of the United States is required to be permitted. The National Pollution Discharge Elimination System permits regulate wastewater discharges by limiting the quantities of pollutant discharges, impose monitoring requirements, and other conditions. The National Pollution Discharge Elimination System is administered by authorized states, with most states being federally approved. If the wastewater is considered for use in irrigation, permits will likely have to be obtained from the appropriate state or local authorities. Many jurisdictions now require the identification of wastewater or effluent use for irrigation.

The process water discharge will vary based on the efficiency of the de-ionizer used. The lower the efficiency of the de-ionizer, the more supply water is required but also the less the process water impurities are concentrated. Using a low efficiency de-ionizer may more easily allow the process water to be used for other purposes. This will be a consideration in the plant design.

\footnotetext{
${ }^{\text {zzz }}$ Federal Water Pollution Control Act (aka Clean Water Act), 33.U.S.C. §§ 1251-1387, as amended through P.L. 107-303, November 27, 2002, Section 402, National Pollution Discharge Elimination System.
} 


\subsubsection{Bulk Storage}

Hydrogen is regulated under the Clean Air Act ${ }^{\text {aaaa }}$ as a regulated flammable substance. Therefore, the amount of hydrogen stored can trigger additional emergency planning, accident prevention, and reporting requirements. Facilities with quantities of a regulated substance exceeding the threshold quantities are required to prepare a risk management plan to address accidental release prevention. ${ }^{\text {bbb }}$ Requirements of the risk management plan include implementing a risk management program that includes an offsite consequence analysis, an accident prevention program, an emergency response program, and a 5-year accident history. Risk management plans are required to be submitted to the Environmental Protection Agency and are required to be updated at least every 5 years.

The threshold quantity for hydrogen is $10,000 \mathrm{lb}$. There is an exclusion from the Environmental Protection Agency risk management plan requirements for hydrogen when it is "used as a fuel or held for sale as a fuel at a retail facility." ${ }^{\text {"cccc }}$ However, a hydrogen production facility that stores quantities of hydrogen onsite greater than the threshold quantity that is not using the hydrogen as a fuel onsite or that is not a retail facility is subject to the risk management plan requirements.

The Compressed Gas Association in its publication CGA P-28, "Risk Management Plan Guidance Document for Bulk Liquid Hydrogen Systems," provides guidance to comply with the risk management plan requirements. The guidance includes information, such as a typical hazard and operability (HAZOP) study, to complete the required hazard assessment.

\subsubsection{Waste}

The types of electrolyzer(s), catalyst(s), and electrodes used for the production of hydrogen will determine what waste, if any, is generated. This waste may be hazardous waste and regulated by the Environmental Protection Agency under the Resource Conservation and Recovery Act. ${ }^{\text {ddd }}$ A regulated hazardous waste that is regulated under the Resource Conservation and Recovery Act Subtitle C is a waste that is either a listed waste or a characteristic waste. The resultant waste needs to be evaluated to determine if it is hazardous waste and subject to the requirements of the Resource Conservation and Recovery Act. ${ }^{\text {eee }}$

Waste generators are regulated depending on the quantity of waste they produce. Large quantity generators are defined as those that generate $1,000 \mathrm{~kg}$ per month or more of hazardous waste, more than $1 \mathrm{~kg}$ per month of acutely hazardous waste, or more than $100 \mathrm{~kg}$ per month of acute spill residue or soil. ${ }^{\mathrm{ffff}}$ Small quantity generators generate more than $100 \mathrm{~kg}$, but less than $1,000 \mathrm{~kg}$, of hazardous waste per month. ${ }^{\text {gggg }}$ Conditionally exempt small quantity generators generate $100 \mathrm{~kg}$ or less per month of hazardous waste, or 1 kilogram or less per month of acutely hazardous waste, or less than 100 kilograms

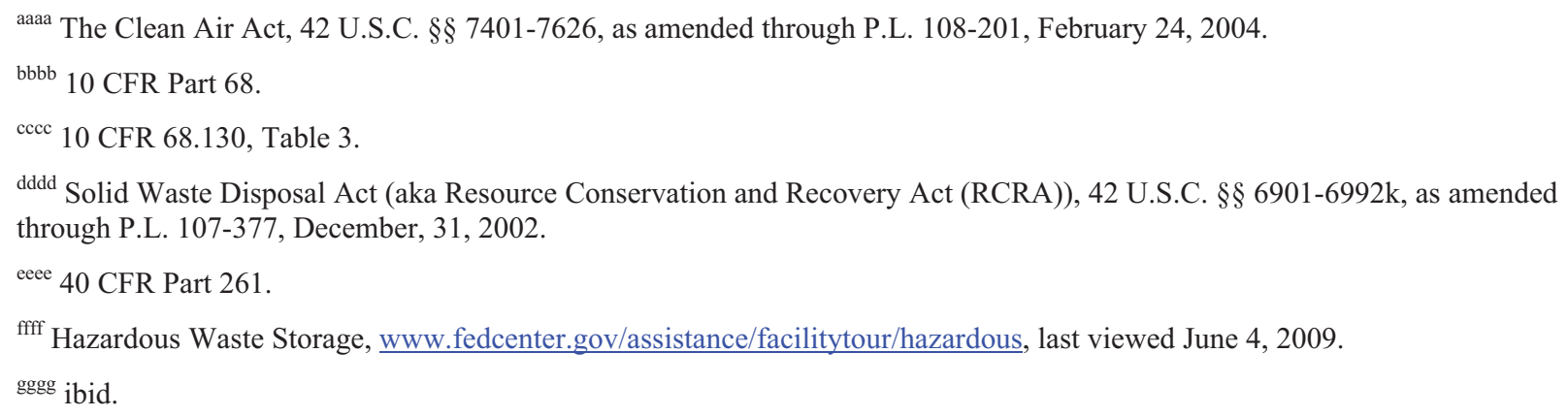


per month of acute spill residue or soil. ${ }^{\text {hhh }}$ Each category of generator is required to comply with its own set of requirements provided in 40 CFR 262. Additionally, all generators are required to do the following:

- $\quad$ Obtain an EPA Identification number (available from state environmental offices)

- Comply with the manifest system

- $\quad$ Handle waste properly before shipment (e.g., packaging, labeling, marking, placarding, and accumulation time)

- Comply with record keeping and reporting requirements

- $\quad$ Comply with any additional state requirements for generators (contact your State environmental office for more information).

Therefore, the types and quantities of waste generated from the production of hydrogen will determine what requirements are applicable.

When co-locating a hydrogen production facility with an existing or new nuclear facility all the waste generated by both may be considered to determine the generator status. The Resource Conservation and Recovery Act definition for facility is based on contiguous land and structures under the control of the same owner or operator. ${ }^{\text {iiii }}$ If the co-located hydrogen production facility is owned and/or operated by the nuclear utility, then the generator status and resulting Resource Conservation and Recovery Act requirements will be from the combination of generated waste. Additionally, other state and local requirements associated with waste generation, reclamation, or disposal may be applicable.

\subsubsection{Other Considerations}

The emergency planning requirements for the hydrogen production facility are determined based on the type and amount of hazards present. The Emergency Planning and Community Right-to-Know Act ${ }^{\mathrm{j} j \mathrm{jj}}$ requirements are applicable to "extremely hazardous substances" listed in 40 CFR 355, Appendix A and $\mathrm{B}$, in quantities that exceed the threshold planning quantities for a given substance. If applicable, the facility will be subject to the Federal Emergency Planning and Community Right-to-Know Act reporting and notification, State Emergency Response Commissions, and Local Emergency Planning Committees requirements. These emergency reporting, notification, and planning requirements are designed to inform the public about the possible hazards associated with an emergency at any given facility and to provide emergency responders information about what hazards they are approaching when responding to an emergency.

\subsection{Licensing and Permitting of Hydrogen Production Facilities}

\subsubsection{Environmental Review}

The National Environmental Policy Act of 1969, Section 102(2)(C) ${ }^{\mathrm{kkkk}}$ requires an environmental impact statement for a proposed facility or activity is that is federally controlled and significantly affects

\footnotetext{
hhhh ibid.

iiii 40 CFR 260.10.

jijj 42 U.S.C $\S \S 11000-11050$.

kkkk 42 U.S.C. $\S \S 4321-4347$.
} 
the quality of the human environment. A project is considered federally controlled when it requires federal action (such as licensing) is federally funded or when the project is undertaken by a federal agency. Because there are currently no federal license requirements for the installation and operation of a commercial hydrogen production facility an environmental impact statement will not be required based on licensing. However, especially in the early development of commercial hydrogen production facilities, it is likely that these commercial facilities will either be federally funded or undertaken by a federal agency. Therefore, it will be necessary for the federal agency "controlling" the facility to perform an environmental impact statement.

An environmental impact statement for a proposed hydrogen facility is required to provide a detailed description of the proposed action, the purpose and the need for the action, reasonable alternatives, an analysis of the anticipated beneficial and adverse effects of the alternatives, and address the total impact on the environment. Additionally, as required by 40 CFR 1502, the environmental impact statement in addressing the impact on the environment should include the direct and indirect effects of the proposed project; the interference with other activities; the energy and resources requirements; conservation and restoration potential; preservation of urban, historic, and cultural quality; and ways to minimize environmental damage.

Additionally, some states have promulgated National Environmental Policy Act of 1969-like environmental planning type regulations for major projects. These states include California, Connecticut, District of Columbia, Georgia, Hawaii, Indiana, Maryland, Massachusetts, Minnesota, Montana, New Jersey, New York, North Carolina, South Dakota, Virginia, Washington, and Wisconsin. The specific environmental impact review requirements for each state should be reviewed.

Included in the determination for need and the evaluation of the reasonable alternatives to the proposed action would be an assessment of the current need for the proposed hydrogen generation. Based on the current demand for commercially available hydrogen for vehicle fueling, it is likely that the need for a large commercial hydrogen facility and its associated impacts will be difficult to justify.

\subsubsection{State and Local Requirements}

Currently, there are no federal permits required for construction and operation of a hydrogen production facility. However, there are likely State and local permits and authorizations required. For example, in Florida a hydrogen production plant generating greater than $75 \mathrm{MW}$ is required to be permitted through the Florida Power Plant Siting Act ${ }^{1111}$, the state's centralized certification process for large power plants. The one certification replaces local and state permits, but does not include licenses required by the federal government. The state agencies and local governments within whose jurisdiction the power plant is to be built participate in the process. "A certification grants approval for the location of the power plant and its associated facilities such as a natural gas pipeline supplying the plant's fuel, rail lines for bringing coal to the site, and roadways and electrical transmission lines carrying power to the electrical grid, among others."

In addition to the certification, the plant generating greater than $75 \mathrm{MW}$ requires a "Needs Determination" conducted by the Florida Public Service Commission. The Public Service Commission reviews the need for the power generated by the proposed facility. Even though the subject hydrogen production facility of this study does not produce electricity, a correlation between the production of hydrogen and electricity can be made. "In making its determination, the commission shall take into

\footnotetext{
${ }^{1111}$ Fla. Stat. $\S \S 403.501-403.518$ (2008).

${ }^{m m m m}$ Florida Department of Environmental Protection, "Overview of Regulations for Renewable Energy Facilities," www.dep.state.fl.us/energy/Permitting_Info/Permitting_Overview.htm, viewed March 9, 2009.
} 
account the need for electric system reliability and integrity, the need for adequate electricity at a reasonable cost, the need for fuel diversity and supply reliability, whether the proposed plant is the most cost-effective alternative available, and whether renewable energy sources and technologies, as well as conservation measures, are utilized to the extent reasonably available." ${ }^{\text {nnnn }}$ Therefore, the need for the hydrogen generated will need to be reviewed. As discussed in the previous section, based on the current need for hydrogen, it is unlikely the Florida Public Service Commission would determine a current need for a large commercial hydrogen production facility.

For plants producing less than $75 \mathrm{MW}$, the permitting and authorizations likely include an environmental resource permit. The environmental resource permit addresses land coverings and corresponding storm water impacts. A consumptive use permit and an industrial wastewater discharge permit are likely required to address the plant's water needs and discharges. In addition, approval and compliance with other county and local city requirements and ordinances is required. ${ }^{0000}$

Other states also have a certification/permitting type process for approving power plants similar to that those discussed for Florida. For example, California has a certified regulatory program under the California Environmental Quality Act which applies to plants $50 \mathrm{MW}$ or larger and includes plant-related activities such as transmission lines, fuel supply, water pipelines, Wisconsin's program, Certification of Public Convenience and Necessity, Public Service Commission 111.53, is applicable to power plants greater than $100 \mathrm{MW}$ and includes a review for "the need for the proposed facility in terms of demand and energy" and the alternative sources of supply. Both California and Wisconsin require evaluation of alternative sites, including those that could avoid some or all of the proposed action's adverse environmental effects and the "no-action" alternative.

Another challenge posed by permitting hydrogen technology is the lack of codes and standards for state and local agencies to use when reviewing or inspecting a particular design or installation. As discussed previously in Section 7.1.2, there is a lack of codes and standards available for the design, construction and operation of commercial hydrogen production facilities. Typically, with large power plant projects, state and local agencies rely on the experience of the industry and of the owner to ensure the safety of the design, construction, and operation of the facility. However, there is no industry experience to look to for commercial hydrogen production and no standardized guidance. Until experience is gained or standardized guidance developed the state and local agencies will have little assurance of safety to the public.

\subsubsection{Liability Insurance}

The financial risks associated with commercial hydrogen production and associated infrastructure are essentially unknown. The International Energy Agency and International Partnership for a Hydrogen Economy state that "the global financial community has little or no experience in underwriting major hydrogen energy projects, in characterizing investment cash-flows, amortization periods, and actuarial tables for major financial risks." ${ }^{\text {pppp }}$ The International Energy Agency and International Partnership for a

\footnotetext{
${ }^{\text {nnnn }}$ Fla. Stat. $§ 403.519$ (2008).

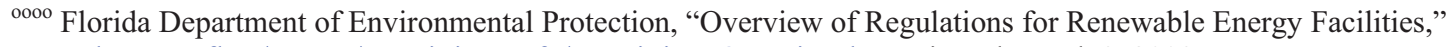
www.dep.state.fl.us/energy/Permitting Info/Permitting_Overview.htm, viewed March 9, 2009.

pppp Building the Hydrogen Economy: Enabling Infrastructure Development, Workshop Report, Detroit Workshop, April 2-4, 2007, pg. 18, www.iea.org/Textbase/work/2007/hydrogen/

Workshop_Report.pdf.
} 
Hydrogen Economy believe that "risk, liability and insurance policies concerning hydrogen infrastructure operations" "qqqq is a primary area of challenge in building a hydrogen economy.

A possible model for limiting liability for potential private owners of hydrogen technologies could be the Price Anderson Act. The Price Anderson Act limited liability to the commercial nuclear industry while allowing for its development and use. Other methods, including joint government projects or government loan guarantees, would limit the potential liabilities associated with commercializing hydrogen technologies.

\subsubsection{Siting}

Issues associated with co-locating a commercial hydrogen production facility with an existing nuclear power plant are examined in Sections 7.6 and 6.5 (discussing water availability). Nuclear regulatory and licensing issues (ability to obtain a license amendment from NRC), including nuclear safety and liability, are determined to be the major issues associated with co-locating a hydrogen production facility within the secured/protected area of an existing nuclear power plant. Co-location within a distance far enough for the hydrogen production facility not to potentially adversely impact the nuclear facility, not within the secured/protected area, would require a modification to the nuclear plant's emergency plan, but is unlikely to create additional nuclear safety or liability concerns. Additional studies will need to be performed to determine the appropriate distance from the nuclear power plant such that an accident at the hydrogen facility does not adversely impact the nuclear plant. Therefore, for co-location with an existing nuclear power plant to be a viable regulatory and licensing option from the perspective of the existing nuclear plant, it is recommended that the hydrogen production facility not be co-located within the nuclear plant's secured/protected area.

\subsection{Water for Nuclear Plant}

Water withdrawal and consumption are necessary for energy production. The availability of water and the impact on water resources caused by co-locating a nuclear power plant with a large commercial hydrogen production facility are examined in this section.

The availability of sufficient water supplies has a direct impact on economic development. Agriculture, power generation, public water systems, and other industries compete for water. The withdrawals of freshwater have exceeded precipitation in many areas of the country. These freshwater shortfalls are most dramatic in the southwest, the high plains, California, and Florida. ${ }^{\text {rrrr }}$

In recent years, a number of power plant projects have been cancelled or postponed because water-use permits could not be obtained because of insufficient supplies of water, either due to drought or population growth. These include the following:

- Tennessee Governor imposed a moratorium in 2002 on the installation of new merchant power plants because of cooling constraints.

- $\quad$ Georgia Power lost a bid to draw water from the Chattahoochee River for power plant cooling.

\footnotetext{
qqqq Ibid, pg. 27.

${ }^{\text {rrrr }}$ Energy Demands on Water Resources: Report to Congress on the Interdependency of Energy and Water," U.S. Department of Energy, December 2006. www.sandia.gov/energy-water/docs/121-RptToCongress-EWwEIAcomments-Final.pdf
} 
- Arizona rejected permitting for a proposed power plant because of potential impact on a local aquifer.

- $\quad$ Southern States Energy Board member states cited water availability as a key factor in the permitting process for new merchant power plants.

- $\quad$ South Dakota Governor called for a summit to discuss drought-induced low flows on the Missouri River and the impacts on irrigation, drinking-water systems, and power plants.

- Washoe County, Nevada, residents expressed opposition to a proposed coal-fired power plant's planned water use.

- Idaho opposed two proposed power plants because of impact on aquifer. .sss $^{\text {. }}$

Thermoelectric generation is responsible for approximately $40 \%$ of the nation's water withdrawals, but only about $3 \%$ of the freshwater consumed. Currently, the freshwater withdrawal value for thermoelectric generation in the United States is estimated at nearly 148 billion gallons per day, while the freshwater consumption is estimated at about 3.8 billion gallons per day. ${ }^{\text {ttt }}$ These values are expected to increase over the years with the growing demand for power. The Energy Information Administration projects that the thermoelectric electric capacity is expected to increase almost $18 \%$ between 2005 and 2030. ${ }^{\text {uuu }}$ By 2030, it is estimated that the average freshwater consumption from thermoelectric power generation, including the additional amount required by the use of carbon capture and sequestration technologies, will be approximately 5.1 billion gallons per day and the estimated freshwater withdrawal as large as 153.7 billion gallons per day. ${ }^{\mathrm{vvv}}$ Based on these projections, freshwater availability to support thermoelectric power generation will remain a major issue in permitting and siting of new power plants.

\section{SUMMARY, OBSERVATIONS, AND RECOMMENDATIONS 8.1 Feasibility of Hydrogen Production at
Existing Nuclear Power Plant}

Section 2 identified that existing nuclear power plants are used for base loading for electricity requirements. These plants would not be available to directly provide the electricity needed for a hydrogen electrolyzer plant. Rather, in today's existing electricity market, the best that can be available with existing nuclear power plants is the generally lower grid prices where nuclear plays a significant role, such as the PVNGS switchyard.

Section 7 identified that there are a number of licensing, codes, and standards works that needs to be done that could impact an existing nuclear plant license and would require new reviews. In addition, issues (e.g., emergency plan and insurance) would need to be revisited. It is unlikely that any economic advantage from hydrogen would be an incentive to incur the costs involved.

\footnotetext{
ssss ibid.

${ }^{t t t t}$ National Energy Technology Laboratory, Estimating Freshwater Needs to Meet Future Thermoelectric Generation Requirements 2008 Update, DOE/NETL-400/2008/1339, September 30, 2008.

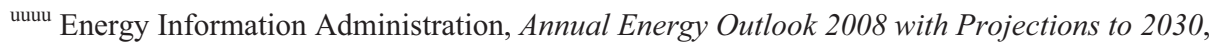
http://www.eia.doe.gov/oiaf/aeo/index.html, June 2008.

${ }^{\mathrm{vvvv}}$ National Energy Technology Laboratory, Estimating Freshwater Needs to Meet Future Thermoelectric Generation Requirements 2008 Update, DOE/NETL-400/2008/1339, September 30, 2008.
} 


\subsection{Feasibility of Hydrogen Production at New Nuclear Power Plant of Current Design}

\subsubsection{Co-Located}

Section 7 identified numerous items of interest associated with co-locating the hydrogen production facility within the protected area or owner-controlled area of a nuclear power plant. Many of these are centered on the lack of current standards and reviews of large-scale hydrogen production facilities. A new licensee would have to address these issues and concerns, as well as the typical nuclear topics. However, once the hydrogen portion of the study is completed, the impact on the nuclear licensing activities may not be significantly increased. Depending on the MW rating of the new plant, the hydrogen production plant may be an added feature that is designed to grow as the market grows. In Section 4, it was noted that a $1-\mathrm{kg} / \mathrm{sec}$ facility does not exist today and the largest PEM design is $500 \mathrm{~kg} / \mathrm{day}$. If a new nuclear facility is designed and licensed to include the hydrogen production facility that would add PEM units as the demand increases and divert an increasing share of its output power to the hydrogen plant, a viable business model may be developed. While designing the supporting systems (e.g., chilled water) to handle a 1-kg/sec facility will be over-design for the first few PEM units, the highest cost of the hydrogen production facility is in fact the PEM units.

By placing the hydrogen production facility within the protected area, the plant is removed from the hydrogen demand sources. Efficient storage and transportation then become important. Piping and storage offsite could be preferable to trucks entering and exiting the protected area.

The water issue identified in Section 6 also would have to be addressed. Lack or shortage of water is a concern for new nuclear plants today and the water requirements of a hydrogen production plant would add to the concern. The topic of water is an area deserving additional study. Reclaimed water is used for many purposes. It would be expected that reclaimed water would be of sufficient purity to provide a source for de-ionized water for a hydrogen plant. Verification of this should be conducted. In addition, the efficiency of the de-ionizer affects the effluent water from that unit. If the de-ionizer is designed specifically to allow the effluent to accomplish other purposes rather than be considered waste, much of the concern for water will be eliminated. Where that point is and how it affects the model should be studied.

Section 5 identified that operating costs of a nuclear plant are indeed low, whereas the electrical output is high and reliable. A public utility may find itself well positioned for the future by designing new nuclear plants with this option in mind.

\subsubsection{Adjacent}

Locating the hydrogen production facility near the nuclear plant runs into many of the same issues as co-location depending on how far from the controlled area the hydrogen plant is located. Many of the combined issues can be avoided by moving the plant enough of a distance away to be outside the owner controlled or exclusion areas, but yet be close enough to minimize transmission costs.

\subsubsection{Distributed}

The distributed model places the plant closer to the demand area but subjects it to transmission costs. As seen in Section 5, the City Gate plant would expect slightly higher breakeven prices for its hydrogen production. 


\subsection{Feasibility of Hydrogen Production at Small Nuclear Power Plant}

Designs of new nuclear plants continue to evolve. Plants that are smaller than those in power production today are being considered. Some are designing plants that can be buried in place to provide local energy requirements. As noted in Section 5, there appears to be a significant financial advantage to using a very small nuclear plant combined with a large hydrogen plant. Current models predict a breakeven price at about $\$ 2.81 / \mathrm{kg}$. Now that capital costs of a large $1-\mathrm{kg} / \mathrm{sec}$ hydrogen plant are identified, additional detailed study of this model should be accomplished. The study should develop a detailed plant design and include a detailed analysis of the nuclear plant safety, licensing, environmental impact, and economic viability of this combined facility. The study may identify specific locations in the United States for possible consideration. Should the study indicate positive results, consideration should be given to construction of a unit of this type - perhaps at or near a petroleum facility where the current hydrogen production demand of steam methane reforming could be phased out in favor of reduced greenhouse gas emissions.

\subsection{Feasibility of Hydrogen Production at Generation 4 Nuclear Power Plant}

The feasibility of hydrogen production at a Generation 4 Nuclear Power Plant will depend on the specifics of that plant design. This is promising for the very high temperature reactor or Hydrogen intermediate and peak electrical system as noted in Section 2; however, such designs are not complete. The feasibility of hydrogen production will be integral to the plant design.

\section{APPENDICES}

Appendix A, Palo Verde Nuclear Generating Station

Appendix B, APS Alternative Fuel Pilot Plant Design Report

Appendix C, CE-FC07-0ID14788 Task 1.3 Final Report

Appendix D, Electricity Costs for PVNGS Switchyard Delivery During Peak and Off-Peak Periods

Appendix E, INL Process Model

Appendix F, Plant Design for $100 \mathrm{~kg} \mathrm{H}_{2} /$ day

Appendix G, Plant Design for $1500 \mathrm{~kg} \mathrm{H}_{2} /$ day

Appendix H, Plant Design for $1 \mathrm{~kg} \mathrm{H}_{2} / \mathrm{sec}$

Appendix I, Silverado HICE Specifications

Appendix J, INL N2H2 Model Scenarios and Comments 


\section{APPENDIX A}

\section{PALO VERDE NUCLEAR GENERATION STATION}




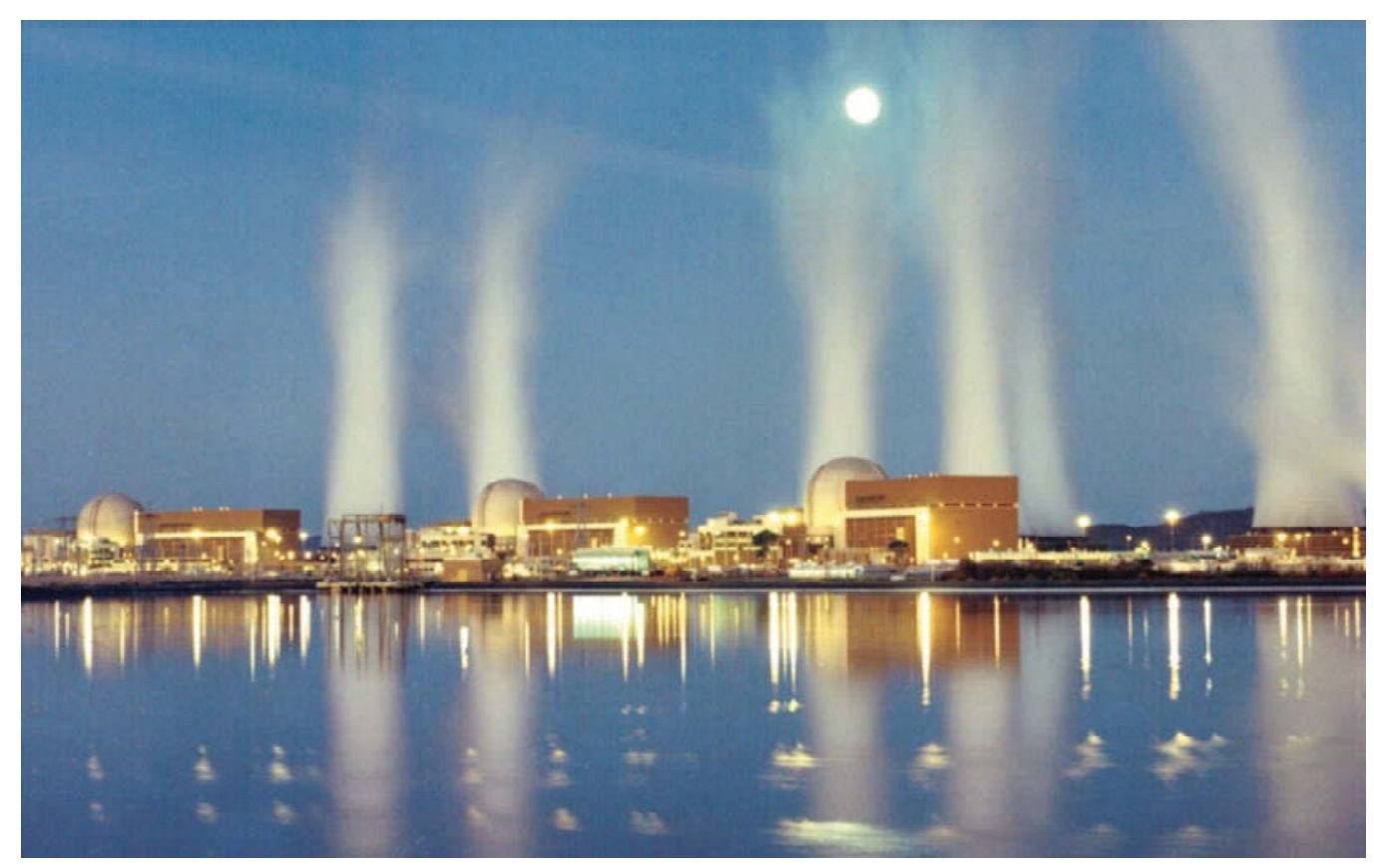

\section{Economic Benefits of Palo Verde \\ Nuclear Generation Station}

An Economic Impact

Study by the

Nuclear Energy Institute

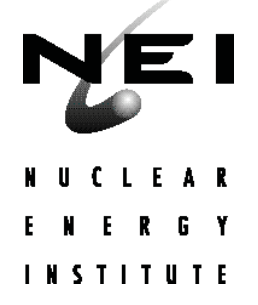




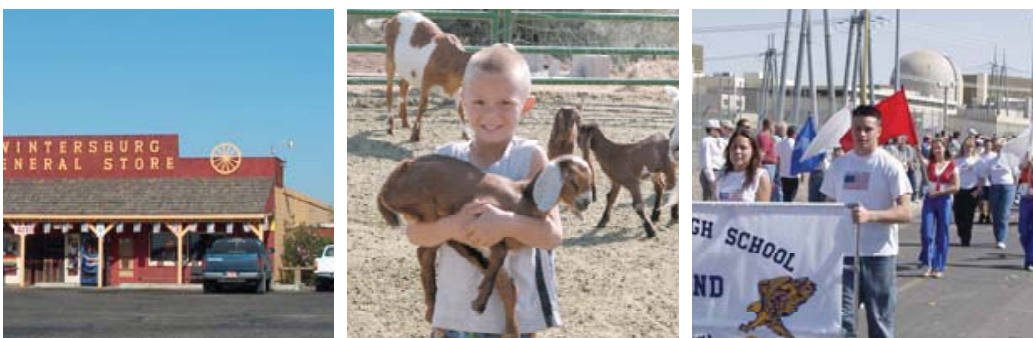

\section{Economic}

Benefits of

Palo Verde

Nuclear

Generation

Station

An Economic Impact

Study by the

Nuclear Energy Institute

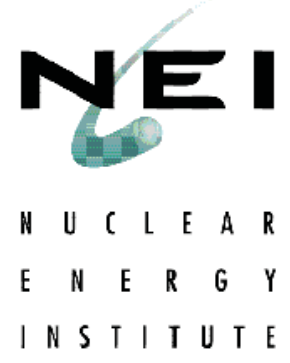




\section{Contents}

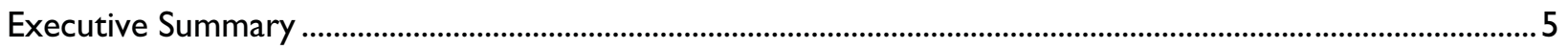

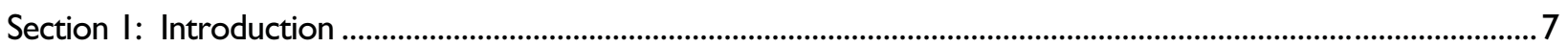

Section 2: The Palo Verde Nuclear Generating Station ............................................................................................. 9

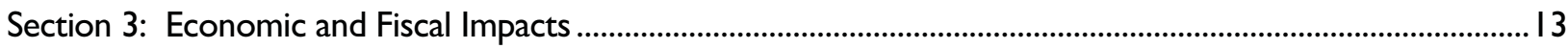

Section 4: Additional Benefits Provided by Palo Verde .........................................................................................22

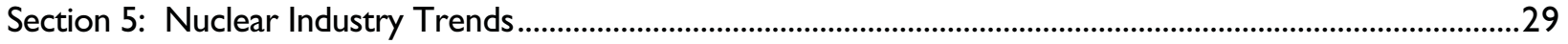

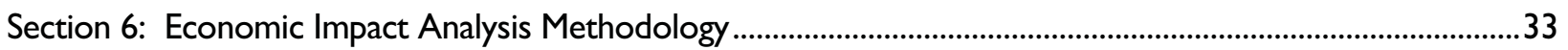




\section{Executive Summary}

The Palo Verde Nuclear Generating Station in Arizona's western Maricopa County is an integral part of the county and state economy. The plant provides jobs and makes purchases that stimulate the local economy directly and indirectly. Additional benefits to the area include higher tax revenue, increased labor income and significant charitable contributions to the local community. In addition, there are important intangible benefits, such as clean air, environmental stewardship and stable, affordable electricity prices. According to this study by the Nuclear Energy Institute, Palo Verde's economic impact reaches beyond the local community to the state and nation.

The Palo Verde plant is operated by Arizona Public Service Co. and jointly owned by Arizona Public Service Co., El Paso Electric Co., Los Angeles Department of Water and Power, PNM Resources, Salt River Project, Southern California Edison, and Southern California Public Power Authority.

In 2002, operation of the Palo Verde Power Nuclear Generating Station increased Maricopa County's economic output by $\$ 149.3$ million. Adding the direct value of the plant's electricity output brings the county's economic output attributable to Palo Verde to $\$ 868.5$ million.

The plant's total economic impact includes direct effects, which comprise the value of electricity produced at the plants, as well as secondary — or indirect - effects resulting from plant operation.

The operation of Palo Verde, and its secondary effects, accounts for 3,943 jobs in Maricopa County. Earnings for these jobs total $\$ 245.2$ million in the county. Additionally, the plant and its related economic activity provide $\$ 62$ million to state and local tax coffers.

The plant is one of the largest employers in the far Southwest Valley area of Maricopa County. The plant directly employs 2,386 people, including long-term contractors and corporate staff. The vast majority of these workers live in Maricopa County. More than one of every 100 working people in the municipalities of Avondale, Buckeye, Goodyear, Litchfield Park and Wickenburg work at Palo Verde. In addition, these jobs pay 13 percent above the average Maricopa County salary.

The economic activity generated by the Palo Verde plant creates another 1,570 jobs in the county. Given the combination of employees at the plant and indirect jobs created by Palo Verde's economic activity, the plant is responsible for 3,943 jobs in Maricopa County.

The plant's principal expenditure in Maricopa County is employee compensation. During 2002, Palo Verde paid \$193.2 million in compensation to employees living in the county. Additionally, the economic activity created by Palo Verde accounted for $\$ 51.9$ million in non-Palo Verde employee compensation in Maricopa County. Together, the direct and indirect compensation from the plant accounted for $\$ 245.2$ million in labor income in the county.

Palo Verde makes substantial purchases in Maricopa County. In 2002, these purchases totaled \$223.4 million, including \$17.8 million in Maricopa County. Economic activity generated by Palo Verde also led to $\$ 149.3$ million in increased output in the county.

Palo Verde pays an estimated \$54.1 million in state and local taxes annually. Additionally, the economic activity generated by Palo Verde contributes another $\$ 7.8$ million in state and local taxes, through increased income, property and sales taxes. By combining direct and indirect taxes, Palo Verde accounts for $\$ 62$ million in state and local tax payments. 
Besides the economic benefits Palo Verde provides, the plant generated 30.9 billion kilowatt-hours of electricity in 2002, approximately 35 percent of Arizona's total electricity generation. This low-cost electricity helped keep energy prices in Arizona affordable. During 2002, Palo Verde had a production cost of 1.33 cents per kilowatt-hour, compared with an average production cost of 2.53 cents per kilowatthour for the rest of the Southwest energy market. Palo Verde did this without producing air pollution typical of some other large power generation sources.

Palo Verde also is an integral part of the local community, as seen in charitable giving by Arizona Public Service Co. and its employees. In 2002, Palo Verde employees donated \$459,564 to charitable organizations. The largest contribution supported local educational programs. Additionally, Palo Verde employees contributed more than 50,000 man-hours of volunteer time to Arizona community events.

The plant also plays a vital role in maintaining regional air quality. Without the plant, nitrous oxide emissions in the local area would increase by 93,000 tons per year and sulfur dioxide emissions would rise by 158,000 tons annually because fossil-fueled power plants would be used to offset electricity generation from nuclear energy. Additionally, carbon dioxide emissions, one of the main greenhouse gases, would increase by 29.1 million tons. 


\section{Section I: Introduction}

This economic impact study by the Nuclear Energy Institute ${ }^{1}$ (NEI) examines the economic, fiscal and other community benefits provided by the Palo Verde Nuclear Generating Station, operated by Arizona Public Service Co. The plant is jointly owned by Arizona Public Service Co., El Paso Electric Co., Los Angeles Department of Water and Power, PNM Resources, Salt River Project, Southern California Edison, and Southern California Public Power Authority.

This study analyzes the economic and other benefits Palo Verde provides to Maricopa County, as well as the state of Arizona and the United States. The analysis uses detailed data from Palo Verde and governmental sources to assess those benefits.

Although this study focuses primarily on benefits to the local community, state and national benefits also are analyzed. These include direct impacts - such as people employed by the plant, plant expenditures within the community and corporate tax payments - and indirect impacts, such as jobs created indirectly by plant expenditures in the local economy. The study also discusses other benefits provided by the plant, such as reliable, low-cost electricity, its contributions to air quality as an emission-free source of electricity, and land stewardship.

Arizona Public Service Co. and NEI cooperated in developing this study. Arizona Public Service Co. and Palo Verde provided data on employment, operating expenditures and tax payments, as well as guidance on details specific to Maricopa County and the plant.

NEI coordinated the project and applied a nationally recognized model to estimate the direct and indirect impacts of the plant on the local community. RTI International, a nonprofit research organization in Research Triangle Park, N.C., developed the methodology employed in this study. This is the sixth such study conducted by NEI.

The remainder of this report contains five sections:

- Section 2 provides background on Palo Verde, including plant history, performance, cost, employment, taxes and local area details, such as total employment and earnings, as well as regional electricity prices.

- Section 3 examines the economic and fiscal impacts of the plant on local, state and national levels.

- Section 4 provides data on benefits not captured by the model, such as the plant's contributions to the community and the environment.

- Section 5 outlines recent trends in the nuclear industry as a whole, including cost, performance and safety.

- Section 6 discusses the methodology used to complete the study and Impact Analysis for Planning, the economic modeling software employed as part of this effort.

\footnotetext{
${ }^{1}$ The Nuclear Energy Institute is the policy organization of the nuclear energy and technologies industry and participates in both the national and global policymaking process.
} 


\section{Section 2: The Palo Verde Nuclear Generating Station}

This section provides background information on Palo Verde and Maricopa County to frame the results of subsequent sections, including a brief history of the plant and information on its cost, employment, performance and taxes. This section also includes information on local area details of Maricopa County, its major cities and the state of Arizona, including total employment, earnings, local tax collections and regional electricity cost.

\subsection{History and Information}

The Palo Verde Nuclear Generating Station, near Wintersburg, Ariz., is about 45 miles west of Phoenix (see Figure 2-2). The facility is the largest nuclear power plant in the United States and has been the top power producer of any kind in the country for 12 consecutive years. The plant lies in Maricopa County, which has a population of about 3.3 million and covers 9,203 square miles. Palo Verde, operated by Arizona Public Service Co., is owned by Arizona Public Service Co., El Paso Electric Co., Los Angeles Department of Water and Power, PNM Resources, Salt River Project, Southern California Edison, and Southern California Public Power Authority.

Table 2-I. Palo Verde Nuclear Power Plant: At a Glance

\begin{tabular}{|l|c|c|c|c|}
\hline Unit & Capacity & $\begin{array}{c}\text { Commercial } \\
\text { Operation Year }\end{array}$ & $\begin{array}{c}\text { License } \\
\text { Expiration Year }\end{array}$ & Reactor Type \\
\hline \hline Unit I & I,243 MW & 1986 & 2024 & PWR \\
Unit 2* & I,243 MW & 1986 & 2025 & PWR \\
Unit 3 & $1,247 \mathrm{MW}$ & 1988 & 2027 & PWR \\
\hline
\end{tabular}

$M W=$ megawatts; $P W R=$ pressurized water reactor

* Unit 2's capacity is larger because of an expansion of plant capacity in 2003.

Throughout its operation, Palo Verde has been a leader in the nuclear energy industry. During most of the 1990s, the Palo Verde reactors maintained capacity factors above the industry average. Capacity factor, a measure of efficiency, is the ratio of actual electricity generated compared with the maximum possible generation if the plant were to operate at full capacity for one year.

Since 1998, all reactors have operated at or near a 90 percent capacity factor on a three-year rolling average basis.

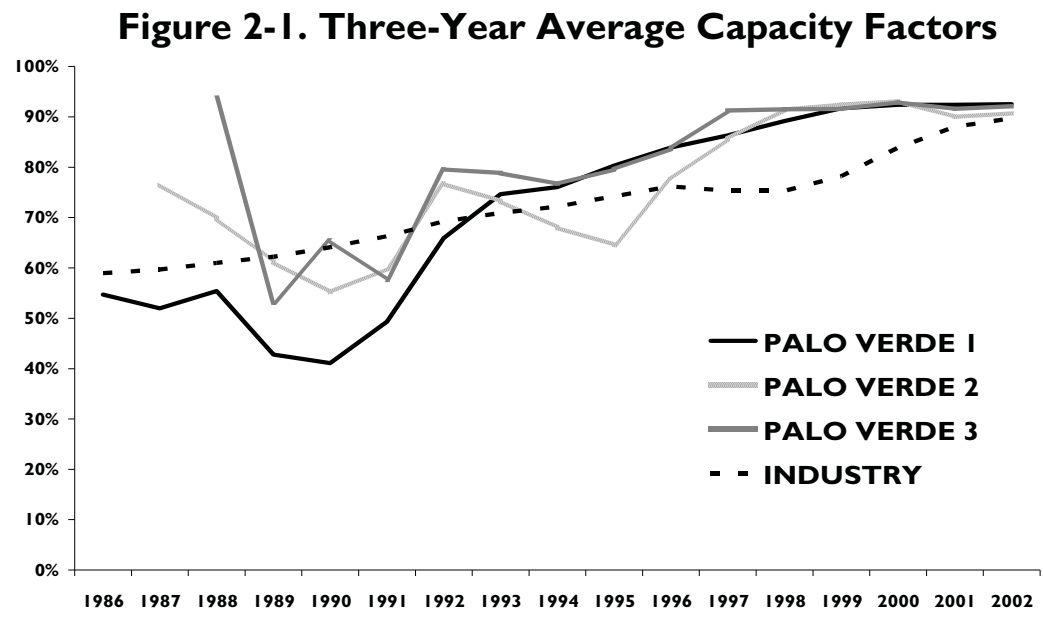


Figure 2-2. The Palo Verde Nuclear Generating Station and Surrounding Area

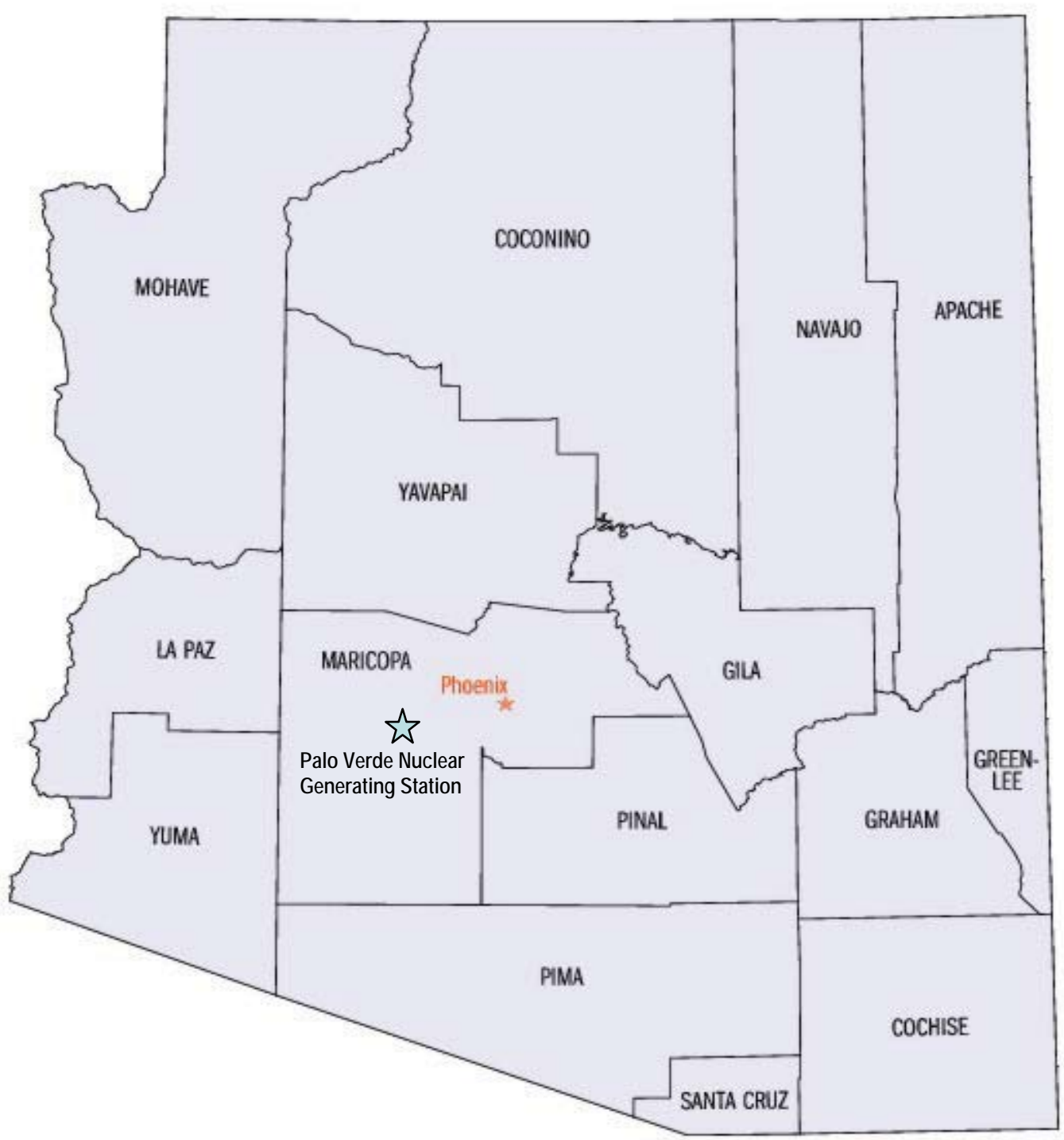




\subsection{Generation}

Palo Verde generated more than 30.9 billion kilowatt-hours of electricity in 2002 -a U.S. generating record. The plant provides about 35 percent of the electricity generated in Arizona each year. Plant output was driven by a high capacity factor that reached 94.4 percent in 2002.

Palo Verde provides power primarily for the Arizona/New Mexico/Nevada Power Area, although it exports some of its power (13 percent) to utilities in California and Texas. Efficient performance has made Palo Verde very cost-competitive in the region. Palo Verde had a production cost of 1.33 cents per kilowatt-hour. By comparison, the three-year average production cost was 2.53 cents per kilowatt-hour for electricity generators in the region.

Production costs represent the operations, maintenance and fuel cost of the plant. They do not include depreciation, interest or ongoing capital cost. Contributions to the Nuclear Waste Fund, established to pay for the disposal of used nuclear fuel from commercial power plants, are contained within fuel cost. Customers of nuclear-generated electricity pay for the fund.

Table 2-2. Regional Power Production Cost and Generation

\begin{tabular}{|l|c|c|}
\hline & $\begin{array}{c}\text { Average Production Cost } \\
\text { (in Cents per Kilowatt-Hour) }\end{array}$ & $\begin{array}{c}\text { Generation } \\
\text { (in Million Megawatt-Hours) }\end{array}$ \\
\hline \hline Palo Verde & 1.33 & 30.9 \\
Coal & 2.26 & 68.8 \\
Natural Gas & 4.54 & 28.1 \\
Hydro & 0.63 & 10.5 \\
\hline Total (including Palo Verde) & $\mathbf{2 . 5 3}$ & $\mathbf{1 3 9 . 6}$ \\
\hline
\end{tabular}

Source: Resource Data International; Region includes Arizona, Nevada and New Mexico.

Palo Verde's low production costs help keep wholesale electricity prices affordable in the region. Although Palo Verde's exact contribution is difficult to measure, it can be estimated by determining how much average 2002 production costs in the region would increase if Palo Verde were replaced, for example, by a combined-cycle natural gas plant (the plant of choice for new generation).

Substituting combined-cycle natural gas plants for Palo Verde in 2002 would have resulted in an increase in average generation costs for the region from 2.53 cents per kilowatt-hour to 3.13 cents per kilowatt-hour.

\subsection{Employment, Spending and Taxes}

Besides providing affordable electricity to the Southwest, Palo Verde is the largest employer in the far Southwest Valley. The plant employs 2,055 full-time on-site workers. Of these employees, 2,042 reside within the county. Full-time employees include 370 people from Glendale, 305 from Phoenix, 276 from Peoria, 211 from Buckeye, 197 from Goodyear, 168 from Avondale, and 153 from Litchfield Park. In a few cities almost one in 10 work at Palo Verde while in several other localities, one of every 100 employed people works at the Palo Verde Nuclear Generating Station. 
Maricopa County, the fourth most populous county in the United States, has a vast employment base, and Palo Verde is responsible for one worker per 1,000 employed people. In addition to these workers, the plant also is responsible for the employment of 151 long-term contractors and 180 employees at Arizona Public Service's corporate offices in Phoenix.

Jobs provided by Palo Verde also are typically higher paying than most jobs in the area. Full-time Palo Verde employees who live in Maricopa County earned, on average, about $\$ 66,000$ in 2002. This was about 13 percent higher than the average earnings of workers in the county, about $\$ 58,600$ a year.

Palo Verde also spends a large amount of money in the local community. During the one-year period of this study, Palo Verde made \$17.8 million in non-labor purchases in Maricopa County.

Palo Verde also made substantial tax payments to the county in 2002. The plant paid $\$ 46.1$ million in county property taxes to Maricopa County, almost 12 percent of Maricopa County’s $\$ 392.8$ million property tax levy.

Table 2-3. Full-Time On-Site Employee and Salary Information by Top- 10 Cities and Towns in Maricopa County

\begin{tabular}{|l|c|c|c|c|c|}
\hline \multirow{2}{*}{ Location } & \multicolumn{3}{|c|}{ Palo Verde } & \multicolumn{2}{c|}{ City/County Total* } \\
\cline { 2 - 6 } & $\begin{array}{c}\text { Permanent On- } \\
\text { Site Employees }\end{array}$ & $\begin{array}{c}\text { \% of Employed } \\
\text { Work Force }\end{array}$ & $\begin{array}{c}\text { Average } \\
\text { Earnings }\end{array}$ & $\begin{array}{c}\text { Employed } \\
\text { Work Force }\end{array}$ & $\begin{array}{c}\text { Average } \\
\text { Earnings }\end{array}$ \\
\hline \hline Glendale & 370 & $0.4 \%$ & $\$ 66,070$ & 103,474 & $\$ 54,391$ \\
Phoenix & 305 & $0.0 \%$ & $\$ 64,448$ & 611,019 & $\$ 54,727$ \\
Peoria & 276 & $0.6 \%$ & $\$ 68,257$ & 49,793 & $\$ 61,113$ \\
Buckeye & 211 & $8.5 \%$ & $\$ 60,746$ & 2,474 & $\$ 50,639$ \\
Goodyear & 197 & $2.6 \%$ & $\$ 68,319$ & 7,651 & $\$ 62,348$ \\
Avondale & 168 & $1.1 \%$ & $\$ 68,057$ & 15,670 & $\$ 56,999$ \\
Litchfield Park & 153 & $9.4 \%$ & $\$ 77,234$ & 1,630 & $\$ 88,323$ \\
Tonopah & 74 & $\mathrm{NA}$ & $\$ 59,816$ & $\mathrm{NA}$ & $\mathrm{NA}$ \\
Surprise & 50 & $0.5 \%$ & $\$ 66,378$ & 10,443 & $\$ 46,902$ \\
Wickenburg & 40 & $2.0 \%$ & $\$ 71,988$ & 1,964 & $\$ 40,530$ \\
\hline Maricopa County & 2,042 & $0.1 \%$ & $\$ 66,006$ & $1,427,292$ & $\$ 58,635$ \\
\hline Total & & & &
\end{tabular}

* Source: Census 2000; NA = Not available

\subsection{Summary}

Palo Verde provides reliable electricity generation and keeps power prices affordable in Arizona. The plant also offers well-paid employment and a large tax base to Maricopa County. However, these are only the direct economic benefits of the plant. As illustrated in the next section, the secondary effects on the local and regional economies are as substantial as the direct benefits. 


\section{Section 3: Economic and Fiscal Impacts}

The economic and fiscal effects of Palo Verde's operation go well beyond what the plant spends on purchases, wages, salaries, employee benefits and taxes. They also reflect the strong stimulus that the plant's large wage and salary payments provide to key measures of economic activity-value of electricity production, employment and labor income - in the local and state economies.

Palo Verde's spending lifts economic activity throughout the local and state economies. Tax payments related to economic activity are another contributing factor. This effect is felt throughout the local and state economies - by the private sector in the form of increased sales and employment, and by the public sector through increased tax revenues to support the provision of public services.

Estimates of these effects were developed by applying the Impact Analysis for Planning (IMPLAN) model to expenditure data provided by Arizona Public Service Co., operator and part owner of Palo Verde. (For more information on IMPLAN, see Section 6.)

\subsection{Plant Expenditures in Maricopa County}

Palo Verde expenditures in Maricopa County totaled \$211 million in 2002. Of those expenditures, labor represented \$193.2 million and goods and services represented \$17.8 million. The labor figure includes on-site employees as well as long-term contractors and corporate staff dedicated to Palo Verde. Spending within the county represents approximately 50 percent of the plant's total spending of $\$ 418$ million and almost all of the $\$ 215.3$ million of spending in Arizona.

The expenditure totals for Maricopa County, provided by Arizona Public Service Co., are shown in Table 3-1. The 10 sectors receiving the largest amount of Palo Verde spending are listed in this table. The categories, chosen from 509 IMPLAN sectors, are listed largely according to the IMPLAN description for each. Total compensation, which includes wages, salaries and benefits, is listed separately.

Similar expenditure totals for the state of Arizona and the United States are presented in Tables 3-2 and 3-3, respectively. 
Table 3-I. Palo Verde Expenditures in Maricopa County

\begin{tabular}{|l|r|}
\hline \multicolumn{1}{|c|}{ Description } & \multicolumn{1}{c|}{ Amount } \\
\hline \hline Business Support Services & $\$ 4,953,156$ \\
Other Maintenance and Repair Construction & $\$ 3,574,866$ \\
Automotive Repair and Maintenance & $\$ 1,467,563$ \\
Other Computer-Related Services & $\$ 1,237,121$ \\
Fabricated Pipe and Pipefitting Manufacturing & $\$ 684,600$ \\
Commercial Machinery Repair and Maintenance & $\$ 639,940$ \\
Industrial Process Variable Instruments & $\$ 548,333$ \\
Miscellaneous Electrical Equipment Manufacturing & $\$ 473,375$ \\
Other Miscellaneous Chemical Product Manufacturing & $\$ 384,175$ \\
Other Miscellaneous Textile Product Mills & $\$ 359,635$ \\
Other & $\$ 3,454,207$ \\
Subtotal & $\$ 17,776,97$ I \\
Total Compensation & $\$ 193,235,557$ \\
\hline TOTAL & $\$ 2$ I I,012,528 \\
\hline
\end{tabular}

${ }^{\mathrm{a}}$ Total compensation includes wages, salaries and fringe benefits based on data provided by Palo Verde.

Total compensation for labor was \$193.2 million - more than 90 percent of Palo Verde's expenditures in Maricopa County. Most of the plant's labor expenditures (wages and employee benefits) stay "home" in the county. As expected, the county's share is much larger than the share at the state or national level.

The largest non-labor expenditures in the county totaled nearly $\$ 5$ million for business support services. This sector represents a wide range of facility services contracted by the plant, such as cafeteria, groundskeeping and janitorial services. Many of these services are purchased from local providers.

The next largest non-labor expenditure in Maricopa County was for maintenance, repair and construction at nearly $\$ 3.6$ million. This sector represents general and specialized contractors, such as welders and pipe fitters, employed by the plant in order to perform necessary maintenance. This maintenance is necessary to ensure the safe and reliable operations of the plant. This includes many local contractors hired when the plant performs its semiannual refueling outages.

Five of the top six sectors in Table 3-1 involve service expenditures. The prevalence of service sectors reflects the heavy reliance of the plant on contracted labor to perform many specialized services. These labor-intensive services tend to produce a substantial number of jobs. 


\subsection{Plant Expenditures in Arizona}

In 2002, Palo Verde spent $\$ 215.3$ million for products and services (including labor) in Arizona. Labor represented $\$ 194.2$ million, while goods and services represented $\$ 21.1$ million. This total includes \$211 million dispersed in Maricopa County, as well as expenditures of \$4.3 million spent in other areas of Arizona.

Almost all of Palo Verde's spending in Arizona occurs in Maricopa County. Expenditures within the state represent approximately 51 percent of the plant's total spending of $\$ 418$ million. Total spending in Arizona is presented in Table 3-2. Total compensation is the largest category at $\$ 194.2$ million, representing about 90 percent of the total.

\section{Table 3-2. Palo Verde Expenditures in Arizona}

\begin{tabular}{|l|r|}
\hline \multicolumn{1}{|c|}{ Description } & \multicolumn{1}{c|}{ Amount } \\
\hline \hline Business Support Services & $\$ 7,467,347$ \\
Other Maintenance and Repair Construction & $\$ 3,612,886$ \\
Automotive Repair and Maintenance & $\$ 1,467,563$ \\
Other Computer-Related Services & $\$ 1,237,121$ \\
Fabricated Pipe and Pipefitting Manufacturing & $\$ 709,325$ \\
Commercial Machinery Repair and Maintenance & $\$ 690,921$ \\
Industrial Process Variable Instruments & $\$ 565,432$ \\
Miscellaneous Electrical Equipment Manufacturing & $\$ 533,322$ \\
Investigation and Security Services & $\$ 392,577$ \\
Other Miscellaneous Chemical Product Manufacturing & $\$ 384,175$ \\
Other & $\$ 4,014,554$ \\
Subtotal & $\$ 21,075,223$ \\
Total Compensation & $\$ 194,230,485$ \\
\hline TOTAL & $\$ 215,305,708$ \\
\hline
\end{tabular}

${ }^{\text {a }}$ Total compensation includes wages, salaries and fringe benefits based on data provided by Palo Verde.

As expected, the spending distribution in Arizona closely mirrors that in Maricopa County. The business support services sector remains the largest non-labor expenditure category for the state at \$7.5 million. Maintenance and repair construction is the second largest category, with \$3.6 million.

Notably, $\$ 5.4$ million of the $\$ 21.1$ million of the plant's non-labor spending in Arizona was contracted to minority- or woman-owned businesses, a total of 45 different suppliers. 


\subsection{Plant Expenditures in the United States}

Palo Verde expenditures for products and services (including labor) purchased in the United States totaled \$418 million in 2002. Besides expenditures of \$215.3 million in Arizona, \$202.7 million was spent elsewhere in the United States. Much of that amount was for specialized products and services unique to the nuclear industry.

These national expenditures are detailed in Table 3-3. Total compensation (\$194.6 million) remains the largest category and represents 47 percent of the total. Compensation as a share of the U.S. total is lower because plant employees live mostly in Arizona (and particularly in Maricopa County), while spending on products and non-labor services is concentrated outside the state.

Total compensation is followed closely by spending in the inorganic chemicals sector $(\$ 136.4$ million). This category represents plant spending on fuel, which is typically purchased outside the county or state in which a plant is located. This category represents roughly 30 percent of Palo Verde's spending nationwide.

Business support services ( $\$ 29.8$ million) is one of the largest expenditure categories in the national data. This category represents a large portion of nuclear plant expenditures because of the many specialized activities required at plants. Many of these services are not required on a continual basis, so nuclear power plants outsource these activities.

Table 3-3. Palo Verde Expenditures in the United States

\begin{tabular}{|l|r|}
\hline \multicolumn{1}{|c|}{ Description } & Amount \\
\hline \hline Other Basic Inorganic Chemical Manufacturing & $\$ 136,417,617$ \\
Business Support Services & $\$ 29,775,593$ \\
Architectural and Engineering Services & $\$ 15,802,260$ \\
Other Maintenance and Repair Construction & $\$ 10,658,978$ \\
Fabricated Pipe and Pipefitting Manufacturing & $\$ 3,052,563$ \\
Other Computer-Related Services & $\$ 2,476,285$ \\
Commercial Machinery Repair and Maintenance & $\$ 2,360,699$ \\
Dry Cleaning and Laundry Services & $\$ 2,299,823$ \\
Employment Services & $\$ 2,005,000$ \\
Automotive Repair and Maintenance & $\$ 1,496,428$ \\
Other & $\$ 17,061,966$ \\
Subtotal & $\$ 223,407,212$ \\
Total Compensation & $\$ 194,579,303$ \\
\hline TOTAL & $\$ 417,986,515$ \\
\hline
\end{tabular}

a Total compensation includes wages, salaries and fringe benefits based on data provided by Palo Verde. 
The remaining sectors in the Top 10 are similar to the sectors for the state. The sole exception is architectural and engineering services. Purchases in this sector are primarily for specialized engineering work that is typically done by engineering firms located outside Arizona.

\subsection{Taxes Paid and Accrued}

Palo Verde pays a substantial amount of taxes primarily in the form of property tax payments to Maricopa County, which totaled \$46.1 million in 2002. When combined with state use and payroll taxes, the plant paid $\$ 54.1$ million in state and local taxes.

At the federal level, Palo Verde made tax payments of $\$ 36.5$ million. These were almost entirely in the form of payroll taxes for its employees. These estimates do not include federal income taxes because these taxes are paid at the corporate level and not by the plant.

\section{Table 3-4. Taxes Paid by Palo Verde}

\begin{tabular}{|l|r|}
\hline \multicolumn{1}{|c|}{ Description } & Amount \\
\hline \hline Federal Government & \\
Payroll Tax & $\$ 35,631,183$ \\
Other Federal Taxes & $\$ 827,258$ \\
Total Federal Taxes & $\$ 36,458,44 I$ \\
\hline State and Local Government & \\
Property Tax & $\$ 46,100,000$ \\
Other State Taxes & $\$ 8,010,844$ \\
Total State and Local Taxes & $\$ 54,110,844$ \\
\hline Total Taxes Paid & $\$ 90,569,285$ \\
\hline
\end{tabular}




\subsection{Economic Impacts by Geographic Area}

Summary economic impacts for each of the three geographic areas-Maricopa County, Arizona and the United States - are presented in Table 3-5. The three economic impact variables are:

- output - the value of production of goods and services

- labor income - the earnings of labor

- employment - measured in jobs provided.

Table 3-5. Impact of Palo Verde on Local, State and National Economies

\begin{tabular}{|l|r|r|r|}
\hline & \multicolumn{1}{|c|}{ Direct } & Indirect/ Induced & \multicolumn{1}{c|}{ Total } \\
\hline \hline Maricopa County & & & \\
Output & $\$ 719,204,589$ & $\$ 149,330,798$ & $\$ 868,535,387$ \\
Labor Income & $\$ 193,235,557$ & $\$ 51,917,990$ & $\$ 245,153,547$ \\
Employment & 2,373 & 1,570 & 3,943 \\
\hline Arizona & & & \\
Output & $\$ 719,204,589$ & $\$ 159,774,713$ & $\$ 878,979,302$ \\
Labor Income & $\$ 194,230,485$ & $\$ 55,118,042$ & $\$ 249,348,527$ \\
Employment & 2,385 & 1,800 & 4,185 \\
\hline United States & & & $\$ 1,723,384,759$ \\
Output & $\$ 719,204,589$ & $\$ 1,004,180,170$ & $\$ 524,554,573$ \\
Labor Income & $\$ 194,579,304$ & $\$ 329,975,269$ & 10,980 \\
Employment & 2,386 & 8,594 & \\
\hline
\end{tabular}

${ }^{a}$ Indirect impacts measure the effect of input suppliers on expenditures by Palo Verde. Induced impacts measure the effects produced by the change in household income that results from Palo Verde expenditures.

These economic impacts are divided into direct and secondary effects. The direct effects reflect the industry sector and geographical distribution of Palo Verde's spending without any subsequent spending effects.

The secondary effects include subsequent spending effects, which can be further divided into two types: indirect and induced. Indirect effects reflect how the plant's spending patterns alter subsequent spending patterns among suppliers. Induced effects reflect how changes in labor income influence the final demand for goods and services, which then has an effect on all sectors producing basic, intermediate and final goods and services.

The direct effects are based on the estimated value of power production from the Palo Verde Nuclear Generating Station of \$719.2 million in 2002. This output value is based on 2002 wholesale market values for the electricity from Palo Verde. 
Wholesale prices are used for two reasons: They provide a market value for electricity in the region, and plant-specific rates are either unavailable or confidential. The wholesale rate used was 2.5 cents per kilowatt-hour, which reflects the average round-the-clock price for power in the region in 2002 .

The revenue or output value of the plant is divided among salaries, taxes, plant purchases, investor returns and consumer benefits. It reflects the total output of products and services associated directly with Palo Verde. This total includes expenditures for products and services (including labor) itemized in Tables 3-1, 3-2 and 3-3.

The direct employment entry (2,386 jobs) for the United States is the Palo Verde employment level over this period, including corporate employees and long-term contractors. Almost all of these jobs are filled by workers in Maricopa County. The direct labor income entries reflect the geographic distribution of Palo Verde employment.

As Table 3-5 indicates, direct effects are typically the largest contributor to total effects for each measure of economic impact for Maricopa County and Arizona. Secondary effects are more important as a share of the total at the national level.

\subsection{Economic Impacts by Local Industry}

Palo Verde's economic impacts are spread over nearly every sector of the economy. Although the direct effects are concentrated in a few sectors, the secondary effects - and especially the induced effects - increase the dispersion of the economic impacts across other sectors. The most-affected sectors vary by geographic area. Table 3-6 presents the 10 sectors most affected by the plant in Maricopa County, based on total output.

The sector most affected in terms of total output is power generation and supply, which includes electricity produced by the plant. Thus, all direct effects are included in this sector. It is also the largest sector, based on total output, in the Arizona and U.S. economies, as shown in Tables 3-7 and $3-8$, respectively.

The second most-affected sector is housing values. This is not a traditional business or industry sector, and so it has no impact on labor income or employment. Instead, it is a special sector developed by the U.S. Department of Commerce that estimates what homeowners would pay if they rented rather than owned their homes. In essence, it creates an industry out of owning a home.

The sole product (or output) of this industry is home ownership, purchased entirely by personal consumption expenditures from household income. In effect, this sector captures increases in housing values caused by increased labor in the area resulting from the plant. 
The other sectors most affected by Palo Verde are related to providing goods and services to the plant's large employment base. These include enterprises such as doctor and dentist practices, restaurants, wholesalers, and automotive dealerships. Indirect spending by plant employees boosts the revenues and work forces of these industries, which are typically run by local small business owners.

Table 3-6. Impact of Palo Verde on the Most-Affected Industries in Maricopa County

\begin{tabular}{|l|r|r|r|}
\hline Industry Description & \multicolumn{1}{|c|}{ Output } & Labor Income & Employment \\
\hline \hline Power Generation and Supply & $\$ 720,572,993$ & $\$ 193,559,211$ & 2,376 \\
Housing Values & $\$ 15,515,384$ & $\$ 0$ & - \\
Food Services and Drinking Places & $\$ 7,974,853$ & $\$ 3,599,947$ & 191 \\
Hospitals & $\$ 7,770,240$ & $\$ 3,077,711$ & 72 \\
Wholesale Trade & $\$ 7,559,040$ & $\$ 2,906,091$ & 51 \\
Physicians, Dentists, Health Care Providers & $\$ 7,349,510$ & $\$ 4,575,335$ & 78 \\
Real Estate & $\$ 6,624,260$ & $\$ 773,137$ & 39 \\
Automotive Repair and Maintenance & $\$ 5,741,478$ & $\$ 1,204,778$ & 41 \\
Monetary Authorities/Depository Credit & $\$ 4,539,561$ & $\$ 957,113$ & 19 \\
Intermediaries & $\$ 3,301,809$ & $\$ 1,752,022$ & 36 \\
Motor Vehicle and Parts Dealers & $\$ 81,586,261$ & $\$ 32,748,202$ & 1,041 \\
Other & $\$ 868,535,389$ & $\$ 245,153,547$ & 3,944 \\
\hline TOTAL & &
\end{tabular}




\subsection{Economic Impacts by State Industry}

Table 3-7 uses the same sectors applied in Table 3-6 to illustrate the plant's economic impacts on the state of Arizona. Again, the power generation and supply, along with housing values, are the most-affected sectors in terms of total output.

The entries in Table 3-7 for the most-affected industries in Arizona are similar to those for Maricopa County. Most of Palo Verde's expenditures and employees in Arizona are in Maricopa County, so the impact distribution in the two regions is almost identical.

Table 3-7. Impact of Palo Verde on the Most-Affected Industries in Arizona

\begin{tabular}{|l|r|r|r|}
\hline Industry Description & \multicolumn{1}{|c|}{ Output } & Labor Income & Employment \\
\hline \hline Power Generation and Supply & $\$ 720,798,307$ & $\$ 194,607,430$ & 2,389 \\
Housing Values & $\$ 16,091,844$ & $\$ 0$ & - \\
Hospitals & $\$ 8,878,398$ & $\$ 3,411,820$ & 83 \\
Food Services and Drinking Places & $\$ 8,275,180$ & $\$ 3,640,010$ & 207 \\
Wholesale Trade & $\$ 8,052,268$ & $\$ 3,087,039$ & 58 \\
Physicians, Dentists, and Health Care Providers & $\$ 7,745,718$ & $\$ 4,813,701$ & 86 \\
Real Estate & $\$ 7,226,388$ & $\$ 843,413$ & 50 \\
Automotive Repair and Maintenance & $\$ 5,923,941$ & $\$ 1,225,263$ & 43 \\
Monetary Authorities/Depository Credit & $\$ 4,835,851$ & $\$ 1,019,584$ & 23 \\
Intermediaries & $\$ 3,464,554$ & $\$ 1,815,919$ & 39 \\
Motor Vehicle and Parts Dealers & $\$ 87,686,855$ & $\$ 34,884,350$ & 1,207 \\
Other & $\$ 878,979,304$ & $\$ 249,348,529$ & $\mathbf{4 , 1 8 5}$ \\
\hline TOTAL & &
\end{tabular}




\subsection{Economic Impacts by U.S. Industry}

Table 3-8 illustrates Palo Verde's economic impact on the United States. Again, the most-affected sector is power generation and supply, in terms of total output.

The second largest sector is the inorganic chemicals sector, which includes nuclear fuel-processing services. These services are performed at a few locations in the United States and around the world.

The 10 most-affected sectors (based on output) in the United States are similar to the 10 mostaffected sectors in Maricopa County and Arizona. The main difference is the architectural and engineering services sector, which includes specialized engineering work often performed by national consultants.

Table 3-8. Impact of Palo Verde on the Most-Affected Industries in the United States

\begin{tabular}{|c|c|c|c|}
\hline Industry Description & Output & Labor Income & Employment \\
\hline Power Generation and Supply & $\$ 732,757,265$ & $\$ 197,789,230$ & $2,4 \mid 4$ \\
\hline Other Basic Inorganic Chemical Manufacturing & $\$ 107,884,496$ & $\$ 22,871,946$ & 278 \\
\hline Wholesale Trade & $\$ 44,432,652$ & $\$ 17,042,076$ & 310 \\
\hline Owner-Occupied Dwellings & $\$ 39,876,392$ & $\$ 0$ & - \\
\hline Real Estate & $\$ 32,658,238$ & $\$ 3,840,114$ & 214 \\
\hline Business Support Services & $\$ 31,581,250$ & $\$ 15,692,044$ & 554 \\
\hline Hospitals & $\$ 25,731,656$ & $\$ 10,289,805$ & 235 \\
\hline Food Services and Drinking Places & $\$ 23,626,708$ & $\$ 10,329,366$ & 595 \\
\hline Architectural and Engineering Services & $\$ 22,457,438$ & $\$ 13,361,34 \mid$ & 244 \\
\hline $\begin{array}{l}\text { Monetary Authorities/Depository Credit } \\
\text { Intermediaries }\end{array}$ & $\$ 21,918,612$ & $\$ 4,585,945$ & 95 \\
\hline Other & $\$ 640,460,052$ & $\$ 228,752,706$ & 6,041 \\
\hline TOTAL & $\$ 1,723,384,759$ & $\$ 524,554,573$ & 10,980 \\
\hline
\end{tabular}




\subsection{Tax Impacts}

The effect of Palo Verde spending extends beyond the taxes paid directly on the plant. This spending has direct impacts on income and value creation, which in turn, affects taxes paid on that income and value. Similarly, the secondary effects of plant spending on other products and services, as well as the increased economic activity itself leads to additional income and value creation — and additional tax revenues.

These additional or "induced" effects on tax payments are much larger than the taxes paid directly. These results are presented in Table 3-9. Palo Verde is responsible for approximately $\$ 62$ million in state and local tax revenue, either directly or indirectly. Much of the indirect expenditures are the result of additional sales tax revenue created by the large number of employees at Palo Verde.

At the federal level, Palo Verde's operations induce $\$ 87.6$ million in tax revenue. Most of that total is from income and Social Security taxes.

Table 3-9. Tax Impacts of Economic Activity Induced by Palo Verde

\begin{tabular}{|c|c|c|c|}
\hline & $\begin{array}{c}\text { Taxes Paid } \\
\text { by Palo Verde }\end{array}$ & $\begin{array}{l}\text { Taxes Induced } \\
\text { by Palo Verde } \\
\text { Expenditures }\end{array}$ & $\begin{array}{c}\text { Total Tax } \\
\text { Impact }^{\text {Im }}\end{array}$ \\
\hline \multicolumn{4}{|l|}{ Federal Government } \\
\hline Payroll Tax & $\$ 35,63|| 83$, & $\$ 35,462,454$ & $\$ 7 I, 093,637$ \\
\hline Corporate Tax & - & $\$ 10,406,055$ & $\$ 10,406,055$ \\
\hline Personal Tax & - & $\$ 35,374,992$ & $\$ 35,374,992$ \\
\hline Business Tax & $\$ 827,258$ & $\$ 6,391,727$ & $\$ 7,218,985$ \\
\hline Total Federal Government & $\$ 36,458,441$ & $\$ 87,635,228$ & $\$ 124,093,669$ \\
\hline \multicolumn{4}{|l|}{ State and Local Government } \\
\hline Payroll Tax & $\$ 6,245,043$ & $\$ 33,850$ & $\$ 6,278,893$ \\
\hline Corporate Tax & - & $\$ 104,768$ & $\$ 104,768$ \\
\hline Personal Tax & - & $\$ 703,804$ & $\$ 703,804$ \\
\hline Business Tax & $\$ 47,865,801$ & $\$ 7,002,439$ & $\$ 54,868,240$ \\
\hline Total State and Local Government & $\$ 54,110,844$ & $\$ 7,844,861$ & $\$ 61,955,705$ \\
\hline TOTAL & $\$ 90,569,285$ & $\$ 95,480,089$ & $\$ 186,049,374$ \\
\hline
\end{tabular}

a The total tax impact includes taxes paid by Palo Verde and other entities as a result of the economic activity created by Palo Verde expenditures. 


\subsection{Summary}

Palo Verde has substantial economic impacts on Maricopa County and Arizona. When compared with their respective economies, the plant's relative impacts are highest for Maricopa County, next highest for Arizona and lowest for the United States. The Palo Verde job creation impact (direct and indirect) of 3,943 jobs in Maricopa County is a significant number of jobs deriving from a single enterprise.

The state and local economic effects of the plant are great, largely because of the buying power created by Palo Verde's high wages and salaries, which are spent on goods and services provided locally. This spending supports many small businesses in the area. 


\section{Section 4: Additional Benefits Provided by Palo Verde}

Besides the economic benefits that Palo Verde contributes to Maricopa County in the form of jobs, incomes and taxes, the plant also contributes to the local community in ways difficult to capture with these measures. Although most businesses tend to provide contributions to their communities, nuclear power plants tend to be significant contributors to their surrounding communities because of the large numbers of well-paid and well-educated people they employ.

\subsection{Introduction}

Because of its rural location, Palo Verde essentially is a self-sufficient municipality with the infrastructure required by any small city. That infrastructure includes a fire department, medical facilities, security services, a Maricopa County Sheriff's substation, training facility, community outreach services and water treatment facility. Because of the size of the plant and the breadth of its resources, Palo Verde and its employees are able to provide many additional benefits to the surrounding community beyond the economic impact of the plant. Educational, environmental and community programs are the primary beneficiaries of the plant's outreach efforts.

\subsection{Education}

Palo Verde makes significant contributions to educational programs in western Maricopa County. Nuclear power plants like Palo Verde need employees with strong backgrounds in science, engineering, business and computer technology, so the plant's strong interest in promoting education is understandable.

Palo Verde employs a large work force, and as with many industries, the nuclear energy sector is faced with an aging worker population. Palo Verde estimates that it will need to replace approximately 10 percent of its workers over the next five years. As part of its work force planning efforts, Palo Verde has invested heavily in educational programs to help local students develop their skills, while the plant develops a potential future work force.

One such educational program at Palo Verde is Quest for Excellence (QFE) — a partnership with Central, Buckeye and Wickenburg high schools that emphasizes the development of math and science skills for juniors and seniors. Each year, 20 to 25 new students enroll in the program, with an average of about 40 students participating at any one time. The students receive a stipend of $\$ 7$ an hour during the summer while participating in advanced math and physics classes.

At the conclusion of the program, students are eligible to move into Palo Verde's QFE college program, which supports students in the fields of engineering, business, supply-chain management and information technology. Participants, who receive tuition scholarships, work as interns at Palo Verde during summer breaks, allowing them to gain valuable on-the-job experience. About five new students enroll in the program each year, with approximately 15 participating in the program at any one time.

For students considering the skilled crafts, Palo Verde sponsors a maintenance intern program, which provides internships to students who want to pursue careers as electricians; heating, ventilation and air-conditioning specialists; instrumentation and control specialists; machinists; mechanics; and welders. Students gain experience at the plant during 20-hour workweeks, while attending classes at a nearby community college. 
Palo Verde has several other programs aimed at improving the quality of education in western Maricopa County. Plant workers serve as substitute teachers for local schools, and Palo Verde's annual financial contributions help fund accelerated reading programs in local elementary schools. The plant also conducts programs for Arizona teachers that provide energy-related lesson plans and teaching materials. Additionally, Palo Verde makes financial and in-kind contributions to area schools to support certain athletic, music and scholastic programs.

\subsection{Environment}

Environmental stewardship is a core value at Palo Verde, starting with the plant's vital contribution to clean air. Palo Verde prevents significant air pollutants and greenhouse gas emissions that would be generated if the same amount of electricity were produced by fossil fuels. In 2002, Palo Verde avoided the emission of 158,000 tons of sulfur dioxide, 93,000 tons of nitrous oxide and 29.1 million tons of carbon dioxide. Sulfur dioxide can produce acid rain and nitrous oxide is a precursor to ground-level ozone. Carbon dioxide is the leading greenhouse gas.

The plant also contributes to clean air through its van pool program. The company provides commuter vans for Palo Verde employees to reduce vehicular emissions resulting from worker commutes. The plant currently maintains about 200 vans as part of its fleet, and nearly 75 percent of the plant's 2,042 employees participate in the program. Officials estimate that this alternative transportation program prevents 823,000 pounds of pollution.

Water is a precious commodity in Arizona, and Palo Verde does its part to conserve that resource. Unlike other nuclear power plants, Palo Verde sits in the desert without a large body of water nearby as its source of cooling water. Instead, treated wastewater from cities in Maricopa County is piped nearly 40 miles to Palo Verde. By using wastewater, the plant conserves natural groundwater resources, while benefiting the local economy through the annual purchase of more than 22 billion gallons of wastewater.

Once the wastewater reaches the plant, Palo Verde treats the water at its own tertiary water treatment facility and makes it available for other uses, such as cooling the nearby Redhawk power plant. Other plants typically use groundwater for their water needs. Redhawk uses water from Palo Verde and avoids the use of nearly 1 billion gallons of groundwater a year.

\subsection{Community Involvement}

Palo Verde is much like a small city unto itself. As such, the plant is able to make many resources available to its surrounding communities in the form of direct financial contributions, in-kind donations and volunteer time. For example, Palo Verde's warehouses store food for the regional food bank and Palo Verde employee volunteers play a major role in distributing the food to local families several times a year.

Additionally, Palo Verde and Arizona Public Service Co. are major contributors to the Valley of the Sun United Way. In 2002, Palo Verde employees contributed \$764,754 to Arizona Public Service's Community Service Fund. Combined with the company's matching gift program, employees provided more than $\$ 1.1$ million to local nonprofit organizations served by the United Way.

Palo Verde makes other donations to the local community. The largest are made through three formal community funds established by the company in 2001 during construction of the nearby Redhawk plant. The funds are administered by the Arizona Community Foundation and overseen 
by community volunteers. Following an initial endowment of $\$ 500,000$ in 2001 , Palo Verde contributes $\$ 52,500$ annually to these funds, which provide a permanent source of financial support for projects that benefit western Maricopa County communities near Palo Verde. The funds can be used for a wide variety of purposes, including the arts, community development, culture, education, the environment and public health.

In 2002, Palo Verde made $\$ 83,090$ in contributions to nonprofit organizations in smaller, more rural communities surrounding the plant that otherwise would not have that source of support. Overall, Palo Verde's financial donations to Maricopa County community organizations totaled $\$ 438,993$ in 2002.

In addition to financial support, Palo Verde makes in-kind donations to the local community. For example, the plant donated its printing services to several nonprofit organizations and neighboring schools. Recipients of Palo Verde's in-kind expenditures, which totaled \$20,571 in 2002, included the Buckeye Union High School, the Tonopah Fire Department and the Wickenburg Mining Museum.

Palo Verde employees also spend their spare time volunteering for local nonprofit organizations to help improve the quality of life for their neighbors. In 2002, plant employees donated approximately 50,000 hours to Arizona community organizations and events.

\section{Figure 4-I. Palo Verde Community Donations}

(2002)

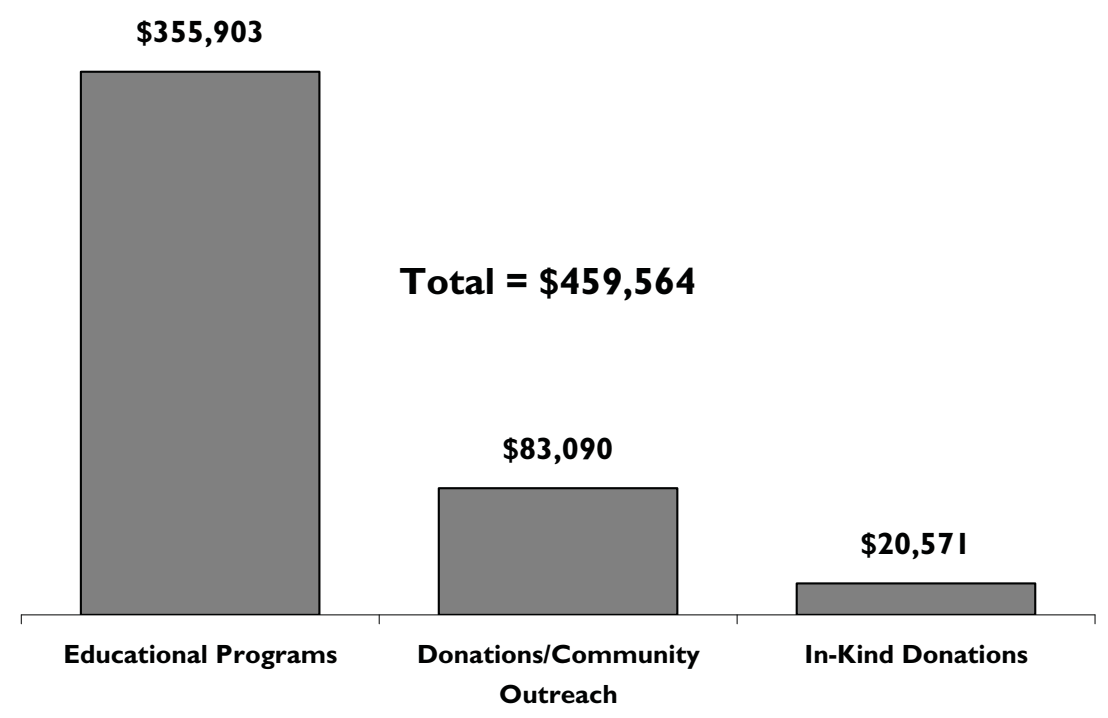




\section{Section 5: Nuclear Industry Trends}

The U.S. nuclear energy industry has steadily improved performance and cost, while improving plant safety. The industry also serves as a model of industrial safety.

Total electricity production for U.S. nuclear power plants reached 764 billion kilowatt-hours in 2003. Power plant performance is measured by capacity factor, which expresses the amount of electricity actually produced by a plant, compared with the maximum achievable. U.S. nuclear power plants achieved a capacity factor of nearly 90 percent in 2003. At the same time, production costs for those plants have been among the lowest of any baseload fuel source.

\subsection{Nuclear Industry Performance}

U.S. nuclear plants have increased their output and improved their performance significantly over the past 10 years. Nuclear energy represents about 20 percent of all electricity generated in the United States. Since 1990, the industry has increased total output equivalent to 26 new, large nuclear plants. The increase in output occurred without building any new nuclear plants.

Meanwhile, overall capacity factors for the U.S. nuclear power plants increased dramatically over the past decade, reaching about 90 percent in 2003. By contrast, the average capacity factor for the industry was 60 percent in the late 1980s. One of the key reasons for these increased capacity factors has been the shortening of refueling outage times.

\section{Figure 5-I. U.S. Nuclear Industry Net Electricity Generation}

(32\% increase from 1990 to 2003 )

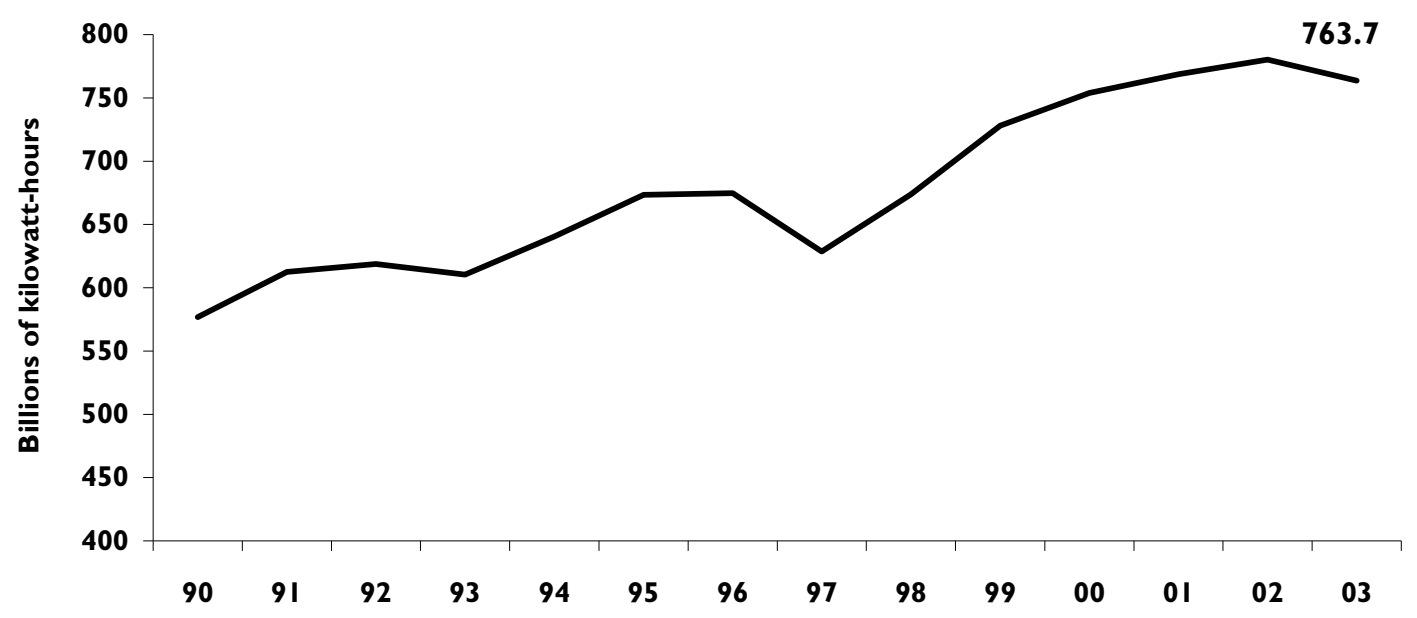

Source: Energy Information Administration 
Nuclear plants need to shut down to refuel approximately every 18 to 24 months. Refueling represents one of the major determinants of nuclear plant availability. In the past 10 years, the durations of refueling outages have been declining. In 1990, the average refueling outage took 105 days to complete. By 2003, this number declined to an average of 40 days, and companies continue to apply best practices to further reduce this average. The record for the shortest refueling outage is 14.67 days for a boiling water reactor and 15.67 days for a pressurized water reactor.

\subsection{Cost Competitiveness}

Along with increasing output, the U.S. nuclear industry has continued to decrease its operations costs. In 2003, nuclear power had a production cost of 1.72 cents per kilowatt-hour. This was significantly lower than the production costs of electricity generated by oil and natural gas and slightly lower than coal. In the past decade, nuclear production costs have dropped by about onethird because of the increased capacity factor of the U.S. plants. Since most nuclear plant costs are fixed, greater electricity production creates lower cost. However, nuclear plants have also taken steps to reduce their total cost through improved work processes.

\section{Figure 5-3. U.S. Electricity Production Costs}

( $1981-2003$ in constant 2003 cents/kWh)

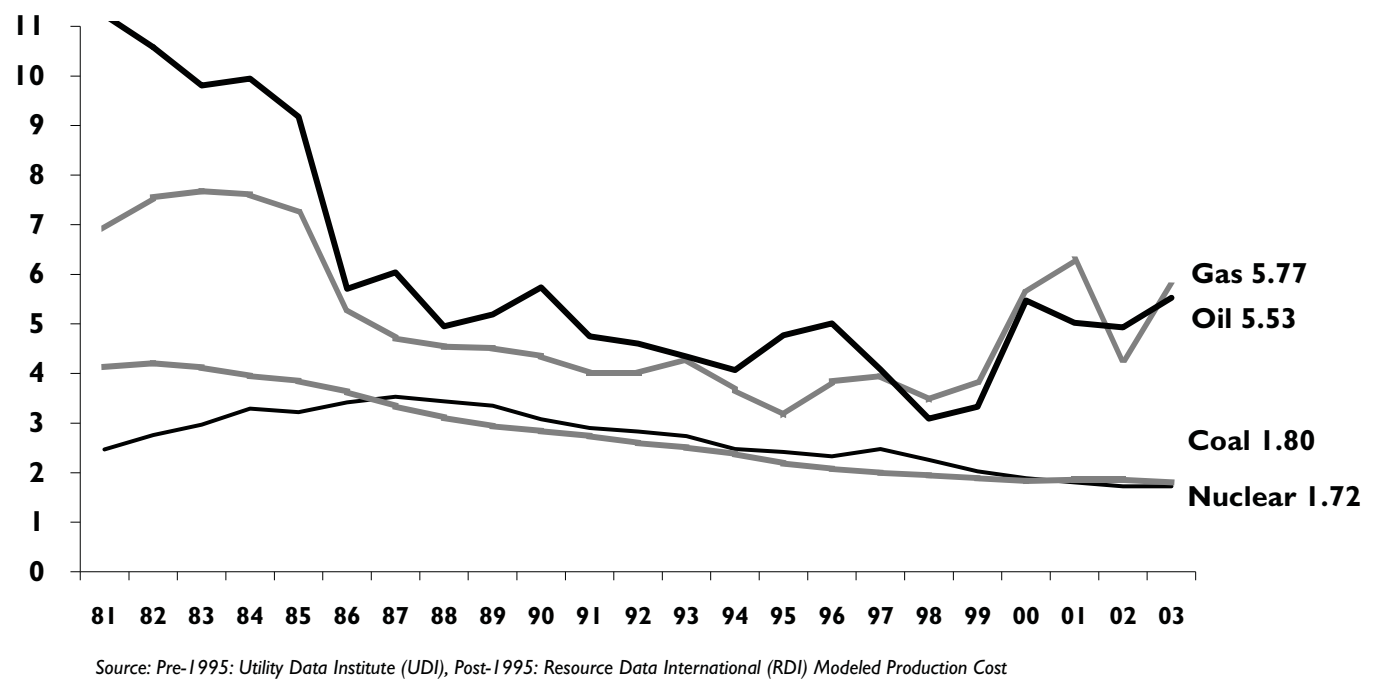


Table 5-I. Wholesale Electricity Prices by Region (cents/kilowatt-hour)

\begin{tabular}{|l|c|c|}
\hline \hline Region & 200I Average 24/7 Power Prices & 2003 Average 24/7 Power Prices \\
\hline New England & 3.3 & 6.6 \\
Mid-Atlantic & 2.6 & 4.1 \\
Tennessee Valley & 2.0 & 2.9 \\
Gulf States & 2.2 & 3.0 \\
Midwest & 2.0 & 2.7 \\
Texas & 2.2 & 3.9 \\
Northwest & 2.2 & 3.8 \\
Southwest & 2.5 & 4.1 \\
\hline
\end{tabular}

Because of low production costs and excellent safety performance, nuclear plants are very competitive in today's energy markets. Ultimately, the primary test of nuclear energy's competitiveness is how well it performs against market prices. In this respect, nuclear energy is highly competitive. Average production cost at the nation's 103 reactors was 1.72 cents per kilowatt-hour in 2003 , lower than the average price in all regional markets. Nuclear energy is also competitive with futures market prices, one of the best ways to judge what prices will be in the year ahead.

Nuclear plants provide a unique degree of price stability for two reasons. First, production costs for nuclear plants are comprised of costs not associated with fuel. Fuel markets tend to be very volatile, so the production costs of generation sources tied to fuel expenses are highly volatile, as they swing with variations in the markets. Fuel represents only 20 percent of the production cost of nuclear energy, but it makes up 60 percent to 80 percent of the cost of natural gas, coal and petroleumfired generation. Second, nuclear fuel prices are much more stable than those of fossil fuels, particularly natural gas and petroleum. Because of its stable, low production cost, nuclear energy can help mitigate large electricity price swings.

Figure 5-4. Monthly Fuel Cost to Electric Generators

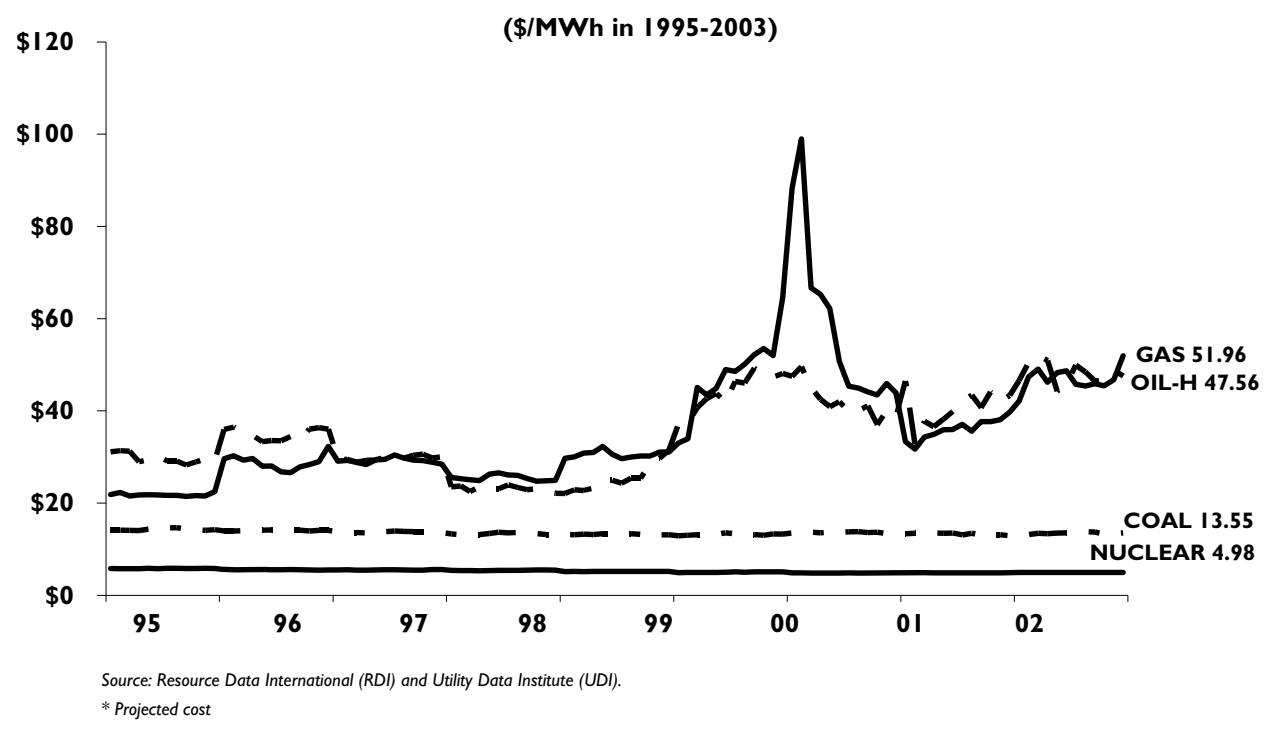




\subsection{Current Industry Events}

The excellent economic and safety performance of the U.S. nuclear power plants has increased interest in nuclear energy by the electric utility industry, the financial community and policymakers. This is evidenced by the increasing number of plants seeking license renewals from the Nuclear Regulatory Commission.

Nuclear plants were originally licensed to operate for 40 years, but can safely operate for longer periods of time. The NRC granted the first 20 -year license renewal to the Calvert Cliffs plant in Maryland in 2000. As of December 2004, 30 plants have received license extensions, and 16 reactors have submitted an application to renew their licenses. License renewal is an attractive alternative to building new electric capacity because of nuclear energy's low production costs and the return on investment for license renewal.

Besides relicensing current plants, interest has recently increased in building new nuclear plants. Three companies-Entergy, Dominion and Exelon-have submitted early site permit applications with the NRC to test the agency's new permitting process for new reactor sites.

Three groups of energy companies are seeking to collaborate with the U.S. Department of Energy to test a new licensing process for building and operating an advanced nuclear reactor called a combined construction and operating license. The effort is part of DOE's Nuclear Power 2010 program, established to foster the development of next-generation nuclear power plants. 


\section{Section 6: Economic Impact Analysis Methodology}

The methodology used to estimate the economic impacts of Palo Verde is commonly referred to as input/output methodology. Several operational input/output models are available in the marketplace, but the market leaders are Impact Analysis for Planning (IMPLAN), REMI and RIMS-II. The IMPLAN model was selected for this study primarily because of the availability of the model and data sets. Other important factors were the relevance of IMPLAN to the particular application, as well as its transparency and ease of use.

This section presents typical applications of the input/output methodology and explains the methodology and its underpinnings. It also describes how Palo Verde data and the IMPLAN model were used to estimate local, state and national economic impacts of plant operation.

\subsection{Use of Input/Output Models}

Input/output models capture input, or demand, and output, or supply, interrelationships for detailed business, industry and government sectors in a geographic region. They also capture the consumption of goods and services for final demand by these sectors and by the household sector.

The basic geographic region is a county, but model results can be developed at the multi-county, state, multi-state and national levels. These results are particularly useful in examining the total effects of an economic activity or of a change in the level of that activity.

These models are typically used when the following key questions need to be addressed:

- How much spending does an economic activity (such as a power plant) bring to a region or local area?

- How much of this spending results in sales growth by local businesses?

- How much income is generated for local businesses and households?

- How many jobs does this activity support?

- How much tax revenue is generated by this activity?

These models also are useful in addressing related questions, such as the geographic and industry distribution of economic impacts. Typical applications of these models include facility or military base openings and closings, transport or other public infrastructure investments, industrial recruitment and relocation, and tourism.

\subsection{Overview of the Input/Output Methodology}

Input/output models link various sectors of the economy-e.g., agriculture, construction, government, households, manufacturing, services and trade-through their respective spending flows in a reference year. These linkages include geographic linkages, primarily at national, state and county levels.

Because of these linkages, the impact of an economic activity in any sector or geographic area on other sectors and areas can be modeled. These impacts can extend well beyond the sector and area in which the original economic activity is located. They include not only the direct, or initial, effects of the economic activity, but also the secondary, or "ripple," effects that flow from this activity. 
Direct effects are analogous to the initial "splash" made by the economic activity, while secondary effects are the subsequent "waves" of economic activity (new employment, income, production and spending) triggered by this splash. A full accounting of the splash's effect must include the waves, as well.

The sum of the direct and secondary effects is called the total effect, and the ratio of the total effect to the direct effect is called the "total effect multiplier," or simply the multiplier effect. Multipliers can be developed for any of the model outputs, such as earned income, employment, industry output and total income (which includes the effect of transfers between institutions).

Multipliers also can be developed for any industry/business sector or geographic area in the model. Multipliers for a county are smaller than for a larger area, such as the state in which the county is located, because some of the spending associated with an economic activity migrates from the small area into the larger area. At the local area level, multipliers are larger if the local area produces the types of goods and services required by the plant.

Secondary effects include two components - indirect and induced effects - that are separately modeled within input/output models. Indirect effects are the effects on the supply chain that feeds into the business/industry sector in which the economic activity is located. For example, when Palo Verde buys a hammer for $\$ 5$, it contributes directly to the economy by this purchase. However, the company that makes the hammer also has to increase its purchases of steel and wood to maintain its inventory, increasing output in the steel and wood industries. These industries will then have to purchase more inputs for their production processes, and so on. The result will be an economic impact that is greater than the $\$ 5$ initially spent for the hammer.

The increased income of plant employees and other regional workers leads to higher spending at the household level. That increased spending is called the induced effect. To illustrate, when a nuclear power plant pays $\$ 5$ for a hammer, a portion of the $\$ 5$ pays the wages of employees at the company that makes the hammer. This portion contributes to labor income, which provides an additional contribution to the economy through its effects on household spending for goods and services.

There also will be a contribution from the effect of this purchase on labor income in the wood and steel industries, and on the resulting household spending on goods and services. Palo Verde's wage and salary expenditures create induced effects as well, and they occur primarily in Maricopa County.

As with any model, input/output models incorporate some simplifying assumptions to make them tractable. There are several key simplifying assumptions in input/output models.

Input/output models assume a fixed commodity input structure. In essence, the "recipe" for producing a product or service is fixed, and there is no substitution of inputs, either of new inputs (which were not in the mix previously) for old inputs, or among inputs within the mix.

Input substitution does not occur if technical improvements in some inputs make them relatively more productive. Nor does input substitution occur if there are relative price changes among inputs. Were any of these types of substitutions to be allowed, they might dampen the multiplier effects, especially for larger geographic areas. 
Another key simplifying assumption is constant returns to scale. A doubling of commodity or service output requires a doubling of inputs, and a halving of commodity or service output requires

a halving of inputs. There is no opportunity for input use relative to commodity or service production levels to change, as those levels expand or contract, so there are no opportunities for either economies or diseconomies of scale. This will not dramatically alter the overall results as long as the economic activity whose effects are being modeled is not large relative to the rest of the sectors.

In other words, the models assume that for every dollar of output, the same dollar amount is required for the various input categories. Returning to the hammer example, if a $\$ 5$ hammer requires $\$ 3$ of steel, then two hammers would require $\$ 6$ of steel.

Although that works for steel and hammers, some inputs do not vary directly with output. For instance, if an oil refinery's efficiency and output increases, a corresponding increase in personnel operating the plant is unlikely. The return-to-scale assumption considers such differences and is necessary for accurate modeling.

Input/output models assume no input supply or commodity/service production capability constraints. This simplifying assumption is related in part to the constant returns to scale assumption, for if there were supply constraints, diseconomies of scale likely would result. As in the case of the constant returns to scale assumption, this "no supply constraints" assumption is not a major concern as long as the economic activity of interest is not large relative to the rest of the sectors.

To illustrate, this assumption presupposes that a hammer manufacturer would purchase all the steel for the same price. If not, doubling the number of hammers sold could mean that the dollar value of the steel might more than double if the manufacturer had to buy more steel at a higher price. This would violate the constant returns-to-scale assumption, which simplifies modeling.

Homogeneity, another key simplifying assumption, characterizes similar firms and technologies within sectors. Although the model allows some editing of its sector files to characterize specialized firms, there is no ability to reflect full diversity of firms within sectors.

\subsection{The IMPLAN Model and Its Application to Palo Verde}

IMPLAN was originally developed by the U.S. Department of Agriculture's Forest Service in cooperation with the Federal Emergency Management Agency and the Department of the Interior's Bureau of Land Management to assist in land and resource management planning. IMPLAN, in use since 1979, is supported by the Minnesota IMPLAN Group Inc.

There are two components of the IMPLAN system: the software and the database. The software performs the necessary calculations, using study area data, to create the models. It also provides an interface for the user to change a region's economic description, create impact scenarios and introduce changes into the local model. The software is described in a user's guide provided by the Minnesota IMPLAN Group. The software was designed to serve three functions: data retrieval, data reduction and model development, and impact analyses.

The IMPLAN database consists of two major parts: national-level technology matrices and estimates of regional data for institutional demand and transfers, value added, industry output and employment for each county in the United States, as well as state and national totals. 
The IMPLAN data and account structure closely follow the accounting conventions used in input/output studies of the U.S. economy by the Department of Commerce's Bureau of Economic Analysis. The comprehensive and detailed data coverage of the entire United States by county, and the ability to incorporate user-supplied data at each stage of the model-building process, provide a high degree of flexibility in terms of both geographic coverage and model formulation.

In applying the IMPLAN model to Palo Verde, three basic types of data were provided by Arizona Public Service Co.:

- purchase order expenditures by Palo Verde purchase order code

- employee compensation expenditures

- tax payment data.

Purchase order expenditures, employee compensation (salary data and an estimate of the value of benefits) and tax payment information were provided for the year 2002. The purchase order data were mapped to IMPLAN's 528 sector codes by comparing the descriptions of the purchase order codes provided by Arizona Public Service Co. with the standard industrial classification codes within IMPLAN's sector codes.

The purchase order and compensation data were then augmented by an estimate of revenues from sales to the wholesale market in 2002. This augmentation was necessary because purchase orders and compensation do not reflect all Palo Verde expenditures. Total expenditures (approximated by total revenues) better reflect the full economic impacts of Palo Verde. Plant revenues were estimated based on kilowatt-hours sold and wholesale prices paid at the Palo Verde hub during this time.

In tailoring the model to Palo Verde, IMPLAN's underlying data sets were reviewed to determine if any of the model's coefficients could be edited to reflect more accurately local conditions. IMPLAN coefficients are based on national relationships, and in some cases may not reflect local conditions. In this report, the coefficients within the electric services sector were edited to reflect a nuclear power plant rather than a "national average power plant of all types."

The IMPLAN model only has a general category for electric services. Since 50 percent of the country's electricity is produced by coal, the electric utility production function has in it large purchases of coal. This would be inappropriate for the impacts of a nuclear power plant.

To correct this, the model instead used actual purchase order data from Palo Verde to produce a production function for the plant. This includes the location of purchases, since many purchases by a nuclear power plant are made outside the county or state. Without regional purchase coefficient editing, the estimates of local purchases would be much higher in general.

Once the data sets were complete, IMPLAN was used to develop the economic impact estimates detailed in this report. 


\section{2 \\ The Power to Make it Happen}

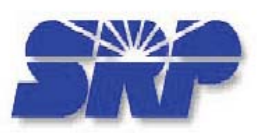

\section{SCPPA}
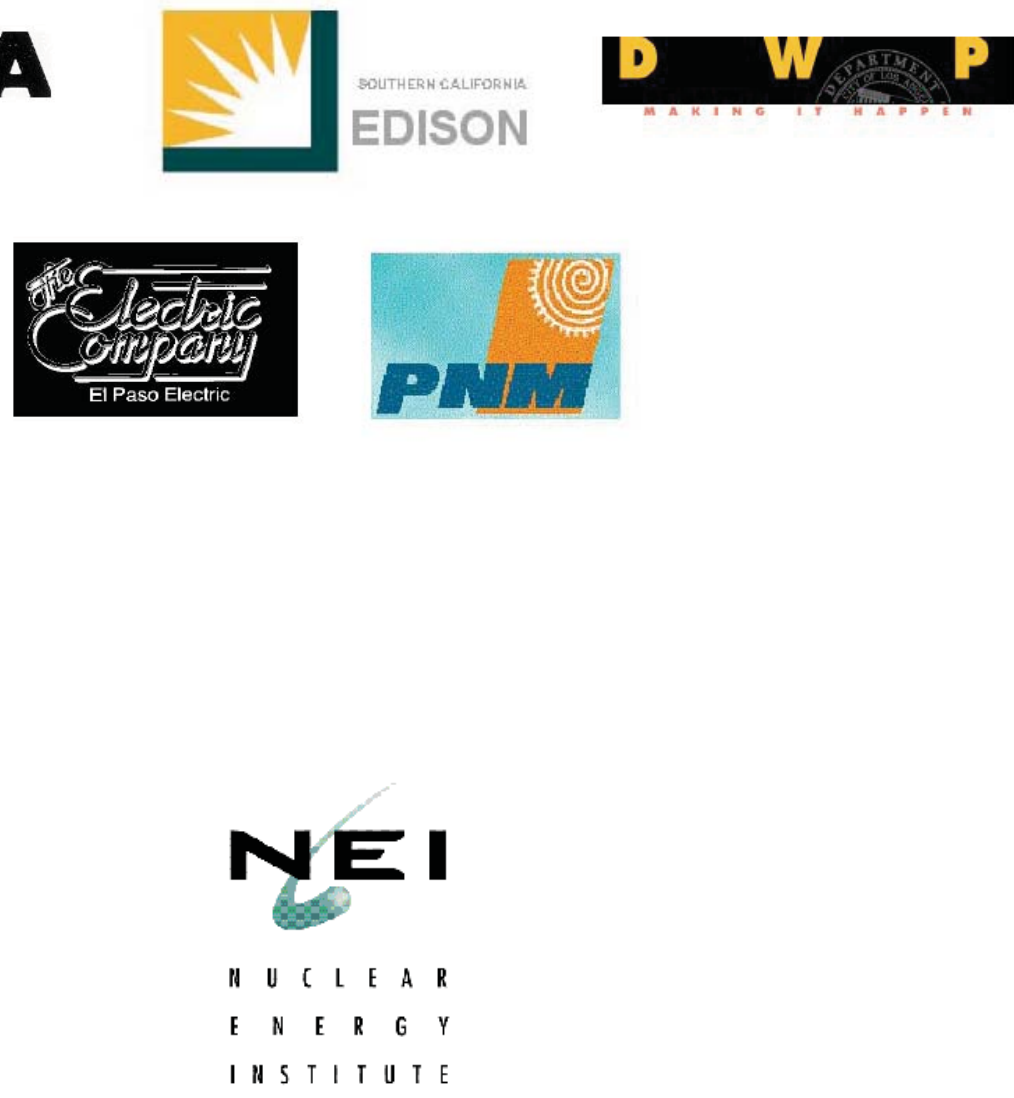

1776 I Street, N.W., Suite 400

Washington, D.C. 20006-3708

Phone: 202.739 .8000

Fax: 202.785.4019

www.nei.org 


\section{APPENDIX B}

APS ALTERNATIVE FUEL PILOT PLANT DESIGN REPORT 
INEEL/EXT-03-00976

U.S. Department of Energy

FreedomCAR \& Vehicle Technologies Program Advanced Vehicle Testing Activity

\title{
Arizona Public Service - Alternative Fuel (Hydrogen) Pilot Plant Design Report
}

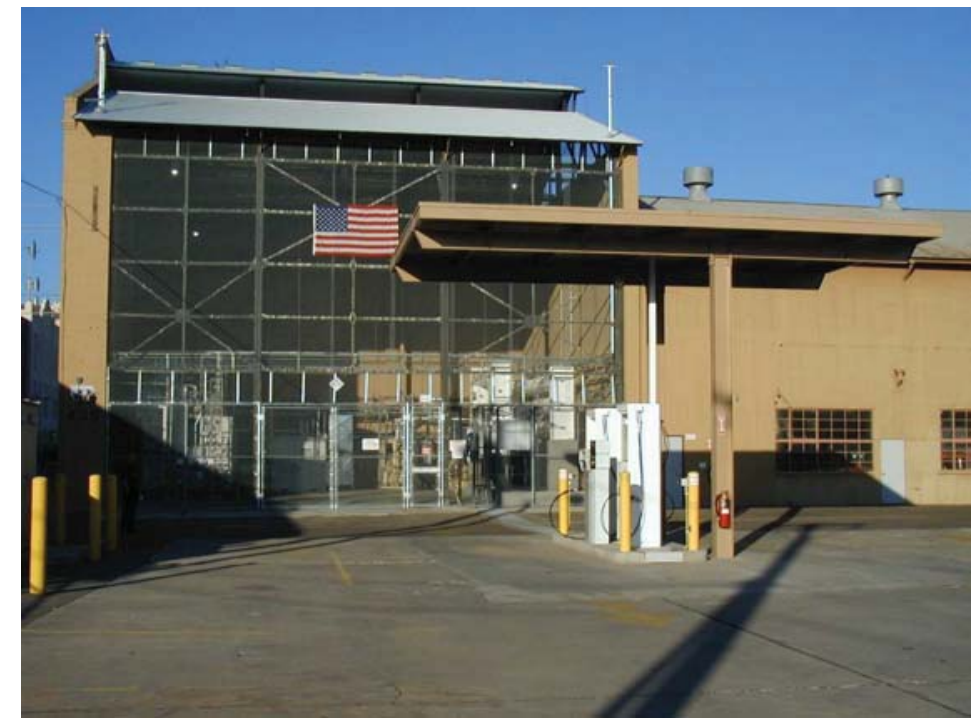

TECHNICAL REPORT

\author{
Don Karner \\ James Francfort
}

December 2003

Idaho National Engineering and Environmental Laboratory Bechtel BWXT Idaho, LLC 


\title{
U.S. Department of Energy FreedomCAR \& Vehicle Technologies Program
}

\author{
Advanced Vehicle Testing Activity \\ Arizona Public Service - Alternative Fuel \\ (Hydrogen) Pilot Plant Design Report
}

\author{
Don Karner \\ James Francfort
}

December 2003

Idaho National Engineering and Environmental Laboratory Transportation Technology and Infrastructure Department Idaho Falls, Idaho 83415

Prepared for the

U.S. Department of Energy

Assistant Secretary for Energy Efficiency and Renewable Energy

Under DOE Idaho Operations Office

Contract DE-AC07-99ID13727 


\section{Disclaimer}

This document highlights work sponsored by agencies of the U.S. Government. Neither the U.S. Government nor any agency thereof, nor any of their employees, makes any warranty, express or implied, or assumes any legal liability or responsibility for the accuracy, completeness, or usefulness of any information, apparatus, product, or process disclosed, or represents that its use would not infringe privately owned rights. Reference herein to any specific commercial product, process, or service by trade name, trademark, manufacturer, or otherwise does not necessarily constitute or imply its endorsement, recommendation, or favoring by the U.S. Government or any agency thereof. The views and opinions of authors expressed herein do not necessarily state or reflect those of the U.S. Government or any agency thereof. 


\section{CONTENTS}

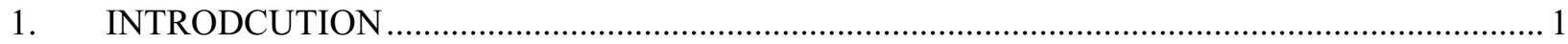

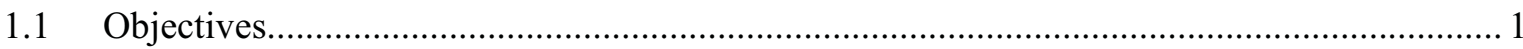

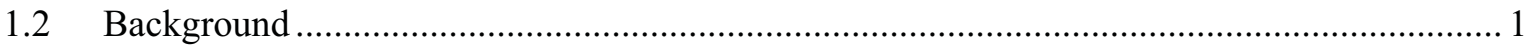

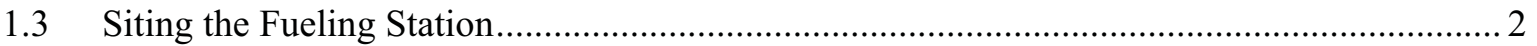

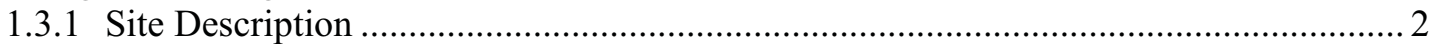

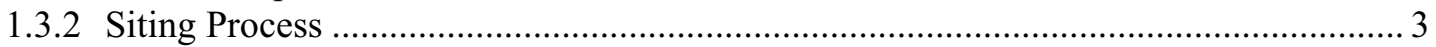

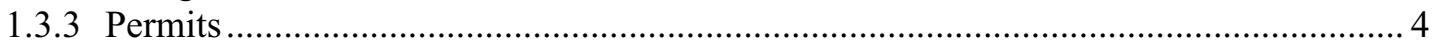

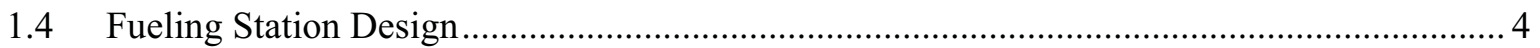

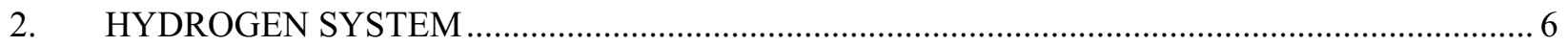

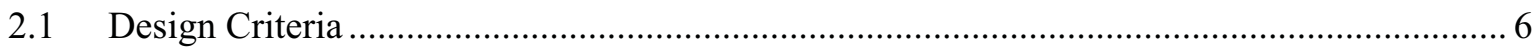

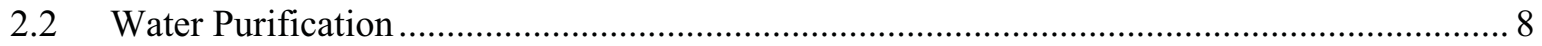

$2.3 \quad$ Hydrogen Production ..................................................................................... 8

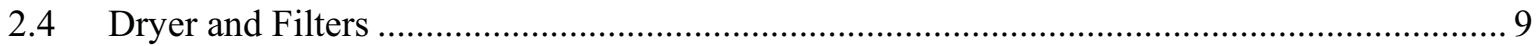

2.5 Low-Pressure Storage ………………………………………………………. 11

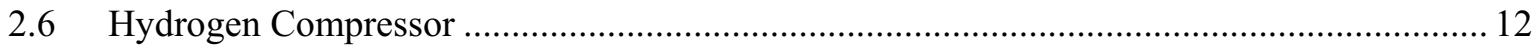

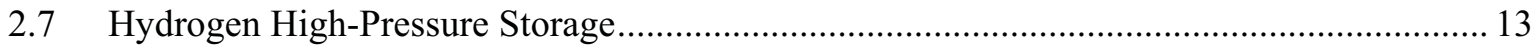

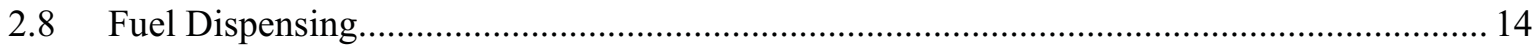

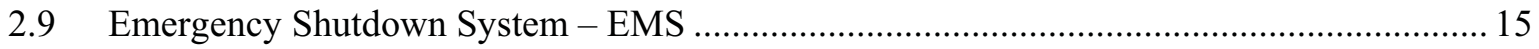

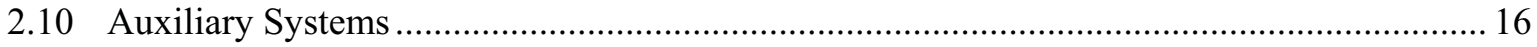

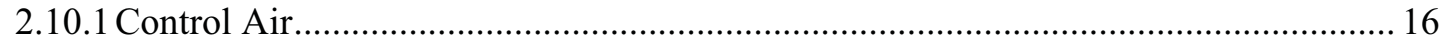

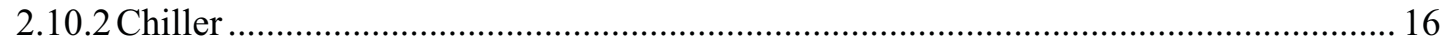

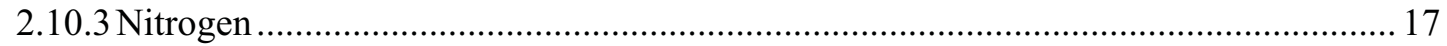

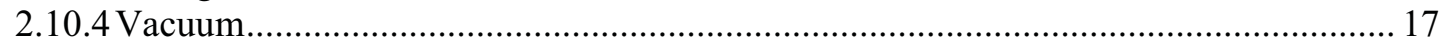

2.11 Drains, Vents, Tubing, Vent Stack, and Blowdown Tank ………………………………... 17

2.12 Hydrogen System Valves ........................................................................................ 18

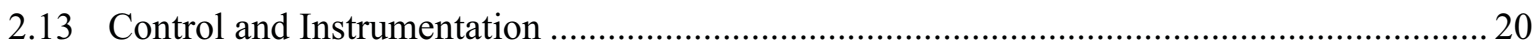

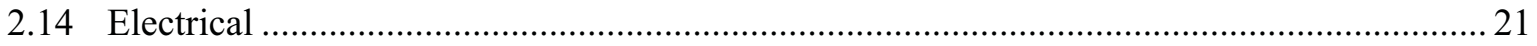

2.15 Color Coding of Fluid Lines ……………………………………………………… 21

2.16 Helium and Fire Sprinkler System ...................................................................... 22

2.17 Flame and Flammable Gas Detection ……………………………………………….....22

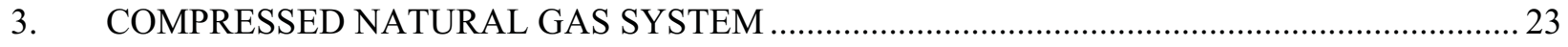

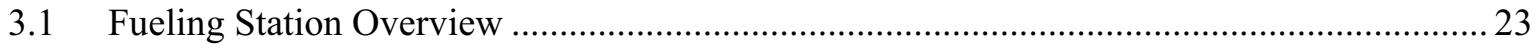

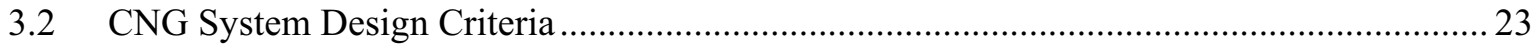

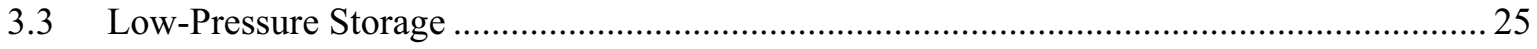

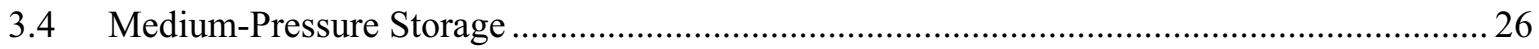




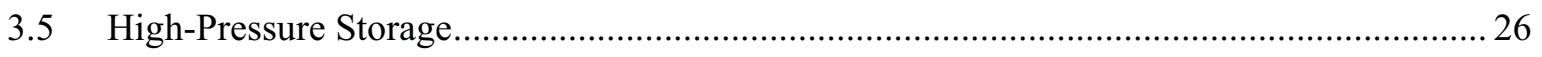

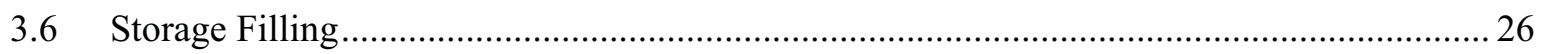

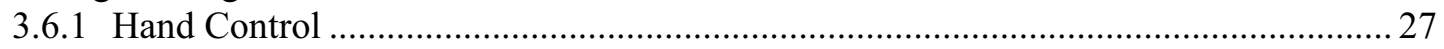

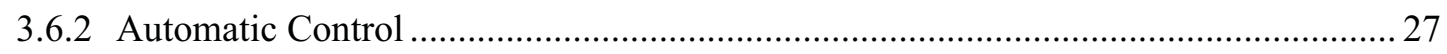

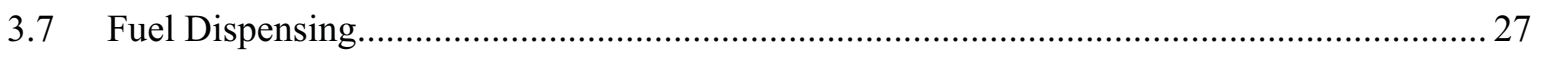

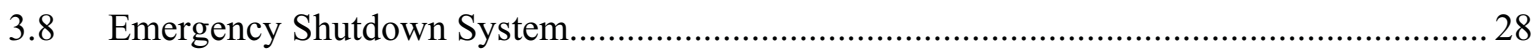

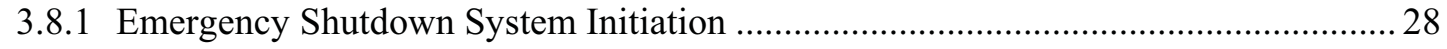

3.8.2 Emergency Shutdown System Automatic Actuations .............................................. 28

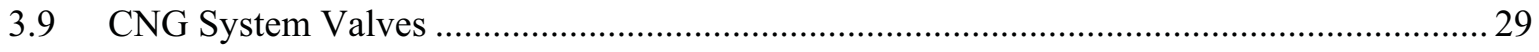

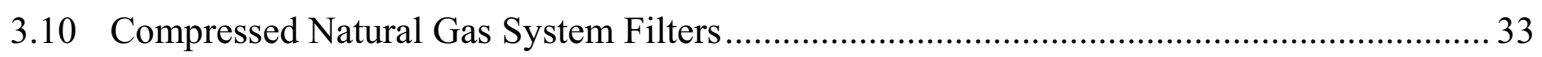

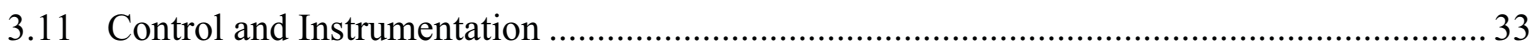

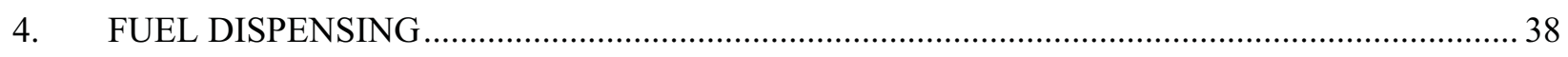

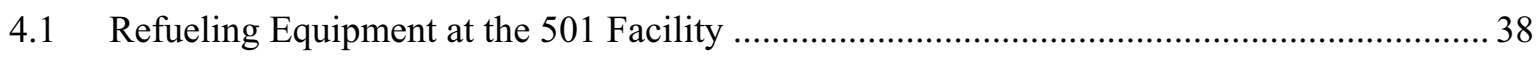

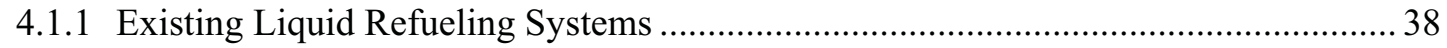

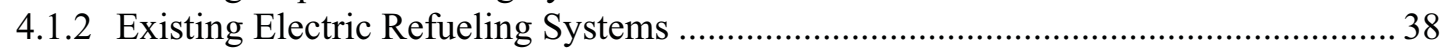

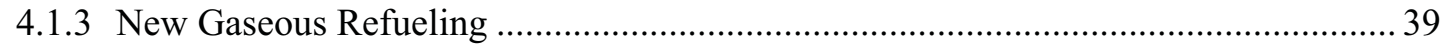

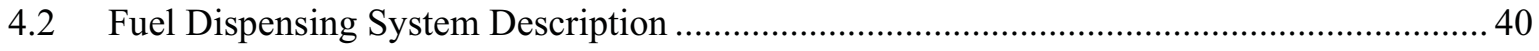

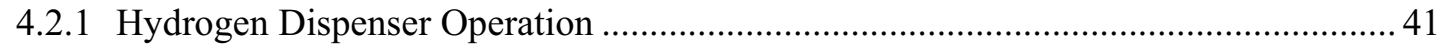

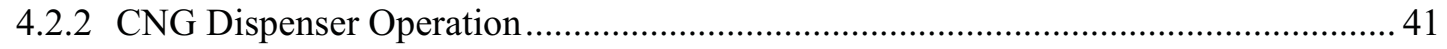

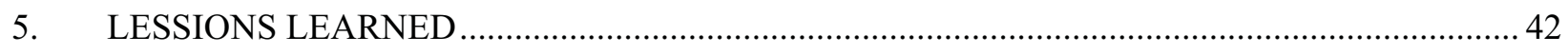

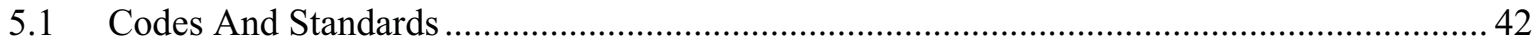

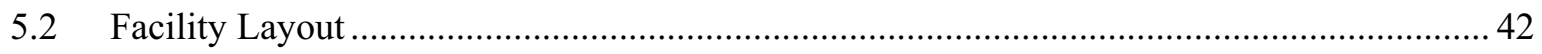

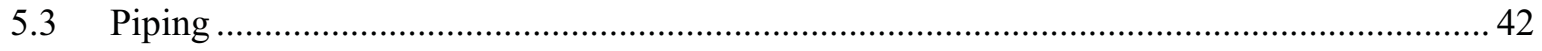

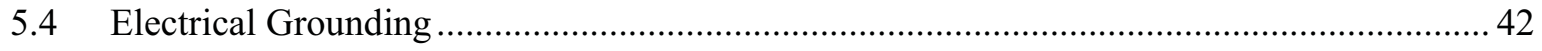

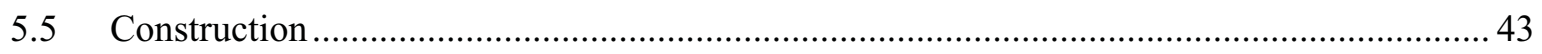

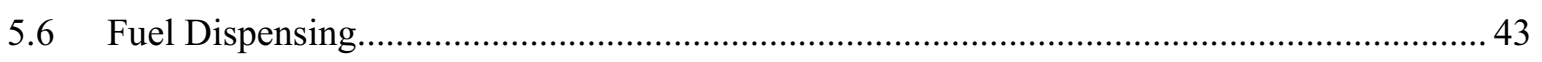

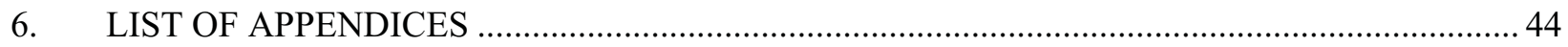




\section{ACRONYMS}

\begin{tabular}{ll} 
AOV & air-operated valve \\
APS & Arizona Public Service \\
BIT & built-in test \\
CNG & compressed natural gas \\
DCS & dispenser control system \\
DI & deionized (water) \\
EMS & emergency shutdown system \\
ESD & emergency shutdown \\
GGE & gasoline gallon equivalent \\
HCNG & hydrogen enriched compressed natural gas \\
HPS & high-pressure storage \\
ID & inside diameter \\
INEEL & Idaho National Engineering and Environmental Laboratory \\
IR & infrared \\
LFL & lower flammability limit \\
LPS & low-pressure storage \\
MAWP & maximum allowable working pressure \\
NFPA & National Fire Protection Association \\
OD & outside diameter \\
Pdc & Pdc Machines, Inc. \\
PLC & programmable logic controller \\
psi & pounds per square inch \\
psid & Pounds per square inch, differential \\
RO & reverse osmosis \\
scf & standard cubic feet \\
scfh & standard cubic feet per hour \\
UV & ultraviolet \\
\hline
\end{tabular}




\section{INTRODCUTION}

Hydrogen has promise to be the fuel of the future. Its use as a chemical reagent and as a rocket propellant has grown to over eight million metric tons per year in the United States. Although use of hydrogen is abundant, it has not been used extensively as a transportation fuel. To assess the viability of hydrogen as a transportation fuel and the viability of producing hydrogen using off-peak electric energy, Pinnacle West Capital Corporation (PNW) and its electric utility subsidiary, Arizona Public Service (APS) designed, constructed, and operates a hydrogen and compressed natural gas fueling station - the APS Alternative Fuel Pilot Plant. This report summarizes the design of the APS Alternative Fuel Pilot Plant and presents lessons learned from its design and construction. Electric Transportation Applications prepared this report under contract to the U.S. Department of Energy's Advanced Vehicle Testing Activity. The Idaho National Engineering and Environmental Laboratory manages these activities for the Advanced Vehicle Testing Activity.

\subsection{Objectives}

The objectives of constructing and operating the Alternative Fuel Pilot Plant have been to:

1. Ascertain the safety issues for a hydrogen production operation in a commercial setting

2. Evaluate the adequacy of existing codes, standards, regulations, and recommended practices within a commercial setting

3. Establish models for future codes and standards for distributed hydrogen generation systems within a commercial setting

4. Determine performance limitations of existing technologies and components

5. Evaluate the practicality of the systems in a commercial facility

6. Evaluate hydrogen and blended $\mathrm{CNG} /$ hydrogen as a potential fuel for internal combustion engines

7. Develop a working model of a refueling system for fuel-cell electric vehicles and internal combustion engine vehicles.

\subsection{Background}

Several stored forms of hydrogen could be considered for use as a transportation fuel: gas, liquid, slush, and metal hydrides. Two common methods of producing hydrogen are reforming of hydrocarbons such as methane and methanol, and electrolysis of water. Reforming of hydrocarbons, although today the most common and economical way of hydrogen production, results in carbon dioxide (a greenhouse gas) as a byproduct. Electrolysis of water produces only hydrogen and oxygen and is of interest to an electric utility company as a means of improving its load factor and increasing energy sales. In contrast to centralized manufacturing of hydrogen and use of tube trailers for delivery (as in gasoline distribution), the electrolysis process can be used with the existing electric distribution system to produce relatively small quantities of hydrogen during off-peak periods at the point of use. This provides the advantage of leveling electric energy usage and eliminating the need for tube trailer transportation.

Due to the very small number of hydrogen refueling stations, there are limited standards for their construction. Five other commercial hydrogen vehicle-refueling stations have been built in the United States: Sun Line Transit in Palm Springs, California; Ford Proving Ground in Dearborn, Michigan; California Fuel Cell Partnership in Sacramento, California; Las Vegas Transit in Las Vegas, Nevada; and the Honda Proving Ground in Torrance, California. Commercial hydrogen refueling stations have also been built in Germany and Iceland. 
Due to the limited standards for the construction of hydrogen refueling stations, fueling station designers must rely on existing compressed gas industry standards and portions of existing building codes, while working very closely with local building inspection and safety departments as well as engineering experts with hydrogen experience. The viability of hydrogen as a transportation fuel depends on the speed and ease of working with local building inspectors, and on the costs associated with compliance to existing codes and standards governing fueling station construction.

\subsection{Siting the Fueling Station}

PNW and APS chose to construct the APS Alternative Fuel Pilot Plant in an urban setting to determine the full impact of existing codes and standards as well as building inspector requirements on station design and on the siting process. This approach is unique to fueling station design in the United States and provides unique insight into the requirements for hydrogen fueling stations to be constructed and operated in commercial, rather than industrial, areas.

\subsubsection{Site Description}

The APS Alternative Fuel Pilot Plant is located in downtown Phoenix, Arizona at 403 South 2nd Avenue. The facility is bordered on the west by 2nd Avenue (a City of Phoenix street) and an area zoned for commercial use, as shown in Figure 1.1. On the south and east, the facility is bordered by an active APS service yard. Meter readers and service men supporting APS electric distribution in the downtown Phoenix area use the yard. Figure 1.2 shows the eastern side of the facility, including the fuel dispensing station. The facility shares a building structure with the offices of Electric Transportation Applications, which is located immediately north. This building was constructed in the early 1900 s and functioned to support lamp gas production from coal for use in streetlights located in downtown Phoenix. The portion of the building housing the APS Alternative Fuel Pilot Plant is constructed of unfired clay brick. The building is open on the east side, with a roof of sheet metal panels.

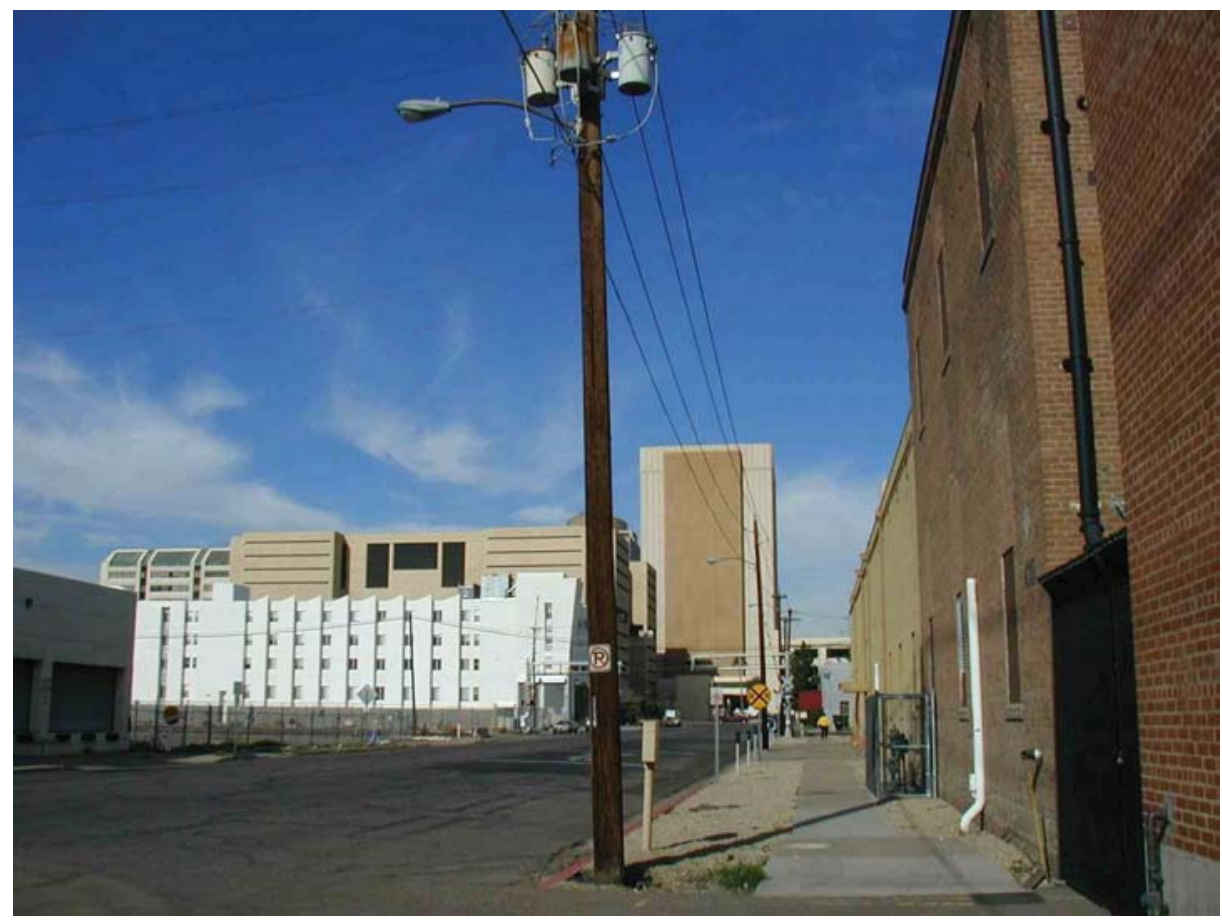

Figure 1.1. West Side of the APS Alternative Fuel Pilot Plant. 


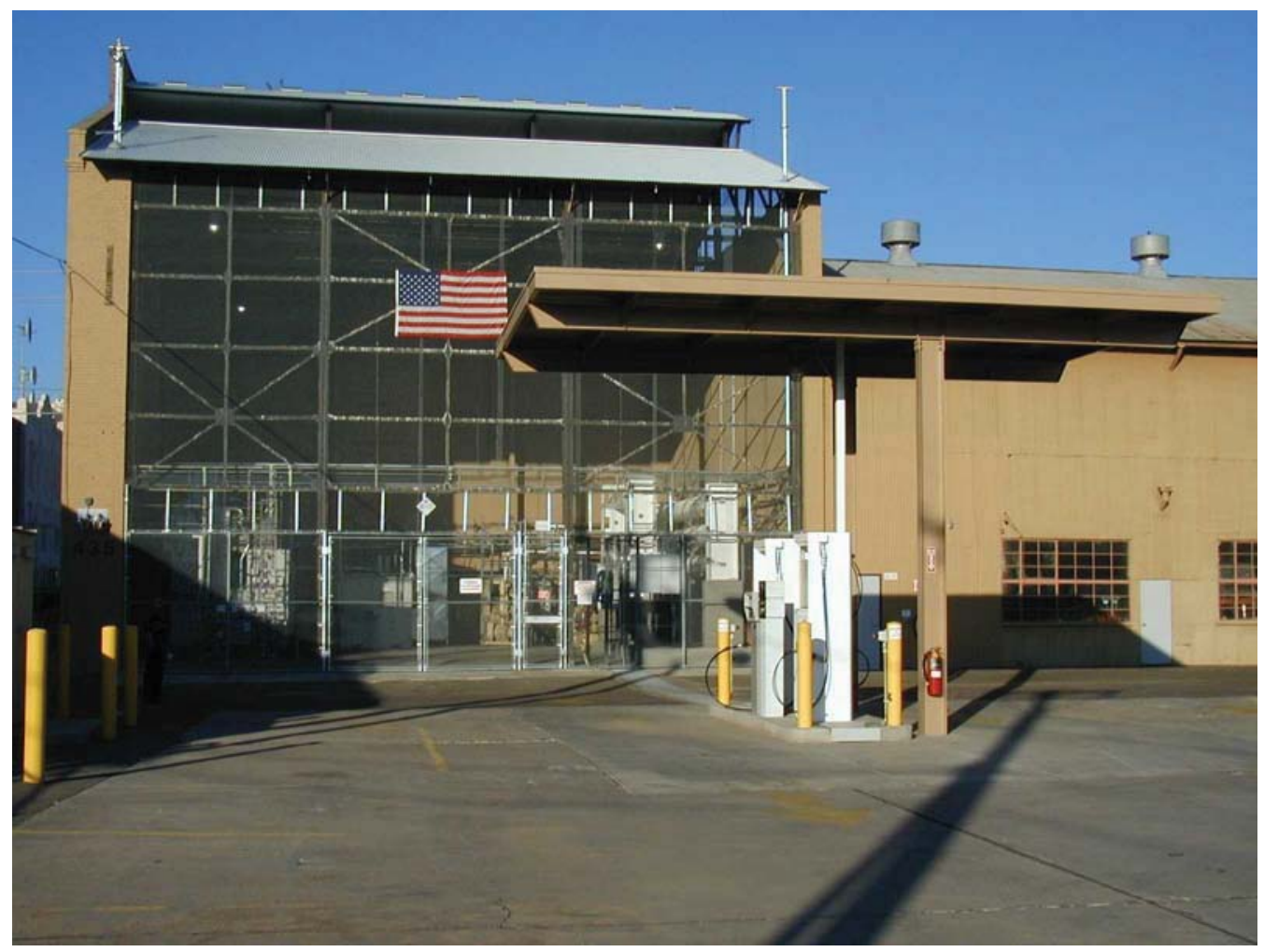

Figure 1.2. East Side of the APS Alternative Fuel Pilot Plant.

\subsubsection{Siting Process}

The process of siting the APS Alternative Fuel Pilot Plant began by conducting an occupancy review to determine zoning requirements that would impact design. This review also included analysis of applicable compressed gas standards, to determine the design requirements. Because the facility was to be located within an existing building, particular attention was given to requirements for indoor facilities. Numerous conflicts between code requirements and station objectives were revealed. In particular, requirements for setbacks between hydrogen and natural gas fuels, and between fuel storage equipment and occupied structures would, if followed, make construction of the APS Alternative fuel Pilot Plant on the site impossible. In addition, using the standards governing natural gas installations, the site was considered an outdoor facility (only 3 walls). However, using the standards governing hydrogen installations, the site was considered an indoor facility. Using the worst-case scenario (indoor facility), analyses were performed to determine if setback requirements could be eliminated and both hydrogen and compressed natural gas $(\mathrm{CNG})$ processes co-located on the site and within the existing building.

The analyses consisted of plume modeling for leaks of various sizes to determine the maximum plume volume. Analyses were then conducted to determine the effects of both deflagration and detonation of the worst-case plume. The analyses showed that with minor reinforcement (surface mounted I-beams, as shown in Figure 1.3) and blow-off roof panels, the existing building would withstand the effects of a detonation of the worst-case plume. These analyses and the design for building reinforcement were reviewed with the chief fire inspector for the City of Phoenix and Dr. Robert Zalosh, consultant to the City of Phoenix and Factory Mutual on the effects of flammable gas detonations. After several rounds of questions on both the analyses and the facility design, the City of Phoenix approved the facility design, as presented in Sections 2, Hydrogen System; 3, Compressed Natural Gas System; and 4, Fuel Dispensing, of this report by issuing a construction permit for the APS Alternative Fuel Pilot Plant. 


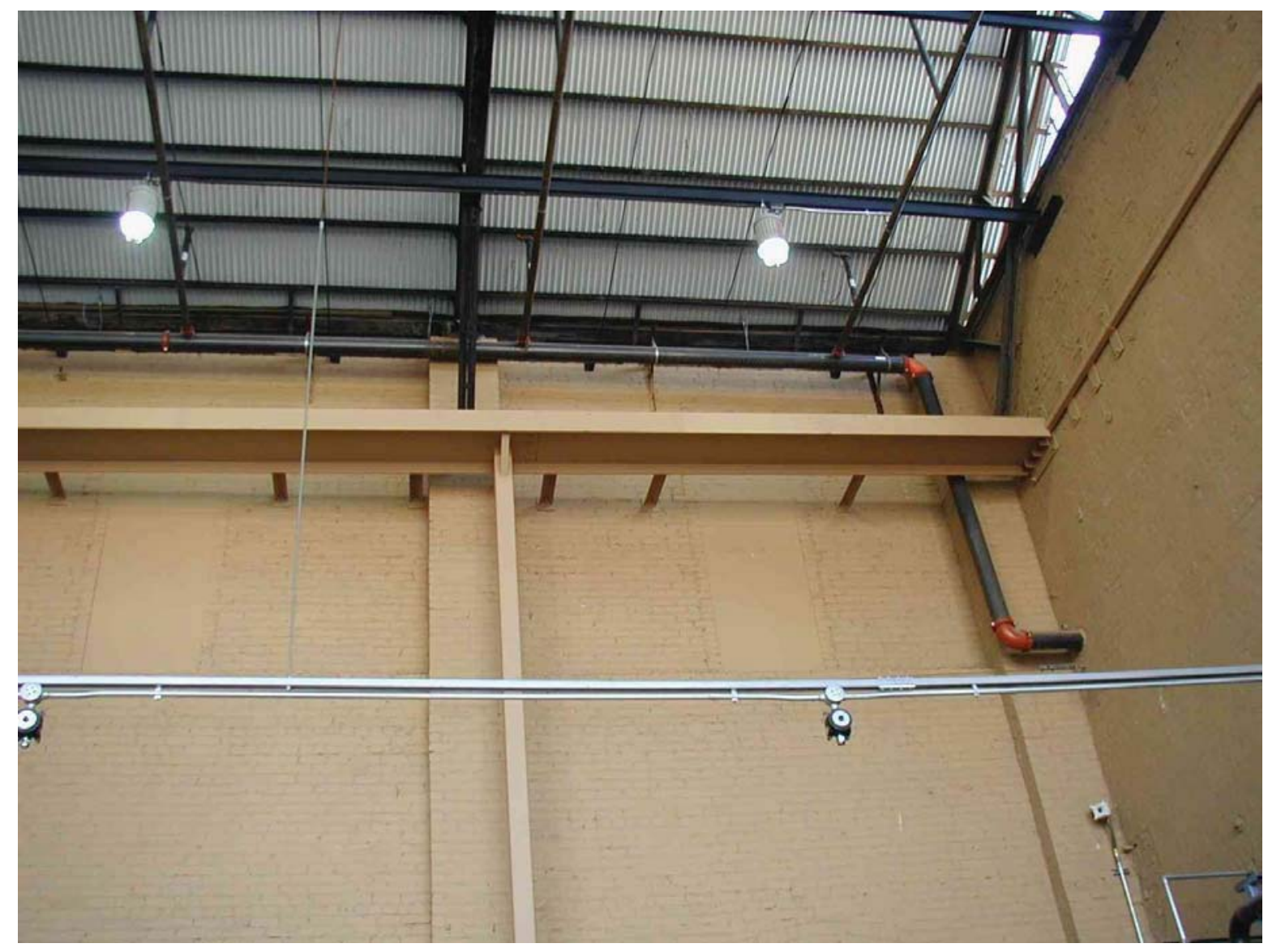

Figure 1.3. Building Reinforcement.

\subsubsection{Permits}

PNW and APS constructed the APS Alternative Fuel Pilot Plant under the close scrutiny and formal inspection of the City of Phoenix. Inspections were performed and releases issued for electrical, plumbing, structural, and piping systems. Inspections were typically performed on facility subsystems, and a final system release was awarded after construction completion. Upon overall facility completion, the City of Phoenix issued permits for both compressed gas storage and motor vehicle fueling.

\subsection{Fueling Station Design}

The APS Alternative Fuel Pilot Plant is a model alternative fuel refueling system, consisting of hydrogen, compressed natural gas (CNG), and CNG/hydrogen blends. Figure 1.2 shows the plant in plan view. The plant distinctly separates the hydrogen system from the natural gas system, but can blend the two fuels at the stationary filling system. Section 2 focuses on the hydrogen portion of the plant. Section 3 focuses on the natural gas portion of the plant, which is similar in various ways.

The plant's hydrogen system consists of production, compression, storage, and dispensing. The hydrogen produced is suitable for use in fuel cell-powered electric vehicles, for which the minimum hydrogen purity goal is $99.999 \%$, and the upper limit of purity is $99.99999 \%$. To obtain these purity levels, the facility uses two methods of production. One method takes advantage of the centralized manufacturing of hydrogen. The other method uses an electrolysis process that separates water into hydrogen and oxygen. At present, the hydrogen is compressed and stored at a maximum operating 
working pressure of 5,800 psi. The facility has over 17,000 scf of high-pressure storage capacity. The stationary filling system can dispense hydrogen at various pressures, up to the 5,800 psi maximum.

In addition to producing hydrogen, the plant also compresses natural gas for use as a motor fuel. CNG vehicles typically require 3,600 psi storage tanks. However, to fill vehicle onboard tanks, storage pressures must be higher. The APS system compresses natural gas to pressures up to 5,000 psi, using a three-stage cascade pressure arrangement. 


\section{HYDROGEN SYSTEM}

\subsection{Design Criteria}

The hydrogen system has six primary functions: water purification, production, compression, storage, dispensing, and venting. Hydrogen is produced from high-purity water using electrolysis, which is compressed up to $5800 \mathrm{psi}$ and stored in high-pressure-rated vessels. The high-pressure vessels supply the hydrogen to an automated refueling location where it is conveniently dispensed. Figure A-3 of Appendix A presents a plan view of the equipment locations for the hydrogen system. Figure A-2 presents a three-dimensional view of the hydrogen system components.

The electrolysis production process is a crucial element of the facility (see Section 2.3). Appendix B contains a Material Safety Data Sheet for hydrogen. The electrolysis equipment used at the facility is a HOGEN 300, manufactured by Proton Energy Systems. It produces 300 scf of hydrogen per hour at $150 \mathrm{psi}$, using high-purity water. The water purification process is one of the primary functions of the facility and significantly influences the purity level of the hydrogen within the system (see Section 2.2). The output of the electrolysis equipment is directed to the low-pressure storage vessel (see Section 2.5), which has a storage capacity of $8,955 \mathrm{scf}$ of hydrogen. This vessel provides capacity when the hydrogen generator is not operating.

The pressure rating of the hydrogen generator and the low-pressure storage vessel is $150 \mathrm{psi}$. In order to provide the desirable dispensing pressures, a three-stage diaphragm compressor is used (see Section 2.6). The compressor is capable of compressing the hydrogen up to $6,000 \mathrm{psi}$ at a rate of 300 $\mathrm{scfh}$. At present, the high-pressure hydrogen system is regulated to 5,800 psi. The normal pipeline from the compressor output fills two high-pressure storage vessels (see Section 2.7). These vessels have a combined storage capacity of 17,386 scf and provide hydrogen for dispensing. The other pipeline from the compressor output provides hydrogen directly to the dispensers.

The capacities of all the storage vessels, the rate of hydrogen production, and the rate of compression can all be coordinated to achieve the required refueling demand. Though only a small mass of hydrogen is produced daily, the system offers model opportunity to evaluate system reliability, cost, and safety, and is a source of fuel for both fuel-cell and combustion engine testing.

The hydrogen system is a completely sealed, closed system. Specifications for hydrogen piping are presented in Appendix C. Proper piping design ensures that hydrogen is not inadvertently released. However, should a hydrogen leak occur, hydrogen gas detectors will signal an alarm and isolate the hydrogen system (see Section 2.9) with automatic shutdown of power to operating equipment (but control power, monitoring systems, and communication system remain energized).

Any venting or draining of the system is to the vent stack, where hydrogen is released above the roofline of the gas building (see Section 2.11). Design of the system eliminates any direct human contact with hydrogen. A helium purge is available to inert the vent stack (see Section 2.16). To quench fires in hydrogen vents is standard practice in the industry.

A nitrogen purge is used as an intermediary in any event that requires opening of the hydrogen system (see Section 2.10). Nitrogen purge points have been strategically designed into the system to adequately provide for safe operation and maintenance measures.

Because hydrogen fires are invisible, the entire equipment room containing the hydrogen system (see Appendix A, Figure A-3) is a controlled area, accessible only to those who are trained and certified to work around hydrogen systems. Arizona Public Service safety programs and procedures, defined in the 
APS Safety Manual, have been applied to the pilot plant. Training programs prepared for the APS Alternative Fuel Pilot Plant are presented in Appendix D.

The gas building is continuously scanned for infrared and ultraviolet radiation, both typical signatures of a hydrogen flame (see Section 2.17). Combustible gas monitors are also used to monitor for hydrogen in the work area (see Section 2.17). These monitors will alarm at $25 \%$ LFL (lower flammability limit) of hydrogen. Equipment has been well grounded to eliminate static electricity as an ignition source (see Section 2.14). Hydrogen, unlike most fluids, does not build up a static charge when flowing; however, particles flowing in the hydrogen stream can create adequate energy to ignite the hydrogen if sufficient oxygen is present.

The EMS (emergency shutdown system) enables complete system shutdown, automatically or manually initiated (see Section 2.9). EMS alarm and annunciation visually and audibly indicate that the EMS has been initiated. If the hydrogen system isolation is breached, as detected by IR (infra-red) and UV (ultraviolet) scanners, gas detectors, or human intervention, the second contingency of isolation is automatically initiated by isolating all hydrogen storage, hydrogen production, and hydrogen dispensing; and by shutting off the power supply to the HOGEN 300 generator, dryer, and compressor.

Under the City of Phoenix ordinances, production of hydrogen gas must be performed in an area zoned A1, whereas retail sale of hydrogen gas can be in areas zoned C3. National Fire Protection Code (NFPA) 50A presents standards for constructing a hydrogen storage facility, but the code does not apply to hydrogen production facilities, per NFPA 50A, 1-3.3. The hydrogen production, compression, and storage equipment is physically located within the gas equipment building, while the water purification equipment, cooling equipment, nitrogen equipment, air compressor, and electrical panels are located in an adjacent room. The hydrogen electrical system within the gas building is engineered as Class 1, Division 2 , in accordance with NFPA 70. Storage of hydrogen and related piping/tubing is in accordance with ASME Code B31.3.

Table 2.1 presents the specifications of the hydrogen production and storage system.

Table 2.1. Hydrogen production and storage.

\begin{tabular}{lll} 
Compressor: power & $5 \mathrm{hp}, 480 \mathrm{~V}, 3 \mathrm{ph}$ & \\
DI Water: consumption & $1.7 \mathrm{gal} / \mathrm{hr}$ & $30 \mathrm{psi}$ \\
Dryer: power & $0.5 \mathrm{kVA}, 120 \mathrm{~V}$ & \\
Effluent: DI water unit & DI water & \\
Effluent: dryer & hydrogen, DI water & \\
Effluent: HOGEN drains, vents, & DI water, oxygen & \\
HOGEN: chilled-water flow & $72 \mathrm{gal} / \mathrm{hr}$ (supply) & $72 \mathrm{gal} / \mathrm{hr}$ (return) \\
HOGEN: daily hydrogen production & $7,200 \mathrm{scf} /$ day & $37.3 \mathrm{lb} / \mathrm{day}$ \\
HOGEN: hourly hydrogen production & $300 \mathrm{scfh}$ & $1.55 \mathrm{lb} / \mathrm{hr}$ \\
HOGEN: make-up Air & $1200 \mathrm{cfm}$ air & \\
HOGEN: power & $57 \mathrm{~kW}$ & $480 \mathrm{volt}$ \\
Instrument air & $90 \mathrm{psi}$ maximum & \\
Purge: nitrogen & $130 \mathrm{psi}$ maximum & \\
Storage: high pressure (6,000 psi) & $17,386 \mathrm{scf}$ & $90.1 \mathrm{lb}$ \\
Storage: low pressure $(150 \mathrm{psi})$ & $8,955 \mathrm{scf}$ & $46.4 \mathrm{lb}$ \\
Storage: total hydrogen storage & $26,341 \mathrm{scf}$ & $136.4 \mathrm{lb}$ \\
Storage: energy release potential & $8,560.5 \mathrm{MBTU}$ & $2,508.4 \mathrm{kWh}$ \\
\hline
\end{tabular}




\subsection{Water Purification}

Potable water is supplied from a Phoenix street potable water supply (30 psi) to a water treatment system designed and manufactured by CIW Services, Inc. The CIW system has a 5- $\mu$ filter, carbon filter, stainless steel pump, reverse osmosis bank, 34-gal storage tank, mixed-bed demineralizer, and a 1.0- $\mu$ exit filter specifically built to accommodate Phoenix water. The maximum system flow rate is 215 gal/day.

The CIW system has two effluent lines: one 1" line from the RO (reverse osmosis) unit, and a second $3 / 4$ " line from the storage tank bleed.

Deionized (DI) water flows to the drain until the minimum quality level is reached, as determined by an analyzer; about 30 gallons of DI water are consumed during startup. Once the water quality threshold has been achieved, the water drain-valve closes, and the supply to the HOGEN opens. During HOGEN shutdown, about 10 gal of DI water is discharged to the drain. A secondary DI water-polishing unit inside the HOGEN further purifies the water and provides backup to the primary DI water system.

\subsection{Hydrogen Production}

The HOGEN 300 is a proton exchange membrane-based system that produces hydrogen by electrolysis (Figure 2-1). It is similar to that used by the U.S. Navy in submarines. Hydrogen purity is between $99.999 \%$ and $99.99999 \%$. The HOGEN uses electric potential across its membrane stack to produce a maximum pressure of $150 \mathrm{psi}$. Small increases in voltage will produce significant increases in pressure. Future systems may reach pressures of 2,000 psi. The HOGEN 300 was built following NFPA standards 496, 50A, and 70 and complies with NEMA 4. It is a one-of-a-kind unit, previously operated, continuously, at the STAR (Solar Test and Research) facility in Tempe, Arizona for 24 months without incident.

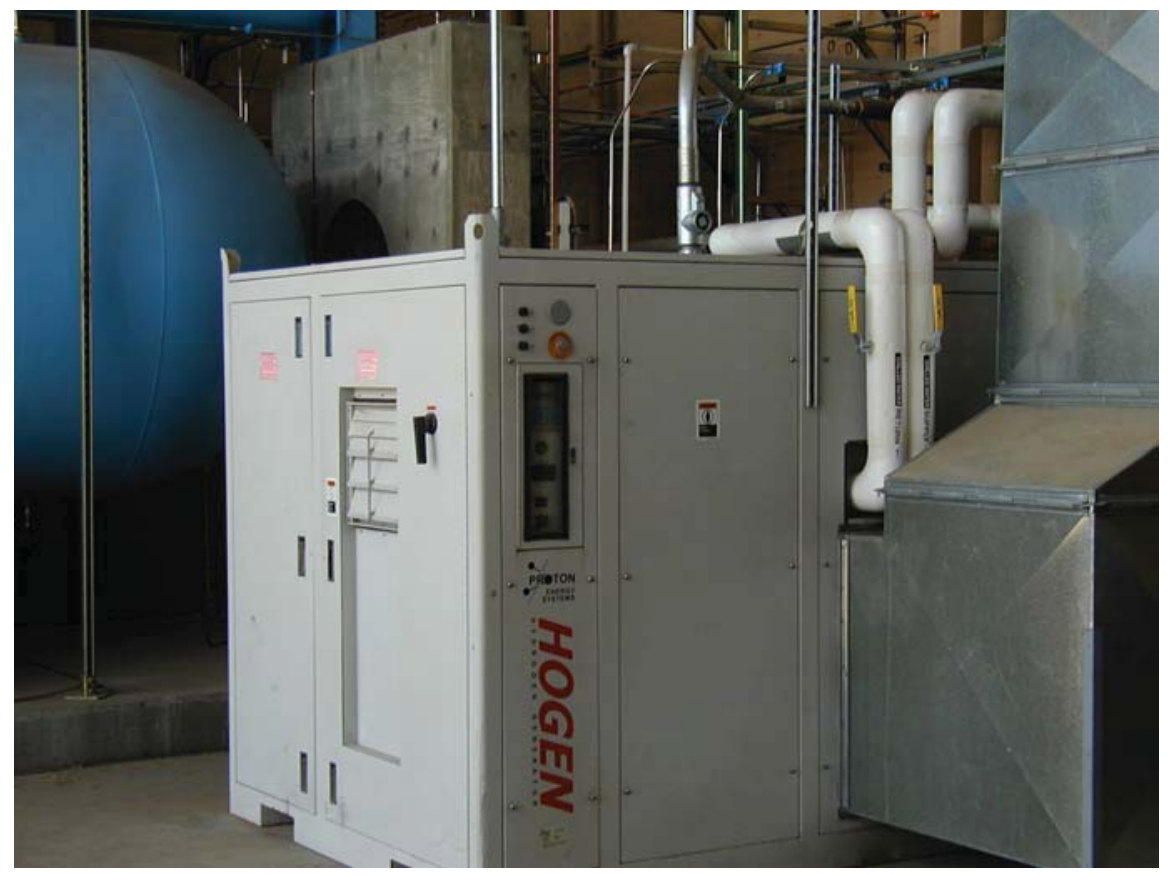

Figure 2-1. HOGEN 300 proton exchange system.

The HOGEN 300 is self-contained and weather proof, complete with control systems, polishers, dryer, and combustibles detector, located inside the gas building. In order to conform to NEC requirements, the unit uses the purge-and-pressurize technique to be acceptable in hazardous locations. 
This requires a fresh air purge (from an unclassified area) at the rate of 1,200 scfm. The HOGEN 300 requires a chilled-water cooling system. This system provides cooling to the power electronics in the hydrogen generator. The chilled-water system is a separate unit located outside of the gas building. This closed-loop system has maximum potential to circulate at a rate of $72 \mathrm{gal} / \mathrm{hr}$. A nitrogen purge port is incorporated into the HOGEN (there is no manufacturer's requirement to use the nitrogen purge for maintenance). The HOGEN needs $57 \mathrm{~kW}$ of electricity from a 480-V, 150-A, 3-phase supply, and ground. The electric installation is installed above ground and complies with NFPA 70. Communications allow remote system monitoring, with alarms and emergency shutdown. Table 2.2 describes the interfacing of all support systems for the HOGEN 300.

Table 2.2. HOGEN 300 systems interfacing.

\begin{tabular}{ll}
\hline \multicolumn{1}{c}{ Element } & \multicolumn{1}{c}{ Required support } \\
\hline Combustible gas mixture detector & Master system alarm \\
Condensate drain & Blow-down tank and vent system \\
Control air & $5 \mathrm{scf}$ daily, 90-psi max pressure, clean dry air \\
Data line & Modem accessible \\
Electric power & $57 \mathrm{~kW}$ (480 V, 150 A) \\
Electrical grounding & NFPA 70 \\
Hydrogen vent (startup) & To vent stack \\
Local shutdown & Master system alarm \\
Oxygen vent & 0.5 in. to building roof, min $25 \mathrm{ft}$ from $\mathrm{H}_{2}$ vent \\
Power electronics cooling & Chiller outside of gas building \\
Purge air & 1,200 scfm, clean outside air \\
Purge nitrogen & 0.5 in. manually activated \\
Remote shutdown & Emergency shutdown system and alarm \\
\hline
\end{tabular}

The hydrogen production rate is $300 \mathrm{scfh}$ at $150 \mathrm{psi}\left(8 \mathrm{NM}^{3} / \mathrm{hr}, 10 \mathrm{bars}, 1.56 \mathrm{lb} / \mathrm{hr}\right)$. The HOGEN requires DI water conductivity better than $1-\mu$ siemen (1M $\Omega-\mathrm{cm}$ resistivity) and preferably better than $0.1-\mu \mathrm{S}(10 \mathrm{M} \Omega-\mathrm{cm})$. Water consumption is $1.7 \mathrm{gal} / \mathrm{hr}$ (or $6.4 \mathrm{l} / \mathrm{hr}$ ) at an average supply pressure of 15 to 60 psi. During startup, hydrogen is initially vented to the vent stack until the quality level is achieved, upon which venting terminates. In normal operation, there is no leakage or venting of hydrogen gas. Oxygen is a byproduct of the HOGEN operation. Oxygen is vented to the outside in a separate vent stack at atmospheric pressure ( $150 \mathrm{scfh}, 12.4 \mathrm{lb} / \mathrm{hr}$ ) from a 0.5 -in. connection on the HOGEN unit, through the gas-building roof. The HOGEN comes prepackaged with its own propriety control system.

\subsection{Dryer and Filters}

Hydrogen produced by the HOGEN 300 contains water. Although water contamination is not a problem for the storage vessels or fuel cells, it reduces the efficiency of the compressor and can result in excess maintenance of the compressor. Since the hydrogen must be compressed, water must be removed. The Lectrodryer, a hydrogen dryer, yields hydrogen with a $-80^{\circ} \mathrm{F}$ dew point. The drain, vent, and safety valves of the dryer are piped to the hydrogen vent system. Isolation of the dryer from the rest of the hydrogen system is accomplished with manual isolation valves.

The Lectrodryer (Figure 2.2) is powered by a $120-\mathrm{V}$ source. The electrical control panel enclosure is a NEMA 4x enclosure. To meet the requirements of Class 1, Division 2, Group B, of the National 
Electrical Code, the enclosure uses purged nitrogen as a hazardous-location protection technique. Features of the dryer include electric reactivation heaters, thermostatic over-temperature protection, nonlubricated transflow valves, dial thermometer in the reactivation exhaust piping, and reactivation indicator lights.

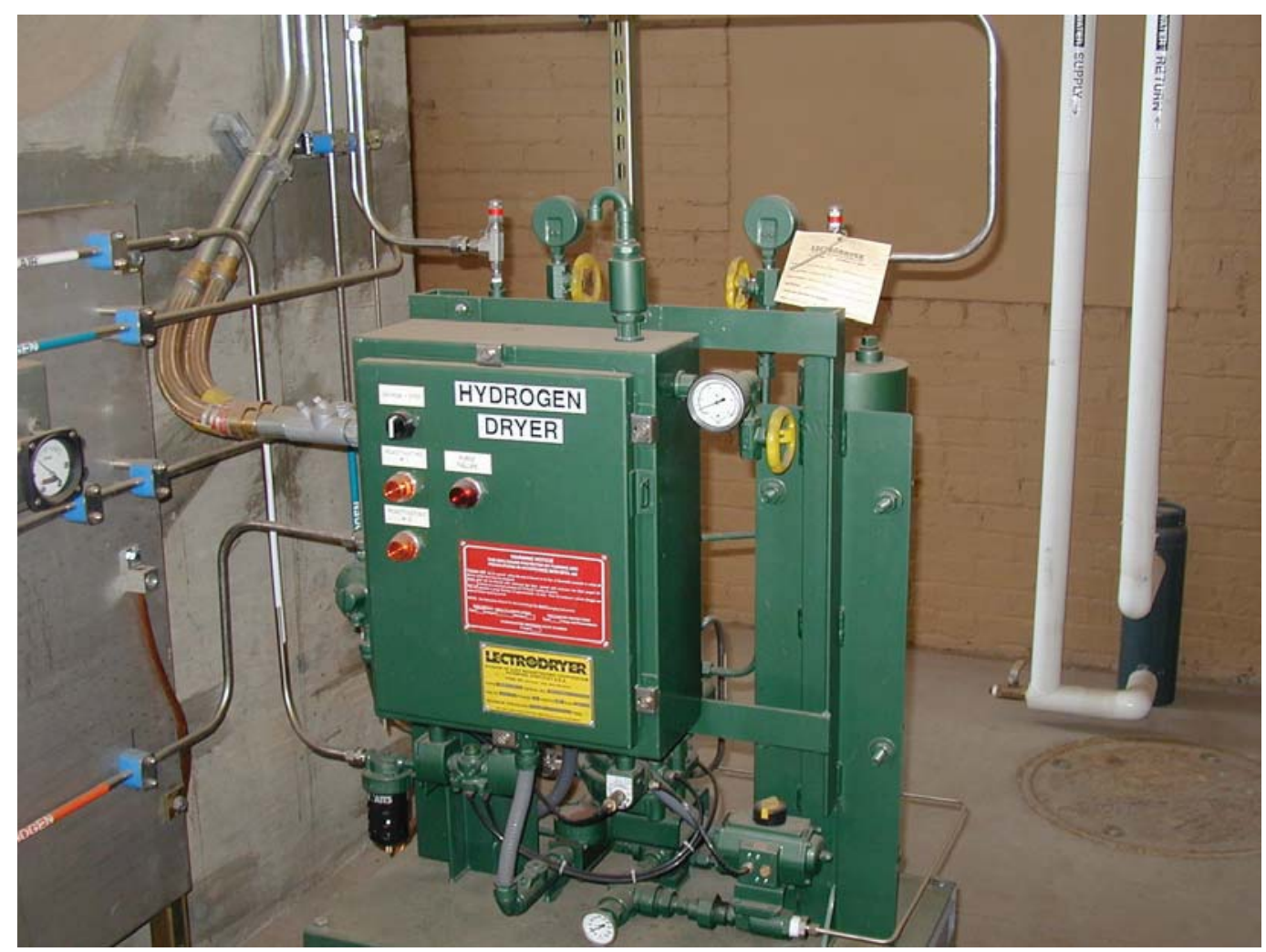

Figure 2.2. Lectrodryer hydrogen dryer.

Hydrogen purity is controlled by the water quality entering the HOGEN unit and by removal of contamination particles (microscopic) from the interior surface of the gas system piping/equipment in contract with the gas stream. A coalescing filter, described in Table 2.3, is installed at the inlet to the dryer. Particulate filters, described in Table 2.3, are installed at outlets of the LPS (low-pressure storage), hydrogen compressor, HPS (high-pressure storage), and dryer. Filters have visual differential pressure indicators. Filters have isolation valves, nitrogen purge, and vents for maintenance.

Table 2.3. High-pressure hydrogen filters.

\begin{tabular}{llllll}
\hline \multicolumn{1}{c}{ Filter } & Dryer Outlet & \multicolumn{1}{c}{ HPS Outlet } & \multicolumn{1}{c}{ LPS Outlet } & \multicolumn{1}{c}{ Oompressor } \\
Tag no. & F-102 & F-401 & F-103 & F201 & F-101 \\
Size & 0.5 in. & 0.5 in. & 0.5 in. & 0.5 -in. & 0.5 in. \\
Port size \& type & 0.5 -in. FPT & 0.5 -in. FPT & 0.5 -in. FPT & 0.5 -in. FPT & 0.5 -in. FPT \\
Design flow & $12,000 \mathrm{scfh}$ & $400 \mathrm{scfh}$ & $12,000 \mathrm{scfh}$ & $400 \mathrm{scfh}$ & $400 \mathrm{scfh}$ \\
Design pressure & $6,000 \mathrm{psi}$ & $6,000 \mathrm{psi}$ & $6,000 \mathrm{psi}$ & $6,000 \mathrm{psi}$ & $6,000 \mathrm{psi}$ \\
Type & Particulate & Particulate & Particulate & Particulate & Coalescing \\
Vendor & Norman & Norman & Norman & Norman & Norman
\end{tabular}




\begin{tabular}{llllll} 
Model & Tee Type 535 & Tee Type 535 & Tee Type 535 & Tee Type 535 & In-line 4200 Series \\
Part No. & 4535TP. & 4535TP. & 4535GP. & 453GP. & 42.5T-4PP \\
& 5ABSFNV & 5ABSFNV & 5ABSFNV & 5ABSFNV & \\
MAWP & $6,000 \mathrm{psi}$ & $6,000 \mathrm{psi}$ & $6,000 \mathrm{psi}$ & $6,000 \mathrm{psi}$ & $6,000 \mathrm{psi}$ \\
Burst pressure & $24,000 \mathrm{psi}$ & $24,000 \mathrm{psi}$ & $24,000 \mathrm{psi}$ & $24,000 \mathrm{psi}$ & $24,000 \mathrm{psi}$ \\
Filter rating & $0.5-\mu \mathrm{m}$, & $0.5-\mu \mathrm{m}$, & $0.5-\mu \mathrm{m}$, & $0.5-\mu \mathrm{m}$, & $0.5-\mu \mathrm{m}$, \\
& sintered 316 SS & sintered 316 SS & sintered 316 SS & sintered 316 SS & sintered 316 SS \\
Temp. rating & $800^{\circ} \mathrm{F}$ & $800^{\circ} \mathrm{F}$ & $800^{\circ} \mathrm{F}$ & $800^{\circ} \mathrm{F}$ & $800^{\circ} \mathrm{F}$ \\
Body material & $316 \mathrm{SS}$ & $316 \mathrm{SS}$ & $303 \mathrm{SS}$ & $303 \mathrm{SS}$ & $304 \mathrm{SS}$ \\
Seal material & Viton & Viton & Viton & Viton & Viton \\
\hline
\end{tabular}

\subsection{Low-Pressure Storage}

The low-pressure storage (LPS) receives hydrogen from the HOGEN. It is a horizontal carbon steel cylindrical vessel measuring $6 \mathrm{ft} 11 \mathrm{in}$. inside diameter, $19 \mathrm{ft}$. long. The LPS vessel has a water volume of 6,565 gal. The LPS (Figure 2.3) was manufactured under the ASME Pressure Vessel Code, Section VIII, Division 22, and is rated for 250-psi maximum pressure at $125^{\circ} \mathrm{F}$. Appendix B presents Form UA1, certifying compliance with the ASME Code (serial number 123982).

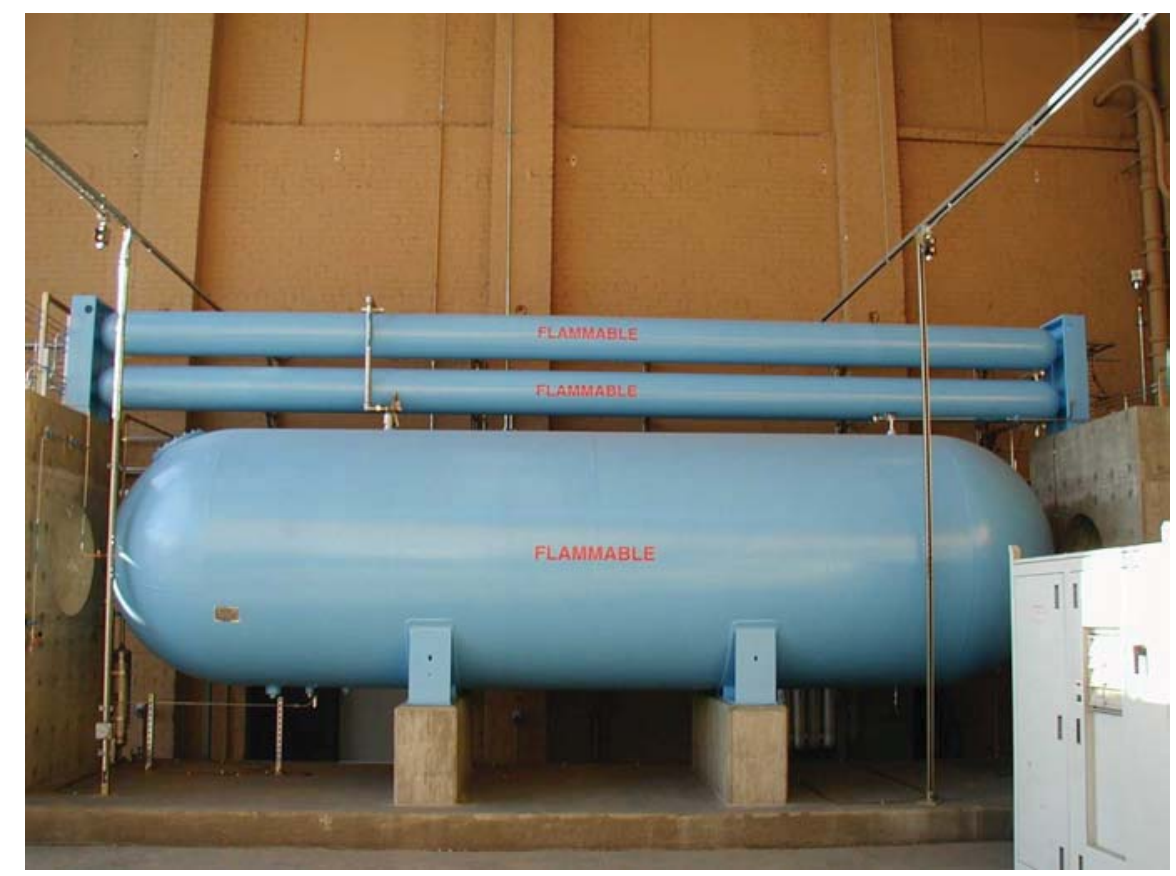

Figure 2.3. Hydrogen low-pressure storage vessel is the large tank on the bottom and the two highpressure storage vessels are on top.

The vessel is protected against over pressurization by an ASME relief valve. Discharge from this valve is piped to the hydrogen vent stack. Hydrogen exits from the LFP to the hydrogen compressor.

The LPS receives dried 150-psi hydrogen gas from the HOGEN 300. About $46.4 \mathrm{lb}$ or 8,955 scf of hydrogen can be contained in the LPS. The safety relief valve mounted on the LPS relieves pressure at 165 psi. Relief vents are piped to the vent stack. The LPS has powered isolation valves installed up- and downstream to permit full isolation of the LPS. These isolation valves can be activated manually or 
automatically by the EMS. Isolation of the LPS includes an activated ball valve (electrically operated) and a manual valve (open in normal operation). The LPS also has two vents: (1) a power-operated vent that discharges to the vent stack and (2) a manually actuated vent for purity control, which has also been piped to the vent stack. A manual drain for water at the low point of the LPS has been piped to the blowdown vent. The LPS is connected to the nitrogen purge system. The nitrogen purge includes isolation valves and check valves to eliminate back flow of hydrogen.

Pressure on the LPS is monitored with a pressure indicator gauge, pressure switch, and with a pressure transmitter for recording data. Should LPS system pressure exceed 165 psi, the HOGEN will ramp down to $130 \mathrm{psi}$, and then shut down, followed by an alarm. Should the LPS pressure be low, an alarm will be initiated, and the hydrogen compressor will shut down if compressing hydrogen. The moisture level in the gas delivered to the LPS is monitored using a dew point meter.

The LPS is electrically grounded. It is labeled with the fire diamond symbol for hydrogen (blue 0 , red 4, yellow 0) and is visible from the building access. In the event of activation of the EMS, the LPS isolation valves will close. After resolving the conditions causing initiation of the EMS, the EMS will be reset, and the LPS isolation valves can be opened and HOGEN production resumed. If for some reason the LPS requires hydrogen dumping, the power vent can be opened and hydrogen will be released to the vent stack. If operation cannot resume, the nitrogen purge system will be activated after the hydrogen is released to vent, and the LPS will be filled with nitrogen.

\subsection{Hydrogen Compressor}

In the high-pressure system, a Pdc Machines, Inc. diaphragm compressor (Figure 2.4) with three stainless steel diaphragms raises the gas pressure to 6,000 psi (Table 2.4). The compressor motor and supporting electrical equipment have been designed to be rated Class 1, Division 2, Group B. The motor is of TEFC design.

The compressor control package monitors discharge pressure, temperature, and motor current. Pressure indicators are installed on the compressor suction, discharge, and DI water supply. The compressor has isolation valves, vents, and nitrogen purge. A discharge filter assembly includes a differential pressure monitor and indicator.

High and low discharge pressure switches are preset. The compressor package includes a leak detecting system that will detect leakage through the diaphragms and signal an alarm and will shut down the compressor. 


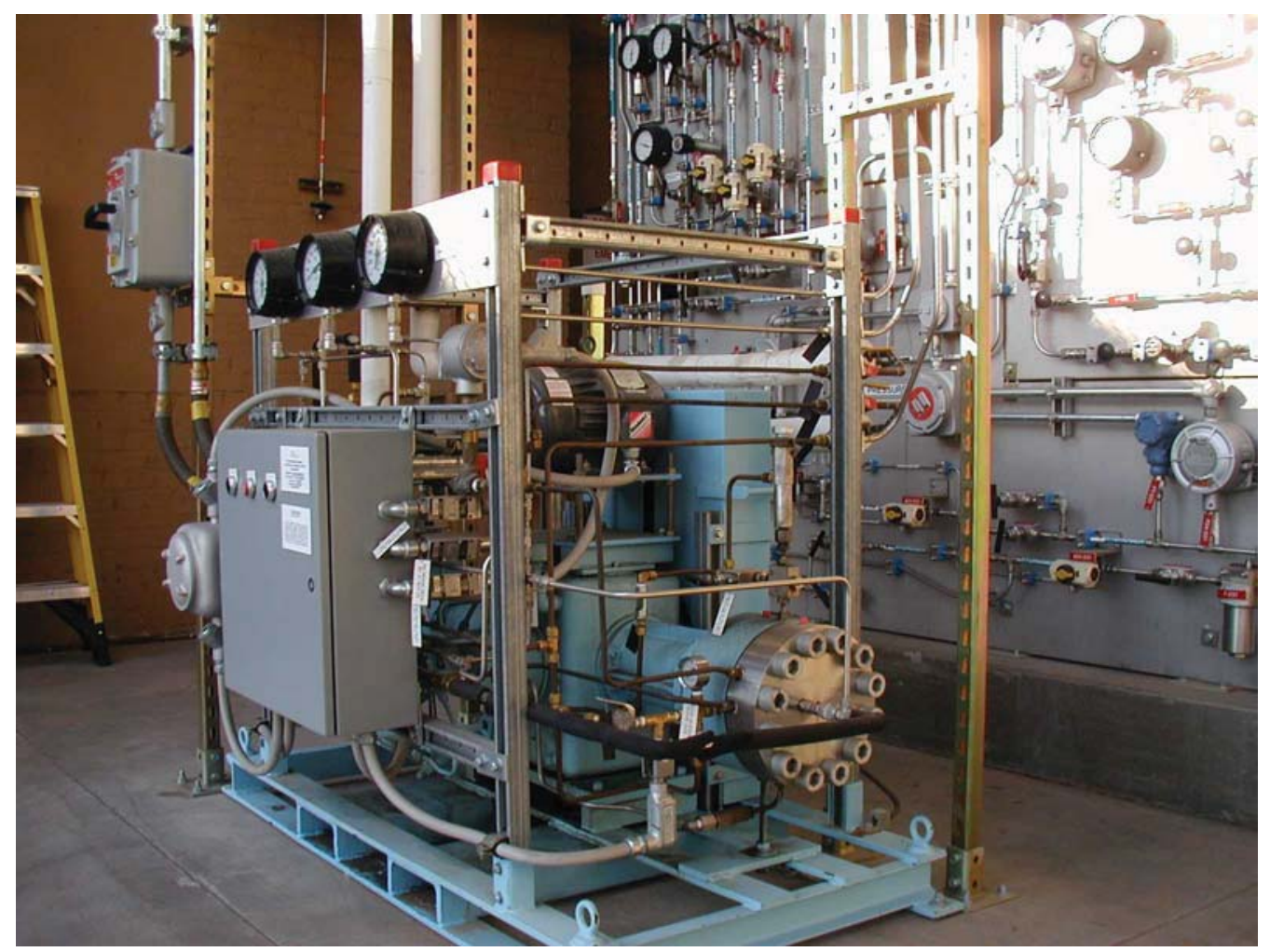

Figure 2.4. Pdc Machines, Inc. diaphragm hydrogen compressor.

Table 2.4. Hydrogen compressor.

\begin{tabular}{ll}
\hline Model & Pdc-4 \\
Motor & $5 \mathrm{hp}$ \\
Volts & 480 \\
Amperes & 10 \\
Phase & 3 \\
Hazardous class & Class I, Division 2, Group B \\
Inlet pressure range & $100-150$ psi, 200-psi max. \\
Output pressure & 6,000 psi \\
Capacity, hydrogen & $300 \mathrm{scfh}$ \\
\hline
\end{tabular}

\subsection{Hydrogen High-Pressure Storage}

Hydrogen high-pressure storage (HPS) is provided in two high-pressure seamless carbon-steel horizontal storage vessels (Figure 2.3) manufactured under 1998 ASME Code, Section VIII, Division 1, Addendum 1999, Appendix 22 (SF3). Appendix B presents Form UA-1, certifying compliance with the ASME Code (serial numbers 46705 and 46708).

The vessels are $28.0 \mathrm{ft}$ long, $16 \mathrm{in}$. outside diameter, and weigh 6,670 lb each. The design pressure is $6,667 \mathrm{psi}$ at $200^{\circ} \mathrm{F}$. The water volume storage per vessel is $27.1 \mathrm{cubic}$ feet, or 54.2 cubic feet total. The 
operating temperature range of the vessels is -20 to $200^{\circ} \mathrm{F}$. The vessel interiors were steam cleaned after being grit blasted to remove loose scale.

The HPS receives dry 6,000-psi hydrogen gas from the hydrogen compressor. About $90.1 \mathrm{lb}$, or $17,386 \mathrm{scf}$, of hydrogen can be contained in the HPS. A safety relief valve mounted to the HPS will relieve pressure at 6,667 psi. The relief valve discharge is piped to the vent stack. The HPS has powered isolation valves installed up- and downstream to permit full isolation of the HPS. These isolation valves can be activated manually or automatically by the EMS. The HPS also has two vents that are piped to the vent stack: (1) a solenoid-operated vent valve piped to the vent stack and (2) a manually operated vent valve for purity control. There is a manual water drain at the low point of the HPS, which is piped to the blow-down vent. The HPS is connected to the nitrogen purge system, which includes isolation and check valves to eliminate backflow of hydrogen.

Pressure on the HPS is monitored with a pressure indicator gauge and with a pressure transmitter for electronic data recording and control. Should the HPS system pressure exceed 6,200 psi, the system will alarm an early warning. If the pressure exceeds $6,300 \mathrm{psi}$, the EMS will shut down the entire hydrogen system and activate the high-pressure alarm.

The HPS is grounded electrically. The HPS is labeled using the fire diamond symbol for hydrogen (blue 0 , red 4, yellow 0) and is visible from the building access. In the event of activation of the EMS, the HPS isolation valves will close. After resolving the conditions causing the initiation of the EMS, the EMS will be reset and the HPS isolation valves can be opened. If for some reason the HPS requires dumping of hydrogen, the power vent can be opened and hydrogen will be released to the vent stack. If operation cannot resume, the nitrogen purge system will be activated after the hydrogen is released to vent, and the HPS will be filled with nitrogen.

There is a $0.5-\mu$ filter in the exit tubing from the HPS and an excess flow control valve and flow switch to detect excess flow, either of which can initiate shutdown of the HPS isolation valves. If tubing or hoses fail downstream of the HPS, the excess flow valve will automatically close. The filter and excess flow valve can be isolated for maintenance.

\subsection{Fuel Dispensing}

The APS Alternative Fuel Pilot Plant has two dual output dispensers (Figure 2.4) manufactured by Fueling Technologies, Inc. One of these units dispenses CNG only at each output. The other unit has a hydrogen output and a CNG/hydrogen blend output. Dispensers are more fully described in Section 4 of this report.

Appendix E presents hydrogen system and hydrogen dispenser operating procedures. 


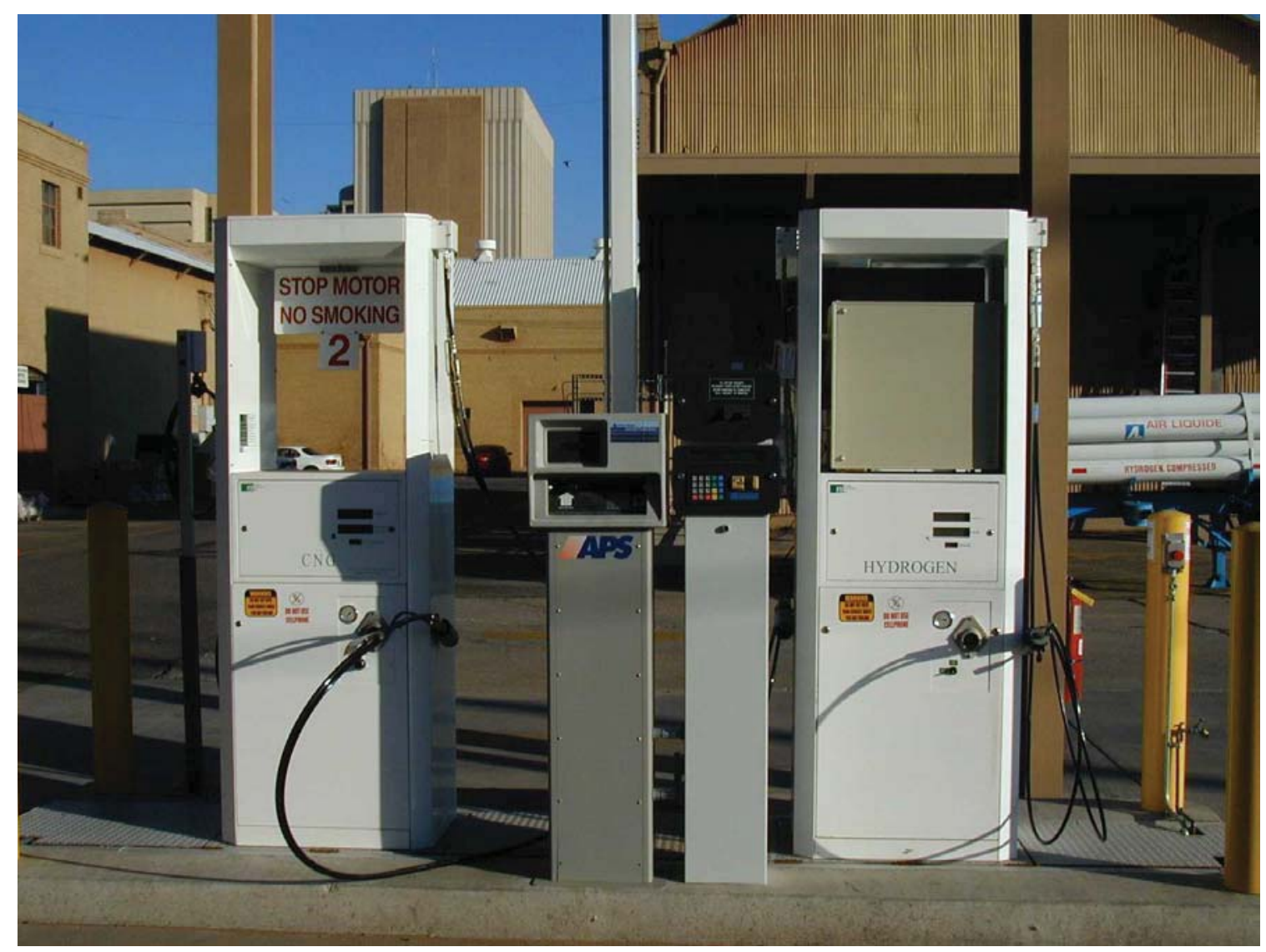

Figure 2.4. CNG only dispenser and hydrogen and CNG/hydrogen blend dispenser.

\subsection{Emergency Shutdown System - EMS}

The EMS is the second-level process control safety system, which reacts after the detected failure of the primary safety system. The primary safety system for hydrogen is isolation; the second level safety system is shutdown. The following components constitute the system.

- Ultra-fast IR/UV detectors

- Combustible gas detector

- Manual and remote trip

- Vent stack temperature monitor

- Alarms horns and strobe lights

- Calibration and testing of the system

- Vent stack fire suppression.

If a hydrogen event is detected or perceived to have occurred, the EMS will isolate sections of the system and de-energize all operating equipment, including the CNG compressor. Audible alarms and visual lights will notify personnel in the area that activation of the EMS has occurred. An alarm located at the PNW security station at the 502 Building will also indicate that an EMS activation has occurred. Activation of the EMS will be a failsafe action. 
A hydrogen event is defined as constituting any of the nine items listed below. Any one of the hydrogen events listed will result in activation of audible alarms, strobe lights, and a Security Station alarm. The EMS map will indicate which activation device authorized activation. The EMS will reset itself after a hydrogen event has cleared.

- Any of the four IR/UV scanners located in the process area testing positive

- The IR/UV scanner located at the fuel-dispensing island testing positive

- Manual activation from the fuel-dispensing island.

- Manual activation from the east side of the control building

- Manual activation from inside the control building

- High-pressure switch activated on the LPS vessel.

- High-pressure switch activated on the HPS vessels

- Flammable gas detects gas leak

- Loss of control of air pressure.

The EMS will activate warning strobe lights when in any of the following incidents:

- The combustible gas detectors detect $25 \%$ of LFL

- High temperature is detected on the vent stack.

- Incipient flame is detected.

The EMS will provide a process system alarm on any of the following conditions:

- Authorization by the vent stack thermocouple to activate helium purge into vent stack

- Activation of the excess flow switch

- Low-pressure switch activated on hydrogen compressor

- Failure of the hydrogen compressor to start

- Low-pressure on the vent stack helium system

- Compressor leak detected

- High pressure detected on LPS

- High pressure detected on HPS.

The EMS has a scanner lockout, which permits calibration of the IR/UV scanners without activating the EMS. Negative scan readings should occur within 5 minutes after activation of the EMS. The EMS alarms will be reset, and the system remains down until released for operation by the authorizing engineer. If the IR/UV scanners continue to scan positive after 5 minutes, the authorizing engineer will be contacted.

\subsection{Auxiliary Systems}

\subsubsection{Control Air}

The control air system consists of a 100-cfm air compressor, 500-scf storage vessel, and piping network. The control system provides clean dry 90-psi air for the hydrogen system.

\subsubsection{Chiller}

The dual-compressor closed-loop chiller provides $293,000 \mathrm{Btu} / \mathrm{h}$ (at $80^{\circ} \mathrm{F}$ ambient) cooling water to the HOGEN and Pdc compressor. The Drake model PACT240D unit requires 480 V, 3-phase power, and produces $12 \mathrm{hp}$ at a flow rate of $66 \mathrm{gpm}$. 


\subsubsection{Nitrogen}

Nitrogen is used as a buffer gas between the air and hydrogen. The nitrogen system consists of a production unit, compressor, storage tank, and piping network. Atmospheric air is processed by the nitrogen generator (PSA type system), which produces $97 \%$ purity nitrogen. Nitrogen is compressed to $100 \mathrm{psi}$ and stored in a 600 -scf vessel. A piping network distributes nitrogen to purge locations on the hydrogen system.

\subsubsection{Vacuum}

During a startup of the hydrogen system, it is necessary to attain the required hydrogen purity, which consumes a minimum duration of time and hydrogen gas. A portable vacuum pump is used to evacuate the pressure vessels of nitrogen before introduction of hydrogen, to reduce the number of purge cycles in meeting the purity goal.

\subsection{Drains, Vents, Tubing, Vent Stack, and Blowdown Tank}

The system of vents and drains constitutes a significant safety system. The vent stack and blowdown tank control the release of hydrogen into the atmosphere. It is assumed that once the hydrogen gas reaches the vent stack, or is released from it, it will react with air and burn. Burning could occur in the stack but is most likely to react at the stack exit. Probably, there will be no reaction, but the design assumption is that it will. The reaction of hydrogen with oxygen produces water; hence, in the worst-case scenario there are no environmentally hazardous emissions from the release of hydrogen into the atmosphere. The release is 10 feet above the Gas Building roofline. The design of the vent stack exit prevents nesting of birds or forces of nature blocking the exit of the gas.

The oxygen vent from the HOGEN unit does not go into the vent stack but is routed separately away from the stack. The oxygen vent is fabricated from 0.5-in. 304 stainless steel tubing and is identified as an oxygen vent.

The vent stack begins at the top of the blowdown tank. Drains are piped into the blowdown tank. Vents are piped into the Vent Stack. The blowdown tank is fully open to the vent stack. At the low point of the blowdown tank, a self-closing drain valve permits safe removal of condensate or oil. The vent stack and blowdown tank are normally under atmospheric pressure. The vent stack posts a sign reading "Venting Hydrogen Gas May Ignite." A helium injection system is installed in the vent stack.

Table 2.5 lists the hydrogen system vents. Vents are fabricated from 0.5 -in. 304 stainless steel Swaglock tubing. A 1-in. color-coded tape is used at 5-foot intervals to identify the tubing as a hydrogen system vent line. Flow direction arrows are also mounted on the vent lines. The vent stack utilized weldolets for vent attachment. The blowdown tank has similar attachments for drains. The vent stack is 3 -in. schedule 40 stainless steel pipe for the intended duty. The blowdown tank is 6 -in. schedule 80 stainless steel pipe. The vent stack is securely anchored to the Gas Building to restrain any thrust from dislodging it, and it is electrically grounded.

Table 2.5. Hydrogen system vents.

\begin{tabular}{lllll}
\hline Vent No. & \multicolumn{1}{c}{ From } & \multicolumn{1}{c}{ To } & \multicolumn{1}{c}{ Size } & \\
\hline OV1 & HOGEN & Top of gas bldg & 0.5 -in. 304 SS & Oxygen vent \\
HV1 & HOGEN & Vent stack & 0.5 -in. 304 SS & HOGEN vent \\
HV2 & Dryer & Vent stack & 0.5 -in. 304 SS & Dryer vent \\
HV3 & LPS - Powered & Vent stack & 0.5 -in. 304 SS & Powered LPS vent \\
HV4 & LPS & Vent stack & 0.5 -in. 304 SS & Purity LPS vent \\
SRV2 & LPS - SRV & Vent stack & 0.5 -in. 304 SS & LPS safety relief
\end{tabular}




\begin{tabular}{lllll} 
SRV2 & LPS - SRV & Vent stack & 0.5 -in. 304 SS & LPS safety relief \\
HV5 & F1 & Vent stack & 0.5 -in. 304 SS & Filter bleed \\
HV6 & H2 Compressor & Vent stack & 0.5 -in. 304 SS & Compressor bleed \\
HV7 & HPS & Vent stack & 0.5 -in. 304 SS & HPS vent \\
HV8 & HPS & Vent stack & 0.5 -in. 304 SS & HPS vent \\
SRV3 & HPS - SRV & Vent stack & 0.5 -in. 304 SS & HPS safety relief \\
SRV4 & HPS - SRV & Vent stack & 0.5 -in. 304 SS & HPS safety relief \\
HV9 & Dispenser filter & Vent stack & 0.5 -in. 304 SS & Filter bleed \\
HV10 & Dispenser vent & Vent stack & 0.5 -in. 304 SS & Dispenser nozzle vent \\
\hline
\end{tabular}

\subsection{Hydrogen System Valves}

Appendix A, Figure A-4, presents the hydrogen system piping and instrumentation diagram. Table 2.6 shows the specifications for low-pressure valves shown in Figure A-4. Table 2.7 shows the specifications for high-pressure hydrogen system valves. All valves are certified by their manufacturers to be suitable for use with hydrogen.

Table 2.6. Low-pressure hydrogen.

\begin{tabular}{|c|c|c|}
\hline Device & Check Valve & Manual Valve \\
\hline Tag No. & CV-XXX & V-XXX \\
\hline Size & 0.5 in. & $0.5 \mathrm{in.}$ \\
\hline $\mathrm{Cv}$ & 1.8 & 0.73 \\
\hline Port size and type & 0.5 -in. Swagelok & 0.5 -in. Swagelok \\
\hline Design flow & $400 \mathrm{scfh}$ & $400 \mathrm{scfh}$ \\
\hline $\mathrm{P} 1$ & 100 psi & 100 psi \\
\hline $\mathrm{P} 2$ & 99 psi & 99 psi \\
\hline P drop & $1 \mathrm{psid}$ & 1 psid \\
\hline Vendor & Swagelok & Swagelok \\
\hline Model & CH Series & 1 Series \\
\hline Part no. & SS-CHS8-1-SC11 & SS-1KS8-SC11 \\
\hline Cracking pressure & $1 \mathrm{psid}$ & $\mathrm{N} / \mathrm{A}$ \\
\hline MAWP & $6000 \mathrm{psi}$ & 5000 psi \\
\hline Burst pressure & $24,000 \mathrm{psi}$ & $24,000 \mathrm{psi}$ \\
\hline Temp. rating & $400^{\circ} \mathrm{F}$ & $100^{\circ} \mathrm{F}$ \\
\hline Temp. derating & $\mathrm{N} / \mathrm{A}$ & 4295 psi@200 $\mathrm{F}$ \\
\hline Seat material & Viton & Kel F \\
\hline Body material & $316 \mathrm{SS}$ & $316 \mathrm{SS}$ \\
\hline Valve style & in-line check & Bonnet needle \\
\hline Seal material & N/A & TFE Packing \\
\hline Seat leak rate & $\mathrm{N} / \mathrm{A}$ & $0.1 \mathrm{scc} / \mathrm{min} \mathrm{N} 2 @ 1000$ psi \\
\hline
\end{tabular}




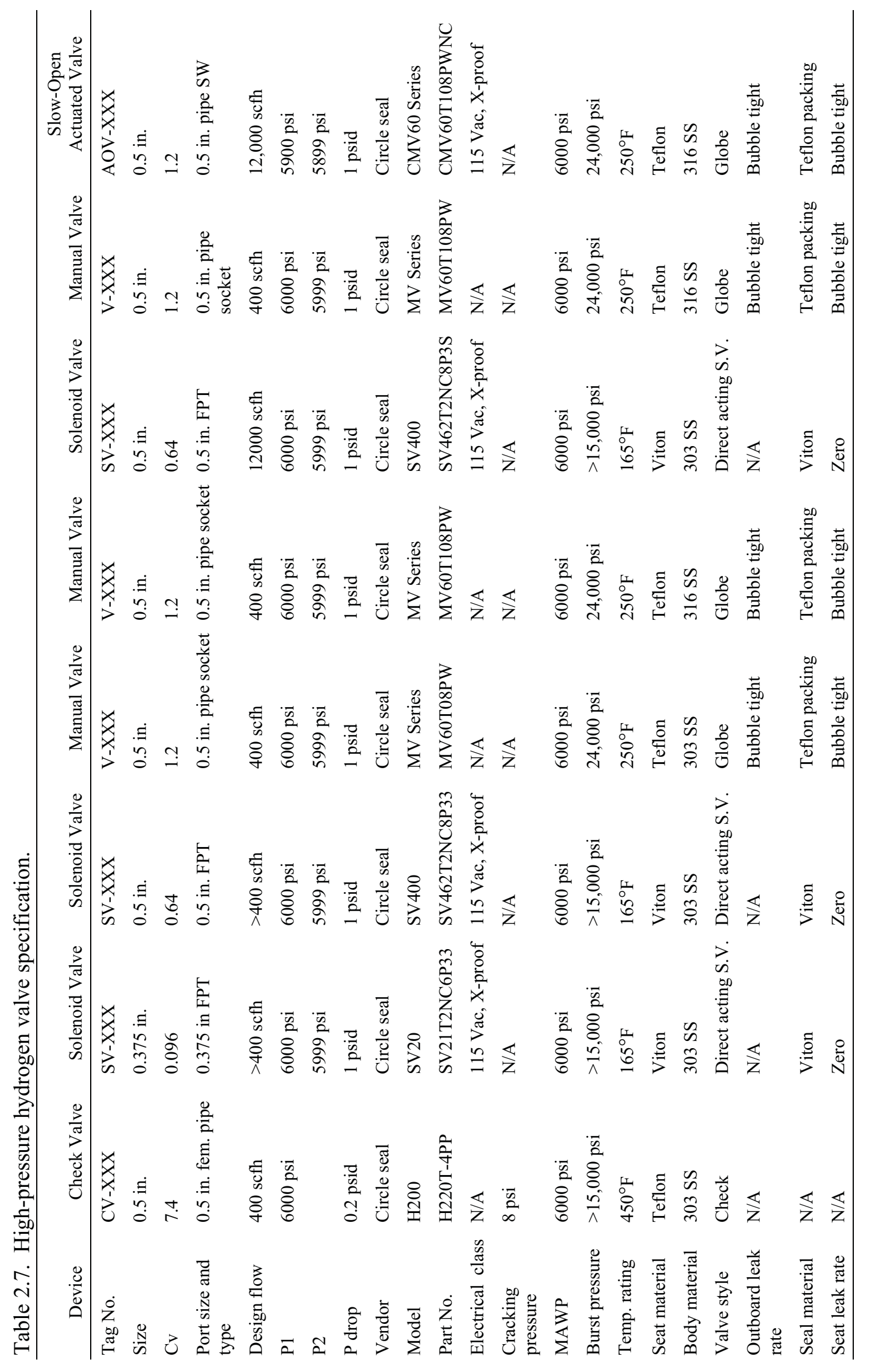




\subsection{Control and Instrumentation}

Table 2.8 lists the hydrogen system controls and instrumentation.

Table 2.8. Controls and instrumentation.

\begin{tabular}{|c|c|c|c|c|}
\hline Device & ID & Local & Indicate $^{a}$ & Monitor $^{\mathrm{b}}$ \\
\hline DI water quality & N/A & DI skid & Yes & No \\
\hline DI water pressure & N/A & DI skid & Yes & No \\
\hline Pressure LPS vessel & PT-104 & LPS tank & Yes & Yes \\
\hline Pressure LPS Vessel & PI-109 & LPS panel & Yes & No \\
\hline Hydrogen sample & PI-106 & HOGEN outlet & Yes & No \\
\hline HOGEN amps & $\mathrm{N} / \mathrm{A}$ & HOGEN skid & Yes & No \\
\hline Compressor inlet pressure & PI-108 & Pdc panel & Yes & No \\
\hline Compressor outlet pressure & PT-112 & HPS panel & Yes & Yes \\
\hline Temperature HPS vessel 1 & TI-101 & HP tank 1 & Yes & No \\
\hline Temperature HPS vessel 1 & TI-102 & HP tank 1 & Yes & No \\
\hline Pressure HPS vessel 1 & PT-113 & HP tank 1 & Yes & Yes \\
\hline Pressure HPS vessel 2 & PT-114 & HP tank 2 & Yes & Yes \\
\hline $\mathrm{H} 2$ pressure to dispenser & PT-402 & HPS Panel & Yes & Yes \\
\hline Diff pressure filter F-101 & DPI-101 & Filter 101 & Yes & No \\
\hline Diff pressure filter F-102 & DPI-102 & Filter 102 & Yes & No \\
\hline Diff pressure filter F-103 & DPI-103 & Filter 103 & Yes & No \\
\hline Diff pressure filter F-201 & DPI-201 & Filter 201 & Yes & No \\
\hline Diff pressure filter F-401 & DPI-401 & Filter 401 & Yes & No \\
\hline Vent stack temperature & TE-104 & Vent stack tee & No & Yes \\
\hline Combustibles analyzer 1 & AIT-101 & Roof Gas Building & Yes & Yes \\
\hline Combustibles analyzer 2 & AIT-102 & Roof Gas Building & Yes & Yes \\
\hline IR/UV scanner 1 & BE-101 & Gas Building & Yes & Yes \\
\hline IR/UV scanner 2 & BE-102 & Gas Building & Yes & Yes \\
\hline IR/UV scanner 3 & BE-103 & Gas Building & Yes & Yes \\
\hline IR/UV scanner 4 & BE-104 & Gas Building & Yes & Yes \\
\hline IR/UV scanner 5 & BE-105 & Gas Building & Yes & Yes \\
\hline IR/UV scanner 6 & BE-106 & Gas Building & Yes & Yes \\
\hline EMS status & N/A & Control room & Yes & No \\
\hline Control air pressure & N/A & Compressor skid & Yes & No \\
\hline Dispenser 1 status & N/A & Dispenser & Yes & No \\
\hline Flow through dispenser & N/A & Dispenser & Yes & No \\
\hline Helium pressure & PT-501 & Helium storage & No & Yes \\
\hline Nitrogen pressure & N/A & Nitrogen skid & Yes & No \\
\hline City water pressure & N/A & DI skid & Yes & No \\
\hline
\end{tabular}

a. Indicate = local visual indication only; no electrical signal to control panel.

b. Monitor $=$ provides an electrical signal to the control panel and produces a visual indication at the control panel; used to generate alarms and shutdowns. 


\subsection{Electrical}

The electrical energy supply is through a 48-V, 600-A, 3-phase load center located in the auxiliary equipment area (unclassified). The interior of the building is considered to be a Class 1, Division 2, area. Wherever possible, electric equipment is placed in an unclassified area outside of the building. Purge air from the control air system is used in panels within the building. Conduits are sealed.

Grounding is with a $2 / 0$ copper grounding grid placed in the concrete floor slab. This grid is bonded to the building steel. The grounding system also extends to the fueling island and its canopy

\subsection{Color Coding of Fluid Lines}

All gas and liquid piping has color-coded labels (Table 2.9) that indicate the kind of fluid in the line and the direction of flow. Labels are at 10-ft intervals, on both sides of wall penetrations. Labeling is as follows:

- Safe colors: white, black

- Danger/fuel: blue (sky, dark), red, yellow

- Inert gas: orange

Table 2.9. Gas and liquid piping labeling used.

\begin{tabular}{ll}
\hline Fluid & Color \\
\hline Deionized water & White/black strip \\
Chilled water & White \\
Potable water & White \\
Compressed air & Black \\
Helium & Orange/2 white stripes \\
Nitrogen & Orange/1 white stripe \\
& \\
Hydrogen & Sky blue \\
Hydrogen vent & Sky blue/2 red stripes \\
& \\
Hydrogen drain & Sky blue/1 red stripe \\
Compressed natural gas & Dark blue/2 red stripes \\
CNG vent & Dark blue/2 red stripes \\
CNG drain & Dark blue/1 red stripe \\
& \\
Hydrogen/natural gas blend & Dark blue/sky blue stripe \\
Oxygen & Green \\
Oxygen vent & Green \\
\hline
\end{tabular}




\subsection{Helium and Fire Sprinkler System}

The gas building is protected with a fuse-link-type fire sprinkler system.

The vent stack has a helium purge system for extinguishing any extensive fires that may develop in the vent stack. A thermocouple installed at the top (exit) of the vent stack triggers an alarm condition if exit gas temperatures reach $250^{\circ} \mathrm{F}$. Release of helium into the vent stack is manually initiated.

\subsection{Flame and Flammable Gas Detection}

Flame detectors are Spectrex Model 20/20LB units. They scan both for IR and UV wavelength or flame signature. Factory Mutual certifies the units. The scanners produce a series of outputs that allow an visual/audible alarm to sound at an incipient fire condition and initiate system shutdown once the detector senses a high level of IR/UV. The unit can sense flames up to 50 feet away. The gas building has five or more detectors located to completely scan the facility. Appendix F presents the coverage envelops for both the IR and UV detectors. A single unit is located at the fuel dispenser island. In this application, this UV/IR device is an industry standard. The scanners have built-in automatic testing to ensure proper operation.

The gas building has two types of gas detectors: hydrogen and natural gas. The technology and vendor for each is different. Both detectors provide an audible/visual alarm at 25\% LFL for hydrogen and initiate system shutdown at 50\% LFL for hydrogen. 


\section{COMPRESSED NATURAL GAS SYSTEM}

\subsection{Fueling Station Overview}

The APS Alternative Fuel Pilot Plant is a model alternative fuel refueling system supplying compressed natural gas $(\mathrm{CNG})$, hydrogen, and a blend of $\mathrm{CNG}$ /hydrogen. Figure A-1 of Appendix A shows a plan of the plant. The hydrogen and natural gas systems are distinctly separate; the stationary filling station blends the two fuels. This section focuses on the natural gas portion of the plant. Section 2 discusses the hydrogen portion, which is similar in various ways.

In addition to hydrogen, the plant also compresses natural gas for use as a motor fuel. CNG vehicles typically require 3,600-psi storage tanks. However, to fill vehicle onboard tanks, storage pressures must be higher. The APS system compresses natural gas to pressures up to 5,000 psi using a three-stage cascade pressure arrangement.

The objectives of constructing and operating the natural gas system are to:

- Evaluate the cost and benefit ratio of operating a natural gas fueling system

- Evaluate the safety of a natural gas fueling system

- Provide a fuel source for APS-operated CNG and hydrogen enriched CNG (HCNG) vehicles.

\subsection{CNG System Design Criteria}

The CNG system has four primary functions: compression, storage, dispensing, and venting. Natural gas provided by Southwest Gas is delivered at $30 \mathrm{psi}$; it is then filtered, compressed to 5,200 psi, and stored in three pressure vessels. Figure A-3 of Appendix A presents a plan of equipment locations for the natural gas system. Figure A-2 presents a three-dimensional view of the CNG system components.

Natural gas is received from Southwest Gas at $30 \mathrm{psi}$ and is then filtered through two filters (see Section 3.10) before being routed to the compressor. The main compressor for the CNG system is a 4-stage 300-cfm Gemini model HPSS-4, described in Table 3.1. It compresses the gas to 5,000 psi. Originally, it was thought that raising the inlet pressure above 30 psi could optimize the Gemini's performance. This led to including an additional compressor in the design.

Table 3.1. Gemini compressor operating conditions.

\begin{tabular}{lll}
\hline \multicolumn{1}{c}{ Gemini Compressor } & Normal & \multicolumn{1}{c}{ Shutdown } \\
\hline Oil pressure & $45-55 \mathrm{psi}$ & $25 \mathrm{psi}$ \\
Gemini suction pressure & $55 \mathrm{psi}$ & $30 \mathrm{psi}$ \\
Gemini suction temperature & $80^{\circ} \mathrm{F}$ & $100^{\circ} \mathrm{F}$ \\
Gemini $1^{\text {st }}$ stage discharge pressure & $237 \mathrm{psi}$ & Lo 180: Hi 300 \\
Gemini $1^{\text {st }}$ stage discharge temperature & $300^{\circ} \mathrm{F}$ & $\mathrm{N} / \mathrm{A}$ \\
Gemini $2^{\text {nd }}$ stage suction temperature & $120^{\circ} \mathrm{F}$ & $@$ \\
Gemini $2^{\text {nd }}$ stage discharge pressure & $593 \mathrm{psi}$ & Lo $500:$ Hi 600 \\
Gemini $2^{\text {nd }}$ stage discharge temperature & $249^{\circ} \mathrm{F}$ & $\mathrm{N} / \mathrm{A}$ \\
Gemini $3^{\text {rd }}$ stage suction temperature & $120^{\circ} \mathrm{F}$ & $@$ \\
Gemini $3^{\text {rd }}$ stage discharge pressure & $1674 \mathrm{psi}$ & Lo $1550:$ Hi 1800 \\
Gemini $3^{\text {rd }}$ stage discharge temperature & $266^{\circ} \mathrm{F}$ & $\mathrm{N} / \mathrm{A}$ \\
Gemini $4^{\text {th }}$ stage suction temperature & $120^{\circ} \mathrm{F}$ & $@$ \\
Gemini $4^{\text {th }}$ stage discharge pressure & $5069 \mathrm{psi}$ & $@$ \\
Gemini $4^{\text {th }}$ stage discharge temperature & $277^{\circ} \mathrm{F}$ & $\mathrm{N} / \mathrm{A}$ \\
CNG compressor discharge temperature & $120^{\circ} \mathrm{F}$ & $@$ \\
CNG compressor discharge pressure & $5000 \mathrm{psi}$ & $@$ \\
\hline
\end{tabular}


A Hy-Bon model AC-8DB boost compressor (Figure 3.1), as described in Table 3.2, was added to the design. The natural gas was routed through this compressor before it was sent to the Gemini (Figure 3.2). The purpose of the Hy-Bon was to raise the pressure of the gas at the inlet of the Gemini with the hope of optimizing Gemini's performance. The Hy-Bon is capable of compressing natural gas to 60 psi. The necessity of the Hy-Bon unit is now being questioned, and tests are underway to determine if the unit adds any benefit to the system.

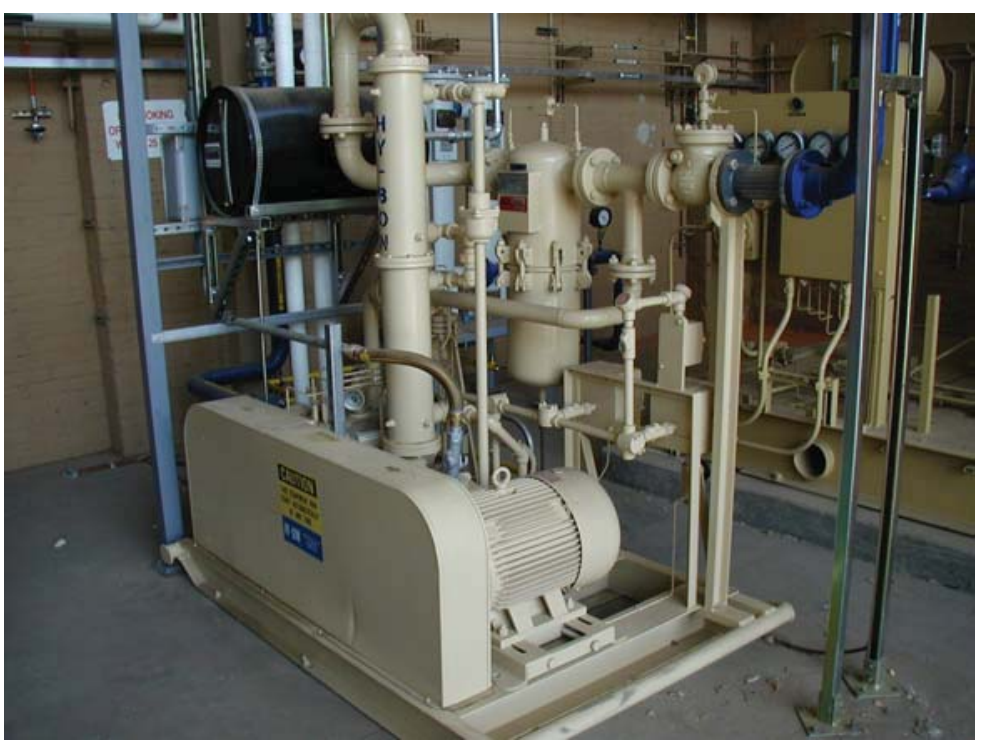

Figure 3.1. Hy-Bon - CNG boost compressor.

Table 3.2. Hy-Bon boost compressor operating conditions.

\begin{tabular}{lc}
\hline \multicolumn{1}{c}{ Hy-Bon } & Normal \\
\hline Booster suction pressure & $30 \mathrm{psi}$ \\
Booster discharge pressure & $55 \mathrm{psi}$ \\
\hline
\end{tabular}

After the natural gas is compressed, it is once again filtered in preparation for storage (Figure 3.3) and dispensing. The compressed gas is stored at three pressures (low, medium, and high), which allows the dispensing pressure to be more closely matched to the receiving pressure, avoiding the thermodynamic losses associated with excessive gas throttling. After filtration, the natural gas control system (see Section 3.11) directs the gas to either the low-pressure vessel (see Section 3.3), the mediumpressure vessel (see Section 3.4), or the high-pressure vessel (see Section 3.5), depending on which vessel requires filling. Solenoid valves (Section 3.9) control the flow of gas to each vessel.

Under normal operations, $\mathrm{CNG}$ is not released into the surrounding area. The entire system is completely sealed to prevent human contact with natural gas. In the event of a CNG leak, combustible detectors will signal an alarm and isolate the entire system by automatically shutting down (see Section 3.8) the power to the operating equipment (control power, monitoring systems, and communication system remain energized).

All venting of natural gas is piped to the vent stack (separate vent stack than for hydrogen). The vent stack releases natural gas above the roofline of the plant. 


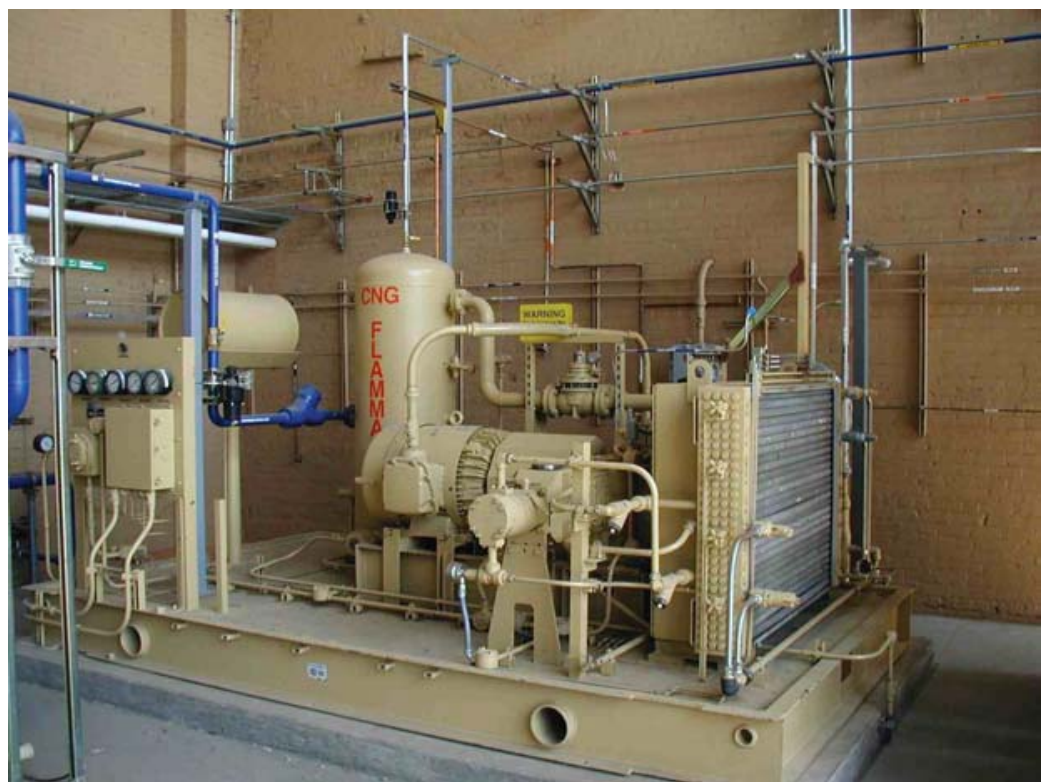

Figure 3.2. Gemini - main CNG compressor.

\subsection{Low-Pressure Storage}

The low-pressure storage system consists of three pressure tanks, each 20 feet long, at 3600 psi. Each tank has a capacity of 11,079 scf, or 262 gallons. The tanks were manufactured under the 1989 ASME code, Section VIII, Division 1, Addendum 1990, Appendix 22 (SF3). Form UA-1, certifying compliance with the ASME Code, is presented in Appendix B (serial numbers 42301, 42302 and 42303). The maximum allowable pressure is $4,000 \mathrm{psi}$ at $200^{\circ} \mathrm{F}$. Each tank is equipped with an ASME safety relief valve, set at 4,000 psi, piped to the $\mathrm{CNG}$ vent stack. The tank is equipped with a manual drain at its low point to drain off any oil or moisture that may be in the CNG. 


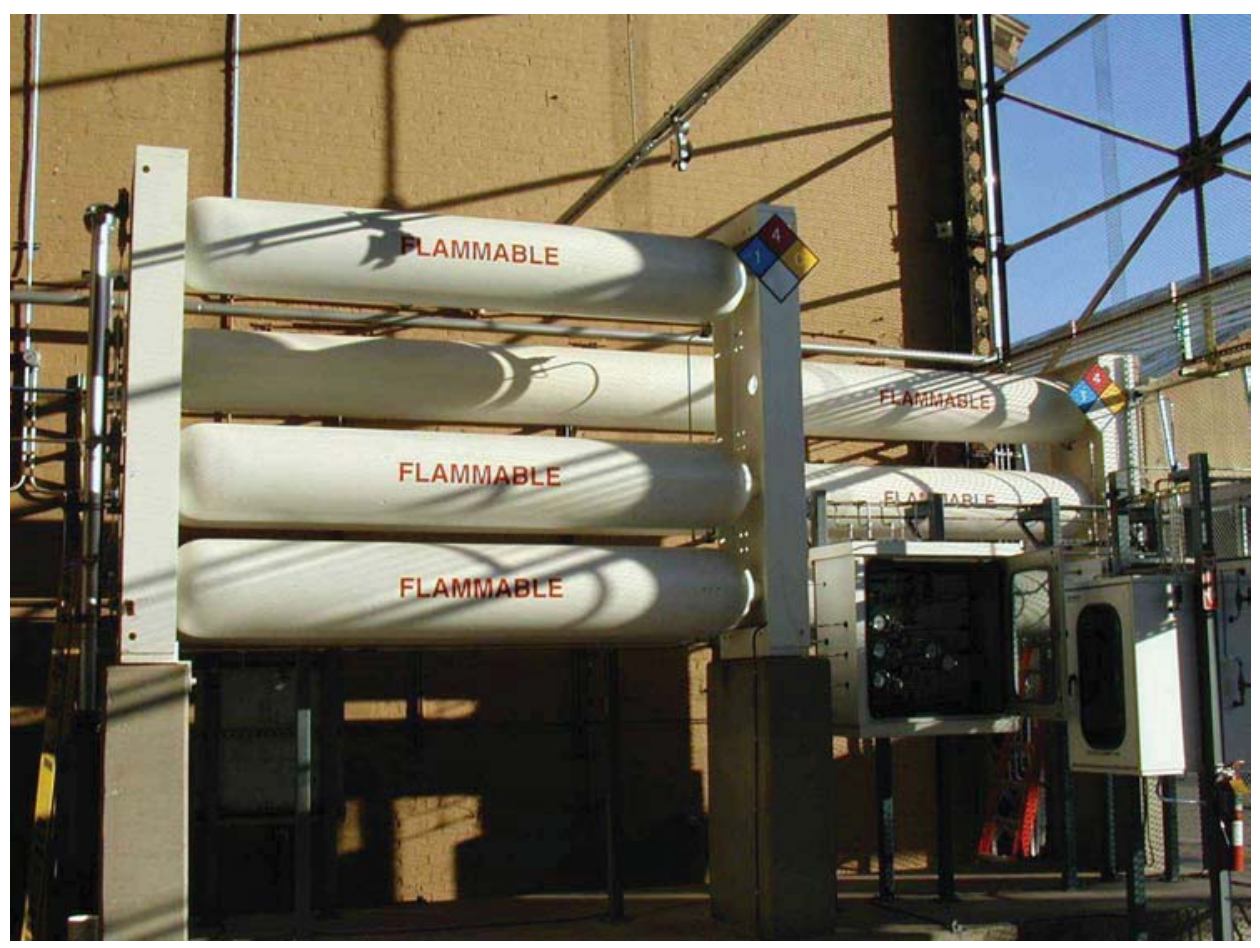

Figure 3.3. CNG storage tanks. The top tank is the high-pressure tank and the two lower tanks are the medium-pressure tanks in the near rack. The three low-pressure tanks are in the far rack.

\subsection{Medium-Pressure Storage}

The medium-pressure storage system consists of two pressure tanks, each 11 feet long, at 4,500 psi. The tanks have a capacity of 5,711 scf, or 120 gallons. They were manufactured under 1992 ASME code, Section VIII, Division 1, Appendix 22 (SF3). Form UA-1, certifying compliance with the ASME Code, is presented in Appendix B (serial numbers 43390 and 43400). Maximum allowable pressure is 5,500 psi at $200^{\circ} \mathrm{F}$. Each tank is equipped with a safety relief valve, set at 5,500 psi, piped to the vent stack. The tank is equipped with a manual drain at its low point to drain off any oil or moisture that may be in the CNG.

\subsection{High-Pressure Storage}

The high-pressure storage system consists of a single pressure tank, 11 feet long, at 5,000 psi. The tank has a capacity of 5,711 scf, or 120 gallons. It was manufactured under 1992 ASME code, Section VIII, Division 1, Appendix 22 (SF3). Form UA-1, certifying compliance with the ASME Code, is presented in Appendix B (serial number 43401). The tank's maximum allowable pressure is 5,500 psi at $200^{\circ} \mathrm{F}$. It is equipped with a safety relief valve, set at 5,500 psi, piped to the vent stack. The tank is equipped with a manual drain at its low point to drain off any oil or moisture that may be in the CNG.

\subsection{Storage Filling}

Each pressure tank in the CNG storage system is equipped with air-actuated solenoid valves (see Section 3.9). Under normal operation, these valves are open. The valves close in the event of failure of the instrument air system. When the air-actuated solenoid valves are closed, no gas can flow into or out of the pressure vessels. The valves will also close if the EMS is activated.

The natural gas can be dispensed to the storage vessels in one of two ways: hand mode or automatic mode. Each mode is controlled by an FW Murphy Mark III control system. 


\subsubsection{Hand Control}

The high-pressure tank is filled first. The control system opens the high-pressure-tank air-operated valve (AOV) if the pressure is below 5,000 psi. The AOV directing the high-pressure tank closes when the pressure reaches 5,200 psi. The safety valves for the high-pressure vessels are set at 5,500 psi.

Upon closure of the high-pressure AOV, the medium-pressure tank AOV opens. Once the mediumpressure tank reaches 4,700 psi, the low-pressure AOV opens, and the medium-pressure tank AOV closes. Safety valves for the medium-pressure vessels are set at 5,500 psi.

Upon closure of the medium-pressure AOV, the low-pressure tank AOV opens. The low-pressure AOV remains open until the storage pressure reaches 3,800 psi. At this pressure, the AOV closes, and the Gemini shuts down. Safety valves for the low-pressure vessels are set at 4,000 psi.

\subsubsection{Automatic Control}

If the high-pressure tank is below 4,000 psi (fill pressure point), no other tank will be filled. At 4,000 psi, the compressor starts. Once the start sequence is complete, the AOV opens, permitting flow of the compressed gas into the high-pressure storage vessel. Once the pressure reaches 5,200 psi, the medium-pressure tank AOV opens, permitting filling of the medium-pressure storage. When the medium-pressure tank reaches 4,700 psi, the medium-pressure AOV closes, and the low-pressure AOV opens, permitting filling of the low-pressure vessels. When the low-pressure vessels reach 3,800 psi, FV 2 closes, and the compressor returns to standby.

If the medium-pressure tank reaches 3,600 psi and the high-pressure storage has not reached $4,000 \mathrm{psi}$, then the compressor auto start sequence will begin. Once the sequence is complete, the medium-pressure AOV opens, permitting filling of the medium-pressure tank. Once the medium-pressure tank reaches 4,700 psi, the medium-pressure AOV closes, and the high-pressure AOV opens, permitting filling of the high-pressure vessel. Once the high-pressure tank reaches 5,200 psi, the high-pressure AOV closes, and the low-pressure AOV opens, permitting filling of the low-pressure vessels. Once the lowpressure tanks reach $3800 \mathrm{psi}$, the low-pressure AOV closes, and the compressor shuts down and returns to standby.

If the low-pressure tank reaches 2,800 psi and the medium-pressure tank has not reached 3,600 psi, and the high pressure tank has not reached $4000 \mathrm{psi}$, then the compressor auto start will begin. Once the start sequence is complete, the low-pressure AOV opens, permitting filling of the low-pressure vessels. Once the low-pressure vessels have reached 3,800 psi, the low-pressure AOV closes, and the mediumpressure AOV opens, permitting filling of the medium-pressure tank. Once the medium-pressure tank has reached 4,700 psi, the medium-pressure AOV closes and the high-pressure AOV opens, permitting filling of the high-pressure vessel. Once the high-pressure vessel has reached 5,200 psi, the high-pressure AOV closes, and the compressor shuts down and returns to standby.

\subsection{Fuel Dispensing}

There are two dual-output dispensers, manufactured by Fueling Technologies, Inc., at the Arizona Public Service Alternative Fuel Pilot Plant. One unit dispenses CNG only, at each output. CNG can be dispensed from the low-, medium-, or high-pressure storage tanks or directly from the Gemini. The other

unit has a hydrogen output and a CNG/hydrogen blend output. The dispensers are more fully described in Section 4 of this report. 


\subsection{Emergency Shutdown System}

The CNG compression/storage system is equipped with pressure transducers, on each compressor stage, that detect low pressures within the system, which could indicate a gas leak. If the pressure drops within a stage to the low pressure shown in Table G-1 of Appendix G, the system will automatically shut down. In addition, natural gas detectors have been installed that will signal the system to shut down if the natural gas present in the air reaches $2 \%$.

The EMS offers both manual and automatic methods of safely and rapidly shutting down the operation of the CNG system and CNG dispensing in the case of an event that could cause harm.

\subsubsection{Emergency Shutdown System Initiation}

- Manual push buttons (5)

- $\quad$ East side of the fueling island

- West side of the fueling island

- $\quad$ East access door to the equipment building

- South access door to the equipment building

- $\quad$ East side access door to the auxiliary room

- Methane Gas detectors (9); 50\% lower flammability limit is detected by any one detector

- $\quad$ Flame detectors (6); UV/IR radiation is detected by any one of the detectors

- $\quad$ Sprinkler system, flow activated

\subsubsection{Emergency Shutdown System Automatic Actuations}

- Emergency horn activation

- Emergency Light Activation

- $\mathrm{CNG}$ low-pressure storage tank isolation

- $\quad$ CNG medium-pressure storage tank isolation

- CNG high-pressure storage tank isolation

- Compressor inlet closes

- Fuel maker supply closes

- Compressor blow down opens

- Buffer tank blow down opens

- Dispenser 1 inlet valve closes

- Dispenser 2 inlet valve closes

- Dispenser 1 LP, MP, HP tank supply closes

- Dispenser 2 LP, MP HP tank supply closes

- Breaker for compressor opens

- Breaker for instrument air compressor opens

- Breaker for blower opens

- Breaker for dispenser 1 opens 
- Breaker for dispenser 2 opens

- Breaker for equipment building lighting opens

\subsection{CNG System Valves}

Appendix A, Figure A-5, presents the CNG system piping and instrumentation diagram. Table 3.3 describes the CNG system safety relief valves. Table 3.4 describes the CNG air-operated solenoid valves and control valves. Table 3.5 describes the manual valves.

Table 3.3. CNG system safety relief valves.

\begin{tabular}{cll}
\hline Tag No. & \multicolumn{1}{c}{ Description } & \multicolumn{1}{c}{ Location } \\
\hline SRV 5 & Safety Hy-Bon outlet & Het at 250 psi \\
SRV 10 & Safety buffer tank & Set at 500 psi \\
SRV 11 & Safety Gemini compressor ${ }^{\text {st }}$ stage & Set at 1000 psi \\
SRV 12 & Safety Gemini compressor 2 ${ }^{\text {nd }}$ stage & Set at 2200 psi \\
SRV 13 & Safety Gemini compressor $3^{\text {rd }}$ stage & Set at 5500 psi \\
SRV 14 & Safety Gemini compressor 4 $4^{\text {th }}$ stage & Low-pressure storage \\
SRV 15 & Mercer, 0.75-in. inlet, 1-in. outlet, set at 4000 psi & Low-pressure storage \\
SRV 16 & Mercer, 0.75-in. inlet, 1-in. outlet, set at 4000 psi & Low-pressure storage \\
SRV 17 & Mercer, 0.75-in. inlet, 1-in. outlet, set at 4000 psi & Medium-pressure storage \\
SRV 18 & Mercer, 0.75-in. inlet, 1-in. outlet, set at 4000 psi & Medium-pressure storage \\
SRV 19 & Mercer, 0.75-in. inlet, 1-in. outlet, set at 4000 psi & High-pressure storage \\
SRV 20 & Mercer, 0.75-in. inlet, 1-in. outlet, set at 4000 psi &
\end{tabular}


Table 3.4. CNG system solenoid valves and control valves.

\begin{tabular}{|c|c|c|}
\hline Tag Number & Description & Location \\
\hline SV-11 & Swagelok 1-in. CFM3, 2200 psi & SWG supply to FM \\
\hline SV-12 & Swagelok, SS68TF32-35C & Inlet Gemini Comp \\
\hline SV-13 & Nutron/Hytork-70 & Startup diverting, Gemini \\
\hline SV-14 & Nutron/Hytork-70 & Startup diverting, Gemini \\
\hline SV 20 & Swagelok, 0.5-in. CF8M & Direct vehicle fill, Desp 1 \\
\hline SV 21 & Swagelok, 0.5-in CF8M & LP Vessel inlet, Panel 1 \\
\hline SV 22 & Swagelok, 0.5-in CF8M & MP Vessel inlet, Panel 1 \\
\hline SV 23 & Swagelok, 0.5-in CF8M & HP Vessel inlet, Panel 1 \\
\hline SV 24 & Nutron, 0.5 -in 6000 psi WOG & No. 1 dispenser LPS, Panel 1 \\
\hline SV 25 & Nutron, 0.5 -in 6000 psi WOG & No. 1 dispenser MPS, Panel 1 \\
\hline SV 26 & Nutron, 0.5 -in 6000 psi WOG & No. 1 dispenser HPS, Panel 1 \\
\hline SV 27 & Parker, 0.5-in 8Z(A)-B8L-T-SS PCTFE 6000 psi & No. 2 dispenser LPS, Panel 2 \\
\hline SV 28 & Parker, 0.5-in 8Z(A)-B8L-T-SS PCTFE 6000 psi & No. 2 dispenser MPS, Panel 2 \\
\hline SV 29 & Parker, 0.5-in 8Z(A)-B8L-T-SS PCTFE 6000 psi & No. 2 dispenser HPS, Panel 2 \\
\hline SV 30 & Parker, 0.5-in 8Z (A)-B8L-T-SS PCTFE 6000 psi & No. 3 dispenser LPS, Panel 2 \\
\hline SV 31 & Parker, 0.5-in 8Z (A)-B8L-T-SS PCTFE 6000 psi & No. 3 dispenser MPS, Panel 2 \\
\hline SV 32 & Parker, 0.5-in 8Z (A)-B8L-T-SS PCTFE 6000 psi & No. 3 dispenser HPS, Panel 2 \\
\hline SV 33 & Habonim, 0.5-in body: F318L ball, class 5000 & No. 1 dispenser trip, FTI \\
\hline SV 34 & Habonim, 0.5-in body: F318L ball, class 5000 & No. 2 dispenser trip, FTI \\
\hline SV 35 & Habonim, 0.5 -in body: F318L ball, class 5000 & No. 3 dispenser trip, FTI \\
\hline SV 40 & Swagelok, & LPS Isolation trip \\
\hline SV 41 & Swagelok, & LPS Isolation trip \\
\hline SV 42 & Swagelok, & LPS Isolation trip \\
\hline SV 43 & Swagelok, & MPS Isolation trip \\
\hline SV 44 & Swagelok, & MPS Isolation trip \\
\hline SV 45 & Swagelok, & HPS Isolation trip \\
\hline PCV 10 & Gemini compressor suction & Set 55 psi at $70^{\circ} \mathrm{F}$ \\
\hline CV 10 & Check valve & Blower discharge \\
\hline CV 11 & Check valve & $\mathrm{N} 2$ compressor discharge \\
\hline CV 35 & Parker, 0.5 -in $8 \mathrm{Z}(\mathrm{A}) \mathrm{C} 8 \mathrm{~L}-1 \mathrm{BN}-\mathrm{SS}$ & Panel 2 \\
\hline CV 36 & Parker, 0.5 -in $8 \mathrm{Z}$ (A) C8L-1BN-SS & Panel 2 \\
\hline CV 37 & Parker, 0.5 -in $8 \mathrm{Z}(\mathrm{A}) \mathrm{C} 8 \mathrm{~L}-1 \mathrm{BN}-\mathrm{SS}$ & Panel 2 \\
\hline CV 38 & Parker, 0.5 -in $8 \mathrm{Z}(\mathrm{A}) \mathrm{C} 8 \mathrm{~L}-1 \mathrm{BN}-\mathrm{SS}$ & Panel 2 \\
\hline CV 39 & Parker, 0.5 -in $8 \mathrm{Z}(\mathrm{A}) \mathrm{C} 8 \mathrm{~L}-1 \mathrm{BN}-\mathrm{SS}$ & Panel 2 \\
\hline CV 40 & Parker, 0.5 -in $8 \mathrm{Z}(\mathrm{A}) \mathrm{C} 8 \mathrm{~L}-1 \mathrm{BN}-\mathrm{SS}$ & Panel 2 \\
\hline
\end{tabular}


Table 3.5. Manual valves.

\begin{tabular}{|c|c|c|}
\hline Tag No. & Description & Location \\
\hline V 1 & Jomar 2-in. T-100 N ball valve-brass, $150 \mathrm{psi}$ & SWG supply \\
\hline V 10 & Jomar 2-in. T-100 N ball valve brass, $150 \mathrm{psi}$ & SWG supply to F10 \\
\hline V 11 & Jomar 3-in. T-100 N ball valve-brass, 150 psi & SWG supply to F11 \\
\hline V 12 & Jomar 3-in. T-100 N ball valve-brass, 150 psi & SWG supply to F12 \\
\hline V 13 & Jomar 3-in. T-100 N ball valve-brass, 150 psi & Isolation for F11 \\
\hline V 14 & Jomar 3-in. T-100 N ball valve-brass, $150 \mathrm{psi}$ & Isolation for F12 \\
\hline V 15 & Jomar 2-in. T-100 N ball valve-brass, 150 psi & Isolation for F10 \\
\hline V 16 & Jomar 2-in. T-100 N ball valve-brass, 150 psi & By-pass for F10 \\
\hline V17 & Jomar 1 -in. $\mathrm{T}-100 \mathrm{~N}$ ball valve-brass, $150 \mathrm{psi}$ & Booster supply to FM \\
\hline V17A & Jomar 1 -in. T-100 N ball valve-brass, $150 \mathrm{psi}$ & Isolation for PVC \\
\hline V17B & Jomar 1 -in. $\mathrm{T}-100 \mathrm{~N}$ ball valve-brass, $150 \mathrm{psi}$ & Isolation for PVC \\
\hline V $18 \mathrm{~A}$ & Jomar 2-in. T-100 N ball valve-brass, 500 psi & Isolation \\
\hline V 19 & Swagelok 0.75-in. SS-12-NBS12, 6000 psi & CF 14 isolation, disch hrdr \\
\hline V 20 & Swagelok 0.75 -in. SS-12-NBS12, $6000 \mathrm{psi}$ & CF 14 isolation, disch hrdr \\
\hline V 20A & Parker 0.5-in. 8Z(A)-B8LJ2-SSP-PCTFE, 6000 psi & Disch hrdr iso., and test point \\
\hline V 20B & Swagelok 0.5-in. SS 1KS8 SC11, 5000 psi & Disch hrdr N2 purge \\
\hline V 21 & Parker 0.5-in. 8Z(A)-B8LJ-SSP-PCTFE, 6000 psi & CF 15 and 16 isolation \\
\hline V $21 \mathrm{~A}$ & Parker 0.5-in. 8Z(A)-B8LJ-SSP-PCTFE, 6000 psi & CF 15 BD \\
\hline V 21B & Parker 0.5-in. 8Z(A)-B8LJ-SSP-PCTFE, 6000 psi & CF 16 DB \\
\hline V 22 & Swagelok 0.5-in. SS 83KS8-PCTFE, 6000 psi & CF 15 and 16 isolation \\
\hline V 23 & Parker 0.5-in. 8Z(A)-B8LJ-SSP-PCTFE, 6000 psi & CF 17 and 18 isolation \\
\hline V $23 \mathrm{~A}$ & Parker 0.5-in. 8Z(A)-B8LJ-SSP-PCTFE, 6000 psi & CF $17 \mathrm{BD}$ \\
\hline V 23B & Parker 0.5-in. 8Z(A)-B8LJ-SSP-PCTFE, 6000 psi & CF 18 BD \\
\hline V 24 & Swagelok 0.5-in. SS 83KS8-PCTFE, 6000 psi & CF 17 and 18 isolation \\
\hline V 25 & Parker, 0.5 -in. IDBT & Isolation, supply to panel 1 \\
\hline V 26 & Parker, 0.5-in. 8Z(A)-B8LJ-SSP-PCTFE, 6000 psi & Isolation, LPS \\
\hline V 27 & Parker, 0.5-in. 8Z(A)-B8LJ-SSP-PCTFE, 6000 psi & Isolation, LPS \\
\hline V 28 & Parker, 0.5-in. 8Z(A)-B8LJ-SSP-PCTFE, 6000 psi & Isolation, LPS \\
\hline V 29 & Parker, 0.5-in. 8Z(A)-B8LJ-SSP-PCTFE, 6000 psi & Isolation, MPS \\
\hline V 30 & Parker, 0.5-in. 8Z(A)-B8LJ-SSP-PCTFE, 6000 psi & Isolation, MPS \\
\hline V 31 & Parker, 0.5-in. 8Z(A)-B8LJ-SSP-PCTFE, 6000 psi & Isolation, HPS \\
\hline V 32 & Not used & \\
\hline V 33 & Not used & \\
\hline V 34 & Not used & \\
\hline V 35 & Parker, 0.5-in. 8Z(A) B8LJ-SSP-PCTFE, 6000 psi & Panel 2 \\
\hline V 36 & Parker, 0.5-in. 8Z(A) B8LJ-SSP-PCTFE, 6000 psi & Panel 2 \\
\hline V 37 & Parker, 0.5-in. 8Z(A) B8LJ-SSP-PCTFE, 6000 psi & Panel 2 \\
\hline V 38 & Parker, 0.5-in. 8Z(A) B8LJ-SSP-PCTFE, 6000 psi & Panel 2 \\
\hline V 39 & Parker, 0.5-in. 8Z(A) B8LJ-SSP-PCTFE, 6000 psi & Panel 2 \\
\hline V 40 & Parker, 0.5-in. 8Z(A) B8LJ-SSP-PCTFE, 6000 psi & Panel 2 \\
\hline V 41 & Parker, 0.5 -in. IDBF & Panel 1 \\
\hline
\end{tabular}


V 42 Parker, 0.5-in. 8Z(A) B8LJ-SSP-PCTFE, 6000 psi

V 43 Parker, 0.5-in. 8Z(A) B8LJ-SSP-PCTFE, 6000 psi

V 43A Parker, 0.5-in. 8Z(A) B8LJ-SSP-PCTFE, 6000 psi

V 43B Parker, 0.5-in. 8Z(A) B8LJ-SSP-PCTFE, 6000 psi

V 44 Parker, 0.5-in. 8Z(A) B8LJ-SSP-PCTFE, 6000 psi

V 45 Parker, 0.5-in. 8Z(A) B8LJ-SSP-PCTFE, 6000 psi

V 45A Parker, 0.5-in. 8Z(A) B8LJ-SSP-PCTFE, 6000 psi

V 45B Parker, 0.5-in. 8Z(A) B8LJ-SSP-PCTFE, 6000 psi

V 46

V 47

$\mathrm{V} 48$

$\mathrm{V} 48 \mathrm{~A}$

$\mathrm{V} 48 \mathrm{~B}$

$\mathrm{V} 48 \mathrm{C}$

$\mathrm{V} 49$

V 50

V 51

V 52

V 53

V 54

V 55

V 56

V 57

V 58

V 60

V 61

V 62

V 63

V-64 Nutron, 0.75-in. ball

V 65 Nutron, 0.75 -in. ball

PCV 10 Gemini compressor suction

CV 10 Check valve

CV 11 Check valve

CV 35 Parker, 0.5-in. 8Z(A) C8L-1BN-SS

CV 36 Parker, 0.5-in. 8Z(A) C8L-1BN-SS

CV 37 Parker, 0.5-in. 8Z(A) C8L-1BN-SS

CV 38 Parker, 0.5-in. 8Z(A) C8L-1BN-SS

CV 39 Parker, 0.5-in. 8Z(A) C8L-1BN-SS

CV 40 Parker, 0.5-in. 8Z(A) C8L-1BN-SS
Panel 2, supply to disp 2

Isolation F 19 and F 20

F 19 BD

F20 BD

Isolation F 19 and F 20

Isolation $F 21$ and $F 22$

F21 BD

F 22 BD

Isolation F 21 and F 22

Panel 2, supply to disp 3

Isolation F23, F24, and F25

F 23 BD

F 24 BD

F 25 BD

Isolation $\mathrm{F}$

FTI, dispenser 1 isolation

FTI, dispenser 2 isolation

FTI, dispenser 3 isolation

Low-pressure storage drain

Low-pressure storage drain

Low-pressure storage drain

Medium-pressure storage drain

Medium-pressure storage drain

High-pressure storage drain

Low-pressure storage SRV isolation

Low-pressure storage SRV isolation

Low-pressure storage SRV isolation

Medium-pressure storage SRV

isolation

Medium-pressure storage SRV

isolation

High-pressure storage SRV isolation

Set 55 psi at $70^{\circ} \mathrm{F}$

Blower discharge

N2 compressor discharge

Panel 2

Panel 2

Panel 2

Panel 2

Panel 2

Panel 2 


\subsection{Compressed Natural Gas System Filters}

Filters in the CNG system remove particulate matter and water. They are positioned as noted in Table 3.6.

Table 3.6. Compressed natural gas system filters

\begin{tabular}{lll}
\hline \multicolumn{1}{c}{ Tag No. } & \multicolumn{1}{c}{ Description } & \multicolumn{1}{c}{ Process Fluid } \\
\hline F 10 & Filter Inc., Model V-1422W, MAWP 50 psi & SWG supply \\
F 11 & $\begin{array}{l}\text { Parker Model HF3-801, element 60US1-280, } \\
\text { MAWP 185 psi at 225 }{ }^{\circ} \mathrm{F}\end{array}$ & SWG supply \\
F 12 & $\begin{array}{l}\text { Parker Model HF3-801, element 60US1-280, } \\
\text { MAWP 185 psi at 225 } \mathrm{F}\end{array}$ & SWG supply \\
F 5 & Hy-Bon & Booster compressor \\
F 13 & Coalescence filter & Gemini Comp discharge \\
F 14 & Coalescing filter & Gemini Comp discharge \\
F 15, 16 & Parker, P/N: J4NF-10CWC15-070B, element & Compressor discharge header \\
F 17,18 & 4CWC15-070, MAWP 5000 psi at 350 $\mathrm{F}$ & \\
F 19, 20 & Parker, P/N: J2SD-10CWC11-035, element & Dispenser 1 CNG supply \\
F 21, 22 & 10CWC11-035B, MAWP 5000 psi at 350 $\mathrm{F}$ & Dispenser 2 CNG supply \\
F 23, 24, 25 & & Dispenser 3 CNG supply \\
F 26 & FTI, P/N: S71, MAWP 5000 psi at 275 ${ }^{\circ} \mathrm{F}$ & Dispenser 1 \\
F 27 & FTI, P/N: S71, MAWP, 5000 psi at 275 ${ }^{\circ} \mathrm{F}$ & Dispenser 2 \\
\hline
\end{tabular}

\subsection{Control and Instrumentation}

CNG system operation is controlled by the FW Murphy Mark III control system. The Murphy system provides system shutdown as shown in Table 3.7.

Table 3.7. Shutdown display messages.

\begin{tabular}{ccl}
\hline Class & Shut Down/Alarm & \multicolumn{1}{c}{ Description } \\
\hline B & Shut down & Low suction pressure \\
A & Shut down & High suction pressure \\
P & Shut down & Low discharge 1 pressure \\
A & Shut down & High discharge 1 pressure \\
P & Shut down & Low discharge 2 pressure \\
A & Shut down & High discharge 2 pressure \\
P & Shut down & Low discharge 3 pressure \\
A & Shut down & High discharge 3 pressure \\
S & Shut down & Run signal failure \\
A & Shut down & Plant emergency shutdown system \\
A & Shut down & Common short cycle SD \\
\hline
\end{tabular}


The Murphy control system provides cascade control of CNG system storage based on the control parameters shown in Table 3.8 and 3.9 (Program 50-34-2101, Rev. C).

Table 3.8. Murphy Mark III settings; access code 61 .

\begin{tabular}{|c|c|c|c|c|c|}
\hline $\begin{array}{l}\text { Point } \\
\text { ID }\end{array}$ & Description & $\begin{array}{l}\text { Setting } \\
\text { (psi) }\end{array}$ & $\begin{array}{l}\text { Actual } \\
\text { (psi) }\end{array}$ & $\begin{array}{l}\text { Default } \\
\text { (psi) }\end{array}$ & $\begin{array}{c}\text { Range } \\
\text { (psi) }\end{array}$ \\
\hline $\mathrm{P}-0$ & Circle to exit & - & - & - & - \\
\hline P-1 & Line 1 selection & - & - & - & - \\
\hline $\mathrm{P}-2$ & Last shutdown & - & - & - & - \\
\hline P-3 & Stop pressure & 5500 & & 3600 & $-100-5000$ \\
\hline P-4 & LP tank fill pressure & 2600 & & 2700 & $-100-5000$ \\
\hline P-5 & LP tank full pressure & 3800 & 3800 & 3000 & $-100-5000$ \\
\hline P-6 & MP tank fill pressure & 3900 & 3900 & 2900 & $-100-5000$ \\
\hline P-7 & MP tank full pressure & 4700 & & 3200 & $-100-5000$ \\
\hline P-8 & HP tank fill pressure & 4500 & & 3100 & $-100-5000$ \\
\hline P-9 & HP tank full pressure & 5200 & & 3400 & $-100-5000$ \\
\hline P-10 & Veh 1 max pressure & NA & & 3000 & $3000 / 3600$ \\
\hline P-11 & Veh 2 max pressure & NA & & 3000 & $3000 / 3600$ \\
\hline P-12 & Slow fill max pressure & 3600 & & 3000 & $3000 / 3600$ \\
\hline P-13 & Slow fill min pressure & 300 & & 300 & $0-5000$ \\
\hline P-14 & Low inlet pressure & 45 & & 5 & $-100-5000$ \\
\hline P-15 & High inlet pressure & 75 & & 20 & $-100-5000$ \\
\hline P-16 & Low discharge pressure stage 1 & 180 & & -3 & $-100-5000$ \\
\hline P-17 & High discharge pressure stage 1 & 300 & & 150 & $-100-5000$ \\
\hline P-18 & Low discharge pressure stage 2 & 500 & & -3 & $-100-5000$ \\
\hline P-19 & High discharge pressure stage 2 & 600 & & 750 & $-100-5000$ \\
\hline $\mathrm{P}-20$ & Low discharge pressure stage 3 & 1550 & & -3 & $-100-5000$ \\
\hline $\mathrm{P}-21$ & High discharge pressure stage 3 & 1800 & & 1750 & $-100-5000$ \\
\hline $\mathrm{P}-22$ & Activity delay & 5 & & 5 & $0-3600$ \\
\hline P-23 & Motor start delay & 2 & & 2 & $0-3600$ \\
\hline P-24 & Motor stop delay & 0 & & 0 & $0-3600$ \\
\hline P-25 & Prelube/accum & 30 & & 30 & $0-999$ \\
\hline P-26 & Lockout delay & 15 & & 15 & $0-999$ \\
\hline P-27 & Idle lockout delay & 30 & & 30 & $0-999$ \\
\hline P-29 & Low Vehicle flow delay & 10 & & 10 & $0-60$ \\
\hline P-30 & Veh stop delay & 10 & & 10 & $0-60$ \\
\hline P-32 & Power up delay & 30 & & 60 & $0-300$ \\
\hline P-33 & Blow down on start & 20 & & 20 & $1-30$ \\
\hline P-34 & Blow down during delay & 5 & & 5 & $1-20$ \\
\hline P-35 & Blow down interval delay & 3600 & & 2700 & $1-3600$ \\
\hline P-36 & Blow down after stop delay & 10 & & 10 & $5-30$ \\
\hline P-37 & Close inlet after stop & 5 & & 5 & $1-30$ \\
\hline P-38 & Common short cycle & 8 & & 5 & $1-20$ \\
\hline P-28 & Vehicle minimum flow rate & 125 & & 125 & $0-1000$ SCFM \\
\hline P-31 & Vehicle stop flow rate & 100 & & 100 & $0-1000$ SCFM \\
\hline
\end{tabular}


Table 3.9. Settings for Murphy Mark III, access code 64.

\begin{tabular}{|c|c|c|c|c|}
\hline S No. & Description & Setting & Default & Range \\
\hline $\mathrm{S}-0$ & Circle to exit & - & - & - \\
\hline S-1 & Line 1 selection & - & - & - \\
\hline S-2 & Set time (minutes) & - & - & - \\
\hline S-3 & Set time (hours) & - & - & - \\
\hline S-4 & Set date (day) & - & - & - \\
\hline S-5 & Set date (month) & - & - & - \\
\hline S-6 & Set date (year) & - & - & - \\
\hline S-7 & Set day of week & - & - & - \\
\hline S-8 & Reset $1 \mathrm{~K}$ hours & - & - & - \\
\hline S-9 & Reset hours & - & - & - \\
\hline S-10 & Inlet pressure maximum & 75 & 300 & $0-1000$ psi \\
\hline S-11 & Inlet pressure offset & 0 & 0 & $-100-1000 \mathrm{psi}$ \\
\hline S-12 & Discharge 1 pressure maximum & 300 & 500 & $0-6000$ psi \\
\hline S-13 & Discharge 1 pressure offset & 0 & 0 & $-100-6000 \mathrm{psi}$ \\
\hline S-14 & Discharge 2 pressure maximum & 600 & 1000 & $0-6000$ psi \\
\hline S-15 & Discharge 2 pressure offset & 0 & 0 & $-100-6000 \mathrm{psi}$ \\
\hline S-16 & Discharge 3 pressure maximum & 1800 & 2000 & $0-6000$ psi \\
\hline S-17 & Discharge 3 pressure offset & 0 & 0 & $-100-6000$ psi \\
\hline S-18 & Slow fill pressure maximum & 4000 & 5000 & $0-6000 \mathrm{psi}$ \\
\hline S-19 & Slow fill pressure offset & 0 & 0 & $-100-6000$ psi \\
\hline S-20 & Low tank pressure maximum & 3600 & 5000 & $0-6000$ psi \\
\hline S-21 & Low tank pressure offset & 0 & 0 & $-100-6000 \mathrm{psi}$ \\
\hline S-22 & Medium tank pressure maximum & 4500 & 5000 & $0-6000$ psi \\
\hline S-23 & Medium tank pressure offset & 0 & 0 & $-100-6000 \mathrm{psi}$ \\
\hline S-24 & High-pressure tank pressure maximum & 5000 & 5000 & $0-6000 \mathrm{psi}$ \\
\hline S-25 & High-pressure pressure offset & 0 & 0 & $-100-6000 \mathrm{psi}$ \\
\hline S-26 & NA - Veh 1 pressure max & --- & 5000 & $0-6000$ psi \\
\hline S-27 & NA - Veh 1 pressure offset & --- & 0 & $-100-6000$ psi \\
\hline S-28 & NA - Veh 1 flow maximum & --- & 800 & 0-2000 SCFM \\
\hline S-29 & NA - Veh 1 flow offset & --- & 0 & $-100-2000$ SCFM \\
\hline S-30 & NA - Veh 2 pressure maximum & --- & 5000 & $0-6000 \mathrm{psi}$ \\
\hline S-31 & NA - Veh 2 pressure offset & --- & 0 & $-100-6000$ psi \\
\hline S-32 & NA - Veh 2 flow maximum & --- & 800 & 0-2000 SCFM \\
\hline S-33 & NA - Veh 2 flow offset & --- & 0 & $-100-2000$ SCFM \\
\hline $\mathrm{S}-34$ & Ambient temperature maximum & 140 & 170 & $0-1000 \mathrm{~F}$ \\
\hline S-35 & Ambient temperature offset & 0 & -20 & $-150-1000 \mathrm{~F}$ \\
\hline
\end{tabular}


The Murphy control system displays system status using front panel display messages, as shown in Table 3.10.

Table 3.10. Murphy control system displays.

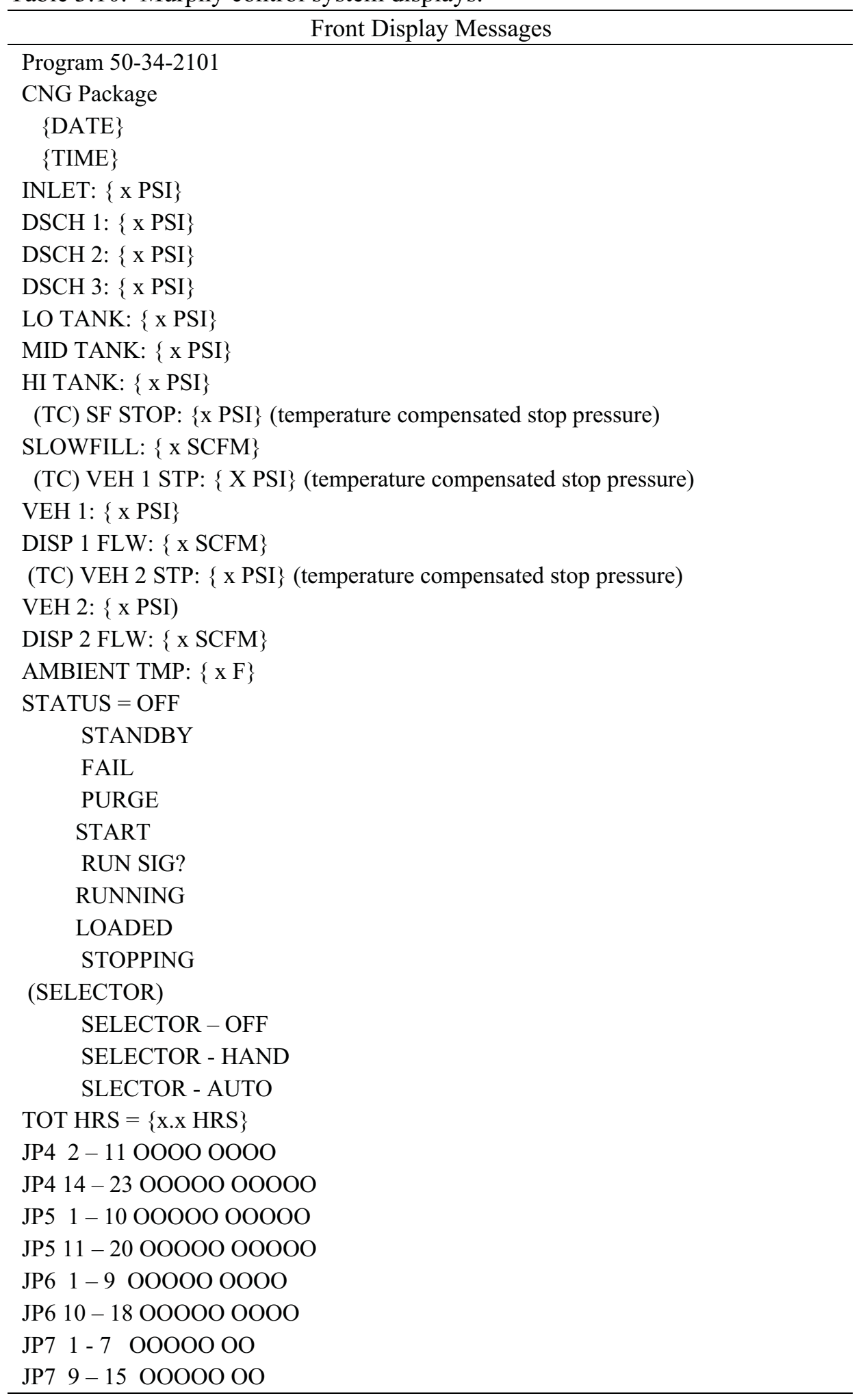


Table 3.11 list the inputs to the Murphy control system.

Table 3.11. CNG System Instrumentation.

\begin{tabular}{|c|c|c|}
\hline Tag No. & Description & Location \\
\hline \multicolumn{3}{|l|}{ PI 12} \\
\hline PI 13 & Ashcroft 2.5 in., $0-60$ psi & SWG supply \\
\hline \multicolumn{3}{|l|}{ PI 14} \\
\hline PI 5 & Murphy & Booster compressor \\
\hline PI 6 & Murphy & Booster compressor \\
\hline PI 17 & Ashcroft 4 in., $0-400$ psi & Gemini panel, suction pressure \\
\hline PI 18 & Ashcroft, 4 in., $0-400$ psi & Gemini panel, $1^{\text {st }}$ stage \\
\hline PI 19 & Ashcroft 4 in., $0-1000$ psi & Gemini panel, $2^{\text {nd }}$ stage \\
\hline PI 20 & Ashcroft 4 in., 0-3000 psi & Gemini panel, $3^{\text {rd }}$ stage \\
\hline PI 21 & Ashcroft 4 in., $0-10000$ psi & Gemini panel, $4^{\text {th }}$ stage \\
\hline PI 22 & Ashcroft 2.5 in., $0-6000$ psi & Panel 1, compressor discharge \\
\hline PI 23 & Ashcroft 2.5 in., $0-6000$ psi & Panel 1, tank low-pressure \\
\hline PI 24 & Ashcroft 2.5 in., $0-6000$ psi & Panel 1, tank medium-pressure \\
\hline PI 25 & Ashcroft 2.5 in., $0-6000$ psi & Panel 1, tank high-pressure \\
\hline PI 26 & Ashcroft 2.5 in., $0-6000$ psi & Panel 1, dispenser 1 \\
\hline PI 35 & & Panel 2, dispenser 2 low-pressure system \\
\hline PI 36 & & Panel 2 dispenser 2 medium-pressure system \\
\hline PI 37 & & Panel 2, dispenser 2 high-pressure system \\
\hline PI 38 & & Panel 2, dispenser 3 low-pressure system \\
\hline PI 39 & & Panel 2, dispenser 3 medium-pressure system \\
\hline PI 40 & & Panel 2, dispenser 3 high-pressure system \\
\hline LG 10 & Level glass, & Gemini buffer tank \\
\hline LG 11 & Level glass, & \\
\hline PSL 5 & Murphy & Hy-Bon compressor \\
\hline PSL 6 & Murphy & Hy-Bon compressor \\
\hline PT 10 & Press. Xmitter, & $1^{\text {st }}$ stage Gemini, Murphy \\
\hline PT 11 & Press. Xmitter & $2^{\text {nd }}$ stage Gemini, Murphy \\
\hline PT 12 & Press. Xmitter & $3^{\text {rd }}$ stage Gemini, Murphy \\
\hline PT 13 & Press. Xmitter & $4^{\text {th }}$ stage Gemini, Murphy \\
\hline PT 14 & Press Xmitter & LP Storage, Murphy \\
\hline PT 15 & Press Xmitter & MP Storage, Murphy \\
\hline PT 16 & Press Xmitter & HP Storage, Murphy \\
\hline PS 14 & Pressure switch, lube oil & Gemini compressor \\
\hline VS 10 & Vibration switch & Gemini compressor \\
\hline TI 5 & & Hy-Bon compressor \\
\hline TI 6 & Murphy & Hy-Bon compressor \\
\hline TCV 6 & Murphy & Hy-Bon compressor \\
\hline TI 7 & & Hy-Bon \\
\hline TS 10 & Temperature switch & Gemini compressor \\
\hline TS 11 & Temperature switch & Gemini compressor \\
\hline TS 12 & Temperature switch & Gemini compressor \\
\hline TS 13 & Temperature switch & Gemini compressor \\
\hline
\end{tabular}




\section{FUEL DISPENSING}

The APS Alternative Fuel Pilot Plant is located within the boundaries of the APS service yard, located at 501 South $2^{\text {nd }}$ Avenue, in Phoenix, Arizona. Fuel is dispensed at the (APS) 501 facility in support of its operating fleet of light- and heavy-duty trucks performing electrical system maintenance and meter reading for APS. The liquid and electric fueling infrastructure was already in place at the 501 facility (described in Sections 4.1.1 and 4.1.2) before the gaseous refueling infrastructure was constructed (described in Section 4.1.3).

\subsection{Refueling Equipment at the $\mathbf{5 0 1}$ Facility}

\subsubsection{Existing Liquid Refueling Systems}

The previously existing petroleum vehicle refueling system is aboveground and dispenses both unleaded gasoline and diesel fuels. It has existed for several years and replaced belowground tanks. It has one 2,000-gallon aboveground gasoline storage tank and one 2,000-gallon aboveground diesel tank. The petroleum refueling equipment is centrally located in the southern parking area, which also serves as an assembly area at the start and at the end of the day shift. No vapor recovery system has been installed on the tank or on dispenser hoses. Tank vent stacks are protected to prevent blockage by insects or birds and from entry of foreign objects. The tanks are free to vent to the atmosphere. A spill prevention dike is installed, but no bollards exist to protect the tanks from vehicle intrusion (hazard exists because maneuvering space in the area for large vehicle operation is limited). The physical and open-air distance between the tanks is 66 inches. No fire containment or barrier wall exists between the tanks. No fire detection equipment or alarms exist on the tank and fuel dispensing systems. And no fire fighting or fogging systems are installed. Flammable material is stored within the fuel dispenser spill containment area (two garbage cans with flammable trash). Hand-held fire extinguishers are mounted on the south outboard canopy post supports, about 21 inches from the longitudinal axis of the tanks. Electrical junction boxes in the fuel dispensing control are not Class 1 , explosion proof. There have been no reported safety incidents, fires, or explosions since installation of this system.

\subsubsection{Existing Electric Refueling Systems}

There is an electric vehicle recharging area (area 401) approximately 400 feet north of the 501

fueling area and north of the meter reader parking area. This area is equipped with the following systems:

- One 150-kW Minit charger (24 to 400 V, 400 amp max., all battery chemistries, non-2293 vehicles)

- One 150-kW Minit charger compatible with 2293 DaimlerChrysler vehicles (model year 1999-2003, $400 \mathrm{amp}$ maximum, all battery chemistries, including $\mathrm{NMH}$ )

- One 120-kW Minit charger (24 to 455 V, 500 amp maximum, all battery chemistries, all vehicles, including 2293 DaimlerChrysler),

- $\quad$ One 33-kW SuperCharge (all vehicles except 2293 DaimlerChrysler)

- $\quad$ Four GM Level II inductive chargers

- $\quad$ One SCI Level II conductive charger

- One Avcon Level II conductive charger.

There are hand-held fire extinguishers in the charging area. There are no emissions from this refueling system, and there is no hazardous material in storage. There have been no safety incidents or fires since installation of these systems. 


\subsubsection{New Gaseous Refueling}

A gaseous refueling area has been constructed west of the meter reader parking area and southwest of the electric vehicle refueling area. There is one dispensing island with two dispensers and each dispenser has dual dispenser hoses. One dispenser is dedicated to CNG and it provides CNG at pressures up to 3,600 psi. The other dispenser provides pure hydrogen at pressures up to 5,000 psi via one dispensing hose, and HCNG at pressures up to 3,600 psi via the second dispensing hose. The dispensers are located a minimum of 50 feet from the closest storage vessel. Gas storage uses pressure vessels built to ASME Code (ASME Code - Section VIII, Appendix 22).

Table 4.1 shows the quantities of gaseous fuel storage. These gases are lighter than air and disperse rapidly. Based on mass weight, the gaseous facility is primarily a typical CNG refueling system such as are found in operation at City of Phoenix facilities east and west of the 501-building complex. In the unlikely event of complete release of all of the energy of the combined gases, it would amount to $22 \%$ of the energy stored in aboveground gasoline tanks at the 501 complex, and $10 \%$ of the combined aboveground petroleum fuel storage at the 501 complex.

Table 4.1. Fuel storage at the 501 facility.

\begin{tabular}{|c|c|c|c|c|c|}
\hline Fuel Type & $\begin{array}{l}\text { Volume } \\
\text { (gallons) }\end{array}$ & $\begin{array}{c}\text { Capacity } \\
\text { (SCF) }\end{array}$ & $\begin{array}{l}\text { Weight } \\
\text { (pounds) }\end{array}$ & $\begin{array}{c}\text { Release Potential } \\
(\mathrm{kWh})\end{array}$ & $\begin{array}{c}\text { Emissions } \\
\left(\mathrm{ft}^{3} / \text { day }\right)\end{array}$ \\
\hline Electric & 0 & 0 & 0 & 0 & 0 \\
\hline Hydrogen & 6,646 & 26,340 & 136.4 & 2,152 & $720^{+}$ \\
\hline $\begin{array}{l}\mathrm{HCNG}(70 \% \mathrm{CNG}, \\
\left.30 \% \mathrm{H}_{2}\right)\end{array}$ & 0 & 0 & 0 & 0 & $0^{*^{+}}$ \\
\hline $\mathrm{CNG}$ & 1,145 & 50,370 & 2,443 & 14,771 & $0^{*^{+}}$ \\
\hline Diesel & 2,000 & NA & 13,583 & 75,792 & $* *$ \\
\hline Gasoline & 2,000 & NA & 12,018 & 70,593 & $* *$ \\
\hline
\end{tabular}

* Natural gas trapped in the filling hose is vented to the atmosphere after vehicle filling. Since venting occurs after vehicle refueling, no leakage is considered to have occurred.

** APS was granted an exemption for the 501 gasoline and diesel refueling system by the ADEQ in 1995. The aboveground tanks are located within 66 inches of each other; no vapor recovery system is installed on either the fuel tank or the dispenser hose. Spill prevention containment is installed, but no barrier protection exists.

+ Note: The CNG and hydrogen systems may vent on occasion, as part of the safety relief system.

Table 4.2 shows the chemical properties of fuels present at the 501 Complex. 
Table 4.2. Fuel properties.

\begin{tabular}{|c|c|c|c|c|c|c|c|}
\hline Property & Hydrogen & Methane & Propane & Gasoline & Diesel & Methanol & Acetylene \\
\hline \multicolumn{8}{|l|}{$\begin{array}{l}\text { Density } \\
\left(20^{\circ} \mathrm{C}, 1 \mathrm{~atm}\right)\end{array}$} \\
\hline $\mathrm{lb} / \mathrm{ft}^{3}$ & 0.00518 & 0.0485 & 0.1168 & 44.95 & 50.8 & 49.4 & 0.0704 \\
\hline $\mathrm{Kg} / \mathrm{l}$ & 0.000083 & 0.00078 & 0.00187 & 0.72 & & & \\
\hline \multicolumn{8}{|l|}{ Specific gravity } \\
\hline $\begin{array}{l}\text { air }=1.0 \\
\text { water }=1.0\end{array}$ & 0.0696 & 0.554 & 1.562 & $\begin{array}{c}3.90 \\
0.733\end{array}$ & 0.814 & 0.791 & 0.92 \\
\hline $\begin{array}{l}\text { Diffusion coefficient } \\
(\mathrm{m} / \mathrm{sec}) \\
\mathrm{ft} / \mathrm{sec}\end{array}$ & $\begin{array}{l}0.0061 \\
0.0200\end{array}$ & $\begin{array}{l}0.0016 \\
0.0052\end{array}$ & $\begin{array}{l}0.0012 \\
0.0039\end{array}$ & $\begin{array}{l}0.008 \\
0.026\end{array}$ & & & \\
\hline \multicolumn{8}{|l|}{$\begin{array}{l}\text { Heat energy (weight } \\
\text { basis) }\end{array}$} \\
\hline $\mathrm{Wh} / \mathrm{kg}$ & 39,472 & 15,425 & 13,891 & 12,922 & 12,276 & 6,332 & 13,892 \\
\hline BTU/lb & 61,095 & 23,875 & 21,500 & 20,000 & 19,000 & 9,800 & 21,502 \\
\hline \multicolumn{8}{|l|}{$\begin{array}{l}\text { Heat Energy } \\
\text { (volume basis) }\end{array}$} \\
\hline $\mathrm{Wh} / 1$ & 3 & 10 & 27 & 8,890 & & & \\
\hline $\mathrm{BTU} / \mathrm{Ft}^{3}$ & 325 & 1,012 & 2,524 & 860 & & 752 & 1,477 \\
\hline \multicolumn{8}{|l|}{ Flammability limits } \\
\hline $\begin{array}{l}\text { Optimum air/fuel } \\
\text { (\% volume in air) } \\
\text { Ignition temperature }\end{array}$ & 2.38 & 9.53 & 23.8 & 1.76 & & & 11.9 \\
\hline${ }^{\mathrm{o}} \mathrm{F}$ & 1,062 & 1,170 & 919 & 536 & $490-560$ & 725 & 581 \\
\hline${ }^{\circ} \mathrm{C}$ & 572 & 632 & 493 & 280 & $254-293$ & 385 & 305 \\
\hline $\begin{array}{l}\text { Ignition energy, air } \\
\text { watt } \\
\text { BTU }\end{array}$ & $\begin{array}{l}6 \times 10^{-9} \\
2 \times 10^{-8}\end{array}$ & $\begin{array}{l}8 \times 10^{-8} \\
3 \times 10^{-7}\end{array}$ & $\begin{array}{l}7 \times 10^{-8} \\
3 \times 10^{-7}\end{array}$ & $\begin{array}{l}7 \times 10^{-8} \\
2 \times 10^{-7}\end{array}$ & & & \\
\hline \multicolumn{8}{|l|}{ Flame temperature } \\
\hline${ }^{\mathrm{o}} \mathrm{F}$ & 3,713 & 3,416 & 3,573 & 4,190 & & 3,460 & 4,207 \\
\hline${ }^{\circ} \mathrm{C}$ & 2,045 & 1,880 & 1,967 & 2,310 & & 1,904 & 2,319 \\
\hline \multicolumn{8}{|l|}{ Flame speed } \\
\hline $\mathrm{ft} / \mathrm{sec}$ & 9.3 & 1.5 & 1.5 & 1.31 & & & 8.8 \\
\hline $\mathrm{m} / \mathrm{sec}$ & 2.83 & 0.46 & 0.46 & 0.40 & & & 2.68 \\
\hline
\end{tabular}

Fuel From Water, eighth edition, Michael A. Peavey, Merit Inc., p. 225.

Petroleum Engineers Handbook, $5^{\text {th }}$ edition, McGraw Hill

\subsection{Fuel Dispensing System Description}

Both hydrogen and CNG vehicular dispensing is performed in the same manner. Fueling Technologies Inc. manufactured the fuel dispensers for each fuel. The hydrogen dispenser is a dual station. One hose dispenses hydrogen into a vehicle with a pressure rating of up to 5,000 psi. The other hose dispenses a hydrogen-enriched CNG at a vehicle pressure rating of up to 3,600 psi.

Each of the dispensers has individual displays. The displays indicate the amount of fuel dispensed in GGE (gasoline gallon equivalent), the total cost for the fuel dispensed, and the unit cost by gallon. The output hose assemblies and the nozzle that connects to the vehicle are coordinated with the type of fuel that is to be dispensed. Thereby, the nozzle from the hydrogen dispenser can be connected only to a vehicle designed for hydrogen, and the nozzle from the CNG dispenser can be connected only to a vehicle designed for CNG. 


\subsubsection{Hydrogen Dispenser Operation}

The hydrogen dispensers have a maximum inlet pressure rating of 5,000 psi. Special nozzle and hose assemblies designed and manufactured by WEH (Germany) provide a mechanical guarantee that CNG vehicles cannot obtain fuel from the hydrogen or HCNG refueling system. In addition to the mechanical incompatibility of fueling nozzles, the system is authorized by an interlocking commercial access system provided by Pickens Fuel. All hose assemblies are also equipped with a breakaway connection at the output of the dispenser housing.

The fuel dispensing system also provides cascade control of the high-pressure storage vessels during refueling. Independent of the fueling control system and emergency shutdown system, excess flow valves in the hydrogen piping to the dispenser protect against pipe and hose failures. If hydrogen flow exceeds a predetermined amount, the flow control will shut off the flow of hydrogen to the dispenser.

\subsubsection{CNG Dispenser Operation}

The natural gas dispensers have a maximum inlet pressure rating of 5,000 psi, a service pressure rating of 3,600 psi, and a flow rate of $0.5 \mathrm{lb} / \mathrm{min}$. Each hose is equipped with a Shurex, NGV1, Type 1, Class A nozzle. These nozzles are unique and are commonly used for compressed natural gas vehicles. The output assembly combines two hoses in one. One hose is used for the process gas. The other hose is used for venting. The process gas hose is Furon/Synflex, 35NG-06, 3/8-in. ID, with a maximum pressure rating of 5,000 psi. The vent hose is Furon/Synflex, 35NG-03, 3/16-in. ID, with a maximum pressure rating of 5,000 psi, and is considered electrically conductive for CNG. These hoses meet the standard, AGA 1-93. All hose assemblies are also equipped with a breakaway connection at the output of the dispenser housing. 


\section{LESSIONS LEARNED}

During the siting process, detailed design, and construction of the APS Alternative Fuel Pilot Plant, numerous lessons were learned that will improve the performance and reduce the cost of the next generation of fueling stations. These lessons learned are presented in the following sections.

\subsection{Codes And Standards}

Existing codes for storage of compressed hydrogen gas present significant obstacles to developing commercial hydrogen fueling stations (Appendix H). The definition of indoor facilities and setback distances are two examples of requirements that will make the size of fueling stations using existing design concepts unacceptable for commercial application. These standards have been developed based on years of experience and a significant body of expertise. They represent best-practice requirements to protect the public from the hazards of stored gas. Future designs will require novel concepts to accommodate these standards within the constraints imposed by a commercial fueling station site. Both new designs and analyses will be required to accomplish the requisite objectives.

\subsection{Facility Layout}

The current state of the art for facility arrangement is represented by industrial gas facilities. These facilities typically use a flat arrangement, where equipment and piping are located at near-ground level. For commercial hydrogen fueling stations, significant reductions in hazards can be achieved by using a three-dimensional layout, including the following design features:

- Elevated or vertical tanks, with penetrations and piping at a level to prevent flame jet impingement on personnel in the event of a high-pressure leak.

- Physical separation of piping associated with different storage vessels to prevent cascading failures resulting from flame jet impingement.

\subsection{Piping}

The current state of the art for piping design of commercial compressed gas facilities is represented by compressed natural gas fueling stations. The standards used by the natural gas industry were found to be inadequate in the following areas:

- Vents and drains are typically open to the atmosphere in a natural gas design. In a hydrogen fueling station, the vents and drains must be piped to a blowdown tank and vent stack to prevent any gas release in occupied areas of the facility.

- Compression fittings are used extensively in the natural gas industry. These fittings are not adequate to ensure the long-term integrity of high-pressure hydrogen piping. All high-pressure hydrogen piping must be welded and inspected as appropriate to ensure weld integrity.

- Care must be taken to ensure that all pressure boundary components are certified by their manufacturer for hydrogen service at the pressures and temperatures required. Many commonly used fittings and valves advertised for hydrogen use are not certified by their manufacturers for such duty.

\subsection{Electrical Grounding}

Elimination of static or lighting-induced sparks in a hydrogen fueling station is imperative. Careful attention must be given to equipment grounding and earth grounding of the facility. 


\subsection{Construction}

Construction of a hydrogen fueling station requires the accommodation of several unique processes:

- A significant amount of high-pressure welding is required. Arrangements for qualified welders and machine welding equipment must be made to facilitate construction.

- $\quad$ Piping system cleanliness must be maintained during construction by the use of precleaned tubing and vessels and exercise of due care during construction to maintain cleanliness.

- Hydrostatic pressure testing of completed piping must be accomplished while maintaining cleanliness requirements.

\subsection{Fuel Dispensing}

Existing fuel dispensers for hydrogen fuel and blends of hydrogen fuel and CNG are not adequate to support commercial hydrogen fueling. Cost reliability and safety must be significantly improved to allow commercial fueling. 


\section{LIST OF APPENDICES}

APPENDIX A - SYSTEM DRAWINGS

APPENDIX B - FORMS AND LISTS

APPENDIX C - GASEOUS HYDROGEN PIPING SPECIFICATION

APPENDIX D - TRAINING PROGRAMS

APPENDIX E - HYDROGEN SYSTEMS OPERATIONS

APPENDIX F - FLAME SCANNERS AND SENSORS

APPENDIX G - COMPRESSED NATURAL GAS SYSTEM OPERATIONS

APPENDIX H - CODES AND STANDARD 


\section{APPENDIX C}

\section{CE-FC07-0ID14788 TASK 1.3 FINAL REPORT}


COOPERATIVE AGREEMENT DE-FC07-06ID14788

\title{
FEASIBILITY STUDY OF HYDROGEN PRODUCTION
} AT EXISTING NUCLEAR POWER PLANTS

\author{
TASK 1.3 FINAL REPORT \\ ECONOMICS OF OPERATION \\ ARIZONA PUBLIC SERVICE \\ ALTERNATIVE FUEL PILOT PLANT
}

SUBMITTED BY

Electric 7ransportation Atpplications 


\section{TABLE OF CONTENTS}

EXECUTIVE SUMMARY

INTRODUCTION

WINTER MODE OPERATIONS

SHOULDER MODE OPERATIONS

SUMMER MODE OPERATIONS

OPERATING COST ANALYSIS 6

\section{APPENDICES}

APPENDIX 1 - Work Breakdown Structure

APPENDIX 2 - Winter Mode Operations Summary Report

APPENDIX 3 - Shoulder Mode Operations Summary Report

APPENDIX 4 - Summer Mode Operations Summary Report 


\section{EXECUTIVE SUMMARY}

Cooperative Agreement DE-FC07-06ID14788 was executed between the US Department of Energy and Electric Transportation Applications (ETA) and the Idaho National Laboratory (INL) to investigate the economics of producing hydrogen by electrolysis using electricity generated by nuclear power. The work under this Agreement is divided into four tasks as follows;

Task 1 - Produce Data And Analyses

Task 2 - Economic Analysis Of Large Scale Alkaline Electrolysis

Task 3 - Commercial Scale Hydrogen Production

Task 4 - Disseminate Data And Analyses

This report summarizes work conducted under Task 1.1 (a sub-task of Task 1). In Task 1.1 data from prior operations of the Arizona Public Service Alternative Fuel Pilot Plant (AFPP) were gathered and analyzed to identify operating strategies for developing costs of hydrogen production. Strategies were developed for operating production equipment in three modes. In Winter Mode, production equipment is operated continuously. In Shoulder Mode, production equipment is operated only when the price of electricity is below a preset maximum of $\$ 55.00 / \mathrm{MWhr}$. In Summer Mode, production equipment is operated only during off peak electric cost periods.

In Task 1.2, the AFPP was operated for three months in each of the three production modes. Costs for hydrogen production were calculated using the actual price for electricity delivered at the Palo Verde Nuclear Generating Station (PVNGS) electrical switchyard in 2006. The price of electricity at the Palo Verde switchyard was used for this simulation of hydrogen production cost, as it represents the opportunity cost for using electricity to produce hydrogen rather than to sell in the wholesale market. AFPP cost of electricity for hydrogen production in each mode were:
Winter Mode
$\$ 9.16 / \mathrm{kg}$
Shoulder Mode
$\$ 3.63 / \mathrm{kg}$
Summer Mode
$\$ 11.80 / \mathrm{kg}$

These costs were significantly influenced by the efficiency of the electrolyzer and by efficiency improvements achieved by implementing lessons learned from operation of the AFPP. Using historical data from AFPP operation and the price of electric energy at the Palo Verde Nuclear Generating Station (PVNGS) electrical switchyard in 2006, the following hydrogen production costs were estimated in Task 1.1 for the AFPP.
Winter Mode
$\$ 5.90 / \mathrm{kg}$
Shoulder Mode
$\$ 5.68 / \mathrm{kg}$
Summer Mode
$\$ 7.57 / \mathrm{kg}$

It can be seen that while the shoulder mode in the least expensive production period, the variation between the shoulder mode and the winter and summer modes is small in comparison to the variation resulting from operation in the three production modes of Task 1.2. The predominate cause for the significant reduction in shoulder mode costs over those achieved in summer and winter modes was the replacement of the electrolyzer at the beginning of the shoulder production mode and the resutant elimination of the losses associated with the hydrogen dryer.. 


\section{INTRODUCTION}

Electric Transportation Applications (ETA) entered into Cooperative Agreement DE-FC07-0614788 with the US Department of Energy (DOE) to evaluate the economics of producing commercial scale quantities $(1 \mathrm{~kg} / \mathrm{s})$ of hydrogen using electricity generated from nuclear energy. The Agreement establishes four Work Tasks, which are detailed in the Work Breakdown Structure presented in Appendix 1. This report documents the results of operations conducted under Task 1.2.

In Task 1.2, the APS Alternative Fuel Pilot Plant (AFPP) was operated in three different modes;

- Winter Mode - Production plant is operated continuously at maximum capacity,

- Shoulder Mode - Production plant is operated to maximize hydrogen production, but only when electricity can be purchased at less than a preset price.

- Summer Mode - Production plant is operated only during off peak (electric demand) periods,

These production modes represent different operating strategies for minimizing hydrogen production cost based on the varying price of electricity. This report summarizes the operation of the AFPP in these three modes (Task 1.2) and analyzes the economics of AFPP operation (Task 1.3).

\section{WINTER MODE OPERATIONS}

The AFPP was operated for three months (February, March and April, 2007) in the winter mode. This operating mode provides for continuous operation of the plant, maximizing hydrogen production, and simulates the cost of production using electricity costs for the months of January, February and March, 2006. A summary report for the winter mode operations is contained in Appendix 2. Table 1 summarizes key plant parameters for the three-month winter mode operating period.

\section{Table 1 - Winter Mode Operations Summary}

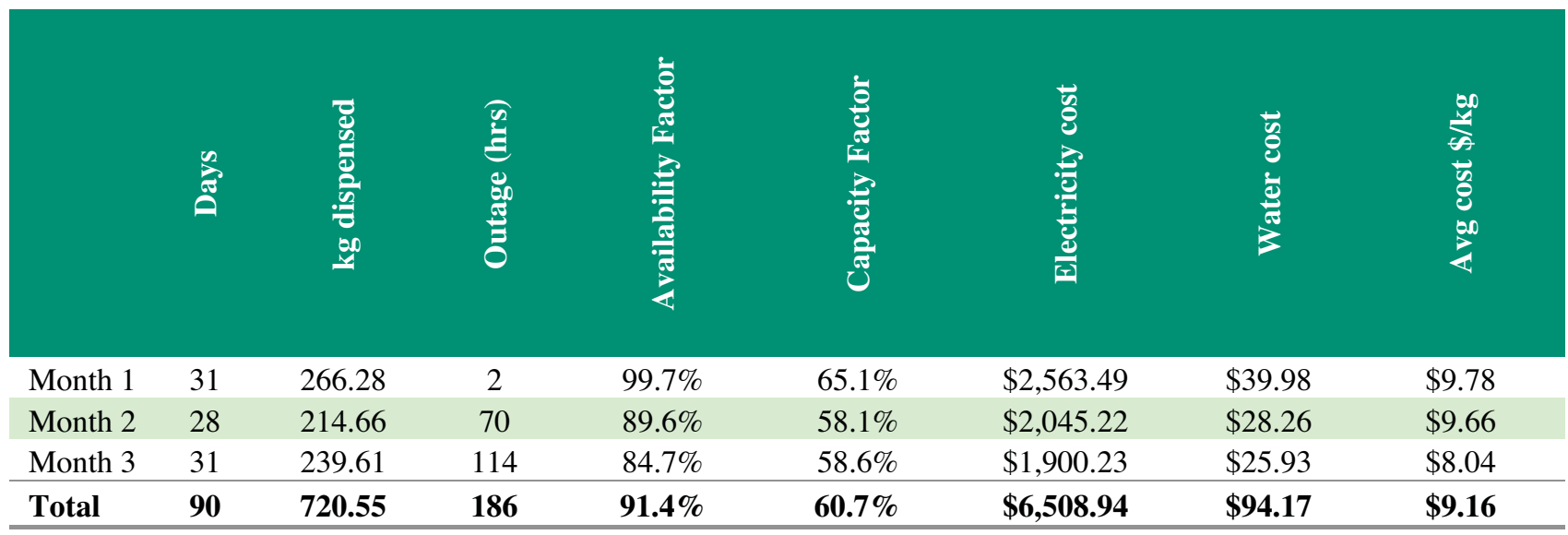

The plant required $180.6 \mathrm{kWhr}$ per kilogram of hydrogen dispensed, for a plant efficiency of $18.5 \%$ (using the LHV of hydrogen as $33.4 \mathrm{kWh} / \mathrm{kg}$ ) during the continuous operation in the winter operating mode. Hydrogen was produced, using nuclear generation, at an average cost of $\$ 9.16 / \mathrm{kg}$ during continuous operation in the winter operating mode. 
Operating the plant continuously at full output during the winter operating mode provided the opportunity to gather excellent data on hydrogen losses within the plant. This data revealed that $17 \%$ of the hydrogen produced by the electrolyzer was lost with regeneration of the hydrogen dryer. If this hydrogen had been dispensed the average cost of hydrogen would have been reduced to $\$ 7.83$. These hydrogen losses were eliminated when the electrolyzer was replaced prior to operation in the shoulder mode.

\section{SHOULDER MODE OPERATIONS}

The AFPP was operated for three months (November and December 2007, and January 2008) in the shoulder mode. In this mode the plant is operated based on the price of electric energy. The plant Production was shut down when electric energy prices were over $\$ 55 / \mathrm{MWhr}$ for electricity as priced at the Palo Verde Switchyard during the months of May, June and July, 2006.

Prior to the start of this operating mode, the electrolyzer was replaced due to failure of the original unit. The replacement electrolyzer is manufactured by Proton Energy to the following nameplate specifications.

\section{Hogen H-Series Nameplate Specifications}

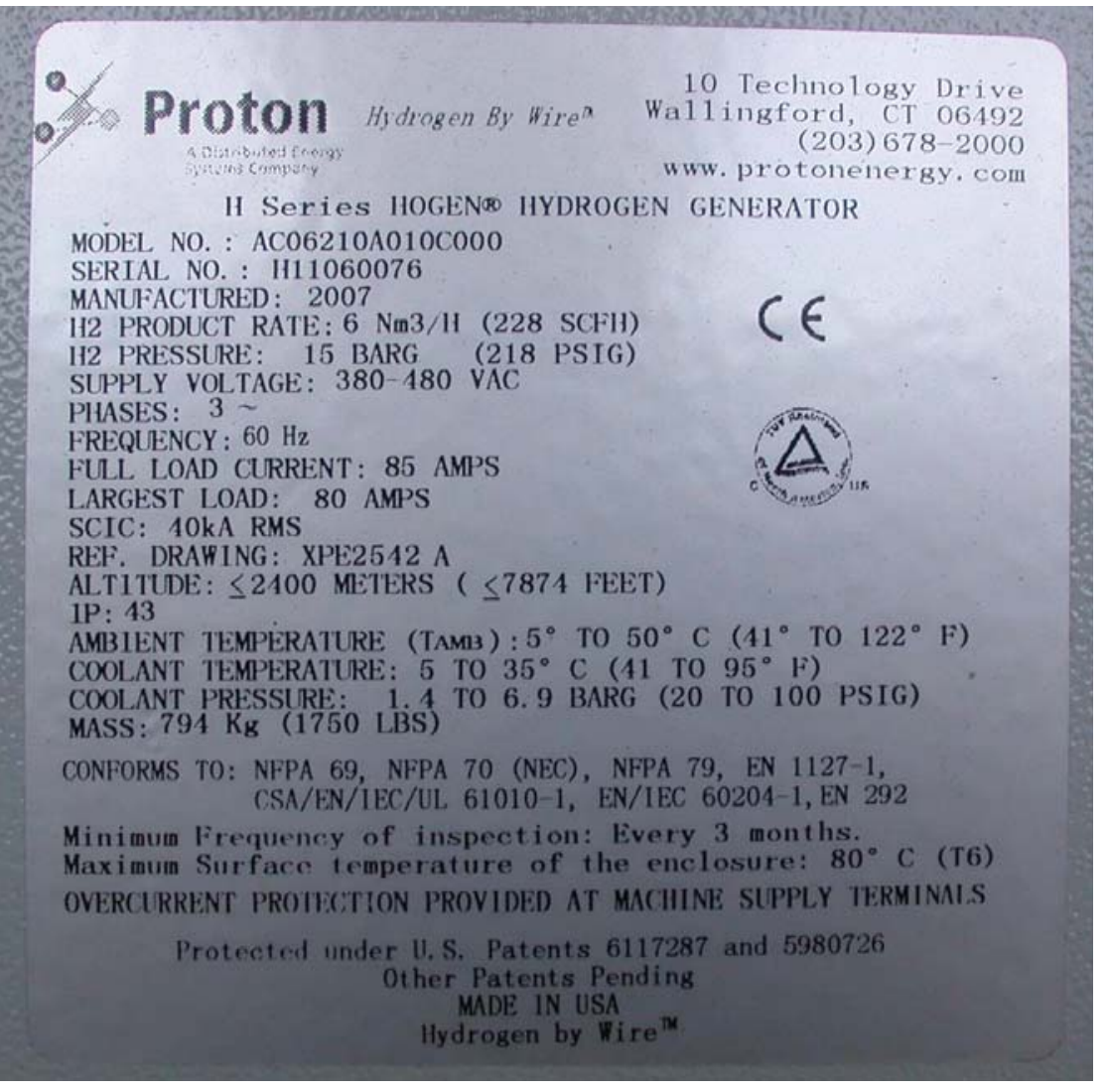

The replacement electrolyzer operated at significantly greater efficiency than the original unit it replaced. Near the end of its life (summer mode), the original production unit required $153.2 \mathrm{kWhr}$ for each kilogram of hydrogen dispensed. The replacement electrolyzer during the shoulder mode required only $92.3 \mathrm{kWhr}$ for each kilogram of hydrogen dispensed - a reduction of $21 \%$. 
The replacement electrolyzer is shown in Figure 1 as installed in the AFPP.

Figure 1: Hogen Electrolyzer Installed in the APS Alternative Fuel Pilot Plant

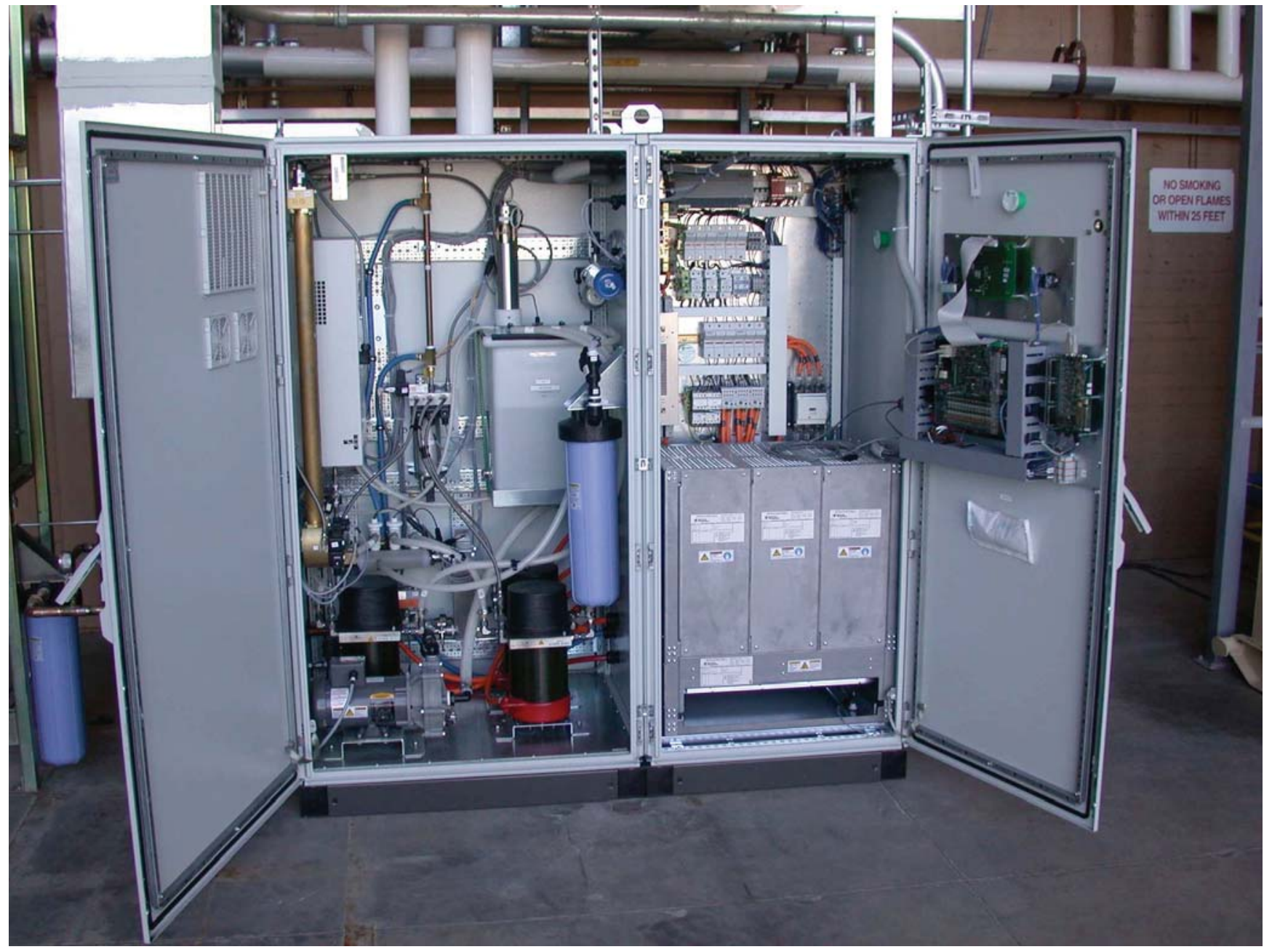

A summary report for the shoulder mode operations is contained in Appendix 3. Table 2 summarizes key plant parameters for the three-month shoulder mode operating period.

\section{Table 2 - Shoulder Mode Operations Summary}

\begin{tabular}{|c|c|c|c|c|c|c|c|c|}
\hline 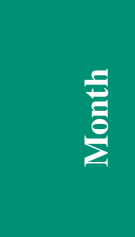 & $\hat{\sigma}_{0}^{\infty}$ & 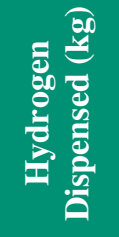 & 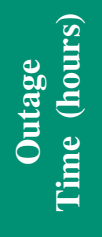 & 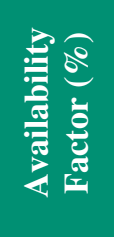 & 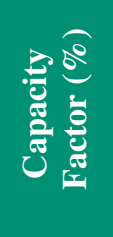 & 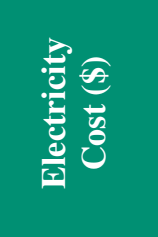 & 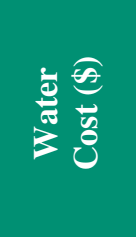 & 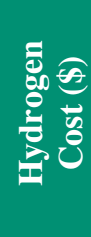 \\
\hline Month 1 & 30 & 236.56 & 181.5 & $74.8 \%$ & $59.7 \%$ & $\$ 831.17$ & $\$ 37.04$ & $\$ 3.67$ \\
\hline Month 2 & 31 & 288.28 & 78.5 & $89.4 \%$ & $66.7 \%$ & $\$ 931.83$ & $\$ 46.50$ & $\$ 3.39$ \\
\hline Month 3 & 31 & 187.50 & 35.5 & $95.2 \%$ & $43.6 \%$ & $\$ 686.85$ & $\$ 30.70$ & $\$ 3.83$ \\
\hline Total & 92 & 712.34 & 295.5 & $87.5 \%$ & $57.3 \%$ & $\$ 2,449.85$ & $\$ 114.24$ & $\$ 3.63$ \\
\hline
\end{tabular}


During the three-months of operation in the shoulder mode, the plant required $153.8 \mathrm{kWhr}$ per kilogram of hydrogen dispensed, for a plant conversion efficiency of only $21.7 \%$ (using the LHV of hydrogen as $33.4 \mathrm{kWh} / \mathrm{kg}$ ) during energy cost limited operation in the shoulder operating mode. Hydrogen was produced, using nuclear generation, at an average cost of $\$ 3.63 / \mathrm{kg}$.

\section{SUMMER MODE OPERATIONS}

The AFPP was operated for two months (June and July, 2007) in the summer mode. This operating mode provides for off peak operation of the plant, maximizing hydrogen production cost, and simulates the cost of production using electricity costs for the months of June and July, 2006. The summer mode was limited to two months of operation due to failure of the hydrogen production unit. A summary report for the summer mode operations is contained in Appendix 4. Table 3 summarizes key plant parameters for the two-month summer mode operating period.

\section{Table 3 - Summer Mode Operations Summary}

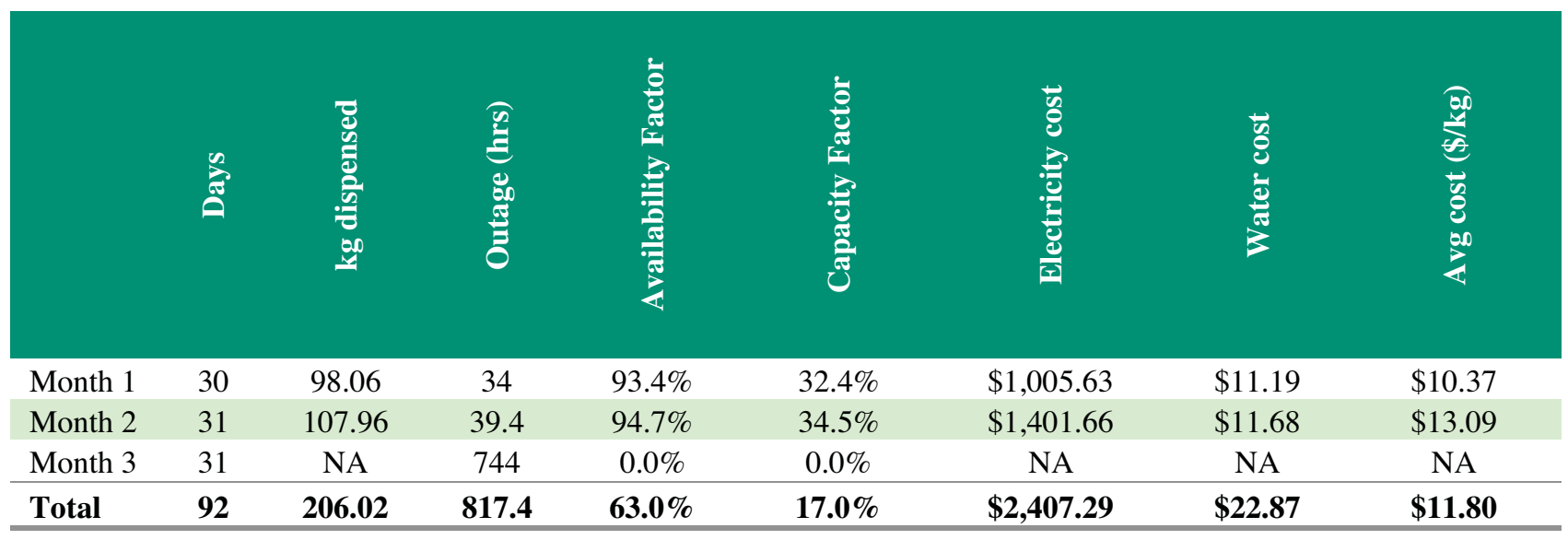

The AFPP required $244.34 \mathrm{kWhr}$ per kilogram of hydrogen dispensed, for a plant conversion efficiency of only $13.7 \%$ (using the LHV of hydrogen as $33.4 \mathrm{kWh} / \mathrm{kg}$ ) during the off peak operation in the summer operating mode. Hydrogen was produced, using nuclear generation, at an average cost of $\$ 11.80 / \mathrm{kg}$ during off peak operating in the summer operating mode.

Operating the plant only intermittently during the summer mode provided the opportunity to gather excellent data on the impact of auxiliary loads on efficiency of the plant. The plant chiller used to provide chilled water to the hydrogen production unit and to the hydrogen compressors is the single greatest auxiliary load, consuming significantly more electricity than the hydrogen compressors. Additionally, the nitrogen supply system air compressor used $4.9 \%$ of the electricity consumed by the AFPP during the summer operating mode. 


\section{OPERATING COST ANALYSIS}

The AFPP operated with an availability of $90.2 \%$ during the three operating periods. Its overall efficiency during each operating mode was as follows;

- Summer Mode

- Shoulder Mode

- Winter Mode
$13.7 \%(234.3 \mathrm{kWh} / \mathrm{kg})$

$21.7 \%(153.8 \mathrm{kWh} / \mathrm{kg})$

$18.5 \%(180.6 \mathrm{kWh} / \mathrm{kg})$

As a result of operating the AFPP in three different modes, the following key issues related to plant efficiency were identified;

- hydrogen drying must be carefully controlled to minimize hydrogen losses on regeneration,

- plant auxiliary electricity use must be minimized, particularly during periods of electrolyzer shutdown, and

- electrolyzer efficiency degradation near end of life may limit electrolyzer economic life.

The combined effect of these issues is significant, particularly plant auxiliaries and electrolyzer degradation.

Table 4 presents the magnitude of electricity used by the plant chiller. From Table 4 , it can be seen that the chiller required $21.8 \%(33.5 \mathrm{kWh} / \mathrm{kg})$ of all electricity consumed by the AFPP and $35.0 \%$ as much electricity as consumed by the electrolyzer $(95.7 \mathrm{kWh} / \mathrm{kg})$. This is particularly significant when a higher efficiency electrolyzer is used. To illustrate this, a comparison can be made between shoulder mode operation, during which the replacement electrolyzer produced $712.3 \mathrm{~kg}$ of hydrogen at an efficiency of $49.0 \%(68.2 \mathrm{kWh} / \mathrm{kg})$. This is in contrast with an overall efficiency for the original electrolyzer in summer and winter mode operation of $28.7 \%(116.6 \mathrm{kWh} / \mathrm{kg})$.

\section{Table 4 - Chiller Electricity Use}

\begin{tabular}{|c|c|c|c|c|c|c|c|c|c|}
\hline & \multicolumn{2}{|c|}{ Chiller (kWh) } & \multicolumn{2}{|c|}{ Electrolyzer (kWh) } & \multicolumn{2}{|c|}{ Total (kWh) } & \multirow{2}{*}{$\begin{array}{c}\mathbf{H 2} \\
(\mathrm{kg})\end{array}$} & \multirow{2}{*}{$\begin{array}{c}\text { Chiller } \\
(\% \text { of Elyzr })\end{array}$} & \multirow{2}{*}{$\begin{array}{c}\text { Chiller } \\
(\% \text { of Total })\end{array}$} \\
\hline & On Peak & Off Peak & On Peak & Off Peak & On Peak & Off Peak & & & \\
\hline Shoulder & $7,576.3$ & $5,346.7$ & $25,812.8$ & $22,741.7$ & $35,747.0$ & $29,972.6$ & 712.3 & $26.6 \%$ & $19.7 \%$ \\
\hline Summer & $9,506.6$ & $1,508.2$ & 836.7 & $21,163.7$ & $18,995.8$ & $38,804.2$ & 216.1 & $50.1 \%$ & $19.1 \%$ \\
\hline Winter & $21,852.4$ & $9,426.5$ & $59,140.2$ & $28,035.6$ & $89,774.9$ & $40,343.3$ & 720.6 & $35.9 \%$ & $24.0 \%$ \\
\hline$\overline{\text { Total }}$ & $38,935.3$ & $16,281.4$ & $\overline{85,789.7}$ & $\overline{71,941.0}$ & $144,517.7$ & $109,120.1$ & $1,649.0$ & $\overline{35.0 \%}$ & $21.8 \%$ \\
\hline
\end{tabular}

If the chiller energy use is eliminated during the shoulder mode, when the high efficiency electrolyzer was employed, an energy efficiency of $74.1 \mathrm{kWh} / \mathrm{kg}$ is achievable. This would increase AFPP efficiency to $45 \%$. It is estimated that the AFPP would operate at this efficiency if the following designs were adopted;

- utilize air cooling or an evaporative cooling tower for plant cooling water,

- minimize the use of nitrogen in plant operations,

- utilize electronic controls rather than pneumatic controls,

- minimize hydrogen losses during dryer regeneration, and

- limit electrolyzer stack life to its economic life. 
The effect of the higher efficiency electrolyzer can also be seen in the cost of hydrogen produced in each operating mode.

- Summer Mode (original electrolyzer)

$\$ 11.80$

- Shoulder Mode (high efficiency electrolyzer)

$\$ 3.63$

- Winter Mode (original electrolyzer)

$\$ 9.16$ 


\section{APPENDIX D}

\section{ELECTRICITY COSTS FOR PVNGS SWITCHYARD DELIVERY DURING PEAK AND OFF-PEAK PERIODS}




\section{Appendix D Electricity Costs for PVNGS Switchyard Delivery During Peak and Off-Peak Periods}

\begin{tabular}{|c|c|c|c|}
\hline \multicolumn{4}{|c|}{ Palo Verde Energy Cost } \\
\hline $\begin{array}{c}\text { Day of } \\
\text { Week }\end{array}$ & $\begin{array}{c}\text { Calendar } \\
\text { Date }\end{array}$ & $\begin{array}{c}\text { On-Peak } \\
\$ / M W h \\
\end{array}$ & $\begin{array}{c}\text { Off-Peak } \\
\$ / M W h \\
\end{array}$ \\
\hline Sunday & 01-Jan-06 & 47.17 & 47.17 \\
\hline Monday & 02-Jan-06 & 47.17 & 47.17 \\
\hline Tuesday & 03-Jan-06 & 62.24 & 35.13 \\
\hline Wednesday & 04-Jan-06 & 67.29 & 38.36 \\
\hline Thursday & 05-Jan-06 & 63.85 & 38.43 \\
\hline Friday & 06-Jan-06 & 63.39 & 41.86 \\
\hline Saturday & 07-Jan-06 & 63.39 & 41.86 \\
\hline Sunday & 08-Jan-06 & 54.80 & 54.80 \\
\hline Monday & 09-Jan-06 & 64.58 & 54.80 \\
\hline Tuesday & 10-Jan-06 & 64.98 & 43.07 \\
\hline Wednesday & 11-Jan-06 & 63.26 & 45.19 \\
\hline Thursday & 12-Jan-06 & 63.26 & 45.19 \\
\hline Friday & 13-Jan-06 & 58.48 & 43.19 \\
\hline Saturday & 14-Jan-06 & 58.48 & 43.19 \\
\hline Sunday & 15-Jan-06 & 52.52 & 52.52 \\
\hline Monday & 16-Jan-06 & 59.38 & 52.52 \\
\hline Tuesday & 17-Jan-06 & 63.71 & 44.47 \\
\hline Wednesday & 18-Jan-06 & 64.79 & 42.25 \\
\hline Thursday & 19-Jan-06 & 64.57 & 40.27 \\
\hline Friday & 20-Jan-06 & 59.02 & 42.07 \\
\hline Saturday & 21-Jan-06 & 59.02 & 42.07 \\
\hline Sunday & 22-Jan-06 & 57.72 & 57.72 \\
\hline Monday & 23-Jan-06 & 64.86 & 57.72 \\
\hline Tuesday & 24-Jan-06 & 61.43 & 43.31 \\
\hline Wednesday & 25-Jan-06 & 60.31 & 43.52 \\
\hline Thursday & 26-Jan-06 & 61.61 & 47.75 \\
\hline Friday & 27-Jan-06 & 54.61 & 47.16 \\
\hline Saturday & 28-Jan-06 & 54.61 & 47.16 \\
\hline Sunday & 29-Jan-06 & 54.35 & 54.35 \\
\hline Monday & 30-Jan-06 & 58.32 & 54.35 \\
\hline Tuesday & 31-Jan-06 & 58.96 & 46.23 \\
\hline Wednesday & 01-Feb-06 & 62.01 & 46.43 \\
\hline Thursday & 02-Feb-06 & 59.73 & 44.29 \\
\hline Friday & 03-Feb-06 & 50.77 & 40.99 \\
\hline Saturday & 04-Feb-06 & 50.77 & 40.99 \\
\hline Sunday & 05-Feb-06 & 47.71 & 47.71 \\
\hline Monday & 06-Feb-06 & 52.67 & 47.71 \\
\hline Tuesday & 07-Feb-06 & 54.86 & 43.98 \\
\hline Wednesday & 08-Feb-06 & 53.69 & 44.27 \\
\hline Thursday & 09-Feb-06 & 55.13 & 44.56 \\
\hline Friday & $10-$ Feb-06 & 51.31 & 41.77 \\
\hline Saturday & 11-Feb-06 & 51.31 & 41.77 \\
\hline
\end{tabular}




\begin{tabular}{|c|c|c|c|}
\hline Sunday & 12-Feb-06 & 46.50 & 46.50 \\
\hline Monday & 13-Feb-06 & 53.98 & 46.50 \\
\hline Tuesday & 14-Feb-06 & 53.03 & 44.76 \\
\hline Wednesday & 15-Feb-06 & 52.66 & 46.90 \\
\hline Thursday & 16-Feb-06 & 52.66 & 46.90 \\
\hline Friday & 17-Feb-06 & 54.67 & 47.16 \\
\hline Saturday & $18-F e b-06$ & 54.67 & 47.16 \\
\hline Sunday & 19-Feb-06 & 53.04 & 53.04 \\
\hline Monday & 20-Feb-06 & 57.42 & 53.04 \\
\hline Tuesday & 21-Feb-06 & 57.90 & 45.45 \\
\hline Wednesday & $22-F e b-06$ & 58.04 & 47.97 \\
\hline Thursday & 23-Feb-06 & 56.68 & 48.68 \\
\hline Friday & 24-Feb-06 & 54.16 & 46.64 \\
\hline Saturday & $25-$ Feb-06 & 54.16 & 46.64 \\
\hline Sunday & $26-F e b-06$ & 49.01 & 49.01 \\
\hline Monday & 27-Feb-06 & 54.43 & 49.01 \\
\hline Tuesday & 28 -Feb-06 & 50.47 & 42.68 \\
\hline Wednesday & 01-Mar-06 & 47.59 & 37.89 \\
\hline Thursday & 02-Mar-06 & 44.89 & 34.46 \\
\hline Friday & 03-Mar-06 & 44.32 & 34.34 \\
\hline Saturday & 04-Mar-06 & 44.32 & 34.34 \\
\hline Sunday & 05-Mar-06 & 40.32 & 40.32 \\
\hline Monday & 06-Mar-06 & 45.32 & 40.32 \\
\hline Tuesday & 07-Mar-06 & 47.92 & 38.24 \\
\hline Wednesday & 08-Mar-06 & 46.83 & 34.20 \\
\hline Thursday & 09-Mar-06 & 46.65 & 32.76 \\
\hline Friday & 10-Mar-06 & 45.98 & 34.26 \\
\hline Saturday & 11-Mar-06 & 45.98 & 34.26 \\
\hline Sunday & 12-Mar-06 & 41.26 & 41.26 \\
\hline Monday & 13-Mar-06 & 47.68 & 41.26 \\
\hline Tuesday & 14-Mar-06 & 48.43 & 36.66 \\
\hline Wednesday & 15-Mar-06 & 48.52 & 35.18 \\
\hline Thursday & 16-Mar-06 & 47.88 & 33.76 \\
\hline Friday & 17-Mar-06 & 47.57 & 33.26 \\
\hline Saturday & 18-Mar-06 & 47.57 & 33.26 \\
\hline Sunday & 19-Mar-06 & 42.46 & 42.46 \\
\hline Monday & 20-Mar-06 & 49.48 & 42.46 \\
\hline Tuesday & 21-Mar-06 & 48.90 & 34.15 \\
\hline Wednesday & 22-Mar-06 & 47.89 & 34.05 \\
\hline Thursday & 23-Mar-06 & 47.77 & 35.42 \\
\hline Friday & 24-Mar-06 & 46.68 & 35.69 \\
\hline Saturday & 25-Mar-06 & 46.68 & 35.69 \\
\hline Sunday & 26-Mar-06 & 41.89 & 41.89 \\
\hline Monday & 27-Mar-06 & 48.59 & 41.89 \\
\hline Tuesday & 28-Mar-06 & 46.05 & 33.77 \\
\hline Wednesday & 29-Mar-06 & 45.66 & 31.87 \\
\hline Thursday & 30-Mar-06 & 45.66 & 31.87 \\
\hline Friday & 31-Mar-06 & 45.29 & 31.34 \\
\hline Saturday & 01-Apr-06 & 46.67 & 33.93 \\
\hline Sunday & 02-Apr-06 & 39.79 & 39.79 \\
\hline
\end{tabular}




\begin{tabular}{|c|c|c|c|}
\hline Monday & 03-Apr-06 & 49.23 & 39.79 \\
\hline Tuesday & 04-Apr-06 & 50.43 & 36.63 \\
\hline Wednesday & 05-Apr-06 & 50.81 & 34.00 \\
\hline Thursday & 06-Apr-06 & 53.33 & 34.73 \\
\hline Friday & 07-Apr-06 & 51.96 & 30.23 \\
\hline Saturday & 08-Apr-06 & 47.13 & 31.35 \\
\hline Sunday & 09-Apr-06 & 31.35 & 31.35 \\
\hline Monday & 10 -Apr-06 & 47.13 & 31.35 \\
\hline Tuesday & 11-Apr-06 & 49.17 & 28.08 \\
\hline Wednesday & 12-Apr-06 & 56.32 & 36.24 \\
\hline Thursday & 13-Apr-06 & 56.32 & 36.24 \\
\hline Friday & 14-Apr-06 & 48.85 & 24.54 \\
\hline Saturday & 15-Apr-06 & 48.85 & 24.54 \\
\hline Sunday & 16-Apr-06 & 26.68 & 26.68 \\
\hline Monday & 17-Apr-06 & 47.16 & 26.68 \\
\hline Tuesday & 18-Apr-06 & 50.90 & 28.37 \\
\hline Wednesday & 19-Apr-06 & 56.25 & 40.56 \\
\hline Thursday & 20-Apr-06 & 55.86 & 32.41 \\
\hline Friday & 21-Apr-06 & 57.17 & 32.58 \\
\hline Saturday & 22-Apr-06 & 57.17 & 32.58 \\
\hline Sunday & 23-Apr-06 & 36.57 & 36.57 \\
\hline Monday & 24-Apr-06 & 53.31 & 36.57 \\
\hline Tuesday & 25-Apr-06 & 52.98 & 28.60 \\
\hline Wednesday & 26-Apr-06 & 51.57 & 25.30 \\
\hline Thursday & 27-Apr-06 & 51.57 & 25.30 \\
\hline Friday & 28-Apr-06 & 50.31 & 25.88 \\
\hline Saturday & 29-Apr-06 & 50.31 & 25.88 \\
\hline Sunday & 30-Apr-06 & 34.25 & 34.25 \\
\hline Monday & 01-May-06 & 50.00 & 27.16 \\
\hline Tuesday & 02-Мay-06 & 51.98 & 26.69 \\
\hline Wednesday & 03-Мay-06 & 51.56 & 28.65 \\
\hline Thursday & 04-Мау-06 & 49.19 & 24.12 \\
\hline Friday & 05-Мay-06 & 45.57 & 21.57 \\
\hline Saturday & 06-Мay-06 & 45.57 & 21.57 \\
\hline Sunday & 07-May-06 & 33.99 & 33.99 \\
\hline Monday & 08-May-06 & 48.73 & 33.99 \\
\hline Tuesday & 09-Мау-06 & 53.45 & 24.17 \\
\hline Wednesday & 10-May-06 & 59.85 & 33.63 \\
\hline Thursday & 11-Мay-06 & 56.15 & 35.15 \\
\hline Friday & 12-May-06 & 55.19 & 30.75 \\
\hline Saturday & 13-Мay-06 & 55.19 & 30.75 \\
\hline Sunday & 14-Мay-06 & 41.48 & 41.48 \\
\hline Monday & 15-Мау-06 & 56.61 & 41.48 \\
\hline Tuesday & 16-Мay-06 & 56.76 & 31.23 \\
\hline Wednesday & 17-May-06 & 59.37 & 31.04 \\
\hline Thursday & 18-May-06 & 63.38 & 28.92 \\
\hline Friday & 19-Мay-06 & 58.41 & 23.84 \\
\hline Saturday & 20-Мay-06 & 58.41 & 23.84 \\
\hline Sunday & 21-Мay-06 & 28.54 & 28.54 \\
\hline Monday & 22-May-06 & 47.65 & 28.54 \\
\hline
\end{tabular}




\begin{tabular}{|c|c|c|c|}
\hline Tuesday & 23-May-06 & 48.75 & 19.15 \\
\hline Wednesday & 24-Мау-06 & 54.04 & 20.00 \\
\hline Thursday & 25-Мау-06 & 54.04 & 20.00 \\
\hline Friday & 26-May-06 & 44.72 & 13.43 \\
\hline Saturday & 27-Мay-06 & 44.72 & 13.43 \\
\hline Sunday & 28-Мау-06 & 23.58 & 23.58 \\
\hline Monday & 29-Мау-06 & 23.58 & 23.58 \\
\hline Tuesday & 30-Мay-06 & 44.13 & 14.95 \\
\hline Wednesday & 31-May-06 & 50.67 & 12.13 \\
\hline Thursday & 01-Jun-06 & 56.91 & 23.47 \\
\hline Friday & 02-Jun-06 & 59.70 & 27.41 \\
\hline Saturday & 03-Jun-06 & 59.70 & 27.41 \\
\hline Sunday & 04-Jun-06 & 39.72 & 39.72 \\
\hline Monday & 05-Jun-06 & 59.53 & 39.72 \\
\hline Tuesday & 06-Jun-06 & 65.99 & 28.92 \\
\hline Wednesday & 07-Jun-06 & 58.68 & 15.35 \\
\hline Thursday & 08-Jun-06 & 55.16 & 12.29 \\
\hline Friday & 09-Jun-06 & 55.69 & 12.27 \\
\hline Saturday & 10-Jun-06 & 55.69 & 12.27 \\
\hline Sunday & 11-Jun-06 & 36.07 & 36.07 \\
\hline Monday & 12-Jun-06 & 57.14 & 36.07 \\
\hline Tuesday & 13-Jun-06 & 59.31 & 16.99 \\
\hline Wednesday & 14-Jun-06 & 55.40 & 17.32 \\
\hline Thursday & 15-Jun-06 & 51.27 & 16.70 \\
\hline Friday & 16-Jun-06 & 52.70 & 16.22 \\
\hline Saturday & 17-Jun-06 & 52.70 & 16.22 \\
\hline Sunday & 18-Jun-06 & 43.46 & 43.46 \\
\hline Monday & 19-Jun-06 & 62.84 & 43.46 \\
\hline Tuesday & 20-Jun-06 & 72.75 & 27.00 \\
\hline Wednesday & 21-Jun-06 & 69.78 & 31.49 \\
\hline Thursday & 22-Jun-06 & 71.90 & 36.90 \\
\hline Friday & 23-Jun-06 & 74.26 & 38.07 \\
\hline Saturday & 24-Jun-06 & 74.26 & 38.07 \\
\hline Sunday & 25-Jun-06 & 52.51 & 52.51 \\
\hline Monday & 26-Jun-06 & 74.67 & 52.51 \\
\hline Tuesday & 27-Jun-06 & 69.64 & 37.13 \\
\hline Wednesday & 28-Jun-06 & 64.63 & 34.24 \\
\hline Thursday & 29-Jun-06 & 64.63 & 34.24 \\
\hline Friday & 30-Jun-06 & 59.30 & 34.43 \\
\hline Saturday & 01-Jul-06 & 55.70 & 35.61 \\
\hline Sunday & 02-Jul-06 & 46.38 & 46.38 \\
\hline Monday & 03-Jul-06 & 59.54 & 46.38 \\
\hline Tuesday & 04-Jul-06 & 42.86 & 42.86 \\
\hline Wednesday & 05-Jul-06 & 60.34 & 42.86 \\
\hline Thursday & 06-Jul-06 & 64.07 & 36.03 \\
\hline Friday & 07-Jul-06 & 55.14 & 31.38 \\
\hline Saturday & 08-Jul-06 & 55.14 & 31.38 \\
\hline Sunday & 09-Jul-06 & 36.86 & 36.86 \\
\hline Monday & 10-Jul-06 & 55.79 & 36.86 \\
\hline Tuesday & 11-Jul-06 & 56.10 & 30.74 \\
\hline
\end{tabular}




\begin{tabular}{|c|c|c|c|}
\hline Wednesday & 12-Jul-06 & 58.17 & 33.09 \\
\hline Thursday & 13-Jul-06 & 66.56 & 35.75 \\
\hline Friday & 14-Jul-06 & 71.80 & 35.95 \\
\hline Saturday & 15-Jul-06 & 71.80 & 35.95 \\
\hline Sunday & 16-Jul-06 & 63.80 & 63.80 \\
\hline Monday & 17-Jul-06 & 94.81 & 63.80 \\
\hline Tuesday & 18-Jul-06 & 106.21 & 41.77 \\
\hline Wednesday & 19-Jul-06 & 92.76 & 36.85 \\
\hline Thursday & 20-Jul-06 & 97.98 & 36.60 \\
\hline Friday & 21-Jul-06 & 99.51 & 37.39 \\
\hline Saturday & 22-Jul-06 & 99.51 & 37.39 \\
\hline Sunday & 23-Jul-06 & 66.89 & 66.89 \\
\hline Monday & 24-Jul-06 & 114.88 & 66.89 \\
\hline Tuesday & 25-Jul-06 & 296.76 & 53.09 \\
\hline Wednesday & 26-Jul-06 & 160.59 & 43.42 \\
\hline Thursday & 27-Jul-06 & 116.05 & 44.56 \\
\hline Friday & 28-Jul-06 & 100.55 & 45.49 \\
\hline Saturday & 29-Jul-06 & 100.55 & 45.49 \\
\hline Sunday & 30-Jul-06 & 52.28 & 52.28 \\
\hline Monday & 31-Jul-06 & 70.99 & 52.28 \\
\hline Tuesday & 01-Aug-06 & 75.55 & 43.97 \\
\hline Wednesday & 02-Aug-06 & 77.35 & 48.53 \\
\hline Thursday & 03-Aug-06 & 75.14 & 41.40 \\
\hline Friday & 04-Aug-06 & 63.70 & 37.94 \\
\hline Saturday & 05-Aug-06 & 63.70 & 37.94 \\
\hline Sunday & 06-Aug-06 & 48.81 & 48.81 \\
\hline Monday & 07-Aug-06 & 66.36 & 48.81 \\
\hline Tuesday & 08-Aug-06 & 66.56 & 38.96 \\
\hline Wednesday & 09-Aug-06 & 70.45 & 43.03 \\
\hline Thursday & 10-Aug-06 & 76.82 & 49.49 \\
\hline Friday & 11-Aug-06 & 72.95 & 48.72 \\
\hline Saturday & 12-Aug-06 & 72.95 & 48.72 \\
\hline Sunday & 13-Aug-06 & 49.10 & 49.10 \\
\hline Monday & 14-Aug-06 & 72.61 & 49.10 \\
\hline Tuesday & 15 -Aug-06 & 62.68 & 41.44 \\
\hline Wednesday & 16-Aug-06 & 59.79 & 39.78 \\
\hline Thursday & 17-Aug-06 & 61.09 & 42.48 \\
\hline Friday & 18-Aug-06 & 59.92 & 42.46 \\
\hline Saturday & 19-Aug-06 & 59.92 & 42.46 \\
\hline Sunday & 20-Aug-06 & 43.13 & 43.13 \\
\hline Monday & 21-Aug-06 & 69.38 & 43.13 \\
\hline Tuesday & 22-Aug-06 & 61.85 & 39.84 \\
\hline Wednesday & 23-Aug-06 & 59.75 & 39.34 \\
\hline Thursday & 24-Aug-06 & 61.24 & 42.38 \\
\hline Friday & 25-Aug-06 & 59.09 & 45.48 \\
\hline Saturday & 26-Aug-06 & 59.09 & 45.48 \\
\hline Sunday & 27-Aug-06 & 50.08 & 50.08 \\
\hline Monday & 28-Aug-06 & 63.66 & 50.08 \\
\hline Tuesday & 29-Aug-06 & 56.99 & 38.12 \\
\hline Wednesday & 30-Aug-06 & 56.17 & 37.68 \\
\hline
\end{tabular}




\begin{tabular}{|c|c|c|c|}
\hline Thursday & 31-Aug-06 & 56.17 & 37.68 \\
\hline Friday & 01-Sep-06 & 57.09 & 39.92 \\
\hline Saturday & 02-Sep-06 & 57.09 & 39.92 \\
\hline Sunday & 03-Sep-06 & 45.13 & 45.13 \\
\hline Monday & 04-Sep-06 & 45.13 & 45.13 \\
\hline Tuesday & 05-Sep-06 & 52.02 & 34.99 \\
\hline Wednesday & 06-Sep-06 & 56.12 & 36.28 \\
\hline Thursday & 07-Sep-06 & 56.86 & 34.52 \\
\hline Friday & 08-Sep-06 & 49.16 & 32.85 \\
\hline Saturday & 09-Sep-06 & 49.16 & 32.85 \\
\hline Sunday & 10-Sep-06 & 36.43 & 36.43 \\
\hline Monday & 11-Sep-06 & 48.06 & 36.43 \\
\hline Tuesday & 12-Sep-06 & 49.64 & 30.17 \\
\hline Wednesday & 13-Sep-06 & 47.75 & 29.08 \\
\hline Thursday & 14-Sep-06 & 43.78 & 29.37 \\
\hline Friday & 15-Sep-06 & 40.33 & 27.28 \\
\hline Saturday & 16-Sep-06 & 40.33 & 27.28 \\
\hline Sunday & 17-Sep-06 & 25.04 & 25.04 \\
\hline Monday & 18 -Sep-06 & 35.80 & 25.04 \\
\hline Tuesday & 19-Sep-06 & 45.22 & 28.49 \\
\hline Wednesday & 20-Sep-06 & 44.33 & 31.06 \\
\hline Thursday & 21-Sep-06 & 43.50 & 32.34 \\
\hline Friday & 22-Sep-06 & 37.36 & 27.89 \\
\hline Saturday & 23-Sep-06 & 37.36 & 27.89 \\
\hline Sunday & 24-Sep-06 & 29.10 & 29.10 \\
\hline Monday & 25-Sep-06 & 37.36 & 29.10 \\
\hline Tuesday & 26-Sep-06 & 39.46 & 25.84 \\
\hline Wednesday & $27-$ Sep-06 & 39.66 & 24.72 \\
\hline Thursday & 28-Sep-06 & 41.40 & 25.30 \\
\hline Friday & 29-Sep-06 & 37.18 & 23.30 \\
\hline Saturday & 30-Sep-06 & 37.18 & 23.30 \\
\hline Sunday & 01-Oct-06 & 26.93 & 26.93 \\
\hline Monday & $02-O c t-06$ & 35.62 & 26.93 \\
\hline Tuesday & 03-Oct-06 & 38.60 & 25.05 \\
\hline Wednesday & $04-O c t-06$ & 39.62 & 26.54 \\
\hline Thursday & $05-O c t-06$ & 44.35 & 29.60 \\
\hline Friday & 06-Oct-06 & 43.37 & 30.58 \\
\hline Saturday & 07-Oct-06 & 43.37 & 30.58 \\
\hline Sunday & 08 -Oct-06 & 30.64 & 30.64 \\
\hline Monday & 09-Oct-06 & 38.96 & 30.64 \\
\hline Tuesday & 10-Oct-06 & 41.79 & 29.22 \\
\hline Wednesday & 11-Oct-06 & 41.67 & 28.11 \\
\hline Thursday & 12-Oct-06 & 47.83 & 31.42 \\
\hline Friday & $13-O c t-06$ & 43.24 & 27.84 \\
\hline Saturday & 14-Oct-06 & 43.24 & 27.84 \\
\hline Sunday & 15-Oct-06 & 28.54 & 28.54 \\
\hline Monday & $16-O c t-06$ & 39.75 & 28.54 \\
\hline Tuesday & 17-Oct-06 & 46.33 & 29.69 \\
\hline Wednesday & 18-Oct-06 & 54.64 & 34.03 \\
\hline Thursday & 19-Oct-06 & 51.57 & 35.36 \\
\hline
\end{tabular}




\begin{tabular}{|c|c|c|c|}
\hline Friday & 20-Oct-06 & 54.50 & 39.72 \\
\hline Saturday & 21-Oct-06 & 54.50 & 39.72 \\
\hline Sunday & 22-Oct-06 & 47.19 & 47.19 \\
\hline Monday & 23-Oct-06 & 59.02 & 47.19 \\
\hline Tuesday & 24-Oct-06 & 65.63 & 48.57 \\
\hline Wednesday & $25-$ Oct-06 & 63.96 & 46.11 \\
\hline Thursday & 26-Oct-06 & 62.34 & 41.39 \\
\hline Friday & 27-Oct-06 & 63.32 & 42.86 \\
\hline Saturday & 28-Oct-06 & 63.32 & 42.86 \\
\hline Sunday & 29-Oct-06 & 45.82 & 45.82 \\
\hline Monday & 30-Oct-06 & 60.40 & 45.82 \\
\hline Tuesday & 31-Oct-06 & 56.66 & 41.66 \\
\hline Wednesday & 01-Nov-06 & 53.97 & 46.73 \\
\hline Thursday & 02-Nov-06 & 58.56 & 42.94 \\
\hline Friday & 03-Nov-06 & 57.90 & 42.14 \\
\hline Saturday & 04-Nov-06 & 57.90 & 42.14 \\
\hline Sunday & 05-Nov-06 & 47.85 & 47.85 \\
\hline Monday & 06-Nov-06 & 60.86 & 47.85 \\
\hline Tuesday & 07-Nov-06 & 55.66 & 38.09 \\
\hline Wednesday & 08-Nov-06 & 54.50 & 36.28 \\
\hline Thursday & 09-Nov-06 & 54.50 & 36.28 \\
\hline Friday & 10-Nov-06 & 56.58 & 37.96 \\
\hline Saturday & 11-Nov-06 & 56.58 & 37.96 \\
\hline Sunday & 12-Nov-06 & 43.31 & 43.31 \\
\hline Monday & 13-Nov-06 & 56.25 & 43.31 \\
\hline Tuesday & 14-Nov-06 & 53.35 & 34.28 \\
\hline Wednesday & 15 -Nov-06 & 53.76 & 39.05 \\
\hline Thursday & 16-Nov-06 & 54.29 & 43.51 \\
\hline Friday & 17-Nov-06 & 54.75 & 38.98 \\
\hline Saturday & 18-Nov-06 & 54.75 & 38.98 \\
\hline Sunday & 19-Nov-06 & 43.22 & 43.22 \\
\hline Monday & 20-Nov-06 & 51.89 & 43.22 \\
\hline Tuesday & 21-Nov-06 & 54.42 & 37.42 \\
\hline Wednesday & 22-Nov-06 & 54.42 & 37.42 \\
\hline Thursday & 23-Nov-06 & 37.98 & 37.98 \\
\hline Friday & 24-Nov-06 & 46.62 & 37.98 \\
\hline Saturday & 25-Nov-06 & 46.62 & 37.98 \\
\hline Sunday & 26-Nov-06 & 41.79 & 41.79 \\
\hline Monday & 27-Nov-06 & 48.03 & 41.79 \\
\hline Tuesday & 28-Nov-06 & 59.82 & 49.95 \\
\hline Wednesday & 29-Nov-06 & 60.07 & 42.04 \\
\hline Thursday & 30-Nov-06 & 62.58 & 49.24 \\
\hline Friday & 01-Dec-06 & 66.60 & 54.23 \\
\hline Saturday & 02-Dec-06 & 66.60 & 54.23 \\
\hline Sunday & 03-Dec-06 & 54.97 & 54.97 \\
\hline Monday & 04-Dec-06 & 66.63 & 54.97 \\
\hline Tuesday & 05-Dec-06 & 61.68 & 48.26 \\
\hline Wednesday & 06-Dec-06 & 57.33 & 43.91 \\
\hline Thursday & 07-Dec-06 & 57.89 & 43.07 \\
\hline Friday & 08-Dec-06 & 56.86 & 43.11 \\
\hline
\end{tabular}




\begin{tabular}{|c|c|c|c|} 
Saturday & 09-Dec-06 & 56.86 & 43.11 \\
Sunday & 10-Dec-06 & 52.68 & 52.68 \\
Monday & 11-Dec-06 & 59.58 & 52.68 \\
Tuesday & 12-Dec-06 & 55.53 & 43.38 \\
Wednesday & 13-Dec-06 & 54.49 & 41.65 \\
Thursday & 14-Dec-06 & 55.44 & 41.26 \\
Friday & 15-Dec-06 & 55.20 & 42.81 \\
Saturday & 16-Dec-06 & 55.20 & 42.81 \\
Sunday & 17-Dec-06 & 50.85 & 50.85 \\
Monday & 18-Dec-06 & 57.43 & 50.85 \\
Tuesday & 19-Dec-06 & 49.66 & 37.81 \\
Wednesday & 20-Dec-06 & 51.11 & 39.77 \\
Thursday & 21-Dec-06 & 51.11 & 39.77 \\
Friday & 22-Dec-06 & 52.45 & 41.55 \\
Saturday & 23-Dec-06 & 52.45 & 41.55 \\
Sunday & 24-Dec-06 & 41.43 & 41.43 \\
Monday & 25-Dec-06 & 41.43 & 41.43 \\
Tuesday & 26-Dec-06 & 50.34 & 42.75 \\
Wednesday & 27-Dec-06 & 48.66 & 36.40 \\
Thursday & 28-Dec-06 & 48.66 & 36.40 \\
Friday & 29-Dec-06 & 46.32 & 40.74 \\
Saturday & 30-Dec-06 & 46.32 & 40.74 \\
Sunday & 31-Dec-06 & 41.88 & 41.88 \\
\hline
\end{tabular}




\section{APPENDIX E}

INL PROCESS MODEL 


\section{Appendix E INL Process Model}

\section{Description of 1-D Integral Electrolyzer Model}

\section{- Energy Equation:}

$$
\mathcal{Q}^{\mathbb{E}} h^{\mathbb{E}}=\sum_{P} N_{i}^{\&}\left[\Delta H_{f}^{o}+H_{i}\left(T_{P}\right)-H_{i}^{o}\right]-\sum_{R} \mathcal{N}_{i}\left[\Delta H_{f}^{o}+H_{i}\left(T_{R}\right)-H_{i}^{o}\right]
$$

Where

$\mathcal{Q}=$ External heat transfer rate to or from the electrolyzer

$V^{\&}=$ Electrical power supplied to the electrolyzer $\mathcal{W}_{i}=\begin{aligned} & \text { Molar flow rate of all constituents (reacting and inert), both anode and cathode } \\ & \text { side }\end{aligned}$

$\Delta H_{f}^{o}+H_{i}\left(T_{R}\right)-H_{i}^{o}=$ Total enthalpy of each constituent

Note that in general, $T_{P}$ is unknown.

\section{- Solution Procedure (non-isothermal cases):}

1. Specify heat transfer (e.g., $\&=0$ for adiabatic) and system pressure, $P$

2. specify flow rates of all constituents; determine inlet mole fractions

3. specify current density and cell area (fixes total current, $I$ )

4. Note that: $\quad \alpha_{i, H 2 O, \min }^{\&}=\Delta \&_{H 2 O}^{\&}=\frac{I}{2 F} N_{\text {cells }}=\frac{i A_{\text {cell }}}{2 F} N_{\text {cells }}=-\Delta \alpha_{H 2}^{\&}$

5. Evaluate outlet molar flow rates and mole fractions

6. Guess a value of $T_{P}$, solve energy equation for $h^{\&}$

7. Evaluate the cell average Nernst potential:

$$
\bar{V}_{\text {Nernst }}=\frac{1}{2 F\left(T_{P}-T_{R}\right)\left(y_{o, O_{2}, A}-y_{i, O_{2}, A}\right)\left(y_{o, H_{2}, C}-y_{i, H_{2}, C}\right)} \times
$$




$$
\int_{T_{R}}^{T_{P}} \int_{y_{i, O 2, A}}^{y_{o, O 2, A}} \int_{y_{i, H 2, C}}^{y_{o, H 2, C}} \Delta G_{R}(T)+R T \ln \left(\frac{1-y_{H_{2}}-y_{N_{2}}}{y_{H_{2}} y_{O_{2}}^{1 / 2}(P / P S t d)^{1 / 2}}\right) d y_{H_{2}} d y_{O_{2}} d T
$$

8. Specify $\operatorname{ASR}\left(T_{P}\right)$ (from empirical data)

9. Evaluate the electrolyzer operating voltage: $V_{o p}=\bar{V}_{\text {Nernst }}+i \cdot \operatorname{ASR}\left(T_{P}\right)$

10. Evaluate $V^{k}=I \cdot V_{o p}$

11. Compare to previous value of th (step6), iterate until converged.

12. Increment the current density value and repeat the process.

This model predicts outlet temperature, mean Nernst potential, operating voltage, efficiency, and outlet composition for specified current density, heat loss or gain, and inlet gas flow rates (steam, hydrogen, nitrogen, air).

- Isothermal Cases

1. $T_{P}$ is known, rhs of energy equation is determined

2. $\bar{V}_{\text {Nernst }}$ must still be evaluated from the triple integral equation

3. $V_{o p}=\bar{V}_{\text {Nernst }}+i \cdot \operatorname{ASR}\left(T_{P}\right)$

$\mathcal{E}_{T}=I \cdot\left(V_{t n}-V_{o p}\right)$ where the thermal neutral voltage is $V_{t n}=\Delta H_{R} / 2 F$

4. Solve energy equation for $h^{\text {\& }}$

5. Compare to $V^{k}=I \cdot V_{o p}$

6. Iterate until converged

This model was initially implemented in MathCad, then incorporated directly into HYSYS. 


\section{APPENDIX F}

\section{PLANT DESIGN FOR $100 \mathrm{KG} \mathrm{H}_{2}$ /DAY}




\section{Appendix F Plant Design for $100 \mathrm{~kg} \mathrm{H}_{2} /$ day}

\section{A. Plant Description}

\begin{tabular}{|c|c|c|c|c|c|}
\hline \multicolumn{6}{|c|}{ Main Capital Items } \\
\hline \multicolumn{2}{|c|}{ Cost Summary 100 KGC (30 SCFM) } & \multicolumn{4}{|c|}{ PEM CY 2011} \\
\hline Item & Basis & Capital Cost & $\begin{array}{c}\text { Site } \\
\text { Installation }\end{array}$ & Total & $\begin{array}{l}\text { Power } \\
\text { kW }\end{array}$ \\
\hline $\begin{array}{l}\text { Hydrogen } \\
\text { Generators }\end{array}$ & $\begin{array}{l}1 @ 100 \mathrm{~kg} / \text { day } \\
30 \mathrm{kWh} / \mathrm{kg} \mathrm{H} 2 \text { chilled water } \\
76 \mathrm{kWh} / \mathrm{kg} \mathrm{H} 2-\text { stack } \\
11 \mathrm{kWh} / \mathrm{kg} \mathrm{H} 2-\text { BOP }\end{array}$ & $\$ 800,000$ & $\$ 200,000$ & $\$ 1,000,000$ & 363 \\
\hline $\begin{array}{l}\text { DI Water } \\
\text { System }\end{array}$ & $\begin{array}{l}25 \mathrm{GPH}-9 \mathrm{~kg} \text { DIW/kg } \\
1 @ .5 \mathrm{CF} \text { Water Softener } \\
11 @ .5 \mathrm{CF} \text { Carbon filters } \\
1 @ 1 \mathrm{GPM} \text { RO Module } \\
1 @ 1 \mathrm{GPM} .5 \mathrm{HPPumps} \\
\text { DI Exchange Tank } \\
\text { Misc Controls } \\
\text { DIW Circ Pump .5HP }\end{array}$ & $\$ 7,400$ & $\$ 2,800$ & $\$ 10,200$ & .8 \\
\hline $\begin{array}{l}\text { Hydrogen } \\
\text { Dryers } \\
\text { Lectrodryer }\end{array}$ & $\begin{array}{l}1 @ \text { GAS-CC- } 40 \text { desiccant } \\
\text { dryer, } 2 \mathrm{~kW} \text { for } 4 \text { hours out } \\
\text { of } 8\end{array}$ & $\$ 13,500$ & $\$ 6,000$ & $\$ 19,500$ & 1 \\
\hline $\begin{array}{l}\text { Low Pressure } \\
\text { Hydrogen } \\
\text { Storage }\end{array}$ & $\begin{array}{l}\text { (LPS, 200-450 PSIG), } \\
\text { Hydrogen - } 12 \text { hrs of } \\
\text { production: I @ } 9000 \\
\text { gallon, horizontal, } 240 \\
\text { PSIG, carbon steel, 21,600 } \\
\text { SCR/tanks, Trinity }\end{array}$ & $\$ 55,000$ & $\$ 20,000$ & $\$ 75,000$ & 0 \\
\hline $\begin{array}{l}\text { Low Pressure } \\
\text { Oxygen } \\
\text { Storage }\end{array}$ & $\begin{array}{l}\text { (LPS, 200-450 PSIG), } \\
\text { Oxygen - 24 hrs of } \\
\text { production: I @ 9000 } \\
\text { gallon, horizontal, 250 } \\
\text { PSIG, carbon steel, 21,600 } \\
\text { SCR/tanks, Trinity }\end{array}$ & $\$ 60,000$ & $\$ 20,000$ & $\$ 80,000$ & 0 \\
\hline $\begin{array}{l}\text { Hydrogen } \\
\text { Compressor }\end{array}$ & Ingersoll - $15 \mathrm{HP}$ & $\$ 65,000$ & $\$ 35,000$ & $\$ 100,000$ & 11 \\
\hline $\begin{array}{l}\text { High Pressure } \\
\text { Hydrogen } \\
\text { Storage }\end{array}$ & $\begin{array}{l}\text { HPS } 2800 \text { psig }-5 \text { hours of } \\
\text { storage ( } 9300 \text { SCF), CPI- } \\
\text { ASME Section VIII, SA372 } \\
\text { Grade J Class 70, 2800 } \\
\text { PSIG, Size 24" O.D. x .817" } \\
\text { M.W. x 24'0" long, 60.2 CF }\end{array}$ & $\$ 38,000$ & $\$ 7,000$ & $\$ 45,000$ & 0 \\
\hline Oxygen Blower & $\begin{array}{l}15 \text { SCFM, } 100 \text { PSIG } \\
\text { discharge } \\
1 \text { @ RIX 4VX, 5HP }\end{array}$ & $\$ 55,000$ & $\$ 25,000$ & $\$ 80,000$ & 4 \\
\hline Compressed Air & $\begin{array}{l}1000 \text { SCFH, } 100 \text { PSIG, RIX } \\
\text { 4VX } 5 \text { HP, Storage Tank: } \\
200 \text { Gallon vertical }\end{array}$ & $\$ 11,200$ & $\$ 3,500$ & $\$ 14,700$ & 4 \\
\hline $\begin{array}{l}\text { Chilled Water } \\
\text { System \& Pump }\end{array}$ & $\begin{array}{l}\text { Pump, } 3 \text { GPM, } 1 \mathrm{HP}, 28 \\
\text { gal } / \mathrm{kg}, 4.8 \mathrm{kWh} / \mathrm{kg}\end{array}$ & $\$ 15,800$ & $\$ 6,800$ & $\$ 22,600$ & 42.4 \\
\hline $\begin{array}{l}\text { Nitrogen } \\
\text { System }\end{array}$ & $\begin{array}{l}\text { ON-Site Gas Systems, N200 } \\
\text { with dryer, compressor: } 20\end{array}$ & $\$ 25,000$ & $\$ 6,000$ & $\$ 31,000$ & 18.65 \\
\hline
\end{tabular}




\begin{tabular}{|l|l|l|l|r|r|}
\hline & $\begin{array}{l}\text { SCFH generated, 3 HP, 200 } \\
\text { gallon storage tank, 600 } \\
\text { SCFH air, dryer }\end{array}$ & & & \\
\hline $\begin{array}{l}\text { Balance of } \\
\text { Plant }\end{array}$ & $\begin{array}{l}\text { Control Wiring, Power } \\
\text { Distribution, Lighting, } \\
\text { HVAC (755 SF, 1 ton), } \\
\text { Chilled water piping (100 } \\
\text { feet), H2 Vent Piping, N2 } \\
\text { Piping (1/2" header, 80ft), } \\
\text { O2 Piping (3/4" main, 80ft) }\end{array}$ & & & $\$ \$ 67000$ & \\
\hline $\begin{array}{l}\text { Mechanical } \\
\text { Control Bldg }\end{array}$ & \$120/SF, 755 SF & & & & \\
\hline Total & & & & $\$ 90,600$ & \\
\hline
\end{tabular}

\section{B. N2H2 Model}

- General

- Current year of study -2007

- Year construction is initiated -2011

- IRR Target $-12 \%$

- $\quad$ Pre-Operation Inputs

- Construction escalation $-2.3 \%$

- Construction contingency rate $-15 \%$

- Capital Construction Project Management - 4\% of Design, Direct and Indirect Costs

- Design \& Public Relations - 7\% of Direct and Indirect Costs

$\circ \quad$ Site Acquisition - \$15,000 per acre

- Direct Plant

- $\quad$ System Chiller - $\$ 22,600$

- Electrolyzer Unit - $\$ 1,000,000$

- $\mathrm{H}_{2}$ Compressor - $\$ 100,000$

- De-ionized Water System - \$10,200

- $\quad$ Oxygen Storage - $\$ 80,000$

- Hydrogen Dryer - $\$ 19,500$

- Instrument Air Storage - \$1,700

- Instrument Air Compressor - $\$ 13,000$

- Nitrogen System - $\$ 31,000$

- Oxygen Blower - $\$ 80,000$

- Low-pressure H2 Storage - \$75,000

- High-pressure H2 Storage - $\$ 45,000$

- Indirect Plant

- Direct Personnel Buildings - $\$ 9,000$

- Administrator Building - $\$ 9,000$

- Mechanical Support \& Buildings - $\$ 90,600$

- $\quad$ Safety Support \& Buildings - $\$ 9,000$

- Maintenance Support \& buildings - $\$ 9,000$

- Balance of Plant - input as 10\% of the rest of plant

- Operations Cost

○ Inflation \& Escalation during Operations - 3.3\% 
○ Operations Contingency $-15 \%$

- Fixed Operation Cost

- $\quad$ Staffing \& Sub-Contract Support

- $\quad$ Plant Supervision- $\$ 100,000$

- $\quad$ Plant Personnel - $\$ 250,000$

- $\quad$ Technical Support - $\$ 10,000$

- $\quad$ Operations Management - \$5,000

- $\quad$ Fixed Taxes \& Fees

- $\quad$ Local Property Taxes $-1 \%$

- $\quad$ Property Insurance $-1.2 \%$

- ESQ\&H Costs

- $\quad$ License \& Permit Maintenance - $\$ 15,000$

- $\quad$ Environmental Health \& Safety - \$50,000

- $\quad$ Security - $\$ 50,000$

- $\quad$ Training - $\$ 15,000$

- Variable Operations Costs

- Direct Plant $-4 \%$

- Indirect Plant - 4\%

- Shutdowns \& Inspections - $\$ 25,000$

- Plant Modifications - $12 \%$

- Waste Management - \$5,000

- Monthly Production Variables

- Monthly Capacity Factor - 97\%

- Capacity Factor during Modifications every 5 years - 97\% except during September, October and November $-50 \%$

- Conversion Efficiency - Electrical to H2

- January $-66 \%$

- February $-66 \%$

- March - 65\%

- April-64\%

- May $-63 \%$

- June - $61 \%$

- July - 60\%

- August - 59\%

- September $61 \%$

- October $-61 \%$

- November $-62 \%$

- December $-64 \%$

- $\quad$ Post-Ops and DD\&D

- Inflation \& Escalation to year of post-operation 3.3\% of the Direct, Indirect Plant \& Design

- Post-Operations Contingency $-30 \%$ of Post-Operations Cost

○ Post - Operations $4.0 \%$ of the Direct, Indirect Plant \& Design

- Total Revenue

○ Market Price escalation of $\mathrm{H}_{2}-4.13 \%$ 
○ $\quad$ Market Price Escalation of $\mathrm{O}_{2}-4.0 \%$

$\circ \quad$ Fixed Price for $\mathrm{O}_{2} / \mathrm{kg}-\$ 0.030$

- Market Price Escalation for Carbon Credit $-4.0 \%$

- Fixed Price for Carbon credit/tonne - $\$ 20.000$ 


\section{APPENDIX G}

\section{PLANT DESIGN FOR $1500 \mathrm{KG} \mathrm{H}_{2}$ /DAY}




\section{Appendix G Plant Design for $1500 \mathrm{~kg} \mathrm{H}_{2} /$ day}

\section{A. Plant Description}

\begin{tabular}{|c|c|c|c|c|c|}
\hline \multicolumn{6}{|c|}{ Main Capital Items } \\
\hline Cost Summary & 1500 KGD & 2011 & & & \\
\hline Item & Basis & Capital Cost & $\begin{array}{c}\text { Site } \\
\text { Installation }\end{array}$ & Total & $\begin{array}{l}\text { Power } \\
\text { kW }\end{array}$ \\
\hline $\begin{array}{l}\text { Hydrogen } \\
\text { Generators }\end{array}$ & $\begin{array}{l}1 @ 1500 \mathrm{~kg} / \mathrm{day} \\
4.8 \mathrm{kWh} / \mathrm{kg} \mathrm{H} 2 \text { chilled } \\
\text { water } \\
45.8 \mathrm{kWh} / \mathrm{kg} \mathrm{H} 2 \text {-stack } \\
1.8 \mathrm{kWh} / \mathrm{kg} \mathrm{H} 2 \text { - BOP }\end{array}$ & $\$ 1,500,000$ & $\$ 300,000$ & $\$ 1,800,000$ & 3275 \\
\hline $\begin{array}{l}\text { DI Water } \\
\text { System }\end{array}$ & $\begin{array}{l}350 \mathrm{GPH}-9 \mathrm{~kg} \text { DIW/kg } \\
1 \text { @ 3CF Water Softener } \\
1 \text { @ } 3 \text { CF Carbon filters } \\
1 @ 10 \mathrm{GPM} \text { RO Module } \\
1 @ 10 \text { GPM } 2 \text { HP Pumps } \\
\text { DI Exchange Tank } \\
\text { Misc Controls } \\
\text { DIW Circ Pump } 1 \mathrm{HP}\end{array}$ & $\$ 39,000$ & $\$ 9,000$ & $\$ 48,000$ & 2.2 \\
\hline $\begin{array}{l}\text { Hydrogen } \\
\text { Dryers } \\
\text { Lectrodryer }\end{array}$ & $\begin{array}{l}1 @ \text { GAS-CC-700 desiccant } \\
\text { dryer, } 35 \mathrm{~kW} \text { for } 4 \text { hours out } \\
\text { of } 8\end{array}$ & $\$ 140,000$ & $\$ 45,000$ & $\$ 185,000$ & 17.5 \\
\hline $\begin{array}{l}\text { Low Pressure } \\
\text { Hydrogen } \\
\text { Storage }\end{array}$ & $\begin{array}{l}\text { (LPS, 200-450 PSIG), } \\
\text { Hydrogen - 45 min of } \\
\text { production: I @ 9000 } \\
\text { gallon, horizontal, 250 } \\
\text { PSIG, carbon steel, 21,600 } \\
\text { SCR/tanks, Trinity }\end{array}$ & $\$ 55,000$ & $\$ 20,000$ & $\$ 75,000$ & 0 \\
\hline $\begin{array}{l}\text { Low Pressure } \\
\text { Oxygen } \\
\text { Storage }\end{array}$ & $\begin{array}{l}\text { (LPS, 200-450 PSIG), } \\
\text { Oxygen - 1.5 hrs of } \\
\text { production: I @ } 9000 \\
\text { gallon, horizontal, 250 } \\
\text { PSIG, carbon steel, 21,600 } \\
\text { SCR/tanks, Trinity }\end{array}$ & $\$ 60,000$ & $\$ 20,000$ & $\$ 80,000$ & 0 \\
\hline $\begin{array}{l}\text { Hydrogen } \\
\text { Compressor }\end{array}$ & Ingersoll - 150 HP & $\$ 250,000$ & $\$ 100,000$ & $\$ 350,000$ & 111.9 \\
\hline $\begin{array}{l}\text { High Pressure } \\
\text { Hydrogen } \\
\text { Storage }\end{array}$ & $\begin{array}{l}\text { HPS } 2800 \text { psig - } 1 \text { hours of } \\
\text { storage (27,900 SCF), CPI- } \\
\text { ASME Section VIII, SA372 } \\
\text { Grade J Class 70, 2800 } \\
\text { PSIG, Size 24" O.D. x .817" } \\
\text { M.W. x 24'0" long, 60.2 } \\
\text { CF, 1@ 3-tank assembly }\end{array}$ & $\$ 110,000$ & $\$ 40,000$ & $\$ 150,000$ & 0 \\
\hline Oxygen Blower & $\begin{array}{l}220 \text { SCFM, } 100 \text { PSIG } \\
\text { discharge } \\
1 \text { @ RIX 4VX, } 40 \text { HP }\end{array}$ & $\$ 85,000$ & $\$ 45,000$ & $\$ 130,000$ & 30 \\
\hline Instrument Air & $\begin{array}{l}1000 \text { SCFH, } 100 \text { PSIG, RIX } \\
\text { 4VX } 5 \text { HP, Storage Tank: } \\
200 \text { Gallon vertical }\end{array}$ & $\$ 11,200$ & $\$ 3,500$ & $\$ 14,700$ & 4 \\
\hline $\begin{array}{l}\text { Chilled Water } \\
\text { System \& Pump }\end{array}$ & $\begin{array}{l}\text { Pump, } 30 \text { GPM, } 5 \mathrm{HP}, 28 \\
\text { gal } / \mathrm{kg}, 4.8 \mathrm{kWh} / \mathrm{kg}\end{array}$ & $\$ 78,000$ & $\$ 19,500$ & $\$ 97,500$ & 322.4 \\
\hline
\end{tabular}




\begin{tabular}{|c|c|c|c|c|c|}
\hline $\begin{array}{l}\text { Nitrogen } \\
\text { System }\end{array}$ & $\begin{array}{l}\text { ON-Site Gas Systems, N200 } \\
\text { with dryer, } \\
\text { compressor:6000 SCFH } \\
\text { generated, } 25 \mathrm{HP}, 200 \\
\text { gallon storage tank, } 6000 \\
\text { SCFH air, dryer }\end{array}$ & $\$ 78,000$ & $\$ 20,000$ & $\$ 98,000$ & 18.65 \\
\hline $\begin{array}{l}\text { Balance of } \\
\text { Plant }\end{array}$ & $\begin{array}{l}\text { Control Wiring, Power } \\
\text { Distribution, Lighting, } \\
\text { HVAC (1950 SF, } 3 \text { ton), } \\
\text { Chilled water piping (100 } \\
\text { feet), H2 Vent Piping, N2 } \\
\text { Piping (1/2" header, 200ft), } \\
\text { O2 Piping (3/4" main, } \\
\text { 100ft) }\end{array}$ & & & $\$ 163,000$ & 9 \\
\hline $\begin{array}{l}\text { Mechanical } \\
\text { Control Bldg }\end{array}$ & $\$ 90 / \mathrm{SF}, 1950 \mathrm{SF}$ & & & $\$ 175,500$ & \\
\hline Total & & & & & 3790 \\
\hline
\end{tabular}

\section{B. N2H2 Model Input}

- General

- Current year of study -2007

- Year construction is initiated -2011

- IRR Target $-12 \%$

- Pre-Operation Inputs

○ Construction escalation $-2.3 \%$

- Construction contingency rate $-12 \%$

- Capital Construction Project Management - 4\% of Design, Direct and Indirect Costs

- Design \& Public Relations $-6 \%$ of Direct and Indirect Costs

$\circ \quad$ Site Acquisition - $\$ 45,000$ per acre

- Direct Plant

- $\quad$ System Chiller - $\$ 97,500$

- $\quad$ Electrolyzer Unit - $\$ 1,800,000$

- $\mathrm{H}_{2}$ Compressor - $\$ 350,000$

- De-ionized Water System - \$48,000

- Oxygen Storage - $\$ 80,000$

- Hydrogen Dryer - $\$ 185,000$

- Instrument Air Storage - \$1,700

- Instrument Air Compressor - $\$ 13,000$

- Nitrogen System - \$98,000

- Oxygen Blower - $\$ 130,000$

- Low-pressure H2 Storage - $\$ 75,000$

- High-pressure H2 Storage - $\$ 150,000$

○ Indirect Plant

- Direct Personnel Buildings - $\$ 10,000$

- Administrator Building - $\$ 100,000$

- Mechanical Support \& Buildings - \$175,500

- $\quad$ Safety Support \& Buildings - \$100,000 
- $\quad$ Maintenance Support \& buildings - $\$ 100,000$

- Balance of Plant - input as $10 \%$ of the rest of plant

- Operations Cost

○ Inflation \& Escalation during Operations - 3.3\%

○ Operations Contingency $-15 \%$

- Fixed Operation Cost

- $\quad$ Staffing \& Sub-Contract Support

- $\quad$ Plant Supervision- $\$ 1,000,000$

- $\quad$ Plant Personnel - $\$ 3,000,000$

- $\quad$ Technical Support - $\$ 100,000$

- $\quad$ Operations Management - \$50,000

- $\quad$ Fixed Taxes \& Fees

- $\quad$ Local Property Taxes $-1 \%$

- $\quad$ Property Insurance - 1\%

- ESQ\&H Costs

- $\quad$ License \& Permit Maintenance - \$15,000

- $\quad$ Environmental Health \& Safety - $\$ 50,000$

- $\quad$ Security - $\$ 50,000$

- $\quad$ Training - $\$ 15,000$

- Variable Operations Costs

- Direct Plant $-4 \%$

- Indirect Plant - 4\%

- Shutdowns \& Inspections - \$75,000

- Plant Modifications - $11 \%$

- Waste Management - $\$ 15,000$

- Monthly Production Variables

- Monthly Capacity Factor - 97\%

- Capacity Factor during Modifications every 5 years - 97\% except during September, October and November $-50 \%$

- Conversion Efficiency - Electrical to H2

- January $-66 \%$

- February $-66 \%$

- March-65\%

- April-64\%

- May $-63 \%$

- June $-61 \%$

- July - 60\%

- August - 59\%

- September $61 \%$

- October $-61 \%$

- November - $62 \%$

- December - 64\%

- $\quad$ Post-Ops and DD\&D

- Inflation \& Escalation to year of post-operation 3.3\% of the Direct, Indirect Plant \& Design 
- Post-Operations Contingency $-25 \%$ of Post-Operations Cost

- $\quad$ Post Ops \& DD\&D - Operations 5.0\% of the Direct, Indirect Plant \& Design

- $\quad$ Total Revenue

○ Market Price escalation of $\mathrm{H}_{2}-4.13 \%$

○ Market Price Escalation of $\mathrm{O}_{2}-4.0 \%$

- $\quad$ Fixed Price for $\mathrm{O}_{2} / \mathrm{kg}-\$ 0.030$

○ Market Price Escalation for Carbon Credit - 4.0\%

- Fixed Price for Carbon credit/tonne - $\$ 20.000$ 


\section{APPENDIX H}

\section{PLANT DESIGN FOR $1 \mathrm{KG} \mathrm{H}_{2} / \mathrm{SEC}$}




\section{Appendix H Plant Design for $1 \mathrm{~kg} \mathrm{H} / \mathrm{sec}$}

\section{A. Plant Description}

\begin{tabular}{|c|c|c|c|c|c|}
\hline \multicolumn{6}{|c|}{ Main Capital Items } \\
\hline \multicolumn{6}{|c|}{ Cost Summary 1 KGS } \\
\hline Item & Basis & Capital Cost & $\begin{array}{c}\text { Site } \\
\text { Installation }\end{array}$ & Total & $\begin{array}{l}\text { Power } \\
\text { kW }\end{array}$ \\
\hline $\begin{array}{l}\text { Hydrogen } \\
\text { Generators }\end{array}$ & $\begin{array}{l}60 @ 1500 \mathrm{~kg} / \text { day } \\
4.8 \mathrm{kWh} / \mathrm{kg} \mathrm{H} 2 \text { chilled } \\
\text { water } \\
45.8 \mathrm{kWh} / \mathrm{kg} \mathrm{H} 2 \text {-stack } \\
1.8 \mathrm{kWh} / \mathrm{kg} \mathrm{H} 2 \text { - BOP }\end{array}$ & $\$ 90,000,000$ & $\$ 9,000,000$ & $\$ 99,000,000$ & 188640 \\
\hline $\begin{array}{l}\text { DI Water } \\
\text { System }\end{array}$ & $\begin{array}{l}20,000 \mathrm{GPH}-9 \mathrm{~kg} \text { DIW/kg } \\
4 \text { @ 35CF Water Softener } \\
4 \text { @ 35 CF Carbon filters } \\
4 \text { @ 100GPM RO Module } \\
4 @ 100 \text { GPM } 10 \text { HP } \\
\text { Pumps } \\
\text { DI Exchange Tank } \\
\text { Misc Controls } \\
\text { DIW Circ Pump } 40 \mathrm{HP}\end{array}$ & $\$ 720,000$ & $\$ 310,000$ & $\$ 1,030,000$ & 70 \\
\hline $\begin{array}{l}\text { Hydrogen } \\
\text { Dryers } \\
\text { Lectrodryer }\end{array}$ & $\begin{array}{l}2 @ \text { GAS-CC-3500 } \\
\text { desiccant dryer, } 110 \mathrm{~kW} \text { for } \\
4 \text { hours out of } 8,3 @ \\
\text { refrigerated dryers, } 150 \mathrm{HP} \text {, } \\
336 \mathrm{~kW}\end{array}$ & $\$ 1,400,000$ & $\$ 500,000$ & $\$ 1,900,000$ & 1118 \\
\hline $\begin{array}{l}\text { Low Pressure } \\
\text { Hydrogen } \\
\text { Storage }\end{array}$ & $\begin{array}{l}\text { (LPS, 200-450 PSIG), } \\
\text { Hydrogen - } 12 \text { min of } \\
\text { production: } 14 @ 9000 \\
\text { gallon, horizontal, } 250 \\
\text { PSIG, carbon steel, 21,600 } \\
\text { SCR/tanks, Trinity }\end{array}$ & $\$ 700,000$ & $\$ 325,000$ & $\$ 1,025,000$ & 0 \\
\hline $\begin{array}{l}\text { Low Pressure } \\
\text { Oxygen } \\
\text { Storage }\end{array}$ & $\begin{array}{l}\text { (LPS, 200-450 PSIG), } \\
\text { Oxygen - } 12 \text { min of } \\
\text { production: } 7 @ 9000 \\
\text { gallon, horizontal, 250 } \\
\text { PSIG, carbon steel, 21,600 } \\
\text { SCR/tanks, Trinity }\end{array}$ & $\$ 385,000$ & $\$ 250,000$ & $\$ 635,000$ & 0 \\
\hline $\begin{array}{l}\text { Hydrogen } \\
\text { Compressor }\end{array}$ & Ingersoll - 7000 HP & $\$ 2,100,000$ & $\$ 1,000,000$ & $\$ 3,100,000$ & 5222 \\
\hline $\begin{array}{l}\text { High Pressure } \\
\text { Hydrogen } \\
\text { Storage }\end{array}$ & $\begin{array}{l}\text { HPS } 2800 \text { psig - } 6 \text { min of } \\
\text { storage, CPI-ASME Section } \\
\text { VIII, SA372 Grade J Class } \\
\text { 70, 2800 PSIG, Size 24" } \\
\text { O.D.x.817” M.W. x 24'0" } \\
\text { long, 60.2 CF, 3@6-tank } \\
\text { assembly }\end{array}$ & $\$ 618,000$ & $\$ 300,000$ & $\$ 918,000$ & 0 \\
\hline Oxygen Blower & $\begin{array}{l}6000 \text { SCFM, } 100 \text { PSIG } \\
\text { discharge } \\
2 \text { @ RIX 2JS, } 220 \text { HP }\end{array}$ & $\$ 1,200,000$ & $\$ 450,000$ & $\$ 1,650,000$ & 181 \\
\hline Instrument Air & $\begin{array}{l}\text { 60,000 SCFH, } 100 \text { PSIG, } \\
\text { RIX 2M } 200 \text { HP, Storage } \\
\text { Tank: } 9000 \text { Gallon vertical }\end{array}$ & $\$ 280,000$ & $\$ 73,000$ & $\$ 353,000$ & 149.2 \\
\hline
\end{tabular}




\begin{tabular}{|l|l|l|l|l|r|}
\hline $\begin{array}{l}\text { Chilled Water } \\
\text { System \& Pump }\end{array}$ & $\begin{array}{l}\text { Pump, 1800 GPM, 200 HP, } \\
\text { 28 gal/kg, 4.8 kWh/kg }\end{array}$ & $\$ 2,515,000$ & $\$ 68,000$ & $\$ 2,583,000$ & 17429.2 \\
\hline $\begin{array}{l}\text { Nitrogen } \\
\text { System }\end{array}$ & $\begin{array}{l}\text { ON-Site Gas Systems, N200 } \\
\text { with dryer, } \\
\text { compressor:2000 SCFH } \\
\text { generated, 30 HP, 900 } \\
\text { gallon storage tank, 100 } \\
\text { SCFM air, dryer }\end{array}$ & $\$ 80,000$ & $\$ 20,000$ & $\$ 100,000$ & 37.3 \\
\hline $\begin{array}{l}\text { Balance of } \\
\text { Plant }\end{array}$ & $\begin{array}{l}\text { Control Wiring, Power } \\
\text { Distribution, Lighting, } \\
\text { HVAC (49,500 SF, 83 ton), } \\
\text { Chilled water piping (100 } \\
\text { feet), H2 Vent } \\
\text { Piping(6"main, 4" header, } \\
\text { 3"drop, 2500 ft), N2 Piping } \\
\text { (1.5” header, 4000ft), O2 } \\
\text { Piping (6" main, 2" header, }\end{array}$ & & & & \\
3"drop 2500ft) & & & & \\
\hline $\begin{array}{l}\text { Mechanical } \\
\text { Control Bldg }\end{array}$ & \$90/SF, 49,500 SF & & & & \\
\hline Total & & & & & \\
\hline
\end{tabular}

\section{B. N2H2 Model Input}

- General

- Current year of study -2007

- Year construction is initiated - 2011

- IRR Target $-8 \%$ Public, $12 \%$ Private

- $\quad$ Pre-Operation Inputs

- Construction escalation $-2.3 \%$

- Construction contingency rate $-10 \%$

- Capital Construction Project Management $-4 \%$ of Design, Direct and Indirect Costs

- Design \& Public Relations $-5 \%$ of Direct and Indirect Costs

- Site Acquisition - \$432,000

- Direct Plant

- $\quad$ System Chiller - $\$ 2,583,000$

- Electrolyzer Unit - $\$ 99,000,000$

- $\mathrm{H}_{2}$ Compressor - $\$ 3,100,000$

- De-ionized Water System - \$1,030,000

- $\quad$ Oxygen Storage - $\$ 635,000$

- Hydrogen Dryer - $\$ 1,900,000$

- Instrument Air Storage - $\$ 68,000$

- Instrument Air Compressor - \$285,000

- $\quad$ Nitrogen System - $\$ 100,000$

- Oxygen Blower - $\$ 1,650,000$

- Low-pressure H2 Storage - $\$ 1,025,000$

- High-pressure H2 Storage - \$918,000

o Indirect Plant

- $\quad$ Direct Personnel Buildings - $\$ 400,000$

- Administrator Building - $\$ 150,000$ 
- $\quad$ Mechanical Support \& Buildings - $\$ 4,455,000$

- $\quad$ Safety Support \& Buildings - $\$ 250,000$

- $\quad$ Maintenance Support \& buildings - $\$ 350,000$

- Balance of Plant - input as 10\% of the rest of plant

- $\quad$ Operations Cost

○ Inflation \& Escalation during Operations - 3.3\%

○ Operations Contingency $-15 \%$

- Fixed Operation Cost

- $\quad$ Staffing \& Sub-Contract Support

- $\quad$ Plant Supervision- $\$ 4,000,000$

- $\quad$ Plant Personnel - $\$ 16,000,000$

- $\quad$ Technical Support - $\$ 1,000,000$

- $\quad$ Operations Management - $\$ 500,000$

- $\quad$ Fixed Taxes \& Fees

- $\quad$ Local Property Taxes $-0.7 \%$

- $\quad$ Property Insurance $-0.8 \%$

- ESQ\&H Costs

- $\quad$ License \& Permit Maintenance - $\$ 15,000$

- $\quad$ Environmental Health \& Safety - $\$ 50,000$

- $\quad$ Security - $\$ 50,000$

- $\quad$ Training - $\$ 15,000$

- Variable Operations Costs

- Direct Plant $-4 \%$

- Indirect Plant - 4\%

- $\quad$ Shutdowns \& Inspections - $\$ 150,000$

- Plant Modifications - $10 \%$

- Waste Management - $\$ 50,000$

○ Monthly Production Variables

- Monthly Capacity Factor - 97\%

- Capacity Factor during Modifications every 5 years - 97\% except during September, October and November $-50 \%$

- Conversion Efficiency - Electrical to $\mathrm{H} 2$

- January-66\%

- February $-66 \%$

- March-65\%

- April-64\%

- May- $63 \%$

- June-61\%

- July $-60 \%$

- August-59\%

- September $61 \%$

- October-61\%

- November $-62 \%$

- December-64\%

- $\quad$ Post-Ops and DD\&D 
- Inflation \& Escalation to year of post-operation 3.3\% of the Direct, Indirect Plant \& Design

- Post-Operations Contingency $-20 \%$ of Post-Operations Cost

○ Post Ops \& DD\&D - Operations 5.0\% of the Direct, Indirect Plant \& Design

- Total Revenue

○ Market Price escalation of $\mathrm{H}_{2}-4.13 \%$

○ Market Price Escalation of $\mathrm{O}_{2}-4.0 \%$

- Fixed Price for $\mathrm{O}_{2} / \mathrm{kg}-\$ 0.030$

- Market Price Escalation for Carbon Credit - 4.0\%

$\circ \quad$ Fixed Price for Carbon credit/tonne - \$20.000 
APPENDIX I

\section{SILVERADO HICE SPECIFICATIONS}




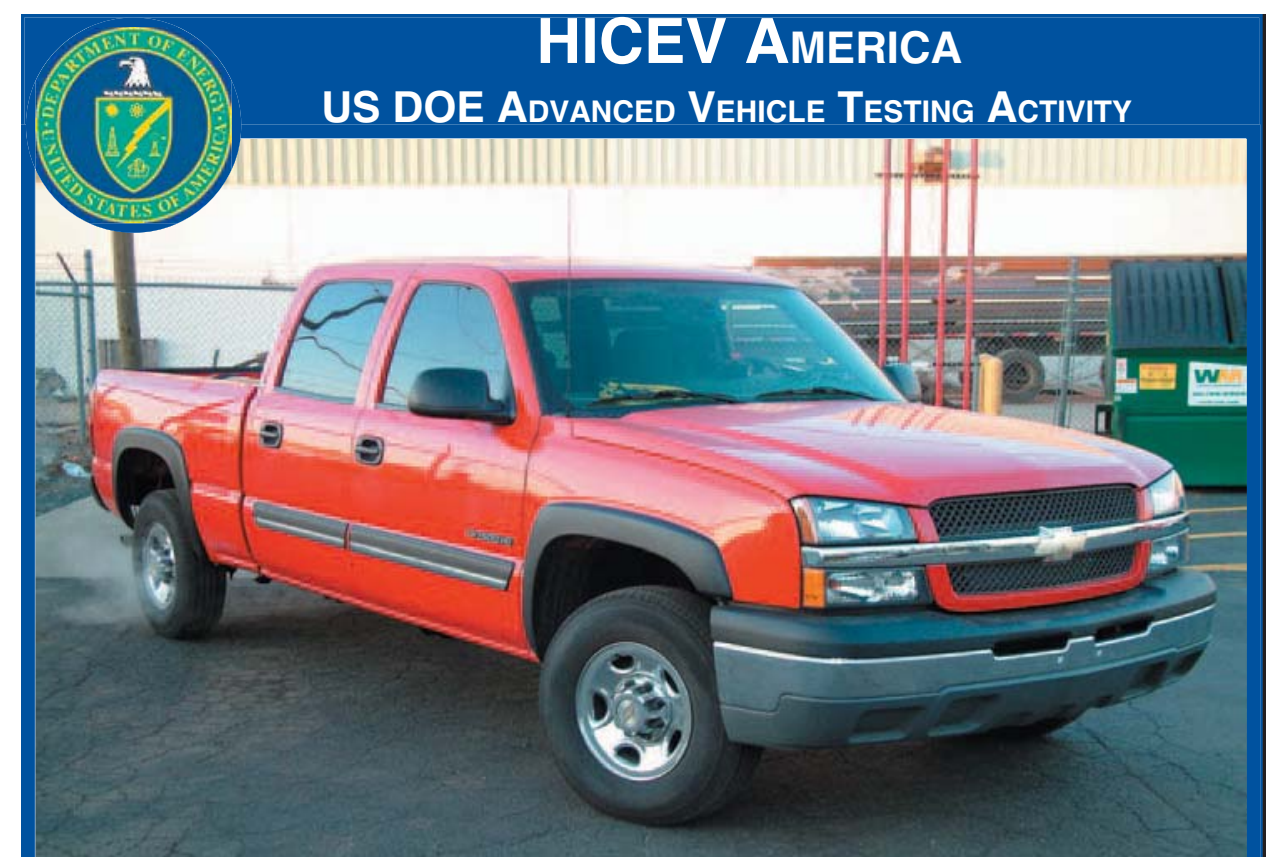

2005 Hydrogen I CE ${ }^{1}$ Truck VEHICLE SPECIFICATIONS

\section{CONVERSION VEHICLE}

Base Vehicle: 2005 Chevy Silverado

VIN: 1GCGC13U95F889816

Seatbelt Positions: Six

Features:

6.0L V8

Fuel Injected

4 Speed Automatic Transmission

Power Locks and Windows

Front and Rear Disk Brakes

Rear Wheel Drive

Power Steering

Air Conditioning

AM/FM Stereo w/ CD Player

Dual Airbags

\section{FUEL TANKS}

Manufacturer: Dynetek

Model: W150H350G8

DOT Type $3^{2}$

Description: Carbon Fiber Wrap/ Aluminum Lined

Number of Tanks: 3

Tank Liquid Volume: 150 liters

Total Liquid Volume: 450 liters

Nominal Pressure: 5000 psi

Maximum Pressure: $6350 \mathrm{psi}$

Fuel Capacity ${ }^{6}$ : 10.5 GGE $^{7}$

Fueling Inlet: WEH C1C136
PERFORMANCE STATISTICS

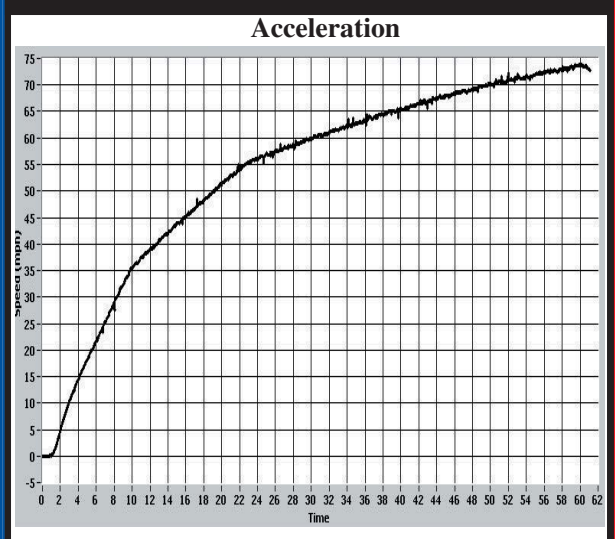

ACCELERATION 0-60 mph

Acceleration Time: 21.98 seconds

Performance Goal: 13.5 seconds

\section{MAXIMUM SPEED}

Speed At One Mile: $79.2^{3} \mathrm{mph}$

Performance Goal: $\geq 70 \mathrm{mph}$

Speed At Quarter Mile: $60.2 \mathrm{mph}$

\section{CONSTANT SPEED FUEL ECONOMY}

Distance Traveled: 61.78 miles

Average Speed: $44.94 \mathrm{mph}$

Fuel Consumed: $2.288^{4} \mathrm{GGE}^{7}$

Fuel Economy: 27.0 miles/GGE

\section{SAE J1634 DRIVING CYCLE}

FUEL ECONOMY (A/C OFF)

Distance Traveled: 35.2 miles

Fuel Consumed: $1.91^{4} \mathrm{GGE}^{7}$

Fuel Economy: 17.7 miles/GGE ${ }^{7}$

\section{SAE J1634 DRIVING CYCLE}

FUEL ECONOMY (A/C ON)

Distance Traveled: 35.2 miles

Fuel Consumed: $2.22^{4} \mathrm{GGE}^{7}$

Fuel Economy: 15.2 miles/GGE ${ }^{7}$

\section{BRAKING FROM $60 \mathrm{mph}$}

Controlled Dry: 246.8 feet

Tire Model: V-Steel 265

Tire Size: 245/75 R16

Tire Pressure F/R: 50/80psi

Spare Included: Yes
GRADEABILITY (CALCULATED)

Maximum Speed @ 3\%: $62.6 \mathrm{mph}$ Maximum Speed @ 6\%: $52.1 \mathrm{mph}$ Maximum Grade: $33.2 \%$

\section{TEST NOTES:}

. Internal Combustion Engine.

49 CFR 571.304

Maximum speed was determined from acceleration runs where overdrive was not used

Fuel consumption was determined using the Ideal Gas Law.

. Rough Road testing showed no damage to the fuel system or any other component of the vehicle.

. At nominal pressure and $25^{\circ} \mathrm{C}$

Gasoline Gallons Equivalent. 


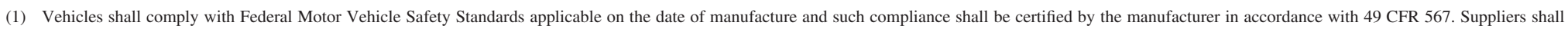

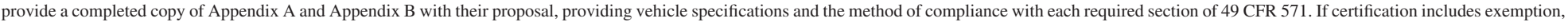

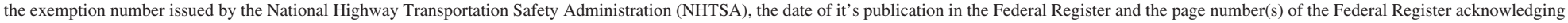
issuance of the exemption shall be provided along with Appendix B. Exemptions for any reason other than non-applicability shall not be allowed

(2) Suppliers shall provide Material Safety Data Sheets (MSDS) for all unique hazardous materials provided with the vehicle.

(3) Compressed gas storage tanks shall comply with the requirements of 49CFR571.304 and ANSI/NGV2-2000.

(4) Suppliers shall provide recycling plans for vehicle hazardous materials including how the plan has been implemented.

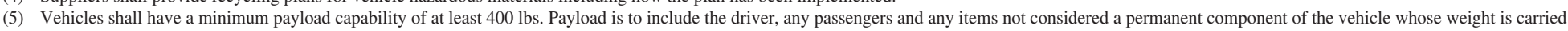
completely by the vehicle.

(6) For conversions of vehicles not manufactured by the HICEV Supplier, OEM gross vehicle weight rating (GVWR) shall not be increased. For conversion vehicles, Suppliers shall specify the OEM's gross vehicle weight rating (GVWR).

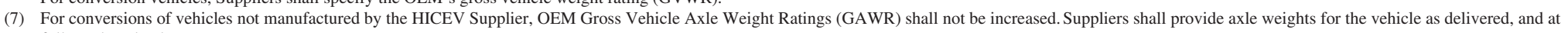
full rated payload.

(8) A speedometer and an odometer shall be provided.

(9) Tires shall be subject to the following requirements:

- Tires provided with the vehicle shall be the standard tire offered by the HICE Supplier for the vehicle being proposed.

- Tires shall correspond to the requirements of the placard installed in accordance with 49 CFR 571.109,110,119 and 120, as applicable.

- Suppliers shall specify manufacturer, model and size of the standard tire.

- Tires sizes and in ation pressures shall be in accordance with the requirements of the placard.

- At no time shall the tire's in ation pressure exceed the maximum pressure imprinted upon that tire's sidewall.

- The tire shall be operable across the entire operation/load range of that vehicle.

- Replacement tires shall be commercially available to the end user in sufficient quantities to support the purchaser's needs.

- If the vehicle may be equipped with more than one standard tire, the afore-mentioned information shall be provided for each type/manufacturer of each standard tire.

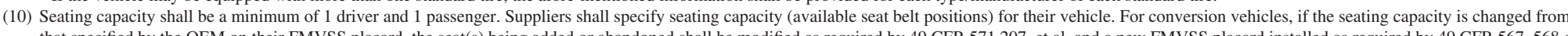

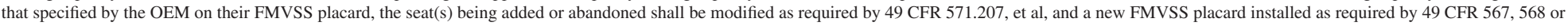
571 , as applicable.

(11) For conversion vehicles, the OEM passenger space shall not be intruded upon by the Hydrogen Fuel Storage System (HFSS) or other conversion components.

(12) The vehicle shall have a parking mechanism as per 49CFR571.102.

(13) The engine shall utilize hydrogen fuel injection with the injectors located to inject fuel at either the throttle body, intake port or directly into the cylinder.

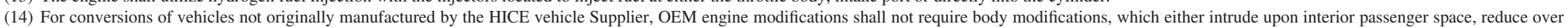
hood visibility or impact vehicle crashworthiness.

(15) Vehicles shall comply with the requirements of 49 CFR 571.105.S5.2.1, or alternatively, 49 CFR 571.105.S5.2.2 for parking mechanisms.

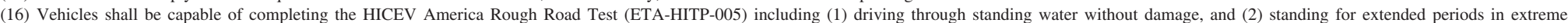

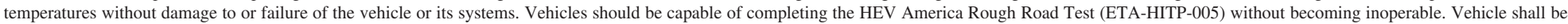
capable of completing all HICEV America tests without repairs exceeding a cumulative total of 72 hours.

(17) Fuel shall be stored onboard the vehicle in gaseous form.

(18) Fuel storage tanks shall be installed as per the requirements of section 5.3 of NFPA 52-2002, Section 5.3

(19) Connection to the fuel storage tank shall utilize the fuel storage tank manufacturer's specified fittings.

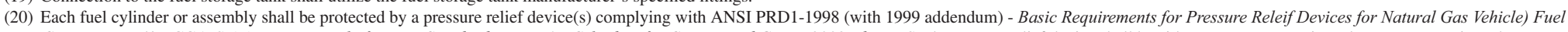

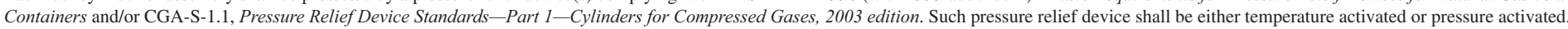

(21) The pressure relieving device(s) shall be rated for hydrogen use by its manufacturer and acceptable for use by the cylinder manufacturer.

(22) The pressure relief device shall be directly connected to the fuel cylinder or assembly or integral with the body of the isolation valve joined to the fuel cylinder or assembly.

(23) A valve shall not be installed between the pressure relief device and the fuel cylinder.

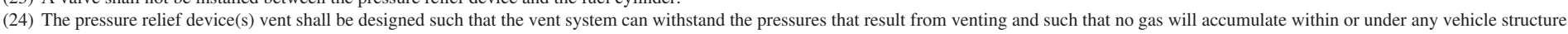

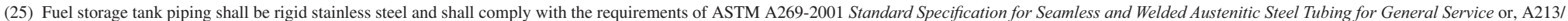
A213M Standard Specification for Seamless Ferritic and Austenitic Alloy-Steel Boiler, Superheater, and Heat-Exchanger Tubes.

(26) Fuel storage tank piping shall be installed as per the requirements of Section 5.5 of NFPA 52-2002.

(27) Fuel piping shall be secured to the vehicle at least every 24 inches.

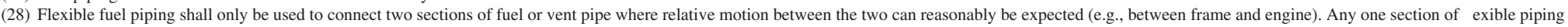
shall be limited to 16 " in length.

(29) Flexible piping or hose shall only be installed downstream of the first pressure regulator.

(30) Flexible piping shall be certified by its manufacturer for use with hydrogen. Such certification shall be provided with the vehicle submittal.

(31) Each fuel storage tank shall be provided with an isolation valve mounted either inside the tank or affixed to the tank manufacturer's outlet.

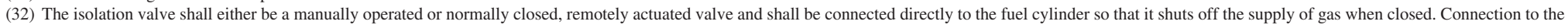
fuel storage tank shall utilize the fuel storage tank manufacturer's specified fittings.

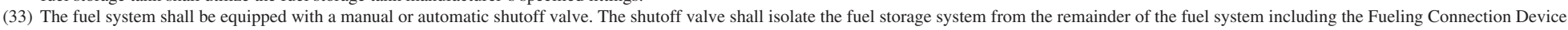

(34) Manual shutoff valves shall require no more than $90^{\circ}$ of handle rotation to close the valve.

(35) The shutoff valve shall be securely mounted to the vehicle and shall not be supported in any way by the fuel piping.

(36) The location of the shutoff valve shall be clearly labeled and shall be accessible from outside the vehicle.

(37) Fuel pressure regulator(s) shall be located as close as practical to the shutoff valve.

(38) A pressure relief valve shall be fitted on the regulated side of the first stage of the regulator with a relief pressure setting designed to protect all components downstream of the regulator.

(39) The pressure relief valve vent shall be designed to withstand the pressures developed during venting and such that vented gasses cannot accumulate within or under any vehicle structure.

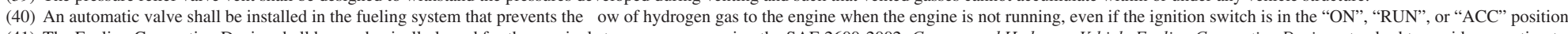

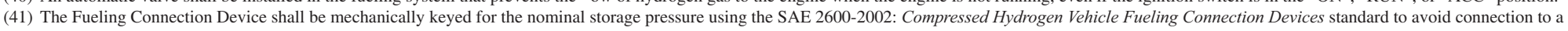
higher than allowable pressure dispenser.

(42) The Fueling Connection Device shall be matched to the nominal design pressure of the fuel storage cylinder(s).

(43) The Fueling Connection Device shall include dual check valves to prevent fuel leakage from the inlet.

(44) The Fueling Connection Device shall be securely mounted to the vehicle and shall not be supported in any way by the inlet piping

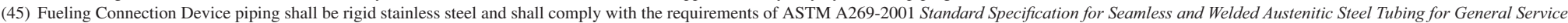
or, A213/A213M Standard Specification for Seamless Ferritic and Austenitic Alloy-Steel Boiler, Superheater, and Heat-Exchanger Tubes.

(46) Fueling Connection Device piping shall be secured to the body and/or frame at least every 24 inches.

(47) Piping connection to the Fueling Connection Device shall utilize the manufacturer's recommended fittings.

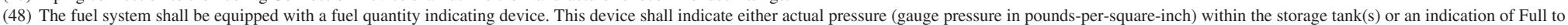
Empty based on, at a minimum, actual pressure within the storage tank(s).

(49) A fuel gauge installed in the passenger compartment shall be electrically operated with the pressurized sending unit installed in the fuel system outside of any passenger spaces

(50) The Supplier shall provide recommended fuel system maintenance requirements, including requirements, if any, for periodic fuel system integrity checks.

(51) Suppliers shall specify all optional equipment required to meet the requirements of this Vehicle Specification.

The installation of options shall not relieve Suppliers of meeting other "shall" requirements.

(52) Non-proprietary manuals for parts, service, operation and maintenance, interconnection wiring diagrams and schematics shall accompany all vehicles submitted for testing.

This information was prepared with the support of the U.S. Department of Energy, FreedomCAR \& Vehicle Technologies Program, Advanced Vehicle Testing Activity under Award No. DE-FC26-05NT42486. However, any opinions, findings, conclusions or recommendations expressed herein are those of the author(s) and may not reflect the views of the U. S. Department of Energy. 


\section{APPENDIX $J$}

\section{INL N2H2 MODEL SCENARIOS AND COMMENTS}




\section{Appendix J INL N2H2 Model Scenarios and Comments}

A matrix of studies was conducted on this model to evaluate the several scenarios. The following table identifies the scenarios considered and the outcomes. CO2 Credit @ \$20/tonne.

\section{1. $97 \%$ Availability}

First, the maximum availability was selected of $97 \%$ for the year 2006 . That led to an average electricity cost of \$49.41/MWH. That electricity price was assumed for both the Plant and City Gate sections. The Retail location was selected to be a more typical $\$ 0.0646 / \mathrm{kWh}$ since the retail location would not be able to take advantage of the lower rates.

\begin{tabular}{|c|c|c|c|c|c|c|}
\hline Scenario & $\begin{array}{l}\text { Production } \\
\text { Rate }\end{array}$ & Ownership & Location & CO2 Credit & $\begin{array}{c}\text { Breakeven } \\
\text { H2 Cost }\end{array}$ & $\begin{array}{l}\text { Notes } \\
\text { Below }\end{array}$ \\
\hline 1 & $100 \mathrm{Kg} /$ day & Public Utility & Plant & No & N/A & 1 \\
\hline 2 & & & & Yes & N/A & 1 \\
\hline 3 & & & City Gate & No & $\$ 17.70$ & 2 \\
\hline 4 & & & & Yes & $\$ 17.60$ & 2 \\
\hline 5 & & & Retail Location & No & $\$ 19.76$ & 3 \\
\hline 6 & & & & Yes & $\$ 19.70$ & 3 \\
\hline 7 & & Private Merchant & Plant & No & N/A & 1 \\
\hline 8 & & & & Yes & N/A & 1 \\
\hline 9 & & & City Gate & No & $\$ 19.58$ & 2 \\
\hline 10 & & & & Yes & $\$ 19.52$ & 2 \\
\hline 11 & & & Retail Location & No & $\$ 21.75$ & 4 \\
\hline 12 & & & & Yes & $\$ 21.68$ & 4 \\
\hline 13 & $1,500 \mathrm{~kg} / \mathrm{day}$ & Public Utility & Plant & No & N/A & 1 \\
\hline 14 & & & & Yes & N/A & 1 \\
\hline 15 & & & City Gate & No & $\$ 7.04$ & 2 \\
\hline 16 & & & & Yes & $\$ 6.98$ & 2 \\
\hline 17 & & & Retail Location & No & $\$ 8.70$ & 4 \\
\hline 18 & & & & Yes & $\$ 8.64$ & 4 \\
\hline 19 & & Private Merchant & Plant & No & $\mathrm{N} / \mathrm{A}$ & 1 \\
\hline 20 & & & & Yes & N/A & 1 \\
\hline 21 & & & City Gate & No & $\$ 7.47$ & 2 \\
\hline 22 & & & & Yes & $\$ 7.41$ & 2 \\
\hline 23 & & & Retail Location & No & $\$ 9.19$ & 4 \\
\hline 24 & & & & Yes & $\$ 9.18$ & 4 \\
\hline 25 & $86,400 \mathrm{~kg} /$ day & Public Utility & Plant & No & $\$ 4.81$ & 5 \\
\hline 26 & & & & Yes & $\$ 4.75$ & 5 \\
\hline 27 & & & City Gate & No & $\$ 4.95$ & 6 \\
\hline 28 & & & & Yes & $\$ 4.89$ & 6 \\
\hline 29 & & & Retail Location & No & $\mathrm{N} / \mathrm{A}$ & 1 \\
\hline 30 & & & & Yes & N/A & 1 \\
\hline 31 & & Private Merchant & Plant & No & $\$ 5.05$ & 7 \\
\hline 32 & & & & Yes & $\$ 4.99$ & 7 \\
\hline 33 & & & City Gate & No & $\$ 5.20$ & 8 \\
\hline 34 & & & & Yes & $\$ 5.14$ & 8 \\
\hline 35 & & & Retail Location & No & $\mathrm{N} / \mathrm{A}$ & 1 \\
\hline 36 & & & & Yes & N/A & 1 \\
\hline
\end{tabular}

General Comments:

\section{2. $85 \%$ Availability}


The maximum purchase price of electricity was selected to be $\$ 60 / \mathrm{MWH}$ in order to have a plant availability of $85 \%$ for the year 2006 . That led to an average electricity cost of $\$ 44.99 / \mathrm{MWH}$. That led to availability variations by month that was factored into the model. That electricity price was assumed for both the Plant and City Gate sections. The Retail location was selected to be a more typical $\$ 0.0646 / \mathrm{kWh}$ since the retail location would not be able to take advantage of the lower rates.

\begin{tabular}{|c|c|c|c|c|c|c|}
\hline Scenario & $\begin{array}{c}\text { Production } \\
\text { Rate }\end{array}$ & Ownership & Location & CO2 Credit & $\begin{array}{c}\text { Breakeven } \\
\text { H2 Cost }\end{array}$ & $\begin{array}{l}\text { Notes } \\
\text { Below }\end{array}$ \\
\hline 1 & $100 \mathrm{Kg} /$ day & Public Utility & Plant & No & $\mathrm{N} / \mathrm{A}$ & 1 \\
\hline 2 & & & & Yes & N/A & 1 \\
\hline 3 & & & City Gate & No & $\$ 17.30$ & 2 \\
\hline 4 & & & & Yes & $\$ 17.23$ & 2 \\
\hline 5 & & & Retail Location & No & $\$ 19.76$ & 3 \\
\hline 6 & & & & Yes & $\$ 19.70$ & 3 \\
\hline 7 & & Private Merchant & Plant & No & N/A & 1 \\
\hline 8 & & & & Yes & N/A & 1 \\
\hline 9 & & & City Gate & No & $\$ 19.17$ & 2 \\
\hline 10 & & & & Yes & $\$ 19.13$ & 2 \\
\hline 11 & & & Retail Location & No & $\$ 21.75$ & 4 \\
\hline 12 & & & & Yes & $\$ 21.68$ & 4 \\
\hline 13 & $1,500 \mathrm{~kg} / \mathrm{day}$ & Public Utility & Plant & No & N/A & 1 \\
\hline 14 & & & & Yes & $\mathrm{N} / \mathrm{A}$ & 1 \\
\hline 15 & & & City Gate & No & $\$ 7.03$ & 2 \\
\hline 16 & & & & Yes & $\$ 6.97$ & 2 \\
\hline 17 & & & Retail Location & No & $\$ 9.05$ & 4 \\
\hline 18 & & & & Yes & $\$ 8.99$ & 4 \\
\hline 19 & & Private Merchant & Plant & No & N/A & 1 \\
\hline 20 & & & & Yes & N/A & 1 \\
\hline 21 & & & City Gate & No & $\$ 7.52$ & 2 \\
\hline 22 & & & & Yes & $\$ 7.46$ & 2 \\
\hline 23 & & & Retail Location & No & $\$ 9.60$ & 4 \\
\hline 24 & & & & Yes & $\$ 9.54$ & 4 \\
\hline 25 & $86,400 \mathrm{~kg} /$ day & Public Utility & Plant & No & $\$ 4.37$ & 5 \\
\hline 26 & & & & Yes & $\$ 4.31$ & 5 \\
\hline 27 & & & City Gate & No & $\$ 4.51$ & 6 \\
\hline 28 & & & & Yes & $\$ 4.44$ & 6 \\
\hline 29 & & & Retail Location & No & $\mathrm{N} / \mathrm{A}$ & 1 \\
\hline 30 & & & & Yes & N/A & 1 \\
\hline 31 & & Private Merchant & Plant & No & $\$ 4.62$ & 7 \\
\hline 32 & & & & Yes & $\$ 4.56$ & 7 \\
\hline 33 & & & City Gate & No & $\$ 4.76$ & 8 \\
\hline 34 & & & & Yes & $\$ 4.70$ & 8 \\
\hline 35 & & & Retail Location & No & N/A & 1 \\
\hline 36 & & & & Yes & N/A & 1 \\
\hline
\end{tabular}

\section{3. $60 \%$ Availability}

The maximum purchase price of electricity was selected to be $\$ 52 / \mathrm{MWH}$ in order to have a plant availability of $60 \%$ for the year 2006. That led to an average electricity cost of $\$ 40.35 / \mathrm{MWH}$. 
That led to availability variations by month that was factored into the model. That electricity price was assumed for both the Plant and City Gate sections. The Retail location was continued at $\$ 0.0646 / \mathrm{kWh}$.

\begin{tabular}{|c|c|c|c|c|c|c|}
\hline Scenario & $\begin{array}{c}\text { Production } \\
\text { Rate }\end{array}$ & Ownership & Location & CO2 Credit & $\begin{array}{c}\text { Breakeven } \\
\text { H2 Cost }\end{array}$ & $\begin{array}{l}\text { Notes } \\
\text { Below }\end{array}$ \\
\hline 1 & $100 \mathrm{Kg} /$ day & Public Utility & Plant & No & N/A & 1 \\
\hline 2 & & & & Yes & $\mathrm{N} / \mathrm{A}$ & 1 \\
\hline 3 & & & City Gate & No & $\$ 16.89$ & 2 \\
\hline 4 & & & & Yes & $\$ 16.83$ & 2 \\
\hline 5 & & & Retail Location & No & $\$ 19.76$ & 3 \\
\hline 6 & & & & Yes & $\$ 19.70$ & 3 \\
\hline 7 & & Private Merchant & Plant & No & $\mathrm{N} / \mathrm{A}$ & 1 \\
\hline 8 & & & & Yes & N/A & 1 \\
\hline 9 & & & City Gate & No & $\$ 18.76$ & 2 \\
\hline 10 & & & & Yes & $\$ 18.70$ & 2 \\
\hline 11 & & & Retail Location & No & $\$ 21.75$ & 4 \\
\hline 12 & & & & Yes & $\$ 21.68$ & 4 \\
\hline 13 & $1,500 \mathrm{~kg} /$ day & Public Utility & Plant & No & N/A & 1 \\
\hline 14 & & & & Yes & N/A & 1 \\
\hline 15 & & & City Gate & No & $\$ 7.97$ & 2 \\
\hline 16 & & & & Yes & $\$ 7.91$ & 2 \\
\hline 17 & & & Retail Location & No & $\$ 10.41$ & 4 \\
\hline 18 & & & & Yes & $\$ 10.34$ & 4 \\
\hline 19 & & Private Merchant & Plant & No & N/A & 1 \\
\hline 20 & & & & Yes & N/A & 1 \\
\hline 21 & & & City Gate & No & $\$ 8.62$ & 2 \\
\hline 22 & & & & Yes & $\$ 8.56$ & 2 \\
\hline 23 & & & Retail Location & No & $\$ 11.14$ & 4 \\
\hline 24 & & & & Yes & $\$ 11.08$ & 4 \\
\hline 25 & $86,400 \mathrm{~kg} /$ day & Public Utility & Plant & No & $\$ 4.25$ & 5 \\
\hline 26 & & & & Yes & $\$ 4.19$ & 5 \\
\hline 27 & & & City Gate & No & $\$ 4.40$ & 6 \\
\hline 28 & & & & Yes & $\$ 4.38$ & 6 \\
\hline 29 & & & Retail Location & No & $\mathrm{N} / \mathrm{A}$ & 1 \\
\hline 30 & & & & Yes & N/A & 1 \\
\hline 31 & & Private Merchant & Plant & No & $\$ 4.57$ & 7 \\
\hline 32 & & & & Yes & $\$ 4.50$ & 7 \\
\hline 33 & & & City Gate & No & $\$ 4.73$ & 8 \\
\hline 34 & & & & Yes & $\$ 4.67$ & 8 \\
\hline 35 & & & Retail Location & No & $\mathrm{N} / \mathrm{A}$ & 1 \\
\hline 36 & & & & Yes & N/A & 1 \\
\hline
\end{tabular}

\section{4. $50 \%$ Availability}

Finally, the maximum purchase price of electricity was selected to be $\$ 48.50 / \mathrm{MWH}$ in order to have a plant availability of $50 \%$ for the year 2006 . That led to an average electricity cost of 
$\$ 38.45 / \mathrm{MWH}$. That led to availability variations by month that was factored into the model. That electricity price was assumed for both the Plant and City Gate sections. The Retail location was continued at $\$ 0.0646 / \mathrm{kWh}$.

\begin{tabular}{|c|c|c|c|c|c|c|}
\hline Scenario & $\begin{array}{c}\text { Production } \\
\text { Rate }\end{array}$ & Ownership & Location & CO2 Credit & $\begin{array}{c}\text { Breakeven } \\
\text { H2 Cost }\end{array}$ & $\begin{array}{l}\text { Notes } \\
\text { Below }\end{array}$ \\
\hline 1 & $100 \mathrm{Kg} /$ day & Public Utility & Plant & No & $\mathrm{N} / \mathrm{A}$ & 1 \\
\hline 2 & & & & Yes & N/A & 1 \\
\hline 3 & & & City Gate & No & $\$ 16.72$ & 2 \\
\hline 4 & & & & Yes & $\$ 16.65$ & 2 \\
\hline 5 & & & Retail Location & No & $\$ 19.76$ & 3 \\
\hline 6 & & & & Yes & $\$ 19.70$ & 3 \\
\hline 7 & & Private Merchant & Plant & No & N/A & 1 \\
\hline 8 & & & & Yes & N/A & 1 \\
\hline 9 & & & City Gate & No & $\$ 18.58$ & 2 \\
\hline 10 & & & & Yes & $\$ 18.52$ & 2 \\
\hline 11 & & & Retail Location & No & $\$ 21.75$ & 4 \\
\hline 12 & & & & Yes & $\$ 21.68$ & 4 \\
\hline 13 & $1,500 \mathrm{~kg} / \mathrm{day}$ & Public Utility & Plant & No & N/A & 1 \\
\hline 14 & & & & Yes & N/A & 1 \\
\hline 15 & & & City Gate & No & $\$ 8.78$ & 2 \\
\hline 16 & & & & Yes & $\$ 8.72$ & 2 \\
\hline 17 & & & Retail Location & No & $\$ 11.43$ & 4 \\
\hline 18 & & & & Yes & $\$ 11.37$ & 4 \\
\hline 19 & & Private Merchant & Plant & No & N/A & 1 \\
\hline 20 & & & & Yes & N/A & 1 \\
\hline 21 & & & City Gate & No & $\$ 9.54$ & 2 \\
\hline 22 & & & & Yes & $\$ 9.48$ & 2 \\
\hline 23 & & & Retail Location & No & $\$ 12.27$ & 4 \\
\hline 24 & & & & Yes & $\$ 12.21$ & 4 \\
\hline 25 & $86,400 \mathrm{~kg} /$ day & Public Utility & Plant & No & $\$ 4.34$ & 5 \\
\hline 26 & & & & Yes & $\$ 4.28$ & 5 \\
\hline 27 & & & City Gate & No & $\$ 4.50$ & 6 \\
\hline 28 & & & & Yes & $\$ 4.44$ & 6 \\
\hline 29 & & & Retail Location & No & N/A & 1 \\
\hline 30 & & & & Yes & N/A & 1 \\
\hline 31 & & Private Merchant & Plant & No & $\$ 4.69$ & 7 \\
\hline 32 & & & & Yes & $\$ 4.63$ & 7 \\
\hline 33 & & & City Gate & No & $\$ 4.87$ & 8 \\
\hline 34 & & & & Yes & $\$ 4.80$ & 8 \\
\hline 35 & & & Retail Location & No & N/A & 1 \\
\hline 36 & & & & Yes & N/A & 1 \\
\hline
\end{tabular}

1. Scenarios rejected because the size of the plant does not justify the investment at the plant location.

2. wheeling cost recovered in $\mathrm{kWh}$ cost but requires $\mathrm{H} 2$ distribution and retail

3. wheeling costs and distribution cost recovered in $\mathrm{kWh}$ cost, and requires no $\mathrm{H} 2$ distribution and retail

4. wheeling costs and distribution cost recovered in $\mathrm{kWh}$ cost, and requires no $\mathrm{H} 2$ distribution and retail

5. no wheeling cost but requires $\mathrm{H} 2$ transport, distribution and retail costs

6. wheeling cost recovered in $\mathrm{kWh}$ cost, but requires $\mathrm{H} 2$ distribution and retail 
7. no wheeling cost but requires $\mathrm{H} 2$ transport, distribution and retail costs

8. wheeling cost recovered in $\mathrm{kWh}$ cost, but requires $\mathrm{H} 2$ distribution and retail 